\title{
Spatiotemporal Controls and Scaling of Stream Water Quality across the East Coast of U.S.A
}

\author{
Shakil Ahmed
}

Follow this and additional works at: https://researchrepository.wvu.edu/etd

\section{Recommended Citation}

Ahmed, Shakil, "Spatiotemporal Controls and Scaling of Stream Water Quality across the East Coast of U.S.A" (2018). Graduate Theses, Dissertations, and Problem Reports. 5037.

https://researchrepository.wvu.edu/etd/5037

This Dissertation is protected by copyright and/or related rights. It has been brought to you by the The Research Repository @ WVU with permission from the rights-holder(s). You are free to use this Dissertation in any way that is permitted by the copyright and related rights legislation that applies to your use. For other uses you must obtain permission from the rights-holder(s) directly, unless additional rights are indicated by a Creative Commons license in the record and/ or on the work itself. This Dissertation has been accepted for inclusion in WVU Graduate Theses, Dissertations, and Problem Reports collection by an authorized administrator of The Research Repository @ WVU.

For more information, please contact researchrepository@mail.wvu.edu. 


\title{
Spatiotemporal Controls and Scaling of Stream Water Quality across the East Coast of U.S.A.
}

\author{
Shakil Ahmed \\ Dissertation submitted \\ to the Benjamin M. Statler College of Engineering and Mineral Resources \\ at West Virginia University \\ in partial fulfillment of the requirements for the degree of \\ Doctor of Philosophy in \\ Civil Engineering
}

Omar I. Abdul-Aziz, Ph.D., Chair

P. V. Vijay, Ph.D.

Seung Ho Hong, Ph.D.

Kakan Dey, Ph.D.

Yanfang Ye, Ph.D.

Department of Civil and Environmental Engineering

\section{Morgantown, West Virginia \\ 2018}

Keywords: Stream water quality, similitude, scaling, land use, climate, hydrology,

biogeochemistry.

Copyright 2018 Shakil Ahmed 


\section{ABSTRACT \\ Spatiotemporal Controls and Scaling of Stream Water Quality across the East Coast of \\ U.S.A. \\ Shakil Ahmed}

Stream water quality and ecosystem health are controlled by a multitude of complex, interacting anthropogenic and natural processes. A generalized understanding of stream water quality dynamics under diverse hydro-climatic and biogeochemical conditions therefore still remains elusive, particularly in the context of coastal urban/natural environments. This dissertation focuses to investigate the major spatiotemporal controls of stream water quality, and leverages the knowledge to investigate stream biogeochemical-ecological similitude (parametric reduction), scaling, and emergent patterns across the East Coast of U.S.A. Total nitrogen (TN), total phosphorus (TP), chlorophyll-a (Chla), and dissolved oxygen (DO) were used to represent the stream water quality. Pearson correlation matrix, principal component analysis, and factor analysis were used to analyze the interrelations and groupings among the environmental drivers alongside tracking their individual linkages with the stream water quality. Partial least squares regression models were then developed to directly estimate the linkages by appropriately resolving multicollinearity among the predictor variables. Spatial analytics on 6 major streams in southeast Florida indicated the external sources (e.g., Everglades) and draining watershed's agricultural lands as the major drivers of in-stream TN, TP, and Chla. However, stream DO was most strongly influenced by the adjacent groundwater depth and watershed (agricultural and built-up) land uses. Spatio-temporal analytics on 50 stream sites across the East Coast showed strong controls of climatic (stream temperature) and biogeochemical ( $\mathrm{pH}$ and salinity) drivers on stream DO. The dominant drivers were then involved in dimensional analysis to formulate mechanistically meaningful dimensionless numbers, which represented the contrasting as well as the collective influence of different hydro-climatic and biogeochemical drivers on stream water quality. A graphical exploration of the driver (predictor) numbers and stream DO number unraveled emergent patterns by collapsing observations from diverse environmental conditions into single dimensionless curves. Two environmental regimes ('climatic' versus 'metabolic' controls) were identified based on the critical threshold of the driver dimensionless number. The dimensionless numbers and emergent patterns led to the estimation of a scaling relationship, which was robust across the different environmental regimes. The scaling relationship was then utilized as a nonlinear empirical model to successfully predict DO from numerous streams across the East Coast of U.S.A. (Nash-Sutcliffe Efficiency $=0.82$ ). The research findings and insights are expected to guide effective water resources management for maintaining healthy stream water quality across the U.S. East Coast and similar regions around the world. 


\section{ACKNOWLEDGMENTS}

First of all, I would like to express my deepest gratitude to Almighty God for bestowing endless blessings upon me, which is inevitable for completion of any good work.

I would like to express my sincere gratitude to my supervisor, Dr. Omar I. Abdul-Aziz for his continuous guidance, valuable suggestions, generous help, encouragement, and unfading enthusiasm at all stages of this study.

I would like specially thank Dr. P. V. Vijay, Dr. Seung Ho Hong, Dr. Kakan Dey, and Dr. Yanfang Ye for serving as members of the examination committee. Their valuable comments played a crucial role to improve the dissertation.

My special thanks to all of my lab-mates for their continuous support and guidance to overcome many challenges faced during the research work.

The dissertation was funded by a National Science Foundation (NSF) CAREER Award to Dr. Omar I. Abdul-Aziz (NSF CBET Environmental Sustainability Award \# 1561942/1454435). The supports are gratefully acknowledged.

Finally, I would like to express my heartiest gratitude to my parents, wife, and sisters whose support and love were inevitable for the completion of this research work. 


\section{Table of Contents}

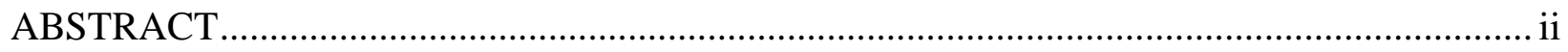

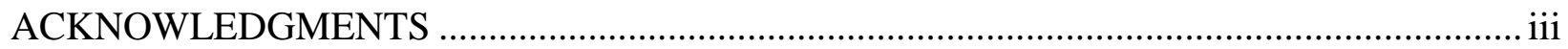

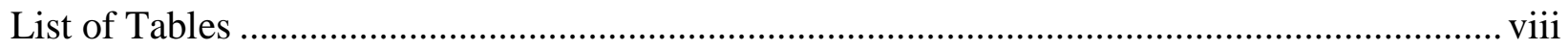

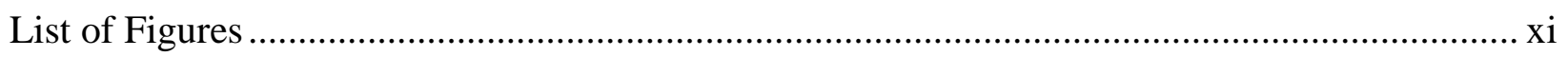

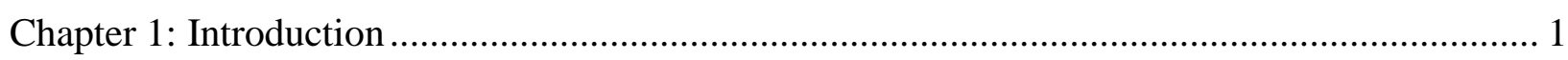

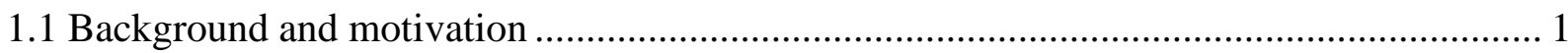

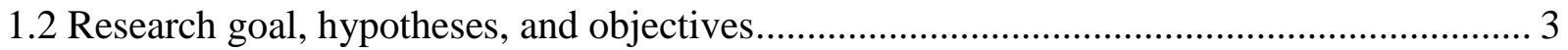

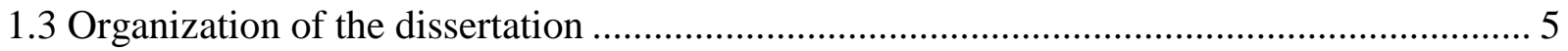

Chapter 2: Relative linkages of stream water quality and environmental health with the land use and hydrologic drivers in the coastal-urban watersheds of southeast Florida ............................... 8

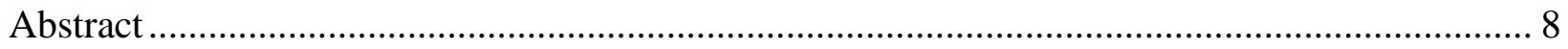

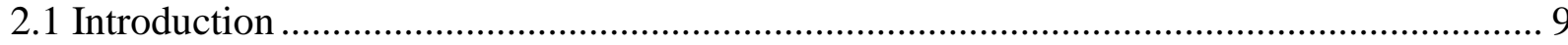

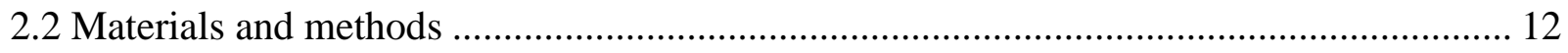

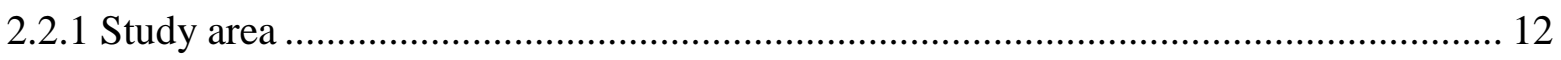

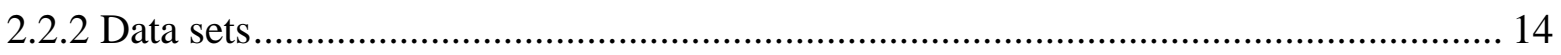

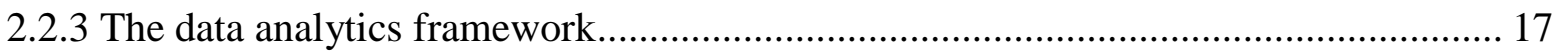

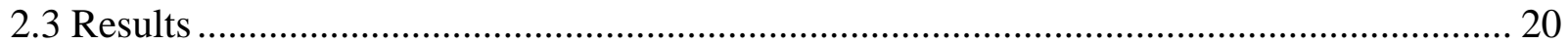

2.3.1 Mutual correspondences of the water quality, hydrologic, and land use variables ...... 20

2.3.2 Relative orientations and groupings of the water quality and driving variables .......... 22

2.3.3 Major water quality drivers based on independent latent factors ............................... 25

2.3.4 Estimations of the relative linkages of water quality indicators with the drivers......... 27

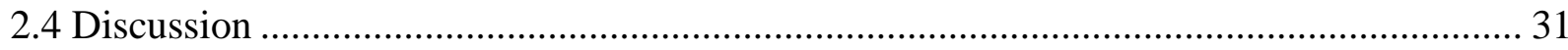

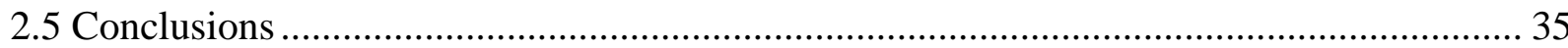

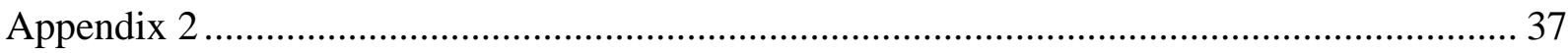

Chapter 3: Evaluating the contrasting hydrologic and land use controls of coastal-urban stream water quality by formulating similitude and dimensionless numbers ........................................ 47

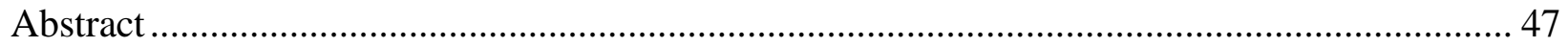

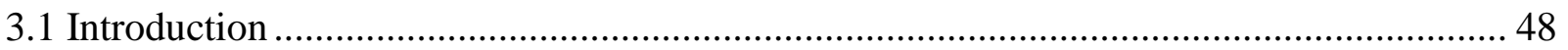

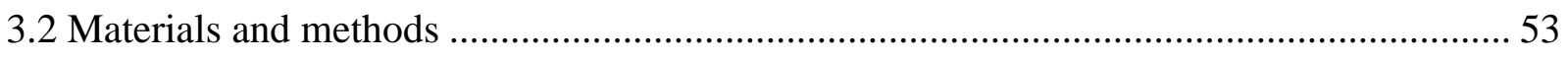

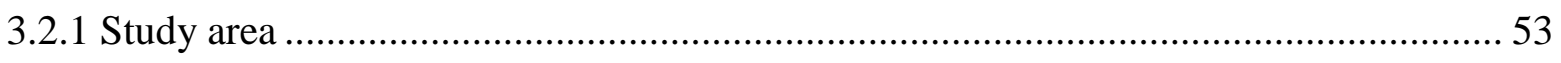

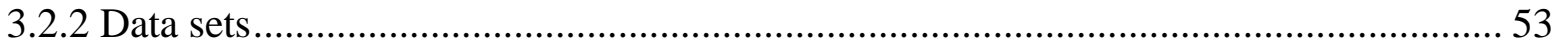

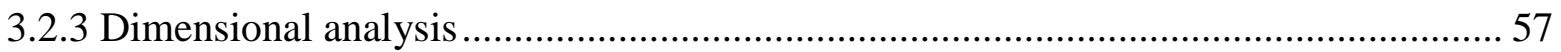




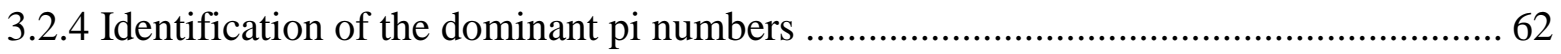

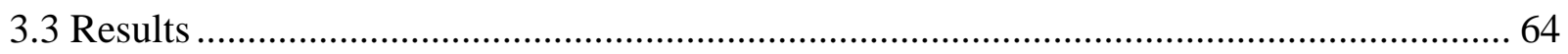

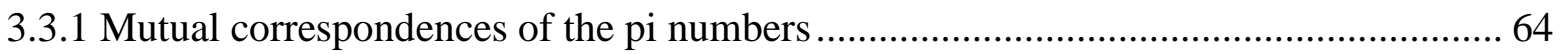

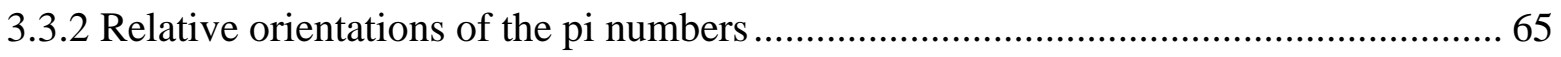

3.3.3 Interrelations among the pi numbers based on independent latent factors ..................... 67

3.3.4 Relative linkages between response and predictor pi numbers .................................... 69

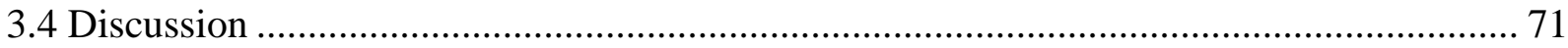

3.4.1 Dominant pi numbers and their relative linkages ................................................... 71

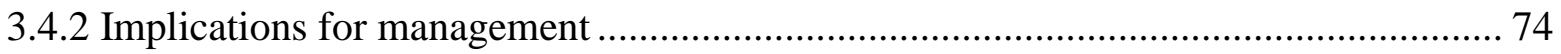

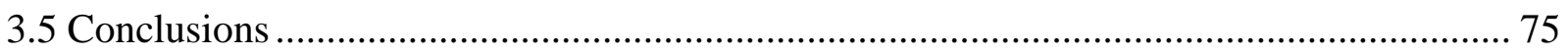

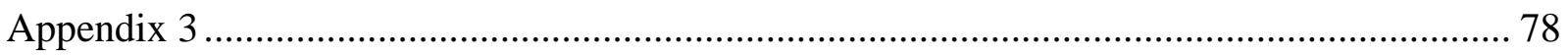

Chapter 4: Relative controls of land use, hydro-climatic, and biogeochemical drivers on stream

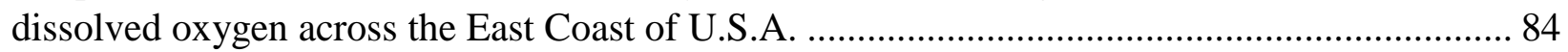

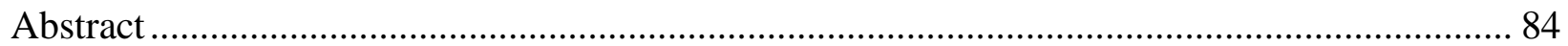

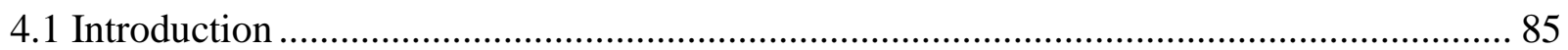

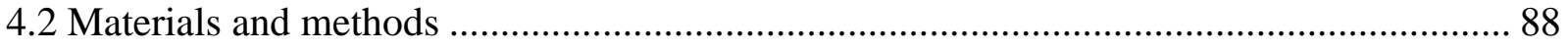

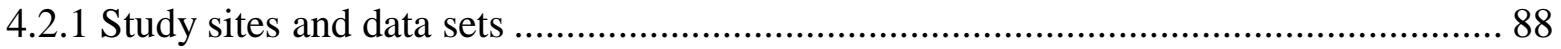

4.2.2 Data analytics of stream DO and pertinent environmental drivers ............................ 92

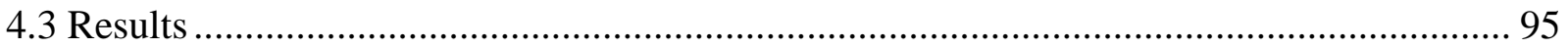

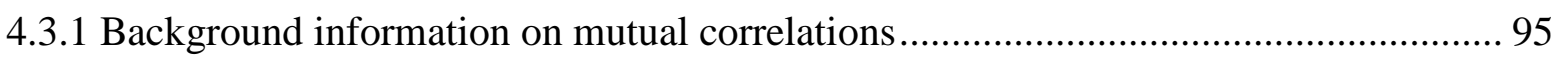

4.3.2 Interrelations among the spatiotemporal drivers to control stream DO ...................... 97

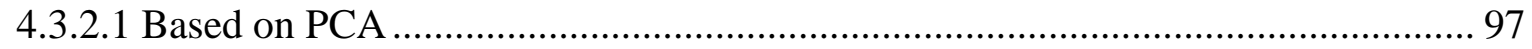

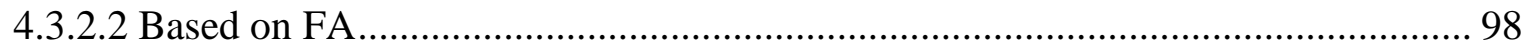

4.3.3 Identification of the dominant drivers by estimating the relative linkages ................ 101

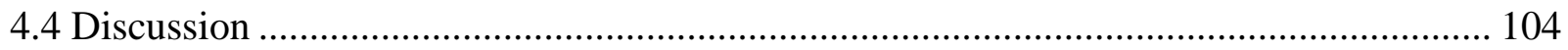

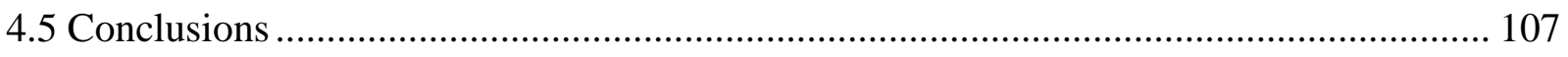

Appendix 4 .............................................................................................................. 109

Chapter 5: Dimensional analysis and similitude to analyze the interactive controls of land use, hydro-climatic, and biogeochemical drivers on stream dissolved oxygen across the East Coast of

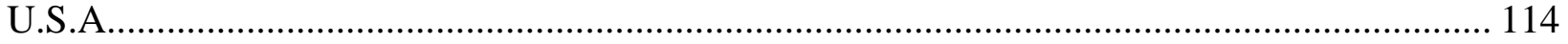

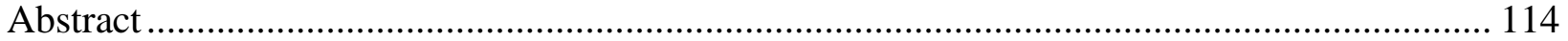

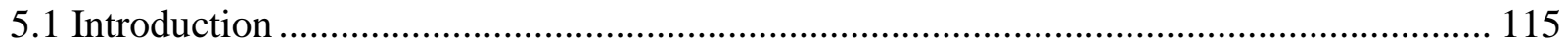

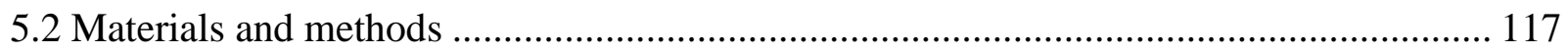




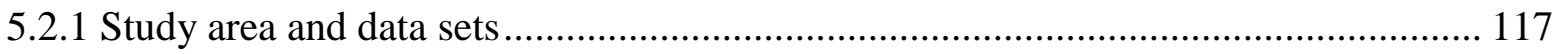

5.2.2 Formulation of the dimensionless numbers ..................................................... 120

5.2.3 Quantifying the relative controls of the pi numbers .............................................. 123

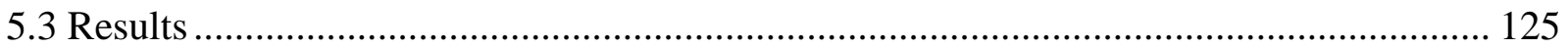

5.3.1 Mutual relationships among the pi numbers................................................... 125

5.3.2 Interrelationships based on the PCA .................................................................. 126

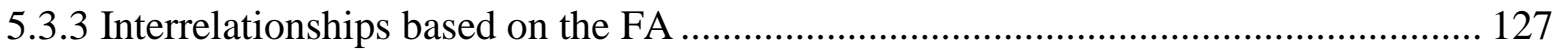

5.3.4 Quantification of the relative controls by PLSR .............................................. 128

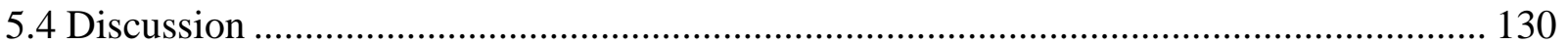

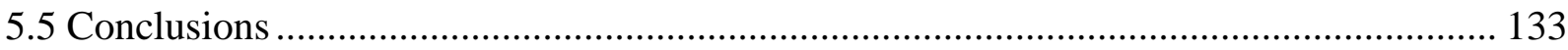

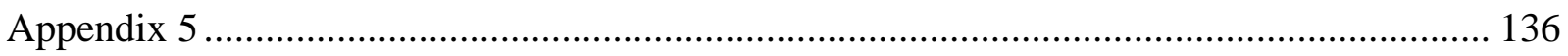

Chapter 6: Dynamic controls of stream dissolved oxygen across the East Coast of U.S.A...... 138

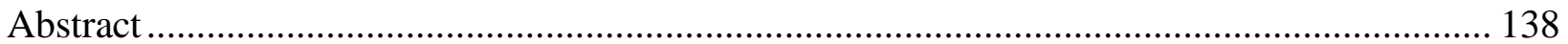

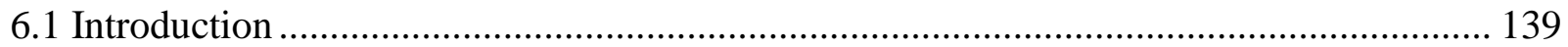

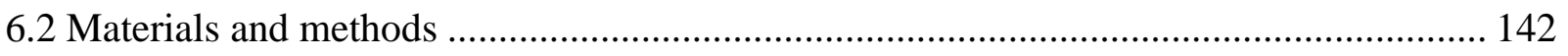

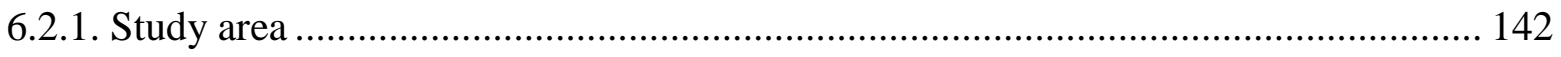

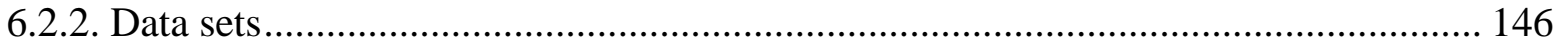

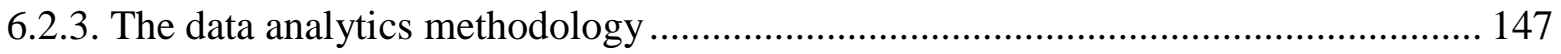

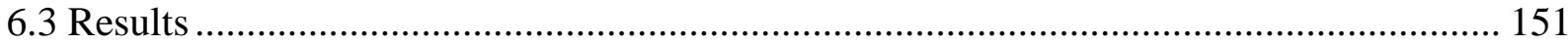

6.3.1. Mutual relationships among DO, hydro-climatic, and biogeochemical drivers ....... 151

6.3.2. Relative controls of the drivers and their interrelations ..................................... 153

6.3.2.1. Relative controls and interrelations based on PCA........................................ 153

6.3.2.2. Relative controls and interrelations based on independent latent factors .......... 156

6.3.3. Quantification of the relative linkages of DO with the drivers ............................. 157

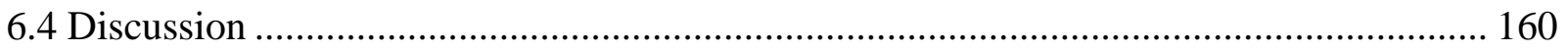

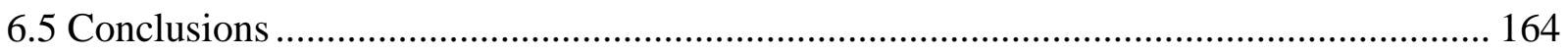

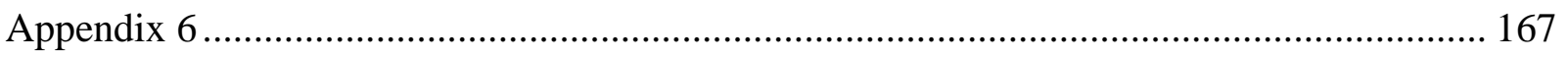

Chapter 7: Similitude and scaling of stream dissolved oxygen with the hydro-climatic and biogeochemical drivers across the East Coast of U.S.A................................................. 175

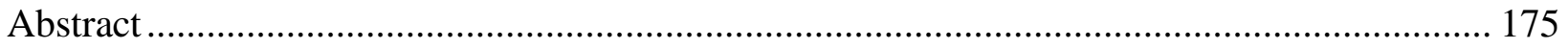

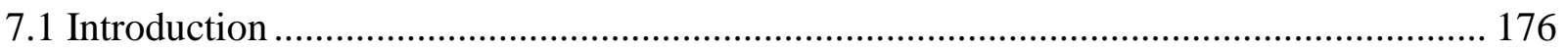

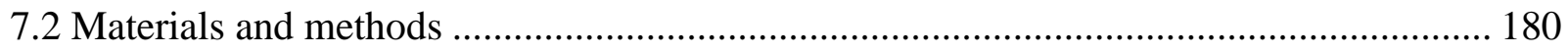

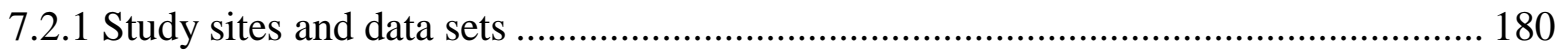




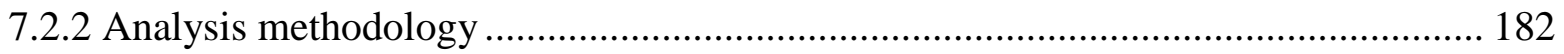

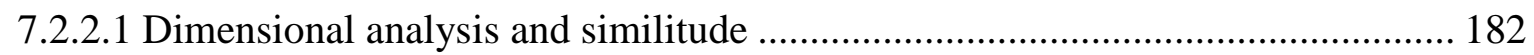

7.2.2.2 Investigation of emergent patterns and environmental regimes ......................... 185

7.2.2.3 Characterization of the environmental regimes ............................................... 186

7.2.2.4 Development of scaling relationship ........................................................... 187

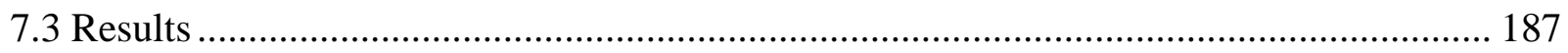

7.3.1 Emergent patterns and environmental regimes ................................................... 187

7.3.2 Characteristics of the environmental regimes ............................................................ 190

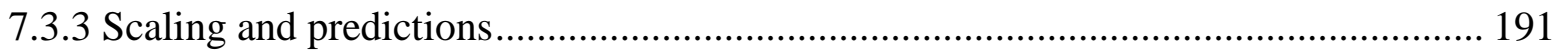

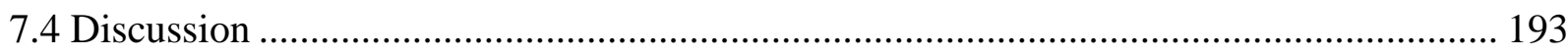

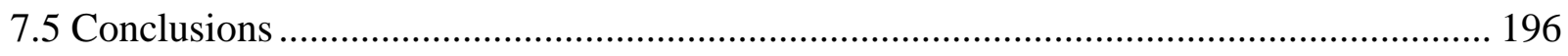

Appendix 7 ....................................................................................................... 198

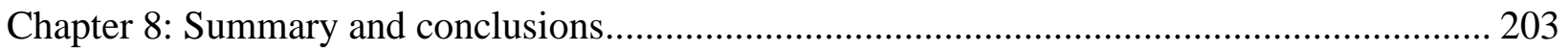

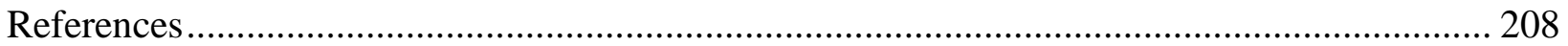




\section{List of Tables}

Table 2.1. Summary of the stream water quality/environmental health indicators, and their land

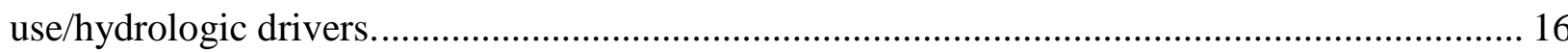
Table 2.2. Pearson correlation coefficients (r) between stream water quality/environmental health

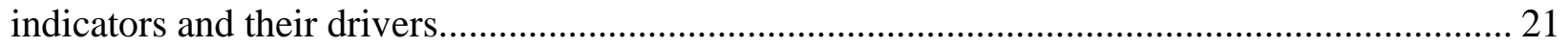

Table 2.3.Major latent factors with their optimized loadings on the participatory variables....... 26

Table 2.4. PLSR model coefficients ( $\beta$ ) of the standardized variables in both wet and dry seasons.

Table 3.1. Summary of the stream water quality indicators and their drivers across all sites

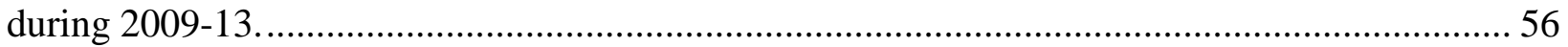

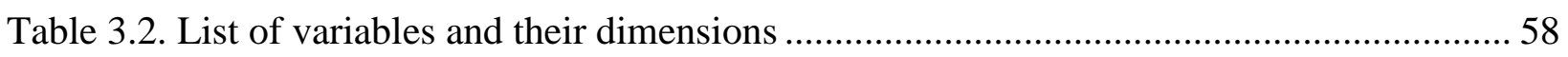

Table 3.3. Pearson correlation coefficients (r) between the response and predictor pi numbers. 65 Table 3.4. Major latent factors with their optimized loadings on the pi numbers. 68

Table 3.5. PLSR model coefficients ( $\beta$ ) of the standardized pi numbers in both wet and dry seasons. 71

Table 4.1. Summary of the stream dissolved oxygen, land use, hydro-climatic, and biogeochemical drivers across all the stream water quality monitoring sites. 91

Table 4.2. Pearson correlation coefficients (r) of DO with land use, hydro-climatic, and biogeochemical drivers. 96 Table 4.3. Major latent factors with their optimized loadings on the participatory variables in wet and dry seasons. 100

Table 4.4. PLSR model coefficients ( $\beta$ ) of the drivers in both wet and dry seasons. 102 
Table 5.1. Summary of the stream dissolved oxygen, land use, hydro-climatic, and biogeochemical drivers across all the stream water quality monitoring sites........................ 120

Table 5.2. List of variables and their dimensions ........................................................... 121

Table 5.3. Pearson correlation coefficients (r) of DO/DO sat with the predictor pi numbers....... 126

Table 5.4. Major latent factors with their optimized loadings on the pi numbers. ................... 127

Table 5.5. PLSR model coefficients $(\beta)$ of the standardized pi numbers across wet and dry seasons.

Table 6.1. Data summary with mean and standard deviation (in parentheses) of stream water quality, hydro-climatic, and biogeochemical variables of the 51 stream water quality monitoring sites across the U.S. East Coast representing diverse environmental conditions. 144 Table 6.2. Pearson correlation coefficients (r) between DO and hydro-climatic/biogeochemical drivers in the environmental regimes.

Table 6.3. Major latent factors with their optimized loadings on the participatory variables for example sites of three environmental regimes. 156

Table 6.4. Ensemble means and standard deviations (in parentheses) of the PLSR model coefficients $(\beta)$, representing the regime-specific relative linkages of DO with the drivers. .. 158 Table 6.5. Ensemble mean and standard deviation (in parentheses) of the aggregated relative linkages of DO with the four environmental process components in different environmental regimes. 160

Table 7.1. Data summary of the stream water quality variables and its drivers in all the stream water quality sites across the U.S. East Coast representing diverse environmental conditions. 182 Table 7.2. List of variables used in dimensional analysis. 183 
Table 7.3. Relative linkages from PLSR model coefficients ( $\beta$ ) across the environmental

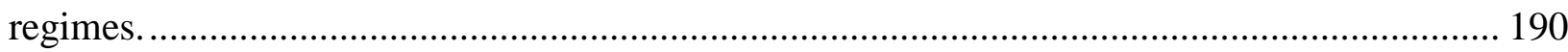

Table 7.4. The predictive modeling results with the dimensionless numbers ............................ 192 


\section{List of Figures}

Figure 2.1. Study area, the major canals, and the location of the water quality monitoring stations. Inset showing the state of Florida is not on scale. 13

Figure 2.2. The data analytics framework to determine the relative linkages of stream water quality and environmental health indicators with their drivers.

Figure 2.3. Biplots from principal component (PC) analysis, showing the relative orientations of the stream water quality/environmental health indicators and their drivers in wet season. Percent variance explained by each $\mathrm{PC}$ is shown in parenthesis. 23

Figure 2.4. Biplots from principal component (PC) analysis, showing the relative orientations of the stream water quality/environmental health indicators and their drivers in dry season. Percent variance explained by each PC is shown in parenthesis.

Figure 2.5. Plot of cross-validated (a) normalized AIC and (b) Nash-Sutcliffe Efficiency (NSE) with the number of incorporated partial least squares components. 28

Figure 3.1. Locations of the water quality monitoring stations in the major canals, and their corresponding watershed boundaries. Inset showing the state of Florida is not on the stated scale.

Figure 3.2. Biplots from principal component analysis showing the interrelation patterns of the predictor pi numbers and response pi number in (a) wet and (b) dry seasons. Percent variance explained by each PC is shown in parenthesis.

Figure 3.3. Plot of cross-validated (a) normalized AIC and (b) fitting efficiency (NSE) (for both wet and dry seasons) with the number of incorporated partial least squares components. 70

Figure 4.1. Locations of the coastal stream water quality monitoring stations across the East

Coast of U.S.A. 
Figure 4.2. The data analytics framework to investigate the interrelations and quantify the relative linkages of dissolved oxygen with the land use, hydro-climatic, and biogeochemical drivers.

Figure 4.3. Biplots from principal component analysis manifesting the interrelation patterns of the stream water quality with the drivers in (a) wet and (b) dry seasons. Percent variance explained by each PC is shown in parenthesis..... 98 Figure 4.4. Plot of cross-validated (a) fitting efficiency (NSE) and (b) normalized AIC (for both wet and dry seasons) with the number of incorporated partial least squares components. 101 Figure 5.1. Locations of the coastal stream water quality monitoring sites across the East Coast of U.S.A. 118

Figure 5.2. PCA Biplots showing the interrelationship patterns among the predictor and response pi numbers in (a) wet and (b) dry seasons. Percent variance explained by each PC is shown in parenthesis. 127 Figure 5.3. Plots of cross-validated (a) fitting efficiency (NSE) and (b) normalized AIC with the number of incorporated partial least squares components. 129 Figure 6.1. Locations of the coastal stream water quality monitoring stations across the U.S. East Coast. 143

Figure 6.2. The data analytics framework to quantify the relative linkages of dissolved oxygen with the hydro-climatic and biogeochemical drivers.

Figure 6.3. Biplots from principal component analysis, showing the interrelations of the water quality and hydro-climatic/biogeochemical variables for example sites of (a) temperature dominated, (b) transitional, and (c) redox dominated regimes. Percent variance explained by each $\mathrm{PC}$ is shown in parentheses. 155 
Figure 7.1. Locations of the coastal stream water quality monitoring stations across the U.S. East Coast.

Figure 7.2. Plot of $\left(A P^{3} \cdot W\right) /\left(c_{p}{ }^{3} \cdot T W^{3} \cdot T P \cdot H \cdot S a l \cdot D\right)$ vs. normalized DO (DO/DO sat) with (a) original data and (b) bin-based averaged data, revealing emergent patterns. 189

Figure 7.3. Observed vs. predicted values of stream DO across the East Coast of U.S.A ......... 192 


\section{Chapter 1: Introduction}

\subsection{Background and motivation}

Clean stream water is crucial for good human health, and a key to sustain the structure and functions of a healthy aquatic ecosystem. Stream water quality is controlled by both anthropogenic and natural drivers (Simeonov et al., 2003; Álvarez-Cabria et al., 2016). Therefore, linking the spatiotemporal changes of stream water quality with its environmental drivers has been a focus of much research (e.g., Kang et al., 2010; Nagy et al., 2012; Wan et al., 2014a,b). However, the spatiotemporal controls and scaling of stream water quality under diverse environmental conditions are yet to be understood well — particularly in the context of dynamic coastal environments. Further, the complex interactions of the biotic and abiotic drivers and their spatiotemporal variation pose a major challenge to develop a generalized modeling and prediction tool of the coastal stream water quality dynamics. It is yet to be known whether the myriad interactions of major stream water quality drivers can be combined to achieve emergent similitude (parametric reductions) and scale-invariant patterns — leading to robust modeling and predictions of coastal stream water quality under a changing environment (Miragliotta, 2011).

A key component to assess the stream water quality and health of aquatic ecosystem is dissolved oxygen (DO) (Markfort and Hondzo, 2009). Aquatic lives are forced to alter their breathing patterns or lower their metabolism in reduced concentration of DO (Cox, 2003). Stream DO is controlled by multitude of land use, hydro-climatic, and biogeochemical drivers. Common sources of stream DO are reaeration and photosynthesis (O'Connor and Hondzo, 2008,

Dick et al., 2016), while the common sinks are respiration and degradation of organic matter (Cai et al., 2011; Xu and $\mathrm{Xu}, 2016)$. Temperature have substantial control on stream DO since many 
biogeochemical and physical processes in water are controlled by temperature (Murdoch et al., 2000). High nutrient (e.g., nitrogen, phosphorus) enrichment in stream can cause eutrophication that also leads to reduced stream DO (Diaz and Rosenberg, 2008). Further, oxygen solubility in water can also be affected by salinity and atmospheric pressure (Chapra, 1997).

Quantification of the relative linkages of stream water quality with its drivers is crucial to develop profound knowledge on major stream water quality processes. However, the assessment of stream water quality often involves a multitude of land use, hydro-climatic, and biogeochemical drivers resulting in multicollinear datasets (high mutual correlations). Therefore, traditional least square regression methods may produce biased results for the highly multicollinear datasets prevalent in water quality analysis. Although multicollinearity may be reduced by eliminating the predictors based on statistical significance, this elimination method may remove variables having significant mechanistic basis. Therefore, it may jeopardize the result of relative linkages of the relevant predictors with their response variables (Ishtiaq and Abdul-Aziz, 2015). Partial least squares regression (PLSR) can overcome this pitfall, since it is performed in the transformed orthogonal planes using the independent PLS components that resolves multicollinearity. PLSR has been successfully employed to study contaminants in road runoff (Mahbub et al., 2011), and watershed sediment yield and stream flow (Yan et al., 2013). The advantage of PLSR to resolve multicollinearity motivates its application to reliably quantify the relative linkages of stream water quality with its drivers from complex set of multicollinear datasets.

Similitude and dimensional analysis have widely been used in many engineering disciplines to achieve insights into the underlying processes and formulate scale-invariant models (Miragliotta, 2011; Hondzo et al., 2013). In the field of classical fluid mechanics and 
hydraulic engineering, similitude has been described as the parametric reduction of physical problems by developing dimensionless numbers, and a dimensionless formulation of the physical system (Kundu and Cohen, 2004). Similitude can be achieved through (i) dimensional analysis using Buckingham pi-theorem, and (ii) normalizing (i.e., scaling) the underlying governing equations by appropriate characteristic parameters. The relationships among the dimensionless numbers enrich the knowledge of the studied phenomenon since each dimensionless number represents the combined interactive control of different environmental processes - leading to emergent patterns and scaling of stream water quality dynamics.

The knowledge gaps in major spatiotemporal controls and scaling of coastal stream water quality under diverse environments motivate further research in this area. This dissertation focuses to investigate the major spatiotemporal controls of coastal stream water quality, and leverages the knowledge to investigate stream biogeochemical-ecological similitude (parametric reduction) and scaling across the East Coast of U.S.A. The research would guide the development of effective management strategies for achieving healthy coastal stream ecosystems.

\subsection{Research goal, hypotheses, and objectives}

The goal of the dissertation is to identify the dominant spatiotemporal controls and scaling of stream water quality in the coastal environments. The central research hypothesis is that biogeochemical-ecological processes of coastal stream water quality follow emergent similitude and scale-invariant patterns (scaling laws) across the East Coast of U.S.A. Specifically, the research quantifies the relative linkages of coastal stream water quality with its drivers, and employs similitude and dimensional analysis to investigate emergent patterns that can lead to 
robust modeling of stream water quality across the East Coast of U.S.A. The research will generate new knowledge, processes understanding, and robust models of stream water quality, which will guide the management of stream ecosystems under diverse coastal environments.

The dissertation is designed to evaluate three research hypotheses and three supporting objectives:

Hypothesis 1: The complex interactions of coastal stream water quality processes are mainly controlled by a small set of dominant environmental drivers across the East Coast of U.S.A.

Hypothesis 2: Coastal stream water quality processes follow emergent similitude and scaling relationships across the East Coast of U.S.A.

Hypothesis 3: The emergent similitude and scaling relationships can lead to spatiotemporally robust predictions of coastal stream water quality across the East Coast of U.S.A.

The research hypotheses are tested based on the following objectives:

1. To identify the major environmental drivers of coastal stream water quality by quantifying its relative linkages with the land-use, hydro-climatic, and biogeochemical drivers across the East Coast of U.S.A.

2. To investigate the similitude and scaling of coastal stream water quality indicators with the dominant drivers by conducting similitude and dimensional analysis.

3. To leverage the knowledge of the dominant drivers, similitude, and scaling in the development of a generalized (i.e., robust) model for coastal stream water quality. 


\subsection{Organization of the dissertation}

The dissertation is organized into 8 chapters. Chapter 1 provides an overview of the dissertation, and describes background, motivation, research goal, hypotheses, and the supporting objectives.

Chapter 2 tests the first hypothesis through objective 1 by considering southeast Florida as a prototype of growing coastal-urban environments. It aims to determine the relative linkages of land uses and hydrologic drivers with important stream water quality indicators (total nitrogen, total phosphorus, chlorophyll a, dissolved oxygen) in the coastal-urban watersheds. The complex interactions and the linkage patterns were investigated by employing a systematic utilization of multivariate data analytics technique. The relative linkages were reliably estimated resolving multicollinearity by employing power law-based PLSR models. The chapter is published with the title, "Relative linkages of stream water quality and environmental health with the land use and hydrologic drivers in the coastal-urban watersheds of southeast Florida" in GeoHealth, 1, 180-195, 2017.

Chapter 3 evaluates the contrasting hydrologic and land use controls of coastal-urban stream water quality by formulating similitude and dimensionless numbers considering southeast Florida as a study area. The chapter tests the hypothesis that coastal stream water quality processes follow distinct biogeochemical-ecological similitude. The knowledge of the dominant drivers from chapter 2 is leveraged in dimensional analysis to formulate mechanistically meaningful dimensionless numbers. The most important dimensionless numbers are then identified using the data analytics framework. The identified important dimensionless numbers are leveraged to investigate the contrasting controls of the environmental drivers on coastal stream water quality. 
Chapter 4 further tests the first hypothesis through objective 1 by investigating the dominant spatiotemporal controls of stream DO — expanding the study area to a large spatial scale across the East Coast of U.S.A. The dominant spatiotemporal controls were investigated by incorporating various land use, hydro-climatic, and biogeochemical drivers. The intricate interrelationships among the drivers and their relative controls on stream DO were identified by appropriately resolving the multicollinearity in the dataset leveraging the multivariate data analytics framework.

Chapter 5 investigates the interactive controls of land use, hydro-climatic, and biogeochemical drivers of stream DO across the East Coast of U.S.A. by employing similitude and dimensional analysis. The knowledge of the dominant drivers from chapter 4 is leveraged to formulate dimensionless numbers to further test the hypothesis that stream water quality follows distinct biogeochemical-ecological similitude. The dominant dimensionless numbers to control stream water quality were identified by employing the data analytics framework. The identified dominant dimensionless numbers represented the interactive and collective controls from various land use, hydro-climatic, and biogeochemical drivers to develop the process-based understanding of coastal stream water quality dynamics in diverse environments.

Chapter 6 investigates the dynamic controls of coastal stream DO in diverse hydroclimatic and biogeochemical environments across the East Coast of U.S.A to test the first hypothesis by objective 1 . The study area included a climatic gradient (temperate to tropical) with large geographical range encompassing eight different U.S. states. The relative controls of the environmental drivers on stream DO were quantified for each stream site separately using the data analytics framework. The quantified relative controls were then compared among the stream 
water quality sites to investigate the effect of diverse environments on the dominant stream water quality processes.

Chapter 7 tests the second and third hypotheses through objective 2 and 3. It leverages the knowledge of the dominant stream water quality processes from previous chapters to investigate the biogeochemical-ecological similitude and emergent patterns across the East Coast of U.S.A. The important stream water quality drivers are incorporated in the dimensional analysis to formulate dimensionless numbers. The dimensionless numbers are employed to investigate potential similitude and emergent patterns through graphical exploration. The knowledge of the similitude and emergent patterns is leveraged to develop scaling relationship and robust model of coastal stream water quality under diverse environments across the East Coast of U.S.A.

Chapter 8 summarizes the overall findings of the dissertation research, and discusses the applications of the research findings for effective management of coastal stream water quality to achieve healthy aquatic ecosystems. The chapter also gives recommendations for further research to improve knowledge on dynamics, controls, and predictions of coastal stream water quality. 


\title{
Chapter 2: Relative linkages of stream water quality and environmental health with the land use and hydrologic drivers in the coastal-urban watersheds of southeast Florida
}

\begin{abstract}
A systematic data analytics was employed to determine the relative linkages of stream water quality and environmental health with the land use and hydrologic drivers in the coastal-urban watersheds of southeast Florida. Power-law based partial least squares regression (PLSR) models were developed to reliably estimate the linkages by appropriately resolving multicollinearity (Nash-Sutcliffe Efficiency, NSE $=0.72-0.95)$. The analytics indicated Everglades as the external and the largest source of total nitrogen $(\mathrm{TN})$ in the coastal-urban streams for both wet (JuneOctober) and dry (November-May) seasons. The 'external driver' exhibited 1.5-2 times stronger control on stream TN than that of the watershed 'land use', 'hydrology', and the 'upstream reach' contributions. In contrast, Everglades appeared to be a minor source of in-stream total phosphorus (TP), which was predominantly controlled by the internal watershed processes. TP was most strongly linked with the upstream reach concentrations and watershed land uses in the wet and dry seasons, respectively. Despite the predominantly built-up fraction (74\%) of the study area, agricultural land was the most substantial watershed source of in-stream nutrients. The linkages of algal biomass (Chla) with the drivers indicated TP as the limiting nutrient. Stream dissolved oxygen (DO) was most strongly influenced by the adjacent groundwater depth and watershed land uses, respectively, in the wet and dry seasons. The estimated relative linkages and insights would be useful to identify the management targets and priorities to achieve healthy coastal-urban stream ecosystems in southeast Florida and around the world.
\end{abstract}




\subsection{Introduction}

Clean water is crucial to sustain the structure and functions of a healthy stream ecosystem. Anthropogenic activities, coupled with the natural processes, drive changes in stream water quality and environmental health (Simeonov et al., 2003; Álvarez-Cabria et al., 2016). Linking the in-stream water quality with the watershed land uses/cover and hydrology has, therefore, been a focus of much research (e.g., Shrestha and Kazama, 2007; Chang, 2008; Kang et al., 2010; Nagy et al., 2012; Wan et al., 2014a,b). However, the relative linkages of stream water quality with the land use and hydrologic drivers are yet to be understood well — particularly in the context of growing coastal-urban environments. The knowledge gaps motivate further research to understand and manage changes in urban stream water quality to ensure clean water for the future (NRC, 2012).

Stream water quality is generally shaped by a multitude of interacting land use/cover, hydrologic and ecological drivers. The characterization and assessment of stream water quality, therefore, often involves multicollinear data sets (high mutual correlations among the drivers), necessitating the application of multivariate statistical techniques. Wan et al. (2014b) provided a comprehensive account of studies, involving multivariate techniques to link stream water quality indicators mainly with their land use and hydrologic drivers. Specifically, the principal component analysis (PCA), factor analysis (FA), and multiple regression modeling have widely been used in empirical investigations of stream water quality. For example, Robinson et al. (2014) employed PCA to report a notable linkage of watershed agricultural and forest lands with the stream nutrients in the Swiss Plateau. Bu et al. (2014) employed FA and multiple regression to demonstrate a strong association of agricultural lands with stream physico-chemical variables (e.g., nutrients) in the Taizi River Basin, China. Using a Bayesian regression model, Wan et al. 
(2014a) reported dominant controls of urban and agricultural land uses on stream nutrients in the Tai Lake Basin, China. Kang et al. (2010) employed multiple linear regressions to demonstrate strong linkages of land uses and hydrologic variables (basin size, slope, and permeability) with the in-stream concentrations of heavy metals and bacteria counts in the Yeongsan Basin, Korea.

Many studies (see references in Carey et al., 2013) exclusively focused on the investigations of the sources and drivers of stream water quality in coastal-urban watersheds. Watershed stormwater runoff, atmospheric deposition, sewage, and effluent of wastewater treatment plants have long been recognized as the main contributors to urban stream water pollutions (Schueler, 2003; Andersen et al., 2004; Ahn et al., 2005). However, following implementations of improved sewage treatments, stormwater runoff often appears to be the primary contributor of pollutants in urban streams (Bay et al. 2003; Ahn et al., 2005). Tu (2009) used a GIS-based watershed loading model for metropolitan Boston — reporting large impacts of climate and land use changes on the watershed nitrogen loads into the receiving streams. Tran et al. (2010) demonstrated strong links of land use/cover with the stream water quality in New York. Newcomer et al. (2012) reported elevated loads of organic carbon in the metropolitan area streams of Baltimore, Maryland. Apart from the land uses, the interaction of surface water with groundwater (Menció and Mas-Pla, 2008), as well as seawater intrusion (Liu et al., 2010), are also known to affect the stream water quality in the urban-coastal watersheds.

Badruzzaman et al. (2012) provided a comprehensive review of nutrient sources in the surface waters across Florida. In a pioneering research, Caccia and Boyer (2005) reported close associations of Biscayne Bay estuary water quality indicators (e.g., nitrogen, phosphorus, dissolved oxygen, chlorophyll a) with the watershed land uses such as the urban and agricultural lands and wetlands. In a follow-up study, Caccia and Boyer (2007) estimated high loadings of 
nutrients (inorganic nitrogen and total phosphorus) into the Biscayne Bay during 1994-2002 from canals, atmospheric depositions and groundwater inputs. Zhang et al. (2009) demonstrated strong correspondences between watershed agricultural runoff and nutrients in Biscayne Bay estuary considering pre- and post-hurricane periods. Carey et al. (2011a) corroborated the previous studies by estimating high nutrient loadings from six canals into the Biscayne Bay during 1992-2006. Carey et al. (2011b) also reported notable links of watershed land uses and human disturbances with the nutrient loadings into five inland canals of Biscayne Bay Watershed during 1995-2004. Furthermore, Wan et al. (2014b) found strong linkages of stream water quality with the hydrometric variables (e.g., rainfall, flow), agricultural and wetland areas, and upstream water controls in the Indian River Lagoon Watershed, Florida.

Overall, the previous research on urban stream water quality for southeast Florida — one of the major urban population centers in the U.S. — is mostly limited to the Biscayne Bay Watershed at the south and the Indian River Lagoon Watershed at the north. Further, most studies for southeast Florida and around the world attempted to infer the linkages between the water quality indicators and their potential drivers using multivariate techniques and traditional regression modeling, which can often lead to biased results due to multicollinearity of data matrix. Although multicollinearity may be reduced by backward elimination (or forward addition) of predictors based on statistical significance, the step-wise selection can exclude mechanistically meaningful variables. Partial least squares regression (PLSR) can overcome this pitfall and resolve multicollinearity by performing the model-fitting on the transformed orthogonal planes (Ishtiaq and Abdul-Aziz, 2015). The estimated PLSR model is then transformed back to the original variable domain to compute regression weights (i.e., coefficients) of individual variables. PLSR has been successfully employed to analyze 
contaminants in road runoff (Mahbub et al., 2011), and watershed sediment yield and stream flows (Yan et al., 2013).

The paper aims to determine the relative linkages of land uses and hydrologic drivers with common stream water quality and environmental health indicators (total nitrogen, TN; total phosphorus, TP; chlorophyll a, Chla; dissolved oxygen, DO) in coastal-urban watersheds. The research is conducted by integrating four complementary layers (correlation matrix, PCA, FA, and PLSR) of data analytics into a single systematic framework to reliably estimate the linkages by resolving multicollinearity. The study expands on the previous research for southeast Florida by investigating the stream water quality of the thriving urban region between the Biscayne Bay and the Indian River Lagoon Watersheds (Figure 2.1). The region also represents a prototype of growing coastal-urban environments around the world. The research provides an objective empirical framework to achieve crucial insights and useful information for managing coastalurban stream water quality in southeast Florida and around the world.

\subsection{Materials and methods}

\subsubsection{Study area}

The study watersheds represent the coastal-urban environments of southeast Florida, encompassing the Broward County and extending partly into the Palm Beach County (Figure 2.1). The densely populated region is located between the Florida Everglades and the Atlantic Ocean. It is drained by an intricate network of more than 266 miles of natural and dredged canals

(Broward County, 2016). The study area has six major canal basins (49-269 $\mathrm{km}^{2}$ ), including the Hillsboro Canal, C-14 Canal (Cypress Creek and Pompano Canal), C-13 Canal, C-12 Canal, North New River Canal, and C-11 Canal (South New River, Dania Cut-off Canal). The six 
canals together with the secondary and tertiary canals drain approximately $914 \mathrm{~km}^{2}$ of mostly highly urbanized areas to the estuarine waters (Cooper and Lane, 1987). Most canals are connected to the Everglades water conservation areas (WCAs) at the upstream and coastal waters at the downstream; WCAs are typically used for managing water resources and wildlife in the Everglades agricultural area. Proximity to the WCAs and the coastlines influence the in-stream biogeochemistry and water quality of the study watersheds (BCEPD, 2007).

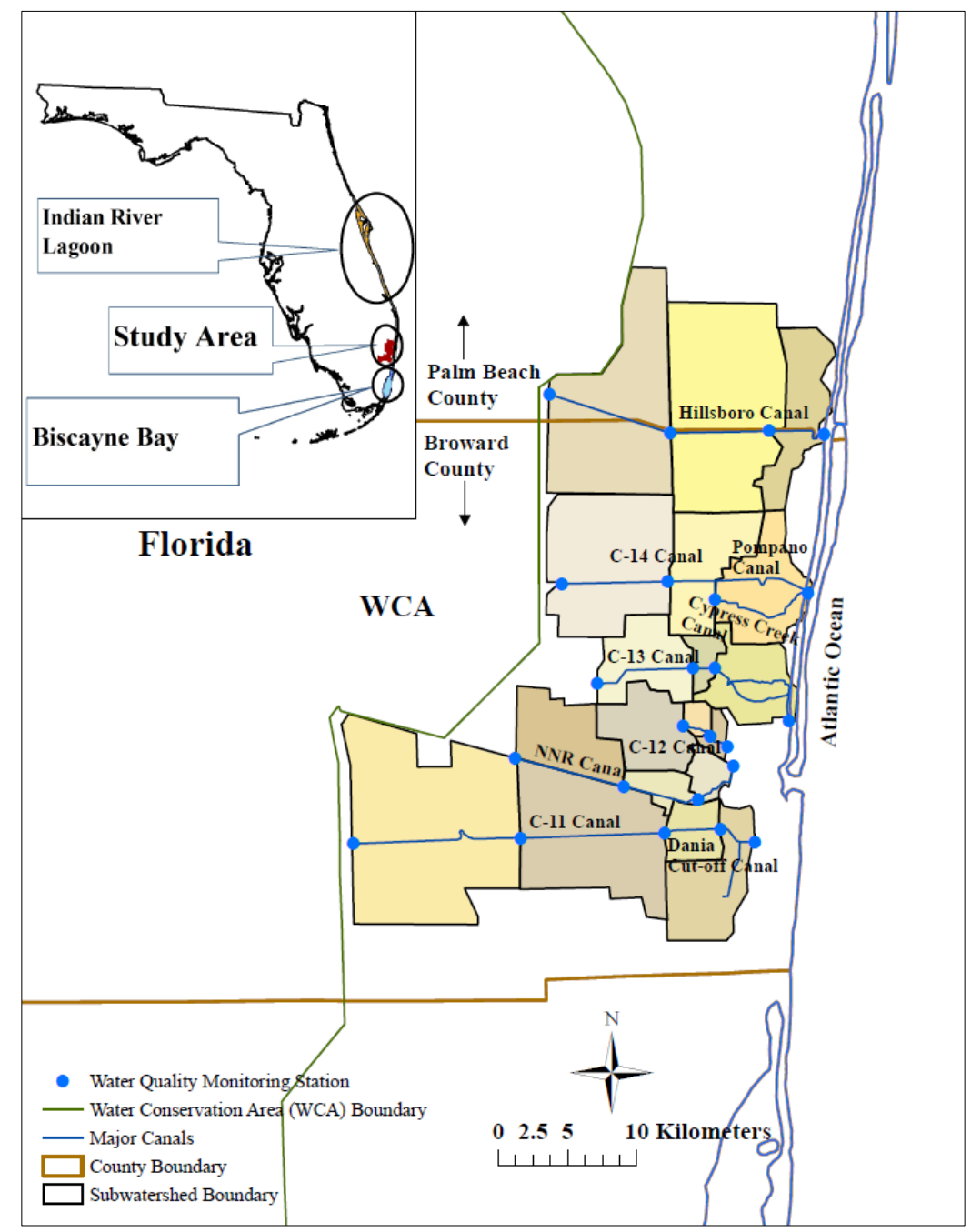

Figure 2.1. Study area, the major canals, and the location of the water quality monitoring stations. Inset showing the state of Florida is not on scale. 


\subsubsection{Data sets}

Quarterly time-series observations of in-stream TN, TP, Chla, and DO during 2009-13 were gathered for 24 monitoring stations across the study area (Figure 2.1) from the Broward County Environmental Planning and Community Resilience Division (BCEPCRD, 2015). Drainage areas (subwatersheds) for 18 monitoring sites (excluding 6 most upstream sites) were generated using ESRI ArcGIS 10.2 based on the waterbody identification number (WBID) of the Florida Department of Environmental Protection (FDEP, 2016), contribution area map provided by Broward County (Robert Bernhard, personal communications, 2012), and 10m DEM (USGS, 2015a). TN represented the summation of total Kjeldahl nitrogen (TKN), nitrate-nitrogen $\left(\mathrm{NO}_{3}\right.$ $\mathrm{N})$, and nitrite-nitrogen $\left(\mathrm{NO}_{2}-\mathrm{N}\right)$. TP was the aggregation of soluble reactive phosphates, condensed phosphates, and organic phosphates. The four variables are commonly used as the primary indicators of stream water quality (Chapra, 1997; Chang, 2008). Chla and DO further indicate the health of a stream ecosystem—representing the combined effects of different pollution sources and drivers (Boyer et al., 2009). Further details on the water quality data, including QA/QC, are given in the Appendix 2.

The hydroclimatic influence on stream water quality was incorporated by conducting separate, comparative analyses for wet (June-October, representing $70 \%$ of the annual rainfall) and dry (November-May) seasons (SFWMD, 2015a). The spatial dataset for each season was obtained by averaging observations of the respective water quality indicators over the 5-year period (2009-13). Subwatershed area (A), mean slope (S), and mean imperviousness (I) were used to represent the corresponding surface runoff. Percent imperviousness for each subwatershed was calculated from the 30m data of National Land Cover Database 2011 (NLCD, 2015). Ambient groundwater depth from the land surface (GWD; which increases with the 
lowering of groundwater table) was used to represent the control of groundwater hydrology on stream water quality. Average GWD for both wet and dry seasons over the 5 years were estimated for each quality station from the groundwater level data of USGS (2015b) (see Figure A2.1 and Appendix 2 for details). The canal centerline distance of individual water quality station from the coastal outlet $\left(D_{c}\right)$ was used to represent the influence of both downstream coastal hydrology and upstream Everglades (except for C-12) on the in-stream water quality. The spatial data for A, S, I, $\mathrm{D}_{\mathrm{c}}$, and GWD were processed on the ArcGIS 10.2 platform.

The fractions of different land use areas over the subwatershed areas were estimated from the land use and land cover (LULC) data of the South Florida Water Management District (SFWMD) (SFWMD, 2015b). Following guidelines of SFWMD (2011), different land use types were aggregated into five broad categories as follows: (1) vegetated land (VEG), including upland forests, wetland forests, and vegetated non-forested wetlands; (2) agricultural land (AGR), including lands for agriculture and grazing; (3) waterbody (WAT), including streams, waterways, lakes, and reservoirs; (4) built-up land (BUL), including residential, commercial, industrial, and transportation areas; and (5) open land (OPN), including barren and recreational lands. Further details into the land use categories are given in the Appendix 2.

For each water quality indicator, the final data set incorporated concentrations at the inlets and outlets ( $\mathrm{C}_{\mathrm{IN}}$ and $\mathrm{C}_{\mathrm{OUT}}$, respectively) of 18 stream reaches/subwatersheds, five land use fractions (VEG, AGR, WAT, BUL, OPN) for individual subwatersheds, as well as the corresponding hydrologic variables $(A, S, I, G W D)$ and distance from coast $\left(\mathrm{D}_{\mathrm{c}}\right)$. Observation at the immediate upstream monitoring station $\left(\mathrm{C}_{\mathrm{IN}}\right)$ was used to represent the upstream-reach contribution to the water quality of a corresponding downstream station (Cout). The sample size (N) of the spatial dataset for each water quality indicator (CouT) was 18 . The data summary 
across the study area (Table 2.1) and individual canal basins (Table A2.1 in Appendix 2) indicated wide ranges and considerable gradients in water quality indicators and the land use/hydrologic drivers.

Table 2.1. Summary of the stream water quality/environmental health indicators, and their land use/hydrologic drivers.

\begin{tabular}{|c|c|c|c|c|c|c|c|c|}
\hline Variables & Mean & $\begin{array}{l}\text { Standard } \\
\text { deviation }\end{array}$ & $\begin{array}{l}\text { Coefficient } \\
\text { of variation }\end{array}$ & Minimum & $\begin{array}{c}25 \text { th } \\
\text { percentile }\end{array}$ & $\begin{array}{c}50 \text { th } \\
\text { percentile }\end{array}$ & $\begin{array}{c}\text { 75th } \\
\text { percentile }\end{array}$ & Maximum \\
\hline $\mathrm{A}\left(\mathrm{km}^{2}\right)$ & 47.49 & 43.08 & 0.91 & 4.47 & 9.91 & 36.06 & 86.31 & 150.66 \\
\hline S (\%) & 2.17 & 0.35 & 0.16 & 1.64 & 1.88 & 2.21 & 2.43 & 2.91 \\
\hline I (\%) & 37.15 & 10.16 & 0.27 & 19.00 & 28.63 & 36.33 & 45.55 & 52.67 \\
\hline $\mathrm{Dc}(\mathrm{km})$ & 9.04 & 5.18 & 0.57 & 1.40 & 5.47 & 8.67 & 12.62 & 21.01 \\
\hline BUL (\%) & 74.3 & 14.5 & 0.20 & 39.3 & 64.9 & 79.8 & 85.6 & 92.2 \\
\hline OPN (\%) & 11.2 & 8.1 & 0.73 & 2.0 & 4.6 & 9.5 & 16.1 & 30.1 \\
\hline $\operatorname{AGR}(\%)$ & 2.53 & 3.47 & 1.37 & 0.02 & 0.25 & 1.32 & 3.61 & 13.51 \\
\hline $\operatorname{VEG}(\%)$ & 3.76 & 4.10 & 1.09 & 0.10 & 0.72 & 2.51 & 5.37 & 12.72 \\
\hline WAT $(\%)$ & 8.25 & 4.68 & 0.57 & 3.48 & 5.07 & 7.72 & 9.74 & 23.42 \\
\hline \multicolumn{9}{|c|}{ Wet Season (June-October) } \\
\hline $\mathrm{TN}(\mathrm{mg} / \mathrm{L})$ & 1.24 & 0.32 & 0.26 & 0.61 & 0.95 & 1.31 & 1.45 & 1.77 \\
\hline $\mathrm{TP}(\mathrm{mg} / \mathrm{L})$ & 0.05 & 0.03 & 0.62 & 0.02 & 0.02 & 0.04 & 0.05 & 0.11 \\
\hline Chla $(\mu \mathrm{g} / \mathrm{L})$ & 7.81 & 4.64 & 0.59 & 1.84 & 5.12 & 6.49 & 8.86 & 23.13 \\
\hline $\mathrm{DO}(\mathrm{mg} / \mathrm{L})$ & 4.10 & 0.94 & 0.23 & 1.61 & 3.36 & 4.43 & 4.76 & 5.67 \\
\hline GWD (m) & 1.84 & 0.69 & 0.37 & 0.79 & 1.39 & 1.56 & 2.45 & 3.11 \\
\hline \multicolumn{9}{|c|}{ Dry Season (November-May) } \\
\hline $\mathrm{TN}(\mathrm{mg} / \mathrm{L})$ & 1.13 & 0.37 & 0.32 & 0.51 & 0.78 & 1.23 & 1.46 & 1.63 \\
\hline $\mathrm{TP}(\mathrm{mg} / \mathrm{L})$ & 0.04 & 0.03 & 0.60 & 0.02 & 0.02 & 0.04 & 0.05 & 0.11 \\
\hline Chla $(\mu \mathrm{g} / \mathrm{L})$ & 5.93 & 5.37 & 0.91 & 1.62 & 2.79 & 4.05 & 6.23 & 22.66 \\
\hline $\mathrm{DO}(\mathrm{mg} / \mathrm{L})$ & 5.97 & 1.06 & 0.18 & 3.34 & 5.75 & 6.13 & 6.44 & 8.67 \\
\hline GWD (m) & 2.00 & 0.72 & 0.36 & 0.77 & 1.56 & 1.71 & 2.52 & 3.42 \\
\hline
\end{tabular}

Notes: A, S, I, D , BUL, OPN, AGR, VEG, WAT, and GWD, respectively, refer to subwatershed area, slope, imperviousness, distance from coast, built-up land, open land, agricultural land, vegetated land, waterbody, and groundwater depth. 


\subsubsection{The data analytics framework}

The research employed a systematic data analytics framework (Figure 2.2), which involves a sequential application of four complementary data-mining techniques - Pearson correlation matrix, PCA, FA, and partial least squares regression (PLSR) (Ishtiaq and Abdul-Aziz, 2015). The 4-step analytics was designed to corroborate findings from different steps and synthesize information toward the overall outcomes. The analytics methods were well-suited for our datasets given their reputation of providing reliable results across small to large samples (Wold et al., 2001; de Winter et al., 2009). Based on a preliminary analysis, data for all response and predictor variables were first logarithmically $\left(\log _{10}\right)$ transformed to incorporate the non-linear interactions. The log-transformed variables were then standardized to bring different scales and units to a comparable reference scale (dimensionless Z-scores) as follows: $Z=(X-\bar{X}) / s_{X}$, where $X=\log _{10}$-transformed variable, $\bar{X}=$ mean of $X$, and $s_{X}=$ standard deviation of $X$. Each layer of the data analytics was performed with the Z-scores using MATLAB.

The correlation matrix was computed to explore the multicollinear structure of the datasets, and achieve first-order information (albeit impacted by multicollinearity) on the correspondences among the water quality, hydrologic, and land use variables. PCA and FA were employed to resolve multicollinearity by using projections on the orthogonal (i.e., independent) planes. Although the approaches of PCA and FA are distinctively different (Jolliffe, 2002), they in concert provide a relatively unbiased and confirmatory representation of the interrelationship and grouping patterns among the participatory variables. PCA derives orthogonal entities called principal components (PCs), which are weighted combinations of all original variables (Jolliffe, 2002; Peres-Neto et al., 2003). FA inherently reduces the dimensions of a multivariate data set by decomposing the participatory variables into fewer unobservable (latent) entities called 
factors (Jolliffe, 2002; Johnson and Wichern, 2007). FA is typically done using a "varimax"

orthogonal rotation, which redistributes the variance of each variable to maximize the total datasystem variance explained, and thereby optimizes the loadings (correlation weights) of individual variables on each factor. An eigenvalue criterion (e.g., eigenvalue >=1.0) is applied to represent the most variance of a data matrix with a minimum number of extracted factors.

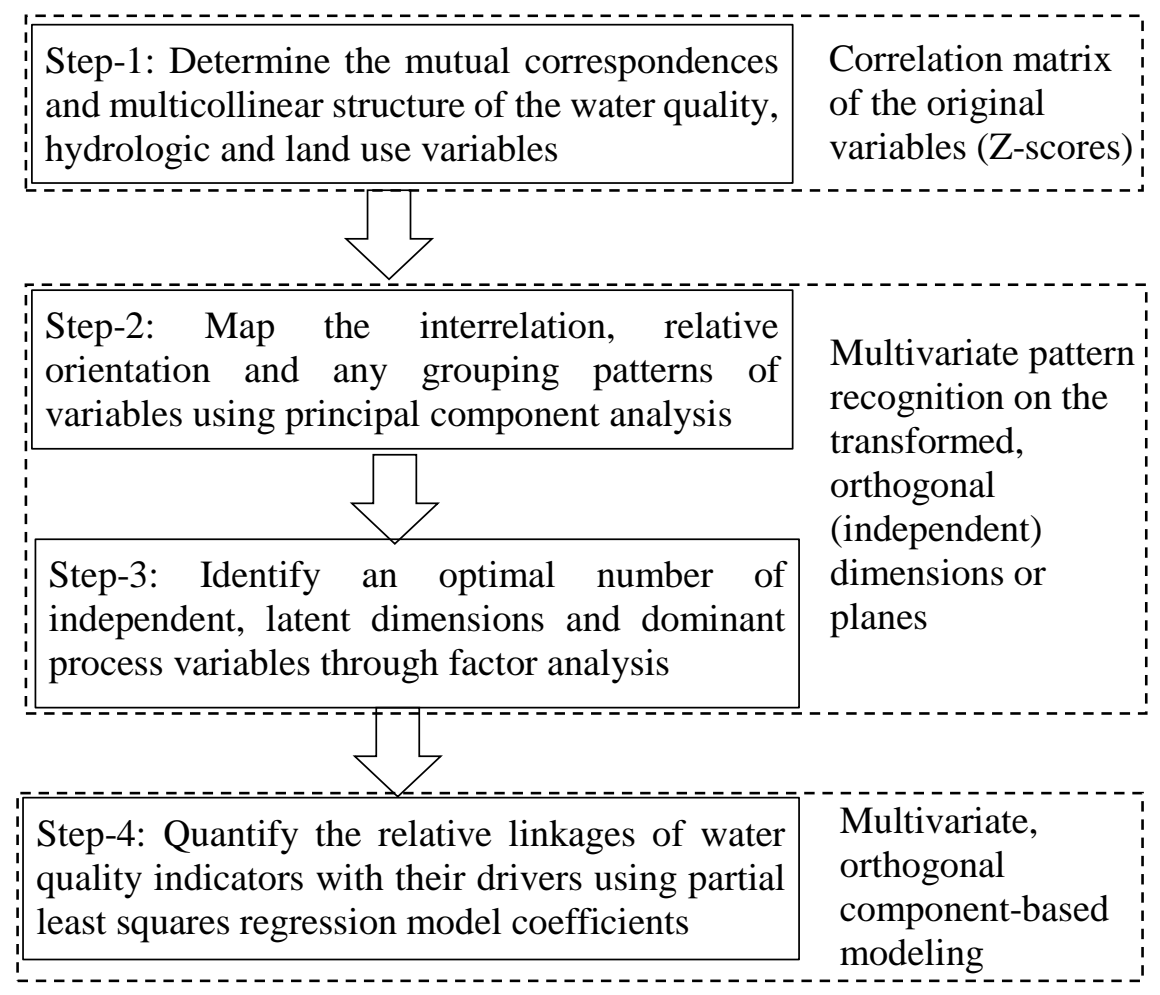

Figure 2.2. The data analytics framework to determine the relative linkages of stream water quality and environmental health indicators with their drivers.

The PLSR modeling combines features from PCA and multiple regressions (Wold et al., 2001). However, for a conventional principal component regression, the PCs of predictors are first derived, and then fitted with the response. In contrast, PLSR computes the orthogonal partial least squares (PLS) components of predictors and fits them with the response through a simultaneous decomposition of all variables (Schumann et al., 2013). We developed PLSR 
model for each water quality indicator by incorporating the outlet concentrations of a stream reach (or subwatershed) as the response variable, and the corresponding inlet concentrations, land use, and hydrologic drivers as the predictors. The PLSR models were reliably estimated with observed data using SIMPLS algorithm (de Jong, 1993; Hubert and Branden, 2003) and a 10-fold cross validation (Kuhn and Johnson, 2013). The optimality (parsimony) of the models was achieved by involving a minimum number of PLS components, which was determined based on a synthesis of the minimum Akaike Information Criterion (AIC) (Akaike, 1974) and the maximum Nash-Sutcliffe Efficiency (NSE) (see Appendix 2).

The final (optimal) model's goodness-of-fit was measured by NSE, and the accuracy of predictions was evaluated by the ratio of root-mean-square error to the standard deviation of observations (RSR). Since the fitting of the optimal PLSR models was performed using the minimum number of independent PLS components, the model bias and instability arising from multicollinearity among the predictors had been optimally resolved (Kuhn and Johnson, 2013). The estimated PLSR models were then transformed back to the original (Z-scores) variable domain to compute the relative linkages (i.e., regression weights, $\beta$ ) of each water quality variable with the land use and hydrologic predictors. The positive or negative sign of $\beta$ indicated the direction of relationship (i.e., increasing or decreasing) between a predictor and a water quality indicator. However, the directions of relationships are mechanistically more meaningful for important predictors than that of the weak predictors. The aggregated linkages of the 'land use' $\left(\beta_{\mathrm{LU}}\right)$, 'hydrology' $\left(\beta_{\mathrm{H}}\right)$, 'upstream reach' $\left(\beta_{\mathrm{CIN}}\right)$, and the 'external driver' (i.e., upstream Everglades and/or downstream coastal; $\left.\beta_{\mathrm{Dc}}\right)$ components were calculated using the method of vector summations as follows: 


$$
\begin{aligned}
& \beta_{L U}=\sqrt{\beta_{B U L}^{2}+\beta_{O P N}^{2}+\beta_{A G R}^{2}+\beta_{V E G}^{2}+\beta_{W A T}^{2}} \\
& \beta_{H}=\sqrt{\beta_{A}^{2}+\beta_{S}^{2}+\beta_{I}^{2}+\beta_{G W D}^{2}} \\
& \beta_{C_{I N}}=\sqrt{\beta_{C_{I N}}^{2}} \\
& \beta_{D c}=\sqrt{\beta_{D c}^{2}}
\end{aligned}
$$

\subsection{Results}

\subsubsection{Mutual correspondences of the water quality, hydrologic, and land use variables}

The non-linear correspondences of stream water quality variables ( $\log _{10}$-transformed and standardized) with the land use and hydrologic drivers were first computed with the correlation coefficients (Table 2.2). In both wet and dry seasons, $\mathrm{TN}$ had a strong correspondence with the distance from coast ( $r=0.77$ to 0.84$)$ and watershed imperviousness ( $r=-0.68$ to -0.73 ), whereas a moderate correlation with the built-up land $(\mathrm{r}=-0.56)$, open land $(\mathrm{r}=0.50$ to 0.57$)$, and upstream reach concentrations $\left(\mathrm{C}_{\mathbb{I N}} ; \mathrm{r}=0.58\right.$ to 0.65$)$. A moderate correspondence $(r=0.57)$ was also noted between TN and waterbody area in the wet season only. In contrast, TP had a strong correlation with the upstream concentrations $(\mathrm{r}=0.64$ to 0.76$)$ and a moderate correlation with agricultural land $(r=0.50$ to 0.51$)$ in both seasons. Further, TP had a moderate correlation with open land $(r=-0.57)$ in the dry season. Similar to TP, Chla represented a moderate correlation ( $r$ $=0.45$ to 0.58 ) with the upstream concentrations and agricultural land in the wet season. In dry season, a moderate correlation of Chla was noted with the inlet concentrations $(r=0.45)$, open land (-0.51), and subwatershed area (-0.58). In both seasons, DO had a moderate correlation with imperviousness ( $r=0.53$ to 0.60$)$, built-up land $(r=0.61$ to 0.65$)$, and agricultural land $(r=-0.47$ to -0.67). DO further represented a moderate/strong correlation with vegetated land $(\mathrm{r}=-0.69)$ in 
the dry season, while a moderate correlation with the distance from coast $(r=-0.59)$,

groundwater depth $(r=0.59)$, and upstream concentrations $(r=0.58)$ in the wet season.

Table 2.2. Pearson correlation coefficients (r) between stream water quality/environmental health indicators and their drivers.

\begin{tabular}{lrrrrrrrr}
\hline Drivers & \multicolumn{2}{c}{ TN } & \multicolumn{2}{c}{ TP } & \multicolumn{2}{c}{ Chla } & \multicolumn{2}{c}{ DO } \\
& Wet & Dry & Wet & Dry & Wet & Dry & Wet & Dry \\
A & 0.27 & 0.37 & -0.12 & -0.43 & -0.22 & $-\mathbf{0 . 5 8}$ & -0.15 & -0.40 \\
S & 0.37 & 0.32 & -0.31 & -0.33 & -0.09 & -0.09 & -0.15 & 0.23 \\
I & $\mathbf{- 0 . 6 8}$ & $\mathbf{- 0 . 7 3}$ & 0.15 & 0.32 & -0.11 & 0.18 & $\mathbf{0 . 6 0}$ & $\mathbf{0 . 5 3}$ \\
D $_{\text {c }}$ & $\mathbf{0 . 7 7}$ & $\mathbf{0 . 8 4}$ & -0.40 & -0.39 & 0.22 & 0.12 & $\mathbf{- 0 . 5 9}$ & -0.06 \\
BUL & $\mathbf{- 0 . 5 6}$ & $\mathbf{- 0 . 5 6}$ & 0.12 & 0.25 & -0.09 & 0.21 & $\mathbf{0 . 6 5}$ & $\mathbf{0 . 6 1}$ \\
OPN & $\mathbf{0 . 5 0}$ & $\mathbf{0 . 5 7}$ & -0.34 & $\mathbf{- 0 . 5 7}$ & -0.27 & $\mathbf{- 0 . 5 1}$ & -0.41 & -0.24 \\
AGR & 0.17 & 0.11 & $\mathbf{0 . 5 0}$ & $\mathbf{0 . 5 1}$ & $\mathbf{0 . 4 7}$ & 0.36 & $\mathbf{- 0 . 4 7}$ & $\mathbf{- 0 . 6 7}$ \\
VEG & 0.22 & 0.09 & 0.22 & 0.05 & 0.15 & -0.08 & -0.16 & $\mathbf{- 0 . 6 9}$ \\
WAT & $\mathbf{0 . 5 7}$ & 0.40 & -0.32 & -0.30 & 0.00 & -0.10 & -0.24 & -0.20 \\
GWD & -0.02 & -0.04 & -0.11 & -0.17 & 0.01 & -0.10 & $\mathbf{0 . 5 9}$ & 0.37 \\
C IN & $\mathbf{0 . 5 8}$ & $\mathbf{0 . 6 5}$ & $\mathbf{0 . 7 6}$ & $\mathbf{0 . 6 4}$ & $\mathbf{0 . 5 8}$ & 0.45 & $\mathbf{0 . 5 8}$ & 0.21 \\
\hline
\end{tabular}

Notes: (1) Data for all variables were $\log _{10}$-transformed to incorporate any non-linear correspondences. (2) Bold indicates significant correlations at the 95\% confidence level (p-values <0.05). (3) A, S, I, $\mathrm{D}_{c}$, BUL, OPN, AGR, VEG, WAT, GWD, and $\mathrm{C}_{\mathrm{IN}}$, respectively, refer to subwatershed area, slope, imperviousness, distance from coast, built-up land, open land, agricultural land, vegetated land, waterbody, groundwater depth, and inlet concentrations.

The correlation matrices (Table A2.2 and A2.3 in Appendix 2) demonstrated high mutual correspondences among the water quality and their driving variables, indicating the presence of a strong multicollinearity in the data matrices for the two seasons. For example, the distance from coast had moderate to strong correlations with the open land $(\mathrm{r}=0.53)$, waterbody area $(\mathrm{r}=$ $0.61)$, built-up land $(\mathrm{r}=-0.63)$, and imperviousness $(\mathrm{r}=-0.73)$. The negative correspondences indicate that the built-up land fraction and imperviousness increase with higher urbanization toward the coastline. In contrast, the open land and waterbody area fractions increase away from the coastline toward the Everglades. The findings were corroborated by scatter-plotting the area fractions and imperviousness with the distance from coast (not shown). Further, the substantially 
stronger correlation of Chla with TP than that with TN indicate that TP is the limiting nutrient in the coastal-urban streams of southeast Florida.

\subsubsection{Relative orientations and groupings of the water quality and driving variables}

The non-linear loadings of different water quality indicators and the driving variables on the first two PCs are presented through biplots for both wet (Figure 2.3) and dry (Figure 2.4) seasons. The percent variance explained by all individual PCs are presented in the Appendix 2 (Table A2.4). Among all water quality indicators and the two seasons, the first two PCs together explained approximately $56 \%$ to $62 \%$ of the total data variance.

The relative orientations of variables (Figures 2.3,2.4) suggested three distinct groups of drivers for all four water quality indicators across the two seasons - (1) drainage area, slope, open land, waterbody, and distance from coast; (2) agricultural and vegetated lands; and (3) built-up land and imperviousness. Based on the closeness to the outlet concentrations vector (Cout, the red line), the driver group-1 appeared to have a strong positive linkage with TN, a moderate negative linkage with TP and Chla, and a relatively weak linkage with DO. The group2 had a moderate to strong positive linkage with TP and Chla, a similar but negative linkage with DO, and a weak to moderate linkage with TN. The group-3 represented a weak linkage with TP and Chla, whereas a moderate to strong negative and positive linkages with TN and DO, respectively. The upstream reach concentrations $\left(\mathrm{C}_{\mathrm{IN}}\right)$ had a strong control on $\mathrm{C}_{\mathrm{OUT}}$ for all quality indicators except for DO in the dry season. The groundwater depth (GWD) appeared to be strongly and positively linked with DO in both seasons. GWD also had a strong negative linkage with group-2 and a moderate positive linkage with group-3 — indicating the opposite effects of increasing agriculture/vegetation and urbanization on the water table (higher vs. lower, respectively). 


\section{Wet season (June-October)}
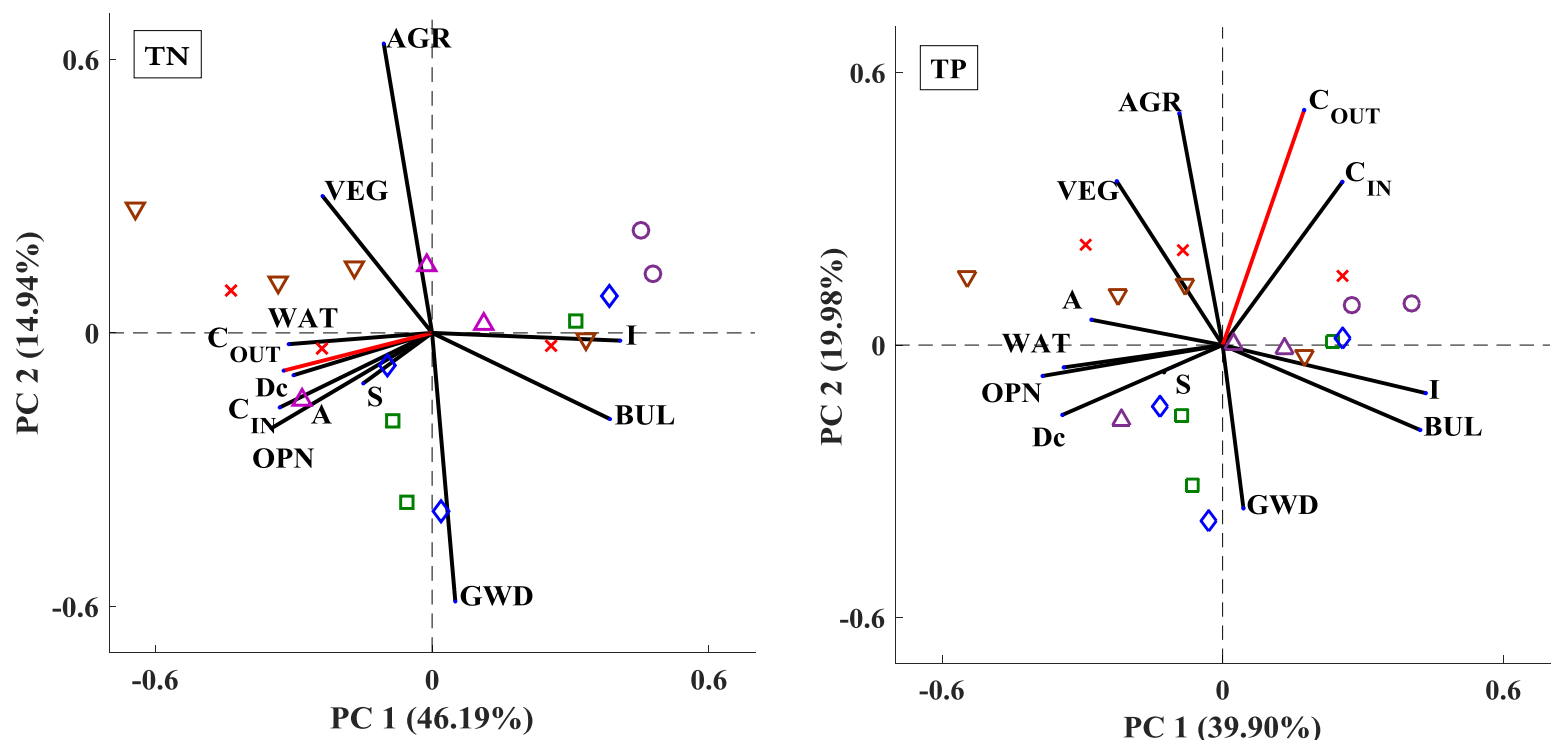

$\times$ Hillsboro Canal

ㄷ-14 Canal

$\diamond$ C-13 Canal

C-12 Canal

$\triangle$ NNR Canal

C-11 Canal
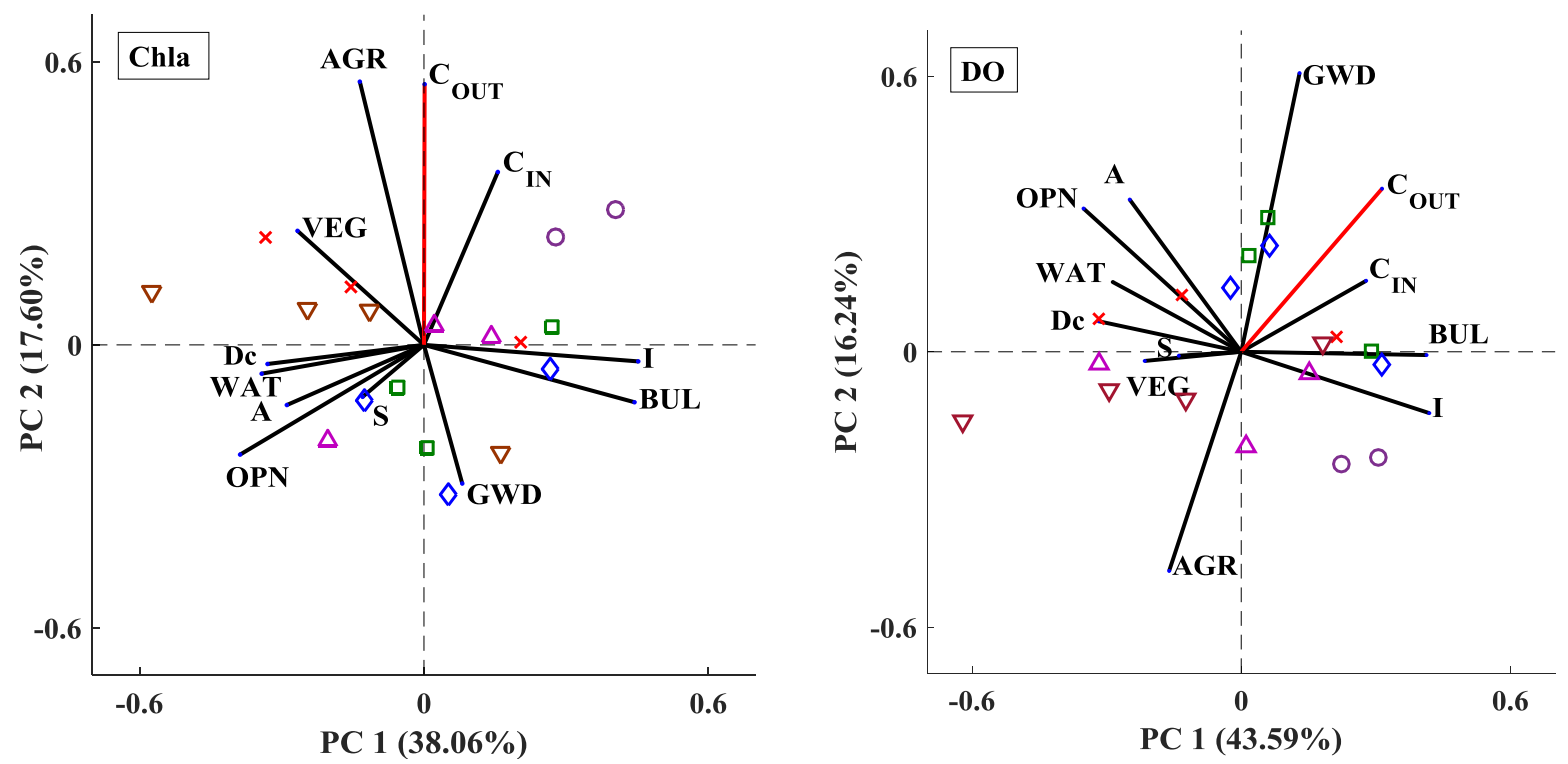

Figure 2.3. Biplots from principal component (PC) analysis, showing the relative orientations of the stream water quality/environmental health indicators and their drivers in wet season. Percent variance explained by each $\mathrm{PC}$ is shown in parenthesis. 


\section{Dry season (November-May)}
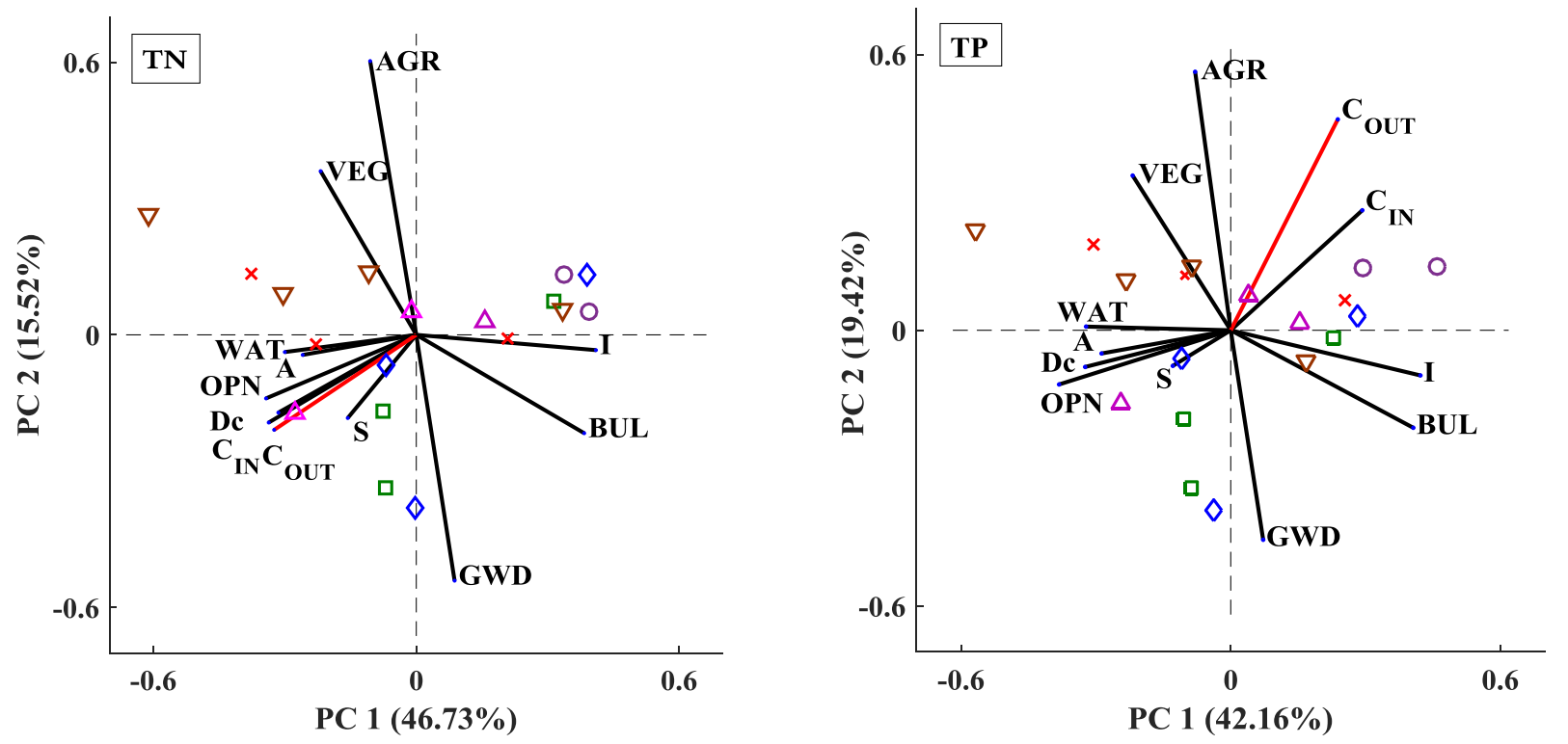

$\times$ Hillsboro Canal $\square$ C-14 Canal $\diamond$ C-13 Canal

O C-12 Canal $\Delta$ NNR Canal $\nabla$ C-11 Canal
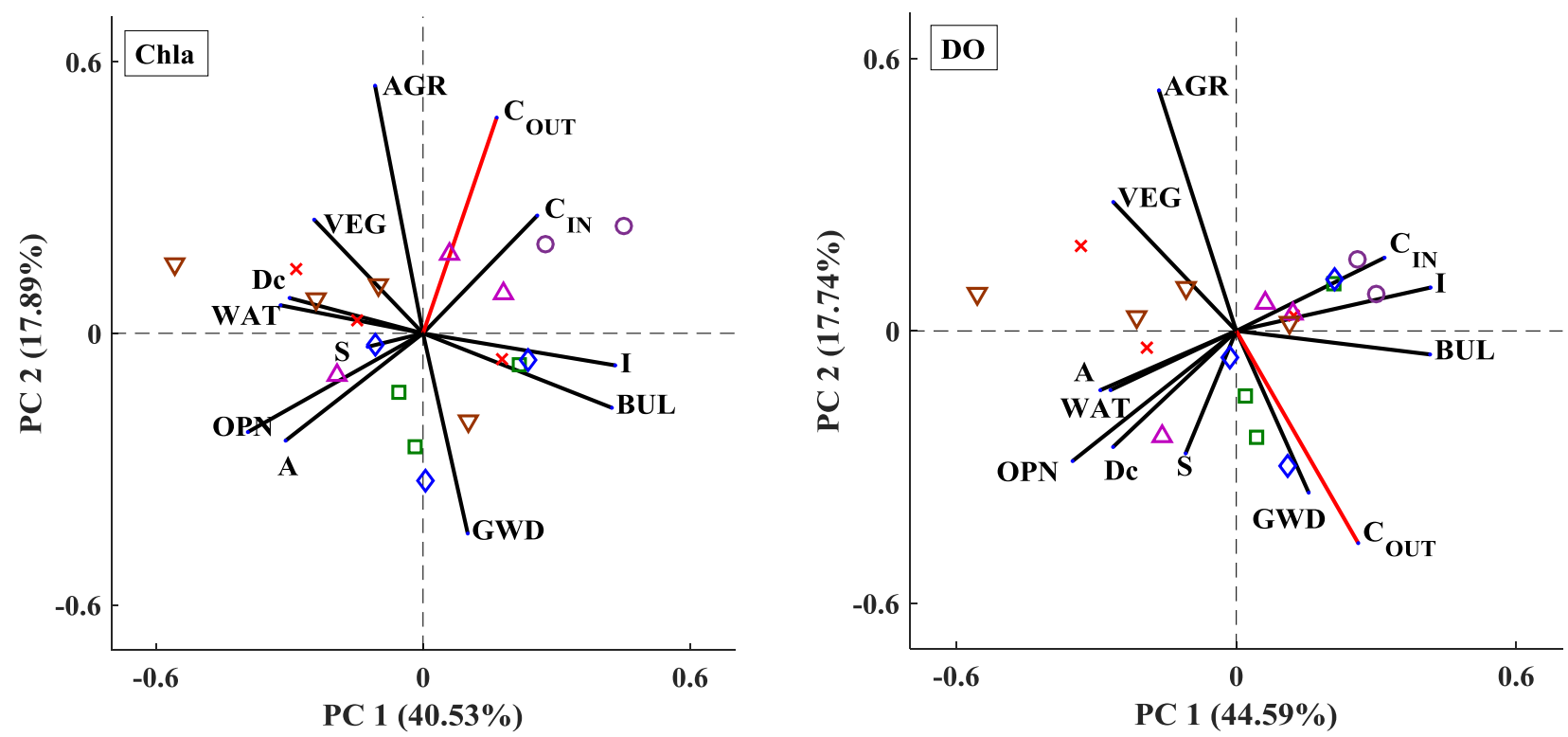

Figure 2.4. Biplots from principal component (PC) analysis, showing the relative orientations of the stream water quality/environmental health indicators and their drivers in dry season. Percent variance explained by each $\mathrm{PC}$ is shown in parenthesis. 
The PC scores on the biplots provide valuable insights into the variation of water quality across the different canal basins. For example, all sites of $\mathrm{C}-12$ are located farther away from the tip of Cout vector for TN than that of other canals (Figures 2.3,2.4) - indicating the lowest concentrations of TN in C-12 that drains an order of magnitude smaller area (Table A2.1 in Appendix 2) and is not directly connected with the Everglades. However, the congregation of most sites toward CouT of TN refer to much higher nitrogen concentrations in other canals that are connected with the Everglades. Further, relatively close proximity of the C-12 and Hillsboro Canal sites to $\mathrm{C}_{\text {OUT }}$ for TP and Chla represent their higher phosphorus and algae concentrations than other canals.

\subsubsection{Major water quality drivers based on independent latent factors}

FA resulted in 4-5 independent latent factors to optimally demonstrate the hidden patterns into water quality and the driving variables (Table 2.3). Variance explained by the first five factors ranged, respectively, from $38 \%$ to $47 \%, 15 \%$ to $20 \%, 10 \%$ to $13 \%, 9 \%$ to $11 \%$, and $7 \%$ to $9 \%$ among the two seasons and six canal basins. Higher loadings of water quality indicators and the land use/hydrologic drivers on the same factors indicate their stronger linkages. 
Table 2.3.Major latent factors with their optimized loadings on the participatory variables.

\begin{tabular}{|c|c|c|c|c|c|c|c|c|c|c|c|c|c|c|}
\hline Indicators & & $\mathrm{F}$ & A & $S$ & I & $\overline{D_{c}}$ & BUL & OPN & AGR & VEG & $\overline{\text { WAT }}$ & GWD & $\mathrm{C}_{\mathrm{IN}}$ & $\mathrm{C}_{\text {OUT }}$ \\
\hline \multirow[t]{8}{*}{$\mathrm{TN}$} & Wet & 1 & 0.005 & 0.18 & -0.63 & 0.99 & -0.55 & 0.41 & 0.06 & 0.02 & 0.58 & -0.06 & 0.24 & 0.74 \\
\hline & & 2 & 0.91 & 0.03 & -0.66 & 0.15 & -0.60 & 0.80 & 0.02 & 0.31 & 0.13 & 0.12 & 0.45 & 0.17 \\
\hline & & 3 & -0.01 & -0.17 & -0.28 & 0.00 & -0.53 & 0.01 & 0.80 & 0.56 & 0.27 & -0.53 & 0.02 & 0.01 \\
\hline & & 4 & 0.18 & 0.51 & -0.24 & 0.03 & -0.18 & 0.20 & -0.09 & 0.43 & 0.45 & 0.01 & 0.83 & 0.38 \\
\hline & Dry & 1 & 0.05 & 0.12 & $\begin{array}{l}-0.63 \\
\end{array}$ & 0.98 & -0.53 & 0.45 & 0.01 & -0.03 & 0.52 & -0.06 & 0.38 & 0.79 \\
\hline & & 2 & 0.95 & 0.05 & -0.60 & 0.08 & -0.52 & 0.74 & 0.02 & 0.33 & 0.05 & 0.01 & 0.30 & 0.29 \\
\hline & & 3 & 0.03 & -0.16 & -0.38 & 0.08 & -0.65 & 0.17 & 0.70 & 0.57 & 0.42 & -0.51 & 0.13 & -0.09 \\
\hline & & 4 & 0.14 & 0.68 & -0.27 & 0.13 & -0.15 & 0.14 & -0.10 & 0.26 & 0.43 & 0.11 & 0.86 & 0.32 \\
\hline \multirow[t]{8}{*}{$\mathrm{TP}$} & Wet & 1 & 0.66 & 0.11 & -0.98 & 0.69 & $\begin{array}{l}-0.89 \\
\end{array}$ & 0.84 & 0.18 & 0.49 & 0.58 & 0.00 & -0.32 & -0.09 \\
\hline & & 2 & -0.01 & -0.07 & 0.08 & -0.36 & 0.16 & -0.23 & 0.22 & 0.25 & -0.30 & 0.01 & 0.85 & 0.92 \\
\hline & & 3 & -0.10 & -0.06 & -0.12 & 0.02 & -0.35 & -0.12 & 0.95 & 0.22 & 0.14 & -0.59 & -0.03 & 0.30 \\
\hline & & 4 & 0.08 & 0.99 & -0.11 & 0.10 & 0.01 & 0.06 & -0.11 & 0.14 & 0.18 & -0.27 & 0.16 & -0.23 \\
\hline & Dry & 1 & 0.10 & 0.23 & -0.80 & 0.90 & $\begin{array}{c}-0.72 \\
\end{array}$ & 0.53 & 0.18 & 0.29 & 0.72 & -0.17 & -0.48 & -0.20 \\
\hline & & 2 & 0.98 & 0.11 & -0.58 & 0.02 & -0.48 & 0.66 & 0.09 & 0.38 & 0.03 & 0.01 & -0.14 & -0.26 \\
\hline & & 3 & -0.17 & -0.23 & 0.03 & -0.21 & 0.04 & -0.32 & 0.53 & 0.18 & -0.18 & -0.16 & 0.56 & 0.93 \\
\hline & & 4 & -0.02 & 0.28 & 0.14 & 0.08 & 0.49 & -0.08 & -0.63 & -0.37 & -0.21 & 0.47 & 0.08 & -0.13 \\
\hline \multirow[t]{9}{*}{ Chla } & Wet & 1 & 0.92 & 0.13 & $\begin{array}{l}-0.80 \\
\end{array}$ & 0.28 & $\begin{array}{l}-0.72 \\
\end{array}$ & 0.85 & 0.10 & 0.43 & 0.23 & 0.03 & 0.05 & -0.13 \\
\hline & & 2 & -0.07 & -0.09 & -0.09 & 0.07 & -0.04 & -0.23 & 0.38 & 0.18 & -0.08 & 0.14 & 0.72 & 0.96 \\
\hline & & 3 & -0.10 & 0.13 & -0.45 & 0.92 & -0.35 & 0.28 & -0.05 & -0.19 & 0.34 & -0.09 & -0.37 & 0.19 \\
\hline & & 4 & -0.05 & 0.20 & -0.33 & 0.26 & -0.40 & 0.18 & 0.18 & 0.46 & 0.91 & 0.11 & -0.29 & 0.05 \\
\hline & & 5 & 0.09 & 0.12 & 0.16 & 0.00 & 0.39 & 0.07 & -0.76 & -0.35 & -0.01 & 0.77 & 0.14 & -0.15 \\
\hline & Dry & 1 & 0.21 & 0.21 & $\begin{array}{l}-0.84 \\
\end{array}$ & 0.89 & $\begin{array}{l}-0.79 \\
\end{array}$ & 0.65 & 0.11 & 0.30 & 0.76 & -0.13 & -0.41 & -0.01 \\
\hline & & 2 & 0.94 & 0.15 & -0.49 & 0.01 & -0.35 & 0.56 & 0.03 & 0.30 & -0.08 & 0.06 & -0.13 & -0.39 \\
\hline & & 3 & 0.04 & -0.25 & -0.19 & -0.09 & -0.47 & -0.03 & 0.86 & 0.46 & 0.09 & -0.56 & 0.07 & 0.18 \\
\hline & & 4 & -0.26 & 0.05 & 0.02 & 0.16 & 0.18 & -0.33 & 0.24 & -0.05 & -0.16 & -0.02 & 0.46 & 0.86 \\
\hline \multirow[t]{9}{*}{ DO } & Wet & 1 & 0.07 & 0.10 & $\begin{array}{l}-0.74 \\
\end{array}$ & 0.89 & $\begin{array}{l}-0.69 \\
\end{array}$ & 0.55 & 0.14 & 0.13 & 0.73 & 0.05 & -0.48 & -0.54 \\
\hline & & 2 & 0.98 & 0.07 & -0.57 & 0.09 & -0.49 & 0.72 & 0.02 & 0.22 & 0.00 & 0.10 & -0.23 & -0.16 \\
\hline & & 3 & 0.05 & -0.07 & 0.16 & -0.08 & 0.31 & 0.00 & -0.61 & -0.14 & 0.12 & 0.89 & 0.42 & 0.71 \\
\hline & & 4 & 0.16 & 0.07 & -0.27 & -0.08 & -0.35 & 0.02 & 0.28 & 0.93 & 0.38 & -0.16 & 0.30 & 0.06 \\
\hline & & 5 & 0.08 & 0.98 & -0.08 & 0.11 & 0.06 & 0.07 & -0.24 & 0.06 & 0.17 & -0.17 & -0.40 & -0.04 \\
\hline & Dry & 1 & 0.87 & 0.29 & -0.62 & 0.16 & $\begin{array}{l}-0.54 \\
\end{array}$ & 0.82 & -0.10 & 0.25 & 0.15 & -0.05 & -0.81 & -0.20 \\
\hline & & 2 & 0.03 & 0.20 & -0.69 & 0.93 & -0.61 & 0.44 & 0.10 & 0.16 & 0.71 & -0.03 & -0.22 & -0.08 \\
\hline & & 3 & -0.25 & 0.35 & 0.36 & 0.05 & 0.45 & -0.05 & -0.64 & -0.63 & -0.14 & 0.22 & -0.03 & 0.96 \\
\hline & & 4 & 0.12 & -0.28 & 0.07 & -0.06 & 0.20 & 0.06 & -0.43 & -0.16 & 0.08 & 0.97 & 0.41 & 0.14 \\
\hline
\end{tabular}

Notes: (1) Bold values indicate variables having moderate to high loadings on factors (F); F1-5 refer to five independent factors. (2) A, S, I, $\mathrm{D}_{\mathrm{c}}$, BUL, OPN, AGR, VEG, WAT, GWD, and $\mathrm{C}_{\mathrm{IN}}$ and $\mathrm{C}_{\mathrm{OUT}}$, respectively, refer to subwatershed area, slope, imperviousness, distance from coast, built-up land, open land, agricultural land, vegetated land, waterbody, groundwater depth, and inlet and outlet concentrations. 
TN in both seasons loaded most strongly on factor-1 (0.74 to 0.79$)$, which had very high loadings of the distance from coast ( 0.98 to 0.99$)$ and moderately strong loadings of imperviousness (-0.63), built-up land (-0.53 to -0.55$)$, and waterbody (0.52 to 0.58$)$. In contrast, TP had the strongest loading on factor-2 (0.92) in wet season and on factor-3 (0.93) in dry season, along with the respective loadings of upstream concentrations ( 0.56 to 0.85 ) and agricultural land (0.53). Similar to TP, Chla loaded most strongly on factor-2 (0.96) in wet season, alongside strong loadings of inlet concentrations (0.72) and a noteworthy loading of agricultural land (0.38). In dry season, the strongest loading of Chla was on factor-4 (0.86), which had notable loadings of upstream concentrations (0.46) and open land (-0.33). DO loaded most strongly on factor-3 ( 0.71 to 0.96 ) in both seasons, alongside the high loadings of groundwater depth (0.89) in wet season, vegetated land (-0.63) in dry season, and agricultural land (-0.61 to -0.64) in both seasons. A moderate loading of wet season DO was also apparent on factor-1 (-0.54), which had moderate to high loadings of open land (0.55), built-up land (-0.69), waterbody (0.73), imperviousness (-0.74), and distance from the coast (0.89).

\subsubsection{Estimations of the relative linkages of water quality indicators with the drivers}

The minimum AIC criteria, in concert with an acceptable NSE, led to the inclusion of 2-4 PLS components to achieve optimum PLSR models for the four water quality indicators (Figure 2.5). Based on Moriasi et al. (2007), the fitting efficiency (NSE $=0.72-0.95)$ and accuracy (RSR = 0.22-0.51) of the optimal models suggested good predictions in both seasons (Table 2.4; Figure A2.2 in Appendix 2). The power-law based PLSR models of Z-scores were significant at the $95 \%$ confidence level for all water quality indicators. 
(a)

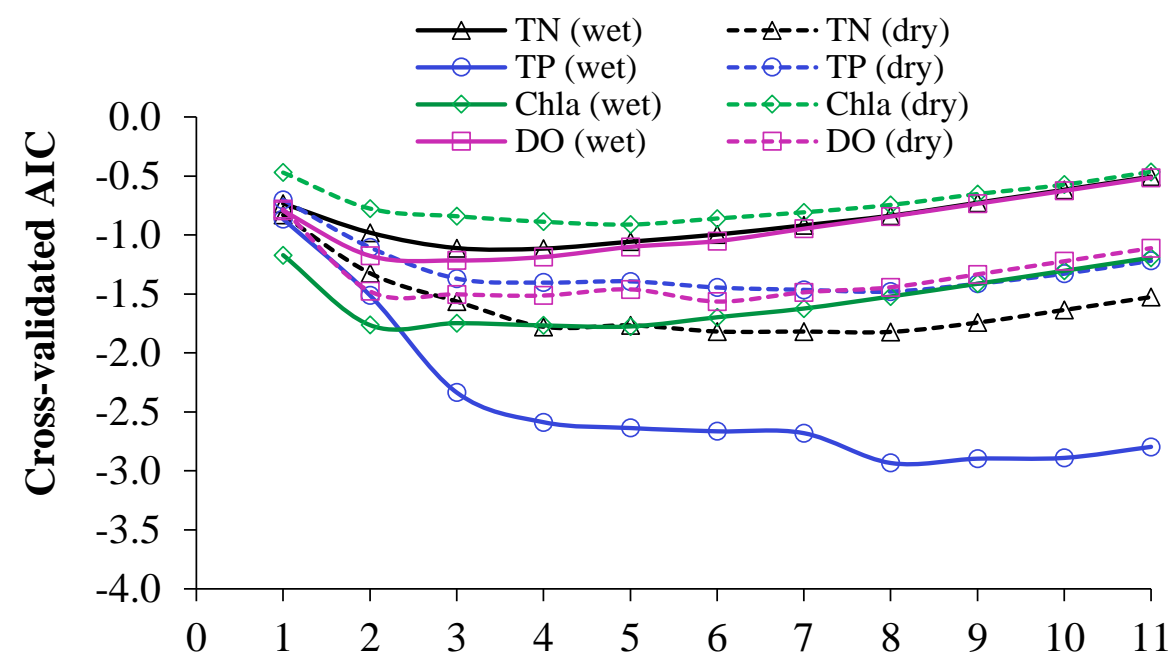

(b)

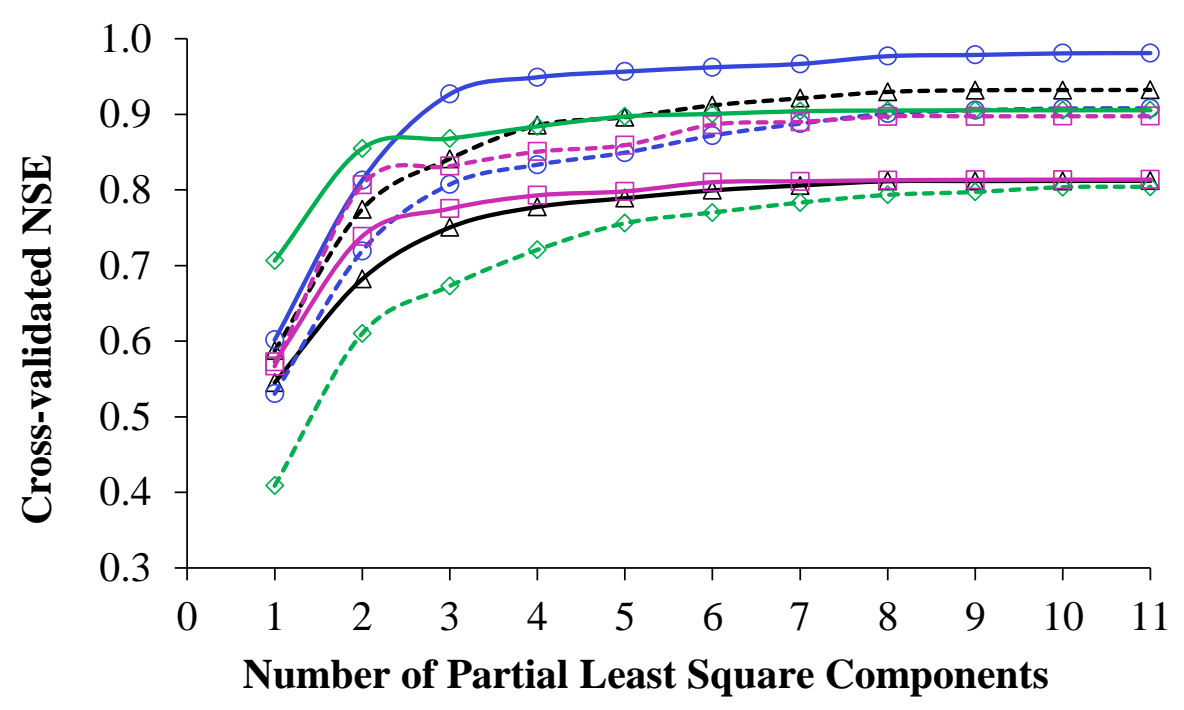

Figure 2.5. Plot of cross-validated (a) normalized AIC and (b) Nash-Sutcliffe Efficiency (NSE) with the number of incorporated partial least squares components. 
Table 2.4. PLSR model coefficients $(\beta)$ of the standardized variables in both wet and dry seasons.

\begin{tabular}{lrrrrrrrr}
\hline & \multicolumn{2}{c}{ TN } & \multicolumn{2}{c}{ TP } & \multicolumn{2}{c}{ Chla } & \multicolumn{2}{c}{ DO } \\
\hline Predictor variables & Wet & Dry & Wet & Dry & Wet & Dry & Wet & Dry \\
A & -0.07 & 0.12 & -0.12 & -0.24 & -0.29 & -0.35 & 0.09 & -0.13 \\
S & 0.20 & 0.10 & -0.25 & -0.25 & -0.01 & 0.08 & 0.01 & 0.25 \\
I & -0.18 & -0.29 & -0.21 & -0.14 & -0.16 & -0.27 & 0.13 & 0.14 \\
D $_{\text {B }}$ & 0.60 & 0.73 & 0.06 & -0.04 & 0.45 & 0.47 & -0.22 & 0.13 \\
BUL & 0.08 & 0.14 & 0.02 & 0.00 & -0.06 & 0.19 & 0.18 & 0.19 \\
OPN & -0.08 & -0.01 & -0.13 & -0.24 & -0.31 & -0.31 & -0.04 & 0.04 \\
AGR & 0.35 & 0.23 & 0.44 & 0.48 & 0.36 & 0.48 & -0.22 & -0.37 \\
VEG & -0.09 & -0.11 & 0.20 & 0.10 & 0.10 & 0.06 & 0.07 & -0.35 \\
WAT & -0.04 & -0.42 & -0.10 & 0.02 & 0.03 & -0.22 & 0.07 & 0.03 \\
GWD & 0.12 & 0.16 & 0.28 & 0.20 & 0.23 & 0.25 & 0.36 & 0.15 \\
C IN & 0.32 & 0.34 & 0.79 & 0.47 & 0.68 & 0.35 & 0.21 & -0.05 \\
Model statistics & & & & & & & & \\
PLS components & 3 & 4 & 4 & 3 & 2 & 4 & 2 & 2 \\
NSE & 0.75 & 0.89 & 0.95 & 0.81 & 0.85 & 0.72 & 0.74 & 0.81 \\
RSR & 0.49 & 0.33 & 0.22 & 0.43 & 0.37 & 0.51 & 0.50 & 0.43 \\
Aggregated linkages & & & & & & & & \\
$\beta_{\text {LU }}$ & 0.38 & 0.51 & 0.51 & 0.55 & 0.49 & 0.64 & 0.30 & 0.55 \\
$\beta_{\mathrm{H}}$ & 0.30 & 0.37 & 0.45 & 0.42 & 0.41 & 0.52 & 0.39 & 0.34 \\
$\beta_{\text {Dc }}$ & 0.60 & 0.73 & 0.06 & 0.04 & 0.45 & 0.47 & 0.22 & 0.13 \\
$\beta_{\text {CIN }}$ & 0.32 & 0.34 & 0.79 & 0.47 & 0.68 & 0.35 & 0.21 & 0.05 \\
\hline
\end{tabular}

Notes: (1) A, S, I, D, BUL, OPN, AGR, VEG, WAT, GWD, and $\mathrm{C}_{\mathrm{IN}}$, respectively, refer to subwatershed area, slope, imperviousness, distance from coast, built-up land, open land, agricultural land, vegetated land, waterbody, groundwater depth, and inlet concentrations. (2) The aggregated relative linkages of the watershed 'land use' $\left(\beta_{L U}\right)$, 'hydrology' $\left(\beta_{H}\right)$, 'upstream reach' $\left(\beta_{C_{I N}}\right)$, and the 'external driver' $\left(\beta_{D c}\right)$ components were calculated, respectively, by using Eqs. 1-4.

TN had the strongest linkage with the distance from coast across wet and dry seasons $(\beta=0.60$ to 0.73 ; Table 2.4). Notable linkages of TN in both seasons were also apparent with the upstream reach concentrations ( $\beta=0.32$ to 0.34$)$, agricultural land $(\beta=0.23$ to 0.35$)$, and imperviousness $(\beta=-0.18$ to -0.29$)$. Further, the waterbody area of the draining subwatershed was moderately 
linked $(\beta=-0.42)$ with TN in the dry season. Based on the aggregated linkages, the 'external driver' component $\left(\beta_{\mathrm{Dc}}\right)$ - reflecting contributions from the upstream Everglades and/or the downstream coast — had 1.5 to 2 times stronger linkages with TN than that of the subwatershed 'land use' $\left(\beta_{\mathrm{LU}}\right)$, 'upstream reach' $\left(\beta_{\mathrm{CIN}}\right)$, and 'hydrology' $\left(\beta_{\mathrm{H}}\right)$ components.

TP was most strongly linked with the upstream concentrations $(\beta=0.47$ to 0.79 ; Table 2.4) and agricultural land ( $\beta=0.44$ to 0.48$)$ in both seasons. Other noteworthy controls of TP included the hydrologic variables (A, S, I), open land, vegetated land, and groundwater depth. However, the distance from coast was weakly linked with TP in both seasons. Contributions of the 'upstream reach' component $\left(\beta_{\mathrm{CIN}}\right)$ had approximately $(\sim) 1.5,2$, and 12 times stronger linkages with TP in wet season than that of, respectively, the 'land use' $\left(\beta_{\mathrm{LU}}\right)$, 'hydrology' $\left(\beta_{\mathrm{H}}\right)$, and the 'external driver' $\left(\beta_{\mathrm{Dc}}\right)$ components. In contrast, the 'land use' contributions component dominated TP in dry season; $\beta_{\mathrm{LU}}$ was $1.2,1.3$, and 15.4 times stronger than $\beta_{\mathrm{CIN}}, \beta_{\mathrm{H}}$, and $\beta_{\mathrm{Dc}}$, respectively.

Similar to TP, Chla had relatively strong linkages with the upstream reach concentrations $(\beta=0.35$ to 0.68 ; Table 2.4$)$ and agricultural land $(\beta=0.36$ to 0.48$)$ across the two seasons. However, unlike TP and alike TN, Chla was strongly linked with the distance from coast $(\beta=$ 0.45 to 0.47 ). Appreciable linkages of Chla in both seasons were also noted with the subwatershed area, imperviousness, open land, and groundwater depth. The 'upstream reach' and 'land use' contributions dominated Chla in, respectively, wet and dry seasons - exhibiting 1.2 to $\sim 2$ times stronger linkages with Chla than that of the other components.

DO was most strongly linked with the groundwater depth $(\beta=0.36$; Table 2.4$)$ in wet season, and with the agricultural and vegetated lands $(\beta=-0.35$ to -0.37$)$ in dry season. Other 
notable linkages of DO in both seasons include that with the subwatershed imperviousness, builtup land, distance from coast, and groundwater depth. The subwatershed 'hydrology' component $\left(\beta_{\mathrm{H}}\right)$ had 1.3 to $\sim 2$ times stronger linkages with DO in wet season than that of 'land use' $\left(\beta_{\mathrm{LU}}\right)$, 'external driver' $\left(\beta_{\mathrm{Dc}}\right)$, and 'upstream reach' $\left(\beta_{\mathrm{CIN}}\right)$. In contrast, the 'land use' predominantly controlled DO in dry season; $\beta_{\mathrm{LU}}$ was $1.6,4.3$, and 10.2 times stronger than $\beta_{\mathrm{H}}, \beta_{\mathrm{Dc}}$, and $\beta_{\mathrm{CIN}}$, respectively.

\subsection{Discussion}

The strong positive linkages of TN with the 'external driver' component (represented by the distance from coast, $D_{c}$; e.g., see Table 2.4) in both seasons underline Everglades as the primary source of nitrogen in the coastal-urban streams of southeast Florida. However, the weak linkage of $\mathrm{TP}$ with $\mathrm{D}_{\mathrm{c}}$ reiterates that the Everglades is a minor source of phosphorus for the southeast Florida streams (Rudnick et al., 1999). The external control of stream TN was further manifested in C-12, which is not directly connected with the Everglades and had much lower concentrations of TN than the other canals (see Table A2.1 in Appendix 2). The positive linkages of TN with $\mathrm{D}_{\mathrm{c}}$ also suggest that the in-stream TN decreases away from the Everglades toward the coast. The majority of Everglades' nitrogen comes from the water conservation area (WCA) and/or agricultural lands as organic nitrogen (particulate and dissolved), compared to the dissolved inorganic forms $\left(\mathrm{NH}_{3}+\mathrm{NO}_{\mathrm{x}}\right)(\mathrm{BCEPD}, 2007)$. The dissolved organic nitrogen reduces through denitrification (Graves et al., 2004), whereas the particulate organic nitrogen tends to settle down at the bottom of the shallow (depth $<10$ feet) freshwater canals. Further, increased salinity toward the coast might impact microbial activities — decreasing the rates of mineralization and transport of settled particulate organic nitrogen into the water column (Rietz and Haynes, 2003; Jackson and Vallaire, 2009). 
The moderate to strong positive linkages between the inlet and outlet concentrations $\left(\mathrm{C}_{\mathrm{IN}}\right.$ and $\left.\mathrm{C}_{\mathrm{OUT}}\right)$ of individual nutrients (TN and TP) emphasize the high influence of upstream reach on the downstream water quality (Alexander et al., 2007). The linkages of TN and TP with the watershed agricultural land can be attributed to the wash-off of fertilizers by rainfall-runoff (Li et al., 2009, Bu et al., 2014, Wan et al., 2014 a, b). Despite the predominantly built-area fraction (74\%) of the study watersheds (Table 2.1), the agricultural land use dominated over the built-up land to contribute in-stream nutrients in both seasons (e.g., Table 2.4). This is consistent with the operation of regional wastewater treatment plants, which stopped discharging directly into the canals since 1989 (BCDPEP, 2001). Further, the negative linkages of TN and TP with the watershed imperviousness suggested the dilution of in-stream nutrients by the corresponding surface runoff. However, the direction of predictor vs. response relationship in PLSR is mechanistically more meaningful for the dominant predictors than that of the less important or weak predictors. For example, the correlation analysis (Table 2.2) showed a moderate positive correlation of open land area fraction (OPN) with TN. In contrast, the PLSR upon resolving multicollinearity estimated a relatively very weak (i.e., not meaningful) negative linkage between OPN and TN (Table 2.4). The moderate positive correlation between OPN and TN is, therefore, indirect and spurious, which can be attributed to the mutual correlation (multicollinearity) between OPN and distance from the coast $\left(D_{c}\right)$. In fact, TN, $D_{c}$ and OPN increase away from the coastline toward the upstream of canals near the Everglades (see more details in section 3.1).

The relative linkages of Chla with the individual drivers and aggregated process components mostly reflected the corresponding linkages of TP, emphasizing the limiting nutrient in the southeast Florida canals. The finding complements the previous studies that mainly focused on the south Florida bays, estuaries, and/or Everglades. For example, Briceño et al. 
(2013) reported the limiting effect of TP on phytoplankton productivity in south Florida's estuaries and bays. Noe et al. (2001) and Childers et al. (2006) reported the phosphorus-limited nature of the large freshwater-estuarine landscape in Florida Everglades. Lapointe and Bedford (2010) reported phosphorus-limited biomass production by algal bloom on coral reefs off the southeast Florida. Our study expanded the research into the urban region between the Biscayne Bay and the Indian River Lagoon Watersheds. Our results indicate that the phosphorus limitation is also prevalent in the inland managed canals of southeast Florida.

The contributions of the 'upstream reach' and 'land use' components dominated both TP and Chla in wet and dry seasons, respectively. The moderate to strong linkages between the upstream and the immediate downstream concentrations ( $\mathrm{C}_{\mathrm{IN}}$ and $\left.\mathrm{COUT}_{\mathrm{T}}\right)$ of Chla appeared to represent the corresponding linkages for the individual nutrients. The positive linkage of Chla with agricultural land can be attributed to the nutrient (TN and TP) runoff from fertilizer usage (Corkum, 1996). Similarly, the positive linkage of Chla with $D_{c}$ reiterates the higher nitrogen availability in the upstream of canals that receives Everglades' runoff, leading to higher phytoplankton biomass (Brand, 2002; NRC, 2002). However, the increased salinity stress and turbidity (tidal mixing and sediment resuspension) may have contributed to the lower in-stream Chla near the coastline by impacting the photosynthetic rates of phytoplankton (Cloern, 1987). Further, the negative linkages of Chla with the subwatershed area, open land, and imperviousness can be attributed to the dilution of in-stream TP and/or TN by the consequent higher runoff generation (Kang et al., 2010).

The positive linkages of the groundwater depth from the land surface (GWD) with the stream nutrients, Chla and DO (Table 2.4) indicated the enhanced interactions of stream flow with the shallow groundwater table in the region (see Table 2.1). The groundwater control of DO 
in the Broward canals was also reported in a previous study (BCEPD, 2007). The linkages can be attributed to the underlying Biscayne aquifer, which has a high transmissivity (Lietz, 1999) and is typically low in DO (median $=0.15 \mathrm{mg} / \mathrm{L}$ ) and nutrients (median $\mathrm{TN}<0.96 \mathrm{mg} / \mathrm{L}$, median TP $<0.01 \mathrm{mg} / \mathrm{L}$ ) (Bradner et al., 2005). The positive linkage of DO with watershed imperviousness (Table 2.4) reiterated the dilution of in-stream nutrients and consequent enhancement of DO by higher runoff generation from the reduced permeability. Further, prohibition of direct effluent discharge from the wastewater treatment plants into the canals has largely reduced the pollution inputs from the urban land (BCDPEP, 2001). This further emphasizes the dilution of nutrients by surface runoff from built-up land - contributing to the improved stream water quality, as evident from its intriguing positive linkage with DO (Table 2.4). Overall, the stronger linkage of stream DO with groundwater in the wet season eventually led to the domination of the 'hydrology' component over the subwatershed 'land use', 'upstream reach', and 'external driver' components. However, the dictating linkage of the 'land use' component with DO in the dry season reflected the deteriorating impacts of incoming nutrients and organic matters (e.g., litters) from, respectively, the agricultural and vegetated lands during the low flow period.

Alongside the characterization and source identification of coastal water quality (e.g., Boyer et al., 1997; Boyer, 2006; Caccia and Boyer, 2007), determination of the relative dominance of one driver over the others is essential to understand the cause and effect relationships (Boyer et al., 2009). Our study advanced the knowledge of coastal-urban water quality by estimating the relative influence of the land use and hydrologic drivers on stream water quality indicators by appropriately resolving multicollinearity. The estimated relative linkages can be utilized to identify the management targets and priorities to achieve/maintain healthy stream ecosystems in southeast Florida and similar regions, as required by the Clean 
Water Act (FWPCA, 2002). Since Everglades (the external driver) is the largest contributor of in-stream $\mathrm{TN}$, the major reduction of nitrogen loads should be achieved in the water conservation areas (WCAs) ecologically and/or by adding engineering solutions (e.g., detention ponds). This reiterates the importance of the Comprehensive Everglades Restoration Plan (CERP) to significantly decrease the nitrogen concentration in the downstream freshwater canals (Wan et al., 2014b). Controlling (e.g., treatment) the watershed agricultural runoff should also receive the highest priority in land management to reduce in-stream nutrients (TN and TP). Further, removal of nutrients at the upstream locations would be effective to improve the downstream water quality. The reduction of nutrients, in turn, would reduce algal biomass (e.g., Chla) and increase DO that was typically low in the coastal-urban streams (see Table 2.1).

\subsection{Conclusions}

The relative linkages of stream water quality and environmental health indicators with the land use and hydrologic drivers were reliably estimated for the coastal-urban watersheds of southeast Florida by resolving multicollinearity through a systematic data analytics framework. The analytics indicated Everglades as the external and the largest source of nitrogen (TN) in the coastal-urban streams for both wet and dry seasons. The 'external driver' exhibited 1.5-2 times stronger control on stream TN than that of the watershed 'land use', 'hydrology', and the 'upstream reach' contributions. In contrast, Everglades appeared to be a minor source of instream phosphorus (TP), which was predominantly controlled by the internal watershed processes. TP was most strongly linked with the upstream reach concentrations and watershed land uses in the wet and dry seasons, respectively. Despite the predominantly built-up fraction (74\%) of the study area, agricultural land was the most substantial watershed source of in-stream nutrients. The linkages of Chla with the drivers mostly reflected that of TP, indicating the 
limiting nutrient. Stream DO was most strongly influenced by the adjacent groundwater depth and watershed land uses, respectively, in the wet and dry seasons. The estimated relative linkages and insights would be useful to identify the key management targets and priorities to achieve healthy coastal-urban stream ecosystems in southeast Florida and around the world.

\section{Acknowledgments}

The research was funded by a National Science Foundation (NSF) CAREER Award to Dr. Omar I. Abdul-Aziz (NSF CBET Environmental Sustainability Award \# 1561942/1454435). We are grateful to Mr. Robert Bernhard of the Broward County, Florida for sharing study area map and reports. 


\section{Appendix 2}

\section{Data QA/QC for stream water quality indicators}

$\mathrm{TN}$ was an aggregation of total Kjeldahl nitrogen $(\mathrm{TKN})$, nitrate-nitrogen $\left(\mathrm{NO}_{3}-\mathrm{N}\right)$, and nitritenitrogen $\left(\mathrm{NO}_{2}-\mathrm{N}\right)$; where $\mathrm{TKN}$ represents the sum of organic nitrogen (particulate and dissolved) and ammonia-nitrogen $\left(\mathrm{NH}_{3}\right)$. Phosphorus may be found in different forms: orthophosphates (reactive phosphates), condensed phosphates (pyro, meta and polyphosphates), and organic phosphates; the summation of all these forms was represented as total phosphorus (TP). Chla is a measure of specific form of chlorophyll used in oxygenic photosynthesis; it was an indicator of the aquatic plant biomass. DO was a biogeochemical indicator, representing the stream oxygen level. The Broward County Environmental Planning and Community Resilience Division (BCEPCRD, 2015) collected grab samples at the depth of 0.5 meters from the stream surface via a Kemmerer/Niskin bottle (BCEPD, 2007). To ensure the data QA/QC, unacceptable data were eliminated from further analysis following the guidelines of FDEP (2012) - e.g., (1) values less than the laboratory method detection limit, (2) questionable data due to improper laboratory or field protocols, and (3) samples held beyond the accepted holding time were deemed unacceptable. Further, the outlying values of water quality indicators were removed by visual inspections of the respective time-series plots.

\section{Average groundwater depth (GWD)}

Ambient groundwater depth from the land surface (GWD; which increases with decreasing groundwater table) was used to represent the control of groundwater hydrology on stream water quality. Average GWD for wet and dry seasons for each quality station during 2009-13 were calculated from the groundwater level data (NGVD 1929) of 29 active sites (Figure A2.1 in 
Appendix 2) of USGS (2015b). Kriging (Goovaerts, 1997; Childs, 2004; Nikroo et al., 2010;

Costelloe et al., 2015) was employed in ArcGIS 10.0 platform to interpolate GWD to the location of each water quality station.

\section{Details of different land use categories}

Built-up land: Fixed single family units (medium and high density), mobile homes units (medium and high density), mixed units (medium and high density), fixed and mobile home units (medium and high density), medium density under construction, multiple dwelling units-low rise, multiple dwelling units-high rise, high density under construction, institutional, educational facilities, military, correctional, commercial and services, shopping centers, wholesale sales and servicesjunk yards, oil and gas storage-not industrial or manufacturing, cemeteries, commercial and services, oil and gas processing, other light industrial, other heavy industrial, strip mines, sand and gravel pits, rock quarries, oil and gas fields, reclaimed lands, holding ponds, abandoned mining lands, electrical power facilities, electrical power transmission lines, water supply plantsincluding pumping stations, sewage treatment, solid waste disposal, other treatment ponds, communications, airports, private airports, grass airports, railroads and railyards, roads and highways, port facilities.

Open land: Open land, inactive land with street pattern, sand other than beaches, exposed rock, disturbed land, borrow pits, spoil areas, dikes and levees, stadiums and academic, fixed single family units (low density), mobile home units (low density), mixed units (low density), fixed and mobile units (low density), rural residential (low density), low density under construction, recreational, swimming beaches, golf courses, race tracks, marinas and fish camps, parks and zoos. Agricultural land: Improved pasture, unimproved pastures, woodland pastures, row crops, field crops, sugar cane, mixed crops, citrus groves, other groves, feeding operations, cattle feeding 
operations, poultry feeding operations, nurseries and vineyards, tree nurseries, sod farms, ornamentals, specialty farms, horse farms, dairies, aquaculture, fallow cropland, herbaceous (dry prairie), upland shrub and brush land, palmetto prairies, coastal shrub, abandoned groves, mixed rangeland.

Vegetated land: Upland coniferous forests, pine flatwoods, longleaf pine-xeric oak, sand pine, pine -mesic oak, upland hardwood forests, xeric oak, Brazilian pepper, melaleuca, live oak, oakcabbage palm forests, cabbage palm, upland mixed coniferous/hardwood, Australian pine, tree plantations, coniferous plantations, hardwood plantations, forest regeneration areas, wetland hardwood forests, bay swamps, bay head, mangrove swamp, mixed wetland hardwoods, mixed shrubs, cabbage palm wetland, wet melaleuca, wetland coniferous forests, cypress, cypressdomes/heads, cypress - mixed hardwoods, cypress-pine-cabbage palm, wet pinelands hydric pine, pine savannah, wetland forested mixed, freshwater marshes/graminoid prairie-marsh, freshwater marshes-saw grass, saltwater marshes/halophytic herbaceous prairie, wet prairies, aquatic vegetation, non-vegetated wetland, tidal flats.

Waterbody: Natural river, stream, waterway, channelized waterways, canals, lakes, reservoirs, embayment opening directly to gulf or ocean, embayment not opening directly to gulf or ocean, saltwater ponds, slough waters, Atlantic ocean.

\section{Model optimization and performance statistics}

The PLSR models were optimized based on Akaike Information Criterion (AIC) (Akaike, 1974) and Nash-Sutcliffe Efficiency (NSE) (Nash and Sutcliffe, 1970). Apart from the model efficiency (NSE), the ratio of root-mean-square error to the standard deviation of observations (RSR) were used to assess model accuracy. Following Abdul-Aziz and Ishtiaq (2014), a modified AIC was computed as follows: 
where $p$ is the total number of the PLS components, $N$ is the total number of observations, $S S E=\sum_{i=1}^{N}\left(Y_{i, \text { mod }}-Y_{i, o b s}\right)^{2}$ is the total sum of squared errors (i.e., deviations) between the modeled and the corresponding observed Z-scores of a water quality indicator $(Y)$.

The Nash-Sutcliffe Efficiency (NSE) was calculated as follows:

$N S E=1-\frac{\sum_{i=1}^{N}\left(Y_{i, o b s}-Y_{i, \text { mod }}\right)^{2}}{\sum_{i=1}^{N}\left(Y_{i, \mathrm{obs}}-Y_{\text {mean }, \text { obs }}\right)^{2}}$

where $N$ is the total number of observations; $Y_{i, \mathrm{mod}}$ and $Y_{i, o b s}$ are, respectively, the i-th model prediction and the corresponding observation; and $Y_{\text {mean,obs }}$ is the mean of all observations. $\mathrm{NSE}=1.0$ for a perfect model; i.e., the predictions exactly represent the respective observations . NSE $<0$ (i.e., negative) for a model that is a worse predictor than the average of all observations as an alternative model.

The ratio of root-mean-square error (RMSE) to the standard deviation of observations (RSR) was calculated as:

$R S R=\frac{\sqrt{\sum_{i=1}^{N}\left(Y_{i, \mathrm{mod}}-Y_{i, o b s}\right)^{2} / N}}{\sigma_{o b s}}$

where $N$ is the total number of observations; $Y_{i, \text { mod }}$ and $Y_{i, o b s}$ are, respectively, the i-th model prediction and the corresponding observation; and $\sigma_{o b s}$ is the standard deviation of observations. A range of RSR values were suggested by Moriasi et al. (2007) for the evaluation of model accuracy: RSR from 0 to 0.50 indicates a perfect to very good model, from 0.50 to 0.60 indicates 
a good model, and from 0.60 to 0.70 refers to a satisfactory model; a model with RSR $>0.70$ is considered unsatisfactory.

Table A2.1: Mean and standard deviation (in parenthesis) of the stream water quality and environmental health indicators and their drivers for the six major canals.

\begin{tabular}{|c|c|c|c|c|c|c|}
\hline Variables & Hillsboro & C-14 & C-13 & $\mathrm{C}-12$ & NNR & C-11 \\
\hline \multirow[t]{2}{*}{$\mathrm{A}\left(\mathrm{km}^{2}\right)$} & 84.95 & 55.51 & 24.35 & 4.54 & 18.57 & 73.89 \\
\hline & (43.17) & $(26.03)$ & $(14.53)$ & $(0.10)$ & (15.39) & (59.38) \\
\hline \multirow[t]{2}{*}{$\mathrm{S}(\%)$} & 2.17 & 2.22 & 1.91 & 1.91 & 2.45 & 2.26 \\
\hline & $(0.47)$ & (0.19) & $(0.26)$ & $(0.23)$ & $(0.51)$ & $(0.27)$ \\
\hline \multirow[t]{2}{*}{$\mathrm{I}(\%)$} & 30.06 & 40.53 & 40.50 & 49.95 & 36.27 & 31.71 \\
\hline & (9.97) & $(10.21)$ & $(9.44)$ & $(3.85)$ & (8.07) & (10.93) \\
\hline \multirow[t]{2}{*}{ Dc $(\mathrm{km})$} & 7.80 & 7.65 & 9.51 & 7.27 & 10.53 & 10.43 \\
\hline & (6.06) & $(5.62)$ & $(5.84)$ & (1.13) & $(4.75)$ & (7.61) \\
\hline \multirow{2}{*}{ BUL (\%) } & 68.08 & 80.33 & 77.24 & 89.39 & 77.25 & 62.35 \\
\hline & (17.71) & (6.20) & $(12.51)$ & (4.03) & (10.54) & (18.35) \\
\hline \multirow[t]{2}{*}{ OPN (\%) } & 12.83 & 8.24 & 9.45 & 2.37 & 11.51 & 17.64 \\
\hline & (6.02) & (2.87) & (5.95) & $(0.48)$ & (11.38) & (10.56) \\
\hline \multirow[t]{2}{*}{$\operatorname{AGR}(\%)$} & 5.32 & 1.09 & 0.44 & 3.53 & 0.88 & 3.84 \\
\hline & (7.17) & (1.75) & (0.34) & $(2.20)$ & $(0.87)$ & (3.16) \\
\hline \multirow[t]{2}{*}{ VEG $(\%)$} & 6.14 & 3.41 & 1.26 & 0.39 & 2.11 & 7.05 \\
\hline & (3.77) & (3.94) & (1.06) & $(0.16)$ & (1.43) & (6.04) \\
\hline \multirow[t]{2}{*}{ WAT (\%) } & 7.63 & 6.93 & 11.61 & 4.32 & 8.26 & 9.13 \\
\hline & (3.34) & (1.51) & (10.26) & (1.19) & (1.97) & (4.17) \\
\hline \multicolumn{7}{|c|}{ Wet Season (June-October) } \\
\hline \multirow[t]{2}{*}{ TN (mg/L) } & 1.29 & 1.24 & 1.15 & 0.88 & 1.47 & 1.28 \\
\hline & $(0.38)$ & $(0.22)$ & $(0.29)$ & $(0.17)$ & $(0.13)$ & $(0.46)$ \\
\hline \multirow[t]{2}{*}{$\mathrm{TP}(\mathrm{mg} / \mathrm{L})$} & 0.08 & 0.03 & 0.03 & 0.07 & 0.03 & 0.04 \\
\hline & $(0.04)$ & $(0.01)$ & $(0.01)$ & $(0.02)$ & $(0.01)$ & $(0.01)$ \\
\hline \multirow[t]{2}{*}{ Chla $(\mu \mathrm{g} / \mathrm{L})$} & 10.60 & 7.44 & 4.83 & 15.63 & 5.67 & 5.27 \\
\hline & $(4.03)$ & $(1.72)$ & $(1.40)$ & $(7.22)$ & $(1.62)$ & $(2.20)$ \\
\hline \multirow[t]{2}{*}{ DO (mg/L) } & 4.22 & 4.78 & 4.46 & 4.45 & 3.37 & 3.54 \\
\hline & $(0.60)$ & $(0.19)$ & $(0.85)$ & (1.18) & $(1.31)$ & $(0.78)$ \\
\hline \multirow[t]{2}{*}{ GWD (m) } & 2.03 & 2.69 & 2.42 & 1.45 & 1.33 & 1.21 \\
\hline & $(0.35)$ & $(0.37)$ & $(0.78)$ & $(0.04)$ & $(0.26)$ & $(0.30)$ \\
\hline \multicolumn{7}{|c|}{ Dry Season (November-May) } \\
\hline \multirow[t]{2}{*}{$\mathrm{TN}(\mathrm{mg} / \mathrm{L})$} & 1.20 & 1.14 & 1.02 & 0.87 & 1.31 & 1.16 \\
\hline & $(0.35)$ & (0.39) & (0.39) & (0.10) & $(0.33)$ & $(0.52)$ \\
\hline \multirow[t]{2}{*}{ TP (mg/L) } & 0.06 & 0.03 & 0.03 & 0.08 & 0.03 & 0.03 \\
\hline & $(0.03)$ & $(0.01)$ & (0.02) & $(0.04)$ & $(0.01)$ & $(0.01)$ \\
\hline \multirow[t]{2}{*}{ Chla $(\mu \mathrm{g} / \mathrm{L})$} & 6.17 & 3.96 & 3.30 & 15.77 & 6.42 & 3.11 \\
\hline & $(0.63)$ & $(0.32)$ & (1.93) & (10.65) & (3.54) & (1.69) \\
\hline \multirow[t]{2}{*}{$\mathrm{DO}(\mathrm{mg} / \mathrm{L})$} & 5.50 & 6.38 & 6.34 & 7.12 & 5.75 & 5.19 \\
\hline & $(0.65)$ & $(0.29)$ & $(0.53)$ & (1.35) & (1.40) & (1.07) \\
\hline \multirow[t]{2}{*}{ GWD (m) } & 2.14 & 2.85 & 2.65 & 1.66 & 1.51 & 1.31 \\
\hline & $(0.26)$ & $(0.37)$ & $(0.86)$ & (0.07) & $(0.23)$ & (0.39) \\
\hline
\end{tabular}


Table A2.2: Correlation matrix of the participatory variables in wet season.

\begin{tabular}{|c|c|c|c|c|c|c|c|c|c|c|c|c|c|c|c|c|c|c|}
\hline & $\mathrm{A}$ & $\mathrm{S}$ & I & $\mathrm{D}_{\mathrm{c}}$ & BUL & OPN & AGR & VEG & WAT & GWD & $\mathrm{TN}_{\mathrm{IN}}$ & TNout & $\mathrm{TP}_{\mathrm{IN}}$ & TP OUT & ChlaIn & Chlaout & DOIN $_{\text {IN }}$ & DOOUT \\
\hline A & 1.00 & 0.16 & -0.65 & 0.15 & -0.56 & 0.75 & 0.02 & 0.37 & 0.13 & 0.11 & 0.55 & 0.27 & -0.14 & -0.12 & 0.06 & -0.22 & -0.22 & -0.15 \\
\hline S & 0.16 & 1.00 & -0.22 & 0.20 & -0.09 & 0.17 & -0.16 & 0.16 & 0.26 & -0.23 & 0.47 & 0.37 & 0.06 & -0.31 & -0.08 & -0.09 & -0.47 & -0.15 \\
\hline I & -0.65 & -0.22 & 1.00 & -0.73 & 0.93 & -0.83 & -0.27 & -0.50 & -0.63 & 0.10 & -0.66 & -0.68 & 0.36 & 0.15 & 0.18 & -0.11 & 0.51 & 0.60 \\
\hline $\mathrm{D}_{\mathrm{c}}$ & 0.15 & 0.20 & -0.73 & 1.00 & -0.63 & 0.53 & 0.06 & 0.07 & 0.61 & -0.04 & 0.33 & 0.77 & -0.56 & -0.40 & -0.36 & 0.22 & -0.51 & -0.59 \\
\hline BUL & -0.56 & -0.09 & 0.93 & -0.63 & 1.00 & -0.76 & -0.46 & -0.56 & -0.64 & 0.24 & -0.56 & -0.56 & 0.40 & 0.12 & 0.25 & -0.09 & 0.45 & 0.65 \\
\hline OPN & 0.75 & 0.17 & -0.83 & 0.53 & -0.76 & 1.00 & -0.02 & 0.25 & 0.47 & 0.08 & 0.62 & 0.50 & -0.37 & -0.34 & -0.25 & -0.27 & -0.51 & -0.41 \\
\hline AGR & 0.02 & -0.16 & -0.27 & 0.06 & -0.46 & -0.02 & 1.00 & 0.34 & 0.15 & -0.52 & -0.03 & 0.17 & 0.08 & 0.50 & 0.14 & 0.47 & -0.19 & -0.47 \\
\hline VEG & 0.37 & 0.16 & -0.50 & 0.07 & -0.56 & 0.25 & 0.34 & 1.00 & 0.44 & -0.26 & 0.50 & 0.22 & 0.00 & 0.22 & -0.04 & 0.15 & 0.09 & -0.16 \\
\hline WAT & 0.13 & 0.26 & -0.63 & 0.61 & -0.64 & 0.47 & 0.15 & 0.44 & 1.00 & 0.06 & 0.58 & 0.57 & -0.47 & -0.32 & -0.44 & 0.00 & -0.26 & -0.24 \\
\hline GWD & 0.11 & -0.23 & 0.10 & -0.04 & 0.24 & 0.08 & -0.52 & -0.26 & 0.06 & 1.00 & 0.03 & -0.02 & -0.15 & -0.11 & 0.16 & 0.01 & 0.37 & 0.59 \\
\hline $\mathrm{TN}_{\mathrm{IN}}$ & 0.55 & 0.47 & -0.66 & 0.33 & -0.56 & 0.62 & -0.03 & 0.50 & 0.58 & 0.03 & 1.00 & 0.58 & -0.32 & -0.34 & -0.24 & -0.23 & -0.51 & -0.10 \\
\hline TNouT & 0.27 & 0.37 & -0.68 & 0.77 & -0.56 & 0.50 & 0.17 & 0.22 & 0.57 & -0.02 & 0.58 & 1.00 & -0.50 & -0.31 & -0.16 & 0.36 & -0.54 & -0.45 \\
\hline $\mathrm{TP}_{\mathrm{IN}}$ & -0.14 & 0.06 & 0.36 & -0.56 & 0.40 & -0.37 & 0.08 & 0.00 & -0.47 & -0.15 & -0.32 & -0.50 & 1.00 & 0.76 & 0.76 & 0.24 & 0.23 & 0.29 \\
\hline TPout & -0.12 & -0.31 & 0.15 & -0.40 & 0.12 & -0.34 & 0.50 & 0.22 & -0.32 & -0.11 & -0.34 & -0.31 & 0.76 & 1.00 & 0.69 & 0.56 & 0.33 & 0.14 \\
\hline Chlain & 0.06 & -0.08 & 0.18 & -0.36 & 0.25 & -0.25 & 0.14 & -0.04 & -0.44 & 0.16 & -0.24 & -0.16 & 0.76 & 0.69 & 1.00 & 0.58 & 0.30 & 0.22 \\
\hline Chlaout & -0.22 & -0.09 & -0.11 & 0.22 & -0.09 & -0.27 & 0.47 & 0.15 & 0.00 & 0.01 & -0.23 & 0.36 & 0.24 & 0.56 & 0.58 & 1.00 & 0.13 & -0.17 \\
\hline DOIN $_{\text {IN }}$ & -0.22 & -0.47 & 0.51 & -0.51 & 0.45 & -0.51 & -0.19 & 0.09 & -0.26 & 0.37 & -0.51 & -0.54 & 0.23 & 0.33 & 0.30 & 0.13 & 1.00 & 0.58 \\
\hline DOout & -0.15 & -0.15 & 0.60 & -0.59 & 0.65 & -0.41 & -0.47 & -0.16 & -0.24 & 0.59 & -0.10 & -0.45 & 0.29 & 0.14 & 0.22 & -0.17 & 0.58 & 1.00 \\
\hline
\end{tabular}

Notes: (1) Data for all variables were $\log _{10}$ transformed to incorporate any non-linear correspondences; (2) the correlations in bold are significant at $95 \%$ level of confidence (p-values < 0.05); (3) A, S, I, D , BUL, OPN, AGR, VEG, WAT, and GWD, respectively, refer to subwatershed area, slope, imperviousness, distance from coast, built-up land, open land, agriculture, vegetation, waterbody, and groundwater depth. The subscripts "IN" and "OUT", respectively, refer to the inlet and outlet of a stream reach (or subwatershed). 
Table A2.3: Correlation matrix of the participatory variables in dry season.

\begin{tabular}{|c|c|c|c|c|c|c|c|c|c|c|c|c|c|c|c|c|c|c|}
\hline & A & $\mathrm{S}$ & I & $\mathrm{D}_{\mathrm{c}}$ & BUL & OPN & AGR & VEG & WAT & GWD & $\mathrm{TN}_{\mathrm{IN}}$ & TNout & $\mathrm{TP}_{\mathrm{IN}}$ & TPout & Chlain & Chlaout & DOIN & DOout \\
\hline A & 1.00 & 0.16 & -0.65 & 0.15 & -0.56 & 0.75 & 0.02 & 0.37 & 0.13 & 0.01 & 0.43 & 0.37 & -0.28 & -0.43 & -0.33 & -0.58 & -0.64 & -0.40 \\
\hline S & 0.16 & 1.00 & -0.22 & 0.20 & -0.09 & 0.17 & -0.16 & 0.16 & 0.26 & -0.21 & 0.62 & 0.32 & -0.05 & -0.33 & -0.10 & -0.09 & -0.39 & 0.23 \\
\hline I & -0.65 & -0.22 & 1.00 & -0.73 & 0.93 & -0.83 & -0.27 & -0.50 & -0.63 & 0.20 & -0.70 & -0.73 & 0.50 & 0.32 & 0.39 & 0.18 & 0.68 & 0.53 \\
\hline $\mathrm{D}_{\mathrm{c}}$ & 0.15 & 0.20 & -0.73 & 1.00 & -0.63 & $\mathbf{0 . 5 3}$ & 0.06 & 0.07 & 0.61 & -0.08 & 0.52 & 0.84 & -0.56 & -0.39 & -0.35 & 0.12 & -0.35 & -0.06 \\
\hline BUL & -0.56 & -0.09 & 0.93 & -0.63 & 1.00 & -0.76 & -0.46 & -0.56 & -0.64 & 0.34 & -0.57 & -0.56 & 0.48 & 0.25 & 0.41 & 0.21 & 0.64 & 0.61 \\
\hline OPN & 0.75 & 0.17 & -0.83 & 0.53 & -0.76 & 1.00 & -0.02 & 0.25 & 0.47 & -0.01 & 0.54 & 0.57 & -0.49 & -0.57 & -0.52 & -0.51 & -0.74 & -0.24 \\
\hline AGR & 0.02 & -0.16 & -0.27 & 0.06 & -0.46 & -0.02 & 1.00 & 0.34 & 0.15 & -0.55 & 0.01 & 0.11 & 0.05 & 0.51 & 0.07 & 0.36 & -0.10 & -0.67 \\
\hline VEG & 0.37 & 0.16 & -0.50 & 0.07 & -0.56 & 0.25 & 0.34 & 1.00 & 0.44 & -0.31 & 0.38 & 0.09 & -0.06 & 0.05 & -0.04 & -0.08 & -0.21 & -0.69 \\
\hline WAT & 0.13 & 0.26 & -0.63 & 0.61 & -0.64 & 0.47 & 0.15 & 0.44 & 1.00 & 0.02 & 0.64 & 0.40 & -0.54 & -0.30 & -0.46 & -0.10 & -0.21 & -0.20 \\
\hline GWD & 0.01 & -0.21 & 0.20 & -0.08 & 0.34 & -0.01 & -0.55 & -0.31 & 0.02 & 1.00 & 0.01 & -0.04 & -0.17 & -0.17 & -0.02 & -0.10 & 0.44 & 0.37 \\
\hline $\mathrm{TN}_{\mathrm{IN}}$ & 0.43 & 0.62 & -0.70 & 0.52 & -0.57 & 0.54 & 0.01 & 0.38 & 0.64 & 0.01 & 1.00 & 0.65 & -0.45 & -0.43 & -0.22 & -0.12 & -0.47 & -0.13 \\
\hline TNouT & 0.37 & 0.32 & -0.73 & 0.84 & -0.56 & 0.57 & 0.11 & 0.09 & 0.40 & -0.04 & 0.65 & 1.00 & -0.47 & -0.32 & -0.22 & 0.22 & -0.44 & -0.03 \\
\hline TPIN & -0.28 & -0.05 & 0.50 & -0.56 & 0.48 & -0.49 & 0.05 & -0.06 & -0.54 & -0.17 & -0.45 & -0.47 & 1.00 & 0.64 & 0.80 & 0.29 & 0.10 & -0.03 \\
\hline TPout & -0.43 & -0.33 & 0.32 & -0.39 & 0.25 & -0.57 & 0.51 & 0.05 & -0.30 & -0.17 & -0.43 & -0.32 & 0.64 & 1.00 & 0.52 & 0.69 & 0.39 & -0.36 \\
\hline Chlain & -0.33 & -0.10 & 0.39 & -0.35 & 0.41 & -0.52 & 0.07 & -0.04 & -0.46 & -0.02 & -0.22 & -0.22 & 0.80 & 0.52 & 1.00 & 0.45 & 0.16 & -0.03 \\
\hline Chlaout & -0.58 & -0.09 & 0.18 & 0.12 & 0.21 & -0.51 & 0.36 & -0.08 & -0.10 & -0.10 & -0.12 & 0.22 & 0.29 & 0.69 & 0.45 & 1.00 & 0.42 & -0.01 \\
\hline DOIN & -0.64 & -0.39 & 0.68 & -0.35 & 0.64 & -0.74 & -0.10 & -0.21 & -0.21 & 0.44 & -0.47 & -0.44 & 0.10 & 0.39 & 0.16 & 0.42 & 1.00 & 0.21 \\
\hline DOOUT & -0.40 & 0.23 & 0.53 & -0.06 & 0.61 & -0.24 & -0.67 & -0.69 & -0.20 & 0.37 & -0.13 & -0.03 & -0.03 & -0.36 & -0.03 & -0.01 & 0.21 & 1.00 \\
\hline
\end{tabular}

Notes: (1) Data for all variables were $\log _{10}$ transformed to incorporate any non-linear correspondences; (2) the correlations in bold are significant at 95\% level of confidence (p-values < 0.05); (3) A, S, I, D , BUL, OPN, AGR, VEG, WAT, and GWD, respectively, refer to subwatershed area, slope, imperviousness, distance from coast, built-up land, open land, agriculture, vegetation, waterbody, and groundwater depth. The subscripts "IN" and "OUT", respectively, refer to the inlet and outlet of a stream reach (or subwatershed). 
Table A2.4: Percent variance explained by each principal component (PC) in separate principal component analyses of four water quality indicators.

\begin{tabular}{crrrrrrrr}
\hline Principal Component & \multicolumn{2}{c}{ TN } & \multicolumn{3}{c}{ TP } & \multicolumn{2}{c}{ Chla } & \multicolumn{2}{c}{ DO } \\
& Wet & \multicolumn{1}{c}{ Dry } & \multicolumn{1}{c}{ Wet } & Dry & Wet & Dry & \multicolumn{1}{c}{ Wet } & Dry \\
\hline PC 1 & 46.19 & 46.73 & 39.90 & 42.16 & 38.06 & 40.53 & 43.59 & 44.59 \\
PC 2 & 14.94 & 15.52 & 19.98 & 19.42 & 17.60 & 17.89 & 16.24 & 17.74 \\
PC 3 & 11.15 & 10.69 & 11.43 & 10.25 & 12.47 & 11.63 & 12.63 & 11.00 \\
PC 4 & 10.11 & 9.82 & 10.14 & 9.58 & 10.70 & 9.09 & 9.20 & 10.60 \\
PC 5 & 6.92 & 7.59 & 6.84 & 6.76 & 8.63 & 6.85 & 8.74 & 7.71 \\
PC 6 & 3.66 & 3.78 & 5.42 & 4.57 & 6.53 & 6.31 & 3.73 & 2.95 \\
PC 7 & 2.72 & 2.92 & 2.80 & 3.18 & 2.88 & 3.18 & 2.23 & 2.55 \\
PC 8 & 2.17 & 1.22 & 2.07 & 2.05 & 1.53 & 2.33 & 1.44 & 1.02 \\
PC 9 & 0.93 & 0.80 & 0.67 & 0.93 & 0.76 & 1.09 & 1.12 & 0.76 \\
PC 10 & 0.73 & 0.62 & 0.45 & 0.65 & 0.39 & 0.57 & 0.51 & 0.67 \\
PC 11 & 0.27 & 0.20 & 0.26 & 0.37 & 0.27 & 0.36 & 0.36 & 0.30 \\
PC 12 & 0.21 & 0.11 & 0.04 & 0.09 & 0.20 & 0.15 & 0.21 & 0.12 \\
\hline
\end{tabular}




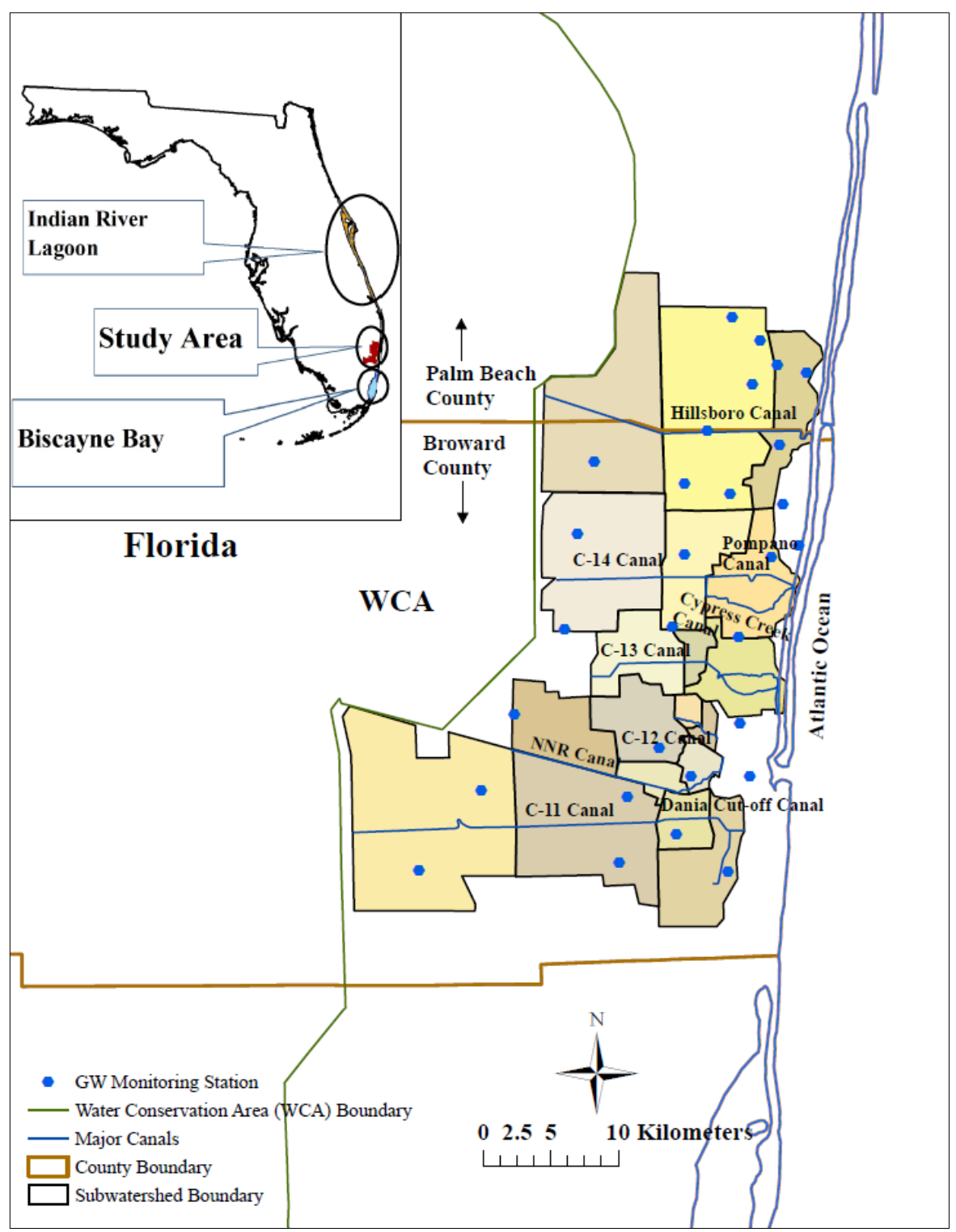

Figure A2.1. Locations of the groundwater monitoring stations. 


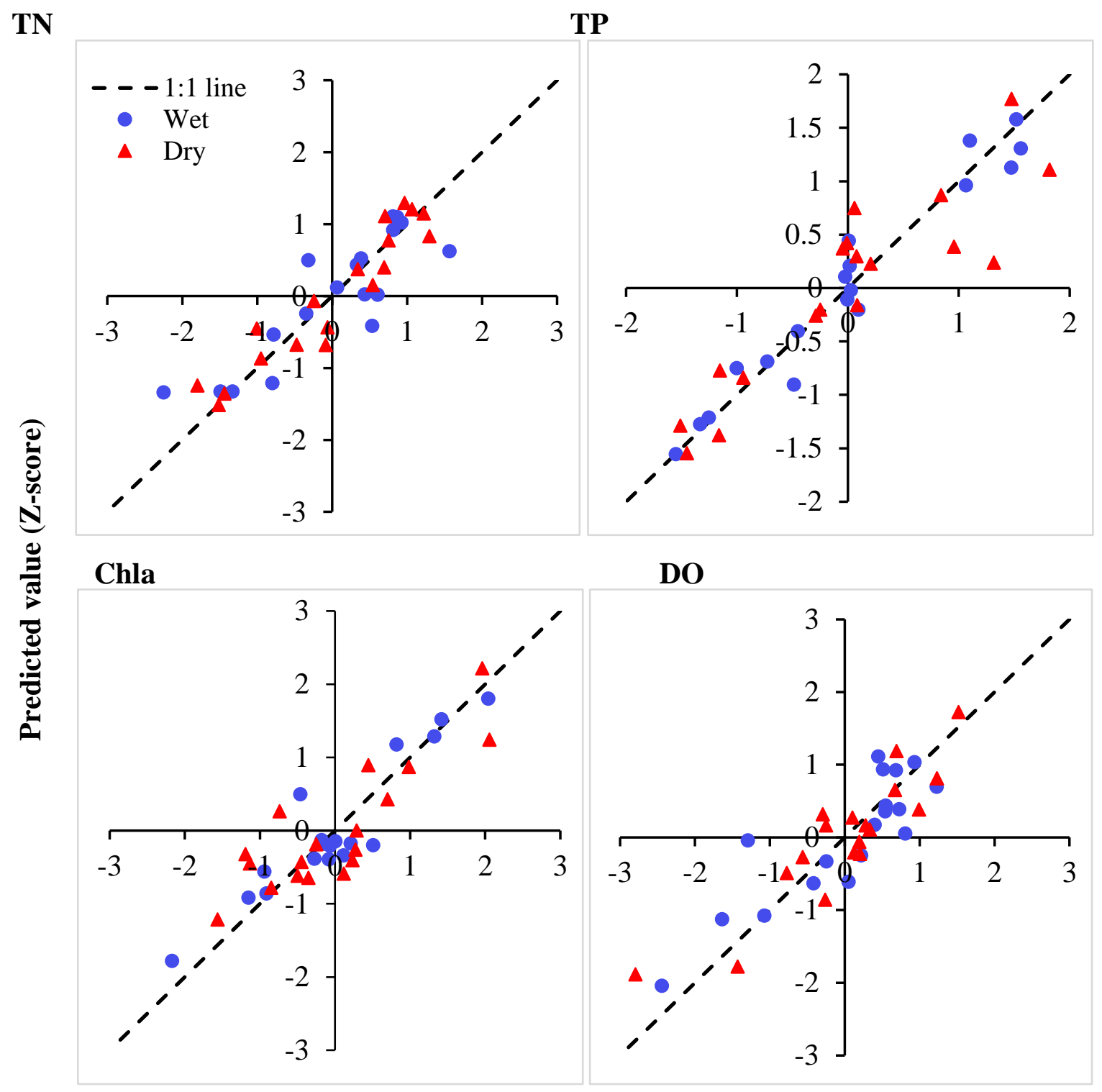

Observed value (Z-score)

Figure A2.2. Observed vs. predicted Z-scores of total nitrogen (TN), total phosphorus (TP), chlorophyll a (Chla), and dissolved oxygen (DO) in the wet and dry seasons. 


\title{
Chapter 3: Evaluating the contrasting hydrologic and land use controls of coastal-urban stream water quality by formulating similitude and dimensionless numbers
}

\begin{abstract}
The contrasting hydrologic and land use controls of coastal-urban stream water quality were evaluated by employing similitude and dimensional analysis, considering southeast Florida a prototype of growing/complex coastal-urban environments around the world. The concentrations of total nitrogen (TN), total phosphorus (TP), and algal biomass (Chla) were normalized by their respective upstream reach concentrations to develop corresponding response dimensionless numbers- $\mathrm{TN} / \mathrm{TN}_{0}, \mathrm{TP} / \mathrm{TP}_{0}$, and Chla/Chla 0 . The dimensionless concentrations offered a similar comparable scale to analyze stream water quality subjected to different upstream contributions. However, dimensionless concentration of dissolved oxygen $\left(\mathrm{DO} / \mathrm{DO}_{\text {sat }}\right)$ was formed through normalizing by its saturated concentration $\left(\mathrm{DO}_{\text {sat }}\right)$ — avoiding misleading scaling by upstream reach concentration due to the presence of DO sag phenomenon. The predictor dimensionless numbers represented collective controls from the interactions of multitude of environmental processes. 'Hydrologic control number' represented the relative control of watershed hydrology vs. external driver (e.g., Everglades), 'salinity number' represented the control from relative increase of salinity, 'land use number' showed the relative control of nonurban to urban land, and 'hyporheic (exchange) number' represented the relative influence of interacting groundwater and watershed hydrology. A systematic data analytics framework implied that the 'hydrologic control number' and the 'salinity number' had been most important to control $\mathrm{TN} / \mathrm{TN}_{0}$ across wet and dry seasons. However, the 'land use number' and the 'hydrologic control number' dominated the $\mathrm{TP} / \mathrm{TP}_{0}$ and Chla/Cha 0 in both seasons. $\mathrm{DO} / \mathrm{DO}_{\text {sat }}$ was dominated by the
\end{abstract}


'hyporheic number' and 'land use number' in wet and dry seasons, respectively. The research validated the hypothesis that coastal-urban stream water quality processes follow distinct 'biogeochemical-ecological' similitude (parametric reductions) — by reducing 9 original variables into 5 dimensionless numbers for each water quality indicator. The knowledge of the similitude and dominant dimensionless numbers are expected to guide effective management to achieve healthy coastal-urban stream ecosystems.

\subsection{Introduction}

Human civilizations have closely been linked with rivers and streams for ages. A healthy stream is, therefore, at the core of good human health. Stream water quality and ecosystem health is shaped by complex interactions of watershed land use/cover, hydrologic, and in-stream drivers (Caccia and Boyer, 2005; Tran et al., 2010; Badruzzaman et al., 2012). The multitude of sources, drivers, and their interplays pose a major challenge to develop a precise and robust understanding into the most dominant processes components of stream water quality, as well as their comparative influences and emerging patterns. The challenge becomes particularly formidable in rapidly expanding coastal-urban environments such as southeast Florida, which represents a low surface elevation, high groundwater table, relatively flat topography, and complex drainage network. It remains an unknown whether the many process drivers of coastalurban stream water quality can be reduced into a smaller set of explicit (rather than latent) and composite but simple and interpretable entities. What are the contrasting roles of draining watershed hydrology vs. the external drivers (upstream inland and downstream coastal), watershed surface vs. groundwater hydrology, and built-up vs. nonurban (e.g., agricultural) land uses in driving coastal-urban stream water quality? What exclusive roles does salinity play in driving the key water quality indicators of coastal-urban streams? Similitude and dimensional 
analysis can help answering these questions by incorporating the important physical, chemical, biological, and ecological processes into a small set of dimensionless entities or numbers (Warnaars et al., 2007). Mechanistically meaningful numbers can indicate the emerging patterns and provide a robust (i.e., generalizable/transferable) understanding into the dynamics of stream water quality and ecosystem health (Miragliotta, 2011).

Many studies reported various land uses/covers as the major drivers of coastal-urban stream water quality. Both urban and non-urban land uses have been identified as strong drivers of elevated level of in-stream nutrients (e.g., nitrogen, phosphorus) and depleted dissolved oxygen in coastal-urban streams (Tufford et al., 2003; Carey et al., 2013; Wan et al., 2014a,b; Xiao et al., 2016). Carey et al. (2011b) found that the watershed land uses had been important sources of nutrient (nitrogen and phosphorus) loadings into the inland canals of Biscayne Bay Watershed, Florida during 1995-2004. Strong association of stream water quality with agricultural land alongside the upstream water control was also reported by Wan et al. (2014b) in the Indian River Lagoon Watershed, Florida. Xiao et al. (2016) studied the relationship between the river water quality and landscape patterns in Huzhou City, China, and found that farmland and built-up land had been the sources of oxygen demanding materials into the stream. Further, they found the relationship between the stream water quality and land uses to vary seasonally. For example, chemical oxygen demand (COD) and petroleum were higher during flood period than low water period, while dissolved total phosphorus and total nitrogen were higher in low water period.

Apart from the land uses, the hydrologic drivers have also been reported to control stream water quality. Kang et al. (2010) reported that watershed hydrology (e.g., size and permeability) had been important factor affecting land use contributions to stream water quality in Yeongsan 
watershed, Korea. Wan et al. (2014a) reported strong influence of watershed size and permeability on the concentration of nutrients (e.g., TN, TP) of the Xitiaoxi River Watershed, China. Tran et al. (2010) studied stream water quality in eastern New York State (upper and lower Hudson Valley, Champlain Valley), where they showed that watershed size had substantial control on how the land uses influence the pollutant concentration of stream. Further, Woodcock et al. (2006) reported the linkage between the distribution of biotic communities (e.g., macroinvertebrate taxa) and hydrologic drivers (e.g., water quantity, drainage patterns etc.) in the stream of Adirondack catchments, New York.

Groundwater hydrology has been found as an important driver of coastal stream water quality. For example, Menció and Mas-Pla (2008) reported that the surface water quality in urbanized Mediterranean streams had been directly linked to the groundwater contributions. Sprague (2005) reported the control of groundwater hydrology on the concentration of dissolved nutrients and calcium bicarbonate in many rivers and streams of South Platte River Basin, Colorado. In addition to the groundwater hydrology, saltwater intrusion has been reported to affect the stream water quality in the coastal watersheds (Liu et al., 2010). Saltwater intrusion affects the characteristics of an aquatic ecosystem, and changes the composition of aquatic community (e.g., ammonia-oxidizing bacteria and phytoplankton) (see references in Xie et al., 2017). Magalhães et al. (2005) reported the effect of salinity on the nitrification rates in sediments and rocky biofilms of the Douro River estuary, Portugal. Hart et al. (1991) reported lethal effects of increased salinity on aquatic plants and invertebrates in the Australian river, stream and wetland ecosystems.

Although numerous literatures studied the coastal stream water quality dynamics, it is yet to be understood well how the watershed land use, hydrologic, in-stream, and external drivers 
mutually interact to collectively control coastal-urban stream water quality. Similitude and dimensional analysis can be leveraged in this regard to identify the collective controls of the drivers and their contrasting roles on coastal stream water quality. Similitude and dimensional analysis have widely been used in many engineering disciplines to gain insights into the relative roles of the dominant process drivers, discover emerging patterns, and formulate robust models (Miragliotta, 2011; Hondzo et al., 2013). In the field of classical fluid mechanics and hydraulic engineering, similitude has been defined as the parametric reduction of physical problems by developing independent dimensionless numbers and a dimensionless formulation of the physical system (Kundu and Cohen, 2004). Each dimensionless number represents the collective influence of different environmental processes, and thus enriches the knowledge of the studied phenomenon (Zeleňáková et al., 2013). Similitude can be achieved through dimensional analysis (e.g., using Buckingham pi-theorem) or through normalizing (i.e., scaling) the underlying governing equations by appropriate characteristic parameters (Kundu and Cohen, 2004).

A classical example of similitude in hydraulic engineering applications can be the Moody chart (Finnemore and Franzini, 2002) for pipe flow design. Dimensional analysis reduced the 7 parameters for pipe flow (flow velocity, pressure, viscosity, density, pipe diameter, length, and roughness) to 3 mechanistically meaningful dimensionless parameters (pipe friction factor, Reynolds number, and relative roughness). Warnaars et al. (2007) applied similitude and dimensional analysis in-stream biogeochemistry and ecology to investigate how biotic (e.g., biomass) and abiotic (e.g., climatic, hydrologic, and geomorphic) variables are interconnected in different streams and rivers across North America. Zeleňáková et al. (2013) applied dimensional analysis in water quality modeling to determine nitrogen and phosphorus concentrations using the corresponding drivers (e.g., flow, catchment area, velocity of stream, and temperature of air 
and water) in the River Laborec located in eastern Slovakia. Hondzo et al. (2013) applied dimensional analysis to investigate how dissolved oxygen mass balance is dominated by photosynthesis, respiration, advection, dispersion, and aeration in the Minnehaha Creek, Minnesota. Guentzel et al. (2014) employed dimensional analysis to study nitrate ( $\mathrm{NO}_{3}^{-}$) uptake by sediment denitrification in the streams of south-central Minnesota. Morris and Hondzo (2013) employed dimensionless numbers to investigate the dissolved oxygen consumption of macroinvertebrate under varying fluid flow conditions in laboratory setting. Abdul-Aziz et al. (2007a,b) scaled stream dissolved oxygen measured at different clock times of the day by a reference time to get dimensionless dissolved oxygen — employed to formulate an extended stochastic harmonic analysis (ESHA). Abdul-Aziz and Ishtiaq (2014) leveraged the dimensionless dissolved oxygen to develop a spatiotemporally robust empirical model to predict the diurnal cycle of stream dissolved oxygen from a single reference observation.

The goal of the study is to evaluate the contrasting hydrologic and land use controls of coastal-urban stream water quality (total nitrogen, TN; total phosphorus, TP; chlorophyll a, Chl a; dissolved oxygen, DO) by formulating similitude and dimensionless numbers. The research tests a fundamental hypothesis that the coastal-urban stream water quality processes follow distinct 'biogeochemical-ecological' similitude. The study leverages southeast Florida as a prototype of growing coastal-urban environments and a living laboratory and hot-spot for climate change and sea level rise around the world. Dimensional analysis is employed to formulate mechanistically meaningful dimensionless numbers, and the most dominant dimensionless numbers are then identified using a data analytics methodology (Ishtiaq and Abdul-Aziz, 2015). The dominant dimensionless numbers are leveraged to investigate the interactive roles of different environmental process components to control coastal stream water quality. The research 
findings are expected to guide water quality management to achieve healthy coastal-urban stream ecosystems.

\subsection{Materials and methods}

\subsubsection{Study area}

To represent growing coastal-urban environments, we selected the watersheds/basins of southeast Florida encompassing the Broward County and a part of Palm Beach County (Figure 3.1). The region is located between the Biscayne Bay and the Indian River Lagoon Watersheds, and primarily drained by an intricate network of several natural and dredged canals (Broward County, 2016). Most of the canals are connected (Figure 3.1) to the Florida Everglades water conservation areas (WCAs) at upstream (to west) and the Atlantic Ocean at downstream (to east). Therefore, proximity to the WCAs and ocean influence the in-stream biogeochemistry and water quality of the study basins (BCEPD, 2007). The study area comprised of five major canal basins in southeast Florida (Figure 3.1): Hillsboro Canal, C-14 Canal (Cypress Creek Canal, Pompano Canal), C-13 Canal, North New River (NNR) Canal, and C-11 Canal. Overall, the five canals represent a good physical range (see Table 3.1) of coastal-urban watersheds, and drain approximately $865 \mathrm{~km}^{2}$ of highly urban areas to the estuarine waters. Details on the canals can be found in Cooper and Lane (1987) and BCEPD (2007).

\subsubsection{Data sets}

We investigated the commonly used water quality indicators for stream water quality studies: total nitrogen (TN), total phosphorus (TP), chlorophyll a (Chla), and dissolved oxygen (DO), accounting for their importance in representing healthy aquatic ecosystem (Chang, 2008; Daniel et al., 2010; Wan et al., 2014a). The hydrologic, land use, and coastal drivers of stream water 
quality were selected based on our process understanding of stream water quality dynamics, and preliminary analysis performed in dimensional domain. Quarterly time-series data of stream water quality (TN, TP, Chla, DO, and salinity) during 2009-13 were collected for 19 monitoring stations across the study area (Figure 3.1) from the Broward County Environmental Planning and Community Resilience Division (BCEPCRD, 2015).

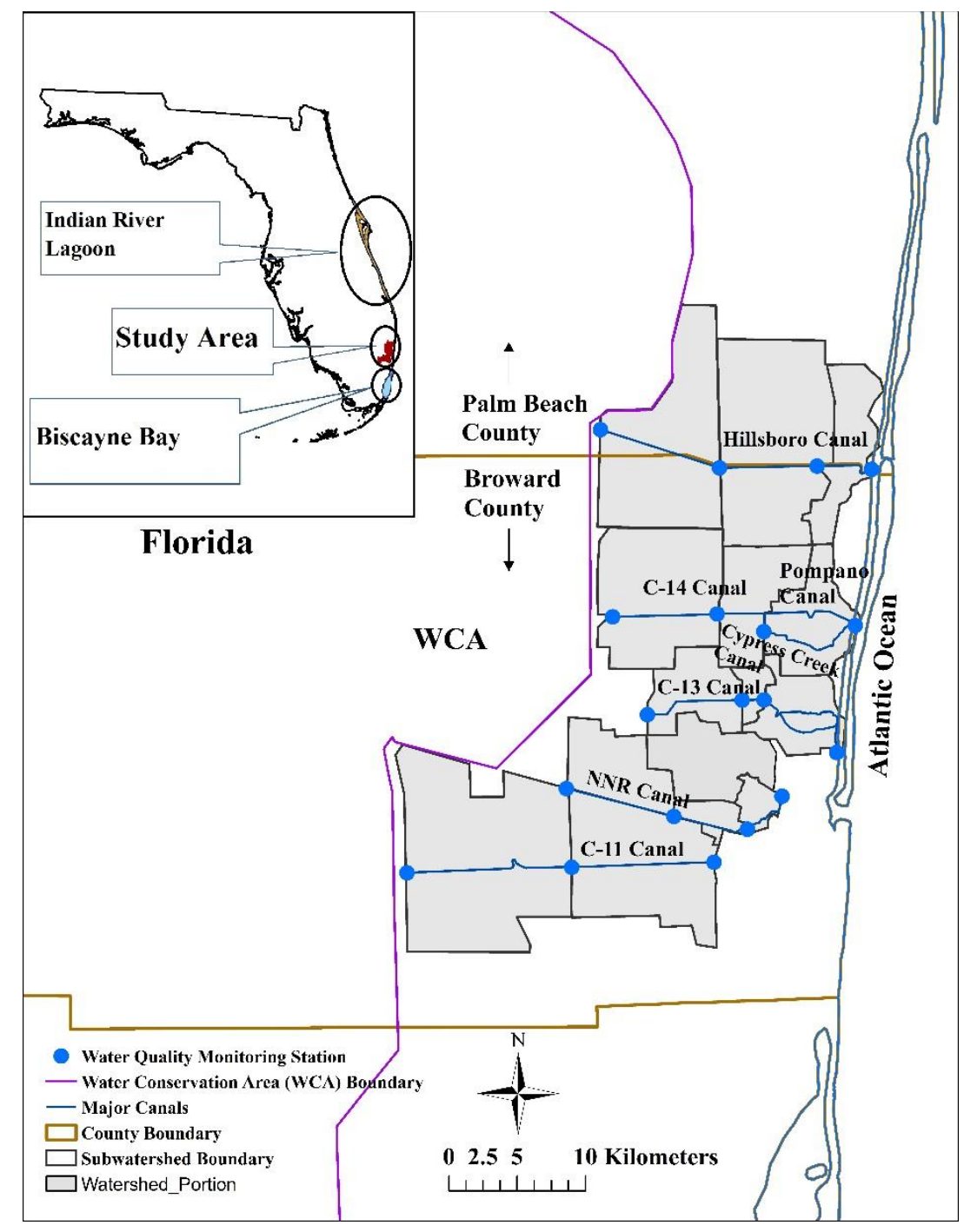

Figure 3.1. Locations of the water quality monitoring stations in the major canals, and their corresponding watershed boundaries. Inset showing the state of Florida is not on the stated scale. 
We developed drainage areas (i.e., subbasins) for the 14 (19 minus the 5 most upstream stations) downstream monitoring stations based on the waterbody identification number of the Florida Department of Environmental Protection (Florida Department of Environmental Protection, 2016), contribution area map provided by the Broward County (Robert Bernhard, personal communications, 2012), and 10m DEM (USGS, 2015a) on ESRI ArcGIS 10.2.

Subbasin characteristic length $\left(\mathrm{L}_{c}\right.$; calculated as the longest flow path to the subbasin outlet) was used to represent controls from the watershed surface hydrologic features. Groundwater depth from the land surface (GWD; which decreases with elevated groundwater table) was used to represent the groundwater hydrologic control. Groundwater level data from 29 monitoring stations of U.S. Geological Survey (USGS, 2015b) were used with kriging interpolation (Goovaerts, 1997; Childs, 2004; Costelloe et al., 2015) to determine the ambient GWD for each water quality station.

The canal centerline distance of each subbasin outlet (i.e., water quality station) from the coastline $\left(D_{c}\right.$; decreases toward the coast and increases toward the Everglades) was computed to represent the effects of both tidal hydrology and Everglades on the stream water quality (Figure 3.1). The coastal control on the in-stream water quality was further represented by the concentration of salinity at the inlet and outlet ( $\mathrm{Sal}_{0}$ and Sal, respectively) of each subbasin. The control of land uses were represented by the built-up areas $\left(\mathrm{A}_{\mathrm{BUL}}\right)$ and nonurban areas $\left(\mathrm{A}_{\mathrm{AGR}}\right.$; agriculture and vegetation). Land use data were collected from the land use and land cover (LULC) database of the South Florida Water Management District (SFWMD) (SFWMD, 2015b). 
Table 3.1. Summary of the stream water quality indicators and their drivers across all sites during 2009-13.

\begin{tabular}{|c|c|c|c|c|c|c|c|}
\hline Variables & Mean & $\begin{array}{c}\text { Standard } \\
\text { Deviation }\end{array}$ & Minimum & $\begin{array}{c}\text { 25th } \\
\text { Percentile }\end{array}$ & $\begin{array}{c}50 \text { th } \\
\text { Percentile }\end{array}$ & $\begin{array}{c}\text { 75th } \\
\text { Percentile } \\
\end{array}$ & Maximum \\
\hline $\mathrm{L}_{\mathrm{c}}(\mathrm{km})$ & 12.26 & 4.20 & 6.71 & 9.17 & 12.10 & 15.04 & 21.31 \\
\hline $\mathrm{D}_{\mathrm{c}}(\mathrm{km})$ & 9.86 & 5.57 & 1.40 & 5.27 & 10.28 & 13.77 & 21.01 \\
\hline $\mathrm{A}_{\mathrm{AGR}}\left(\mathrm{km}^{2}\right)$ & 5.61 & 9.42 & 0.06 & 0.31 & 1.37 & 7.07 & 29.37 \\
\hline$A_{B U L}\left(\mathrm{~km}^{2}\right)$ & 36.32 & 23.31 & 4.88 & 19.84 & 29.98 & 54.97 & 79.77 \\
\hline \multicolumn{8}{|c|}{ Wet Season (June-October) } \\
\hline $\mathrm{TN}(\mathrm{mg} / \mathrm{L})$ & 1.33 & 0.28 & 0.75 & 1.25 & 1.41 & 1.48 & 1.77 \\
\hline $\mathrm{TP}(\mathrm{mg} / \mathrm{L})$ & 0.04 & 0.03 & 0.02 & 0.02 & 0.03 & 0.05 & 0.11 \\
\hline Chla $(\mu \mathrm{g} / \mathrm{L})$ & 7.03 & 2.93 & 3.39 & 5.12 & 6.46 & 8.61 & 15.94 \\
\hline $\mathrm{DO}(\mathrm{mg} / \mathrm{L})$ & 4.02 & 0.96 & 1.61 & 3.24 & 4.50 & 4.77 & 5.21 \\
\hline $\mathrm{DO}_{\text {sat }}(\mathrm{mg} / \mathrm{L})$ & 7.51 & 0.31 & 7.02 & 7.16 & 7.63 & 7.73 & 7.92 \\
\hline Sal (ppt) & 3.07 & 5.93 & 0.13 & 0.18 & 0.28 & 1.58 & 19.40 \\
\hline GWD (m) & 1.96 & 0.74 & 0.79 & 1.38 & 1.84 & 2.63 & 3.11 \\
\hline \multicolumn{8}{|c|}{ Dry Season (November-May) } \\
\hline $\mathrm{TN}(\mathrm{mg} / \mathrm{L})$ & 1.23 & 0.34 & 0.57 & 0.95 & 1.29 & 1.49 & 1.63 \\
\hline $\mathrm{TP}(\mathrm{mg} / \mathrm{L})$ & 0.04 & 0.02 & 0.02 & 0.02 & 0.03 & 0.05 & 0.09 \\
\hline Chla $(\mu \mathrm{g} / \mathrm{L})$ & 4.76 & 2.26 & 2.13 & 2.73 & 4.19 & 6.18 & 10.37 \\
\hline $\mathrm{DO}(\mathrm{mg} / \mathrm{L})$ & 5.81 & 0.99 & 3.34 & 5.72 & 6.13 & 6.28 & 7.10 \\
\hline $\mathrm{DO}_{\text {sat }}(\mathrm{mg} / \mathrm{L})$ & 8.13 & 0.54 & 7.34 & 7.51 & 8.47 & 8.56 & 8.72 \\
\hline Sal (ppt) & 5.64 & 9.14 & 0.03 & 0.04 & 0.08 & 14.98 & 24.13 \\
\hline GWD (m) & 2.11 & 0.78 & 0.77 & 1.53 & 1.99 & 2.86 & 3.42 \\
\hline
\end{tabular}

Notes: $\mathrm{L}_{\mathrm{c}}, \mathrm{D}_{\mathrm{c}}, \mathrm{GWD}, \mathrm{A}_{\mathrm{AGR}}, \mathrm{A}_{\mathrm{BUL}}$, respectively, refer to sub-basin characteristic length, distance of subbasin outlet from the coastline, groundwater depth from land surface, agricultural land area, and built-up land area.

Acknowledging the seasonal variation of climate and hydrology, we performed separate, comparative analyses for the wet (June-October) and dry (November-May) seasons (SFWMD, 2015a). For each season, the spatial dataset was determined by averaging observations of the respective water quality and groundwater data over the 5-year period (2009-13). The concentrations at the immediate upstream monitoring stations $\left(\mathrm{TN}_{0}, \mathrm{TP}_{0}\right.$, and Chla 0$)$ were leveraged to represent the upstream-reach contributions to the downstream stations (TN, TP, and Chla). However, for DO, we leveraged saturated concentration of dissolved oxygen ( $\left.\mathrm{DO}_{\text {sat }}\right)$ 
instead of its upstream concentration - accounting for the fact that the presence of DO sag phenomenon might form misleading dimensionless number while normalizing with upstream concentration. $\mathrm{DO}_{\text {sat }}$ was estimated as a nonlinear function of water temperature, salinity, and atmospheric pressure (Chapra, 2008). Water temperature data were collected from National Water Quality Monitoring Council (NWQMC) (NWQMC, 2017). However, three stations had been missing water temperature data - where it was estimated by employing linear regression between water temperature data from nearby water quality station and corresponding air temperature data from National Solar Radiation Data Base (NSRDB) (NSRDB, 2017). Atmospheric pressure data were collected from South Florida Water Management District (SFWMD, 2016c).

For each water quality indicator (except DO), the final data set (Table 3.1) incorporated concentrations at the inlets and outlets of 14 stream reaches/subbasins, areas of two distinct land uses ( $\mathrm{A}_{\mathrm{AGR}}$ and $\left.\mathrm{A}_{\mathrm{BUL}}\right)$, hydrologic features ( $\mathrm{L}_{\mathrm{c}}$ and $\mathrm{GWD}$ ), salinity (Sal and $\mathrm{Sal}_{0}$ ), and distance from coast $\left(\mathrm{D}_{\mathrm{c}}\right)$. A similar data set was used for $\mathrm{DO}$ - with the exception that saturated concentration of DO had been used instead of the inlet concentration. The data summary across the study area (Table 3.1) and the individual canal basins (Table A3.1 in Appendix 3) suggested wide ranges of water quality indicators and their drivers.

\subsubsection{Dimensional analysis}

We employed dimensional analysis using Buckingham's pi theorem (Finnemore and Franzini 2002; Kundu and Cohen, 2002), which is based on the principle of dimensional homogeneity. The pi theorem states that ' $n$ ' dimensional variables can be combined to form (n-r) dimensionless (pi or П) numbers, where $r$ is the number of relevant fundamental dimensions. The method requires the incorporation of mechanistically relevant and important drivers of individual water 
quality variables. The important variables for the water quality indicators (TN, TP, Chla, DO) were identified based on existing knowledge and a preliminary analysis of our observational datasets. Taking TN as an example, a functional relationship with the relevant predictor variables can be expressed as follows:

$f\left(T N, T N_{0}, S a l, S a l_{0}, L_{c}, D_{c}, G W D, A_{A G R}, A_{B U L}\right)=0$

Therefore, the total number of variables, $n=9$; number of relevant fundamental dimensions, $r=$ 2 (mass: M; length: L) (see Table 3.2 for dimensions of all variables); and the total possible dimensionless $(\Pi)$ numbers $=n-r=7$. Thus, Eq. (1) can be rewritten in terms of pi numbers as follows:

$\phi\left(\Pi_{1}, \Pi_{2}, \Pi_{3}, \Pi_{4}, \Pi_{5}, \Pi_{6}, \Pi_{7}\right)=0$

Table 3.2. List of variables and their dimensions

\begin{tabular}{ll}
\hline Variables & Dimension \\
\hline Concentration of water quality indicators and salinity at & {$\left[\mathrm{M} / \mathrm{L}^{3}\right]$} \\
watershed outlet $(\mathrm{TN}, \mathrm{TP}, \mathrm{Chla}, \mathrm{DO}, \mathrm{Sal})$ & \\
Concentration of water quality indicators and salinity at & {$\left[\mathrm{M} / \mathrm{L}^{3}\right]$} \\
watershed inlet $\left(\mathrm{TN}_{0}, \mathrm{TP}_{0}, \mathrm{Chla}_{0}, \mathrm{Sal}_{0}\right)$ & \\
Saturated concentration of dissolved oxygen $\left(\mathrm{DO}_{\mathrm{sat}}\right)$ & {$\left[\mathrm{M} / \mathrm{L}^{3}\right]$} \\
Characteristic length of sub-watershed $\left(\mathrm{L}_{\mathrm{c}}\right)$ & {$[\mathrm{L}]$} \\
Distance from cost $\left(\mathrm{D}_{\mathrm{c}}\right)$ & {$[\mathrm{L}]$} \\
Groundwater depth from land surface $(\mathrm{GWD})$ & {$[\mathrm{L}]$} \\
Agricultural land $\left(\mathrm{A}_{\mathrm{AGR}}\right)$ & {$\left[\mathrm{L}^{2}\right]$} \\
Built-up land $\left(\mathrm{A}_{\mathrm{BUL}}\right)$ & {$\left[\mathrm{L}^{2}\right]$} \\
\hline
\end{tabular}

The pi theorem led to the selection of two $(r=2)$ "repeating variables", which must contain all the relevant fundamental dimensions ( $\mathrm{M}$ and $\mathrm{L}$ for this study) and must not form a dimensionless number by themselves. Each pi number was formulated by combining the two repeating 
variables with one of the remaining variables. For example, considering $\mathrm{TN}_{0}$ and $\mathrm{L}_{\mathrm{c}}$ as the repeating variables, the first pi number was formulated as follows:

$\Pi_{1}=T N_{0}^{a} D_{c}^{b} L_{c}$

For $\Pi_{1}$ to be dimensionless, the following equation was obtained using the principle of dimensional homogeneity:

$M^{0} L^{0}=\left(\frac{M}{L^{3}}\right)^{a}(L)^{b}(L)=M^{a} L^{-3 a+b+1}$

Equating the exponents on both sides, we got $\mathrm{a}=0, \mathrm{~b}=-1$; therefore,

$$
\Pi_{1}=\left(T N_{0}\right)^{0}\left(D_{c}\right)^{-1}\left(L_{c}\right)=\left(\frac{L_{c}}{D_{c}}\right)
$$

Similarly, the other pi numbers $\left(\Pi_{2}\right.$ to $\left.\Pi_{7}\right)$ were formulated as follows:

$$
\Pi_{2}=\frac{G W D}{L_{c}} ; \Pi_{3}=\frac{T N}{T N_{0}} ; \Pi_{4}=\frac{A_{A G R}}{L_{c}^{2}} ; \Pi_{5}=\frac{A_{B U L}}{L_{c}^{2}} ; \Pi_{6}=\frac{T N_{0}}{S a l} ; \Pi_{7}=\frac{T N_{0}}{S a l_{0}}
$$

Based on the pi theorem, the functional relationship between the response and predictor pi numbers can be expressed as follows:

$$
\frac{T N}{T N_{0}}=\phi\left[\left(\frac{L_{c}}{D_{c}}\right)\left(\frac{G W D}{L_{c}}\right)\left(\frac{A_{A G R}}{L_{c}^{2}}\right)\left(\frac{A_{B U L}}{L_{c}^{2}}\right)\left(\frac{T N_{0}}{S a l}\right)\left(\frac{T N_{0}}{S a l_{0}}\right)\right] .
$$

Different combinations of repeating variables can result in different sets of pi numbers. Various sets of pi numbers were derived by changing the repeating variables for TN, TP, Chla, and DO; only the mechanistically meaningful sets of pi numbers were retained for further analysis. The pi theorem allows combining relevant pi numbers to derive a new pi number (e.g., $A_{A G R} / L_{c}^{2}$ and $A_{B U L} / L_{c}^{2}$ to $A_{A G R} / A_{B U L} ; T N_{0} / S a l$ and $T N_{0} / S a l_{0}$ to $\left.S a l / S a l_{0}\right)$. Following numerous diligent iterations, we obtained meaningful sets of 5 pi numbers (Eqs. 3-6) for each 
water quality and ecosystem health indicator. Based on the pi theorem, the response pi numbers can be expressed as function of the predictor pi numbers as follows:

$$
\begin{aligned}
& \frac{T N}{T N_{0}}=\phi\left[\left(\frac{L_{c}}{D_{c}}\right)\left(\frac{G W D}{L_{c}}\right)\left(\frac{A_{A G R}}{A_{B U L}}\right)\left(\frac{S a l}{S a l_{0}}\right)\right] \\
& \frac{T P}{T P_{0}}=\phi\left[\left(\frac{L_{c}}{D_{c}}\right)\left(\frac{G W D}{L_{c}}\right)\left(\frac{A_{A G R}}{A_{B U L}}\right)\left(\frac{S a l}{S a l_{0}}\right)\right] \\
& \frac{C h l a}{C h l a_{0}}=\phi\left[\left(\frac{L_{c}}{D_{c}}\right)\left(\frac{G W D}{L_{c}}\right)\left(\frac{A_{A G R}}{A_{B U L}}\right)\left(\frac{S a l}{S a l_{0}}\right)\right] \\
& \frac{D O}{D O_{s a t}}=\phi\left[\left(\frac{L_{c}}{D_{c}}\right)\left(\frac{G W D}{L_{c}}\right)\left(\frac{A_{A G R}}{A_{B U L}}\right)\left(\frac{S a l}{S a l_{0}}\right)\right]
\end{aligned}
$$

The response pi numbers $\mathrm{TN} / \mathrm{TN}_{0}, \mathrm{TP} / \mathrm{TP}_{0}$, and Chla/Chla 0 represented, respectively, the outlet concentrations of TN, TP, and Chla for each subbasin, as normalized by their respective inlet concentrations. The dimensionless concentrations bring water quality indicators of different subbasins to a similar scale with respect to their inlet concentrations — offering generalized entities to investigate stream water quality in the regional scale and beyond. However, $\mathrm{DO} / \mathrm{DO}_{\text {sat }}$ represented the outlet concentrations of DO normalized by the corresponding oxygen dissolution capacity of stream water (i.e., DO at saturation, $\mathrm{DO}_{\text {sat }}$ ). The scaling helped to avoid a misleading scaling of DO by the corresponding upstream reach concentration (i.e., $\mathrm{DO}_{0}$ ), which can be impacted by the well-known DO sag phenomenon in streams (Chapra, 2008).

The predictor pi numbers represented the collective as well as the relative controls of different environmental processes on stream water quality. $L_{c} / D_{c}$ represented the control of watershed hydrology relative to the external drivers (upstream Everglades and downstream tidal hydrology), and can therefore be termed the 'hydrologic control number'. GWD/L $\mathrm{L}_{c}$ represented 
the relative influence of groundwater hydrology to the watershed surface hydrology, and was termed the 'hyporheic (exchange) number'. $\mathrm{A}_{\mathrm{AGR}} / \mathrm{A}_{\mathrm{BUL}}$ represented the relative control of agricultural and vegetated land to built-up land, and was termed the 'land use number'. Further, the salinity number $\mathrm{Sal} / \mathrm{Sal}_{0}$ represented the relative control of salinity on the downstream water quality compared to that at the immediate upstream reach. The data summary of the pi numbers across the study area (Table A3.2 in Appendix 3) and the individual canal basins (Table A3.3 in Appendix 3) suggested their wide ranges and variability.

For each water quality parameter (TN, TP, Chl a, DO), dimensional analysis reduced the 9 original variables to a set of 5 meaningful pi numbers. Recalling the definition of similitude from fluid mechanics (Kundu and Cohen, 2002), such parametric reductions of stream water quality process was termed 'stream biogeochemical-ecological similitude' in this research. The functional relationships between the response and the predictor pi numbers can be expressed as a power-law equation as follows:

$$
\Pi_{1}=k \Pi_{2}^{a} \Pi_{3}^{b} \Pi_{4}^{c} \Pi_{5}^{d}
$$

where the coefficient $(k)$ and exponents $(a, b, c, d)$ have to be estimated by fitting with observational data for the respective pi numbers. However, upon data standardization and resolution of any multicollinearity (mutual correlations among pi numbers), the estimation process would indicate the relative strength and independent contribution of each predictor pi number on the water quality response pi number. This would identify a much smaller set of effective and dominant predictor pi numbers for each response (water quality) pi number contributing further into the parametric reductions and stream ecological-biogeochemical 
similitude. Meaningful dimensionless groups can provide important insights and understanding into the processes of coastal-urban stream water quality and ecosystem health.

\subsubsection{Identification of the dominant pi numbers}

We employed a data analytics framework (Ishtiaq and Abdul-Aziz, 2015; Abdul-Aziz and Ahmed, 2017) to identify the dominant, mechanistically meaningful predictor (land use and hydrologic) pi numbers for each response (water quality) pi number. The analytics involved a systematic and sequential utilization of four multivariate pattern recognition techniques: (i) Pearson correlation matrix, (ii) principal component analysis (PCA), (iii) factor analysis (FA), and (iv) partial least squares regression (PLSR). The 4-step analytics — rather than any individual analysis step — was designed to corroborate and synthesize converging information from different steps to achieve the overall outcomes. The data analytics were performed with logarithmically transformed and standardized (dimensionless Z-score) data. The logarithmic transformation of the data accounts for the non-linear interaction in the system, and the Z-score brings different pi numbers in a similar comparable reference scale. The Z-score was calculated

as follows: $Z=(X-\bar{X}) / s_{X}$, where $X=\log _{10}$-transformed variable, $\bar{X}=$ mean of $X$, and $s_{X}$ $=$ standard deviation of $X$. The analyses and modeling were performed using MATLAB.

The Pearson correlation matrix provided background information on the mutual correspondences (i.e., multicollinearity) among the pi numbers. PCA and FA were then employed to examine the interrelationship patterns among the pi numbers by resolving multicollinearity in the orthogonal (independent) domain (Jolliffe, 2002). PCA derives orthogonal entities called principal components (PCs) where each PC is a linear combination of all original variables. However, FA involves the decomposition of the original variables into a 
smaller set of latent entities called factors. A varimax orthogonal rotation is typically performed to optimize loadings of all original variables on each factor. The number of optimal factors to describe most data-system variance was determined by using an eigenvalue criteria such as eigenvalue $\geq 1$. Given the reverse but complementary methodologies, PCA and FA were used in concert to represent a relatively unbiased and confirmatory representation of the interrelations among the pi numbers. Finally, PLSR model was employed to quantify the relative linkages between the response and predictor pi numbers. PLSR model combines features from PCA and multiple linear regressions to predict the relationships between the response and predictor variables (Wold et al., 2001). Unlike conventional principal component regression, PLSR finds the orthogonal partial least squares (PLS) components of predictors and fits them with the response through a simultaneous decomposition of all predictor as well as the response variables (Schumann et al., 2013). Since PLSR is performed on transformed orthogonal planes, the model instability and error caused by multicollinearity among the predictors are appropriately resolved. Further details into the data analytics can be found in Ishtiaq and Abdul-Aziz (2015).

The PLSR models were optimized using a synthesis of the minimum Akaike Information Criterion (AIC) and the maximum Nash-Sutcliffe efficiency (NSE) criteria (Nash and Sutcliffe, 1970; Ishtiaq and Abdul-Aziz, 2015). The optimized PLSR models were computed with observed data using SIMPLS algorithm (de Jong, 1993; Hubert and Branden, 2003) and a 10fold cross validation method (Kuhn and Johnson, 2013). The PLSR model coefficients (BETA) represented the estimated relative linkages between the response and predictor pi numbers. The efficiency and accuracy of the final model were, respectively, measured by NSE and the ratio of root-mean-square error to the standard deviation of the observations (RSR). An NSE of 1.0 indicates a perfect model, whereas NSE $<0$ refers to a model that is a worse predictor than the 
mean of observations as the alternative model (Moriasi et al., 2007). The RSR values of $0-0.5$, 0.5-0.6, 0.6-0.7, and $>0.70$ indicate respectively, "very good", "good", "satisfactory", and "unsatisfactory" models (Moriasi et al., 2007).

\subsection{Results}

\subsubsection{Mutual correspondences of the pi numbers}

The mutual nonlinear correspondences between the response and predictor pi numbers $\left(\log _{10^{-}}\right.$ transformed and standardized) were first examined by computing correlation coefficients (r) for both wet and dry seasons (Table 3.3). Results showed that $\mathrm{TN} / \mathrm{TN}_{0}$ had strong correlations with $\mathrm{L}_{\mathrm{c}} / \mathrm{D}_{\mathrm{c}}(\mathrm{r}=-0.62$ to -0.75$)$ and $\mathrm{Sal} / \mathrm{Sal}{ }_{0}(\mathrm{r}=-0.78$ to -0.87$)$ across the two seasons; suggesting that the nitrogen dynamics was dominated by the 'hydrologic control number' and 'salinity number'. However, $\mathrm{TP} / \mathrm{TP}_{0}$ was dominated by $\mathrm{A}_{\mathrm{AGR}} / \mathrm{A}_{\mathrm{BUL}}(\mathrm{r}=0.49$ to 0.62$)$ in both seasons; indicating the strongest control of basin 'land use number' on the in-stream TP dynamics. In contrast, Chla/Chlan showed moderate/strong correlations with $\mathrm{L}_{\mathrm{d}} / \mathrm{D}_{\mathrm{c}}$ in both seasons $(\mathrm{r}=-0.60$ to -0.66$)$ and with $\mathrm{A}_{\mathrm{AGR}} / \mathrm{A}_{\mathrm{BUL}}(\mathrm{r}=0.57)$ in wet season - indicating the dominant controls of "hydrologic control number' and 'land use number' on the in-stream Chla dynamics. However, DO/DO ${ }_{\text {sat }}$ showed most strong correlations with $\mathrm{GWD} / \mathrm{L}_{\mathrm{c}}(\mathrm{r}=0.70)$ and $\mathrm{A}_{\mathrm{AGR}} / \mathrm{A}_{\mathrm{BUL}}(\mathrm{r}=-0.74)$, respectively, in the wet and dry seasons. Further, moderate correlations with $\mathrm{DO} / \mathrm{DO}_{\text {sat }}$ were also found with $\mathrm{L}_{\mathrm{c}} / \mathrm{D}_{\mathrm{c}}(\mathrm{r}=0.48)$ and Sal/Sal$l_{0}(\mathrm{r}=0.55)$ in wet season, and with $\mathrm{GWD} / \mathrm{L}_{\mathrm{c}}(\mathrm{r}=0.57)$ in dry season. 
Table 3.3. Pearson correlation coefficients ( $\mathrm{r}$ ) between the response and predictor pi numbers.

\begin{tabular}{lrrrrrrrr}
\hline & \multicolumn{2}{c}{$\mathrm{TN}^{2} \mathrm{TN}_{0}$} & \multicolumn{2}{c}{$\mathrm{TP}^{2} \mathrm{TP}_{0}$} & \multicolumn{2}{c}{ Chla/Chla 0} & \multicolumn{2}{c}{$\mathrm{DO} / \mathrm{DO}_{\text {sat }}$} \\
\hline & Wet & Dry & Wet & Dry & Wet & Dry & Wet & Dry \\
$\mathrm{L}_{\mathrm{c}} / \mathrm{D}_{\mathrm{c}}$ & $\mathbf{- 0 . 7 5}$ & $\mathbf{- 0 . 6 2}$ & -0.18 & -0.23 & $\mathbf{- 0 . 6 6}$ & $\mathbf{- 0 . 6 0}$ & 0.48 & 0.11 \\
$\mathrm{GWD} / \mathrm{L}_{\mathrm{c}}$ & -0.11 & -0.34 & -0.03 & 0.00 & -0.06 & 0.01 & $\mathbf{0 . 7 0}$ & $\mathbf{0 . 5 7}$ \\
$\mathrm{A}_{\mathrm{AGR}} / \mathrm{A}_{\mathrm{BUL}}$ & 0.16 & 0.16 & $\mathbf{0 . 6 2}$ & 0.49 & $\mathbf{0 . 5 7}$ & 0.29 & -0.40 & $\mathbf{- 0 . 7 4}$ \\
$\mathrm{Sal}_{\mathrm{Sal}} \mathrm{l}_{0}$ & $\mathbf{- 0 . 7 8}$ & $\mathbf{- 0 . 8 7}$ & -0.10 & 0.28 & -0.37 & 0.22 & $\mathbf{0 . 5 5}$ & 0.40 \\
\hline
\end{tabular}

Note: (1) Data for all pi numbers were $\log _{10}$ transformed to incorporate any nonlinear correspondences. (2) Correlations in bold are significant at the $95 \%$ level of confidence from a two-tailed test.

The correlation matrices (Tables A3.4 and A3.5 in Appendix 3) represented mutual correlations among the predictor pi numbers, indicating multicollinearity in the data matrix. For example, strong correlation $(r=0.74)$ was found between $S a l / S a l_{0}$ and $L_{d} / D_{c}$ in wet season. The positive correspondence can be explained by the increasing salinity (i.e., increasing $\mathrm{Sal} / \mathrm{Sal}_{0}$ ) and decreasing $D_{c}$ (i.e., increasing $L_{c} / D_{c}$ ) toward the coast. However, in dry season the correlation was much reduced $(r=0.47)$; which might be due to the frequent operation of the salinity control structures in dry period when salinity intrusion toward inland is higher due to reduced upstream flow (Xie et al., 2017). Further, moderate negative linkage $(r=-0.55$ to -0.57$)$ between GWD/L $\mathrm{L}_{\mathfrak{c}}$ and $\mathrm{A}_{\mathrm{AGR}} / \mathrm{A}_{\mathrm{BUL}}$ indicated that the relative ratio of nonurban (high permeability) to urban (low permeability) land has substantial control on the interaction of groundwater and surface water hydrology by aquifer recharge through infiltration.

\subsubsection{Relative orientations of the pi numbers}

The nonlinear loadings of the pi numbers on the first two PCs are shown through biplots in wet (Figure 3.2a) and dry (Figure 3.2b) seasons. The first two PCs explained approximately $65 \%$ to $71 \%$ of the total data variances for the pi numbers across the two seasons (see Table A3.6 in 
Appendix 3). Based on the relative orientations and length of the vectors, strong negative linkages of TN/TN 0 was apparent with $\mathrm{Sal} / \mathrm{Sal}_{0}$ and $\mathrm{L}_{\mathrm{c}} / \mathrm{D}_{\mathrm{c}}$ in both seasons, reiterating that $\mathrm{TN}$ dynamics is primarily controlled by 'hydrologic control number' and 'salinity number'. However, $\mathrm{TP} / \mathrm{TP}_{0}$ and $\mathrm{Chla} / \mathrm{Chla} 0$ showed moderate to strong positive linkage with $\mathrm{A}_{\mathrm{AGR}} / \mathrm{A}_{\mathrm{BUL}}$ across both seasons, suggesting that relatively higher ratio of nonurban (e.g., agricultural and vegetated) to urban land contributed to in-stream TP and Chla. DO/DO ${ }_{\text {sat, }}$ in wet season, showed moderate to strong positive linkages with $\mathrm{GWD} / \mathrm{L}_{\mathrm{c}}, \mathrm{L}_{\mathrm{c}} / \mathrm{D}_{\mathrm{c}}$, and $\mathrm{Sal} / \mathrm{Sal} \mathrm{l}_{0}$, whereas moderate negative linkage with $\mathrm{A}_{\mathrm{AGR}} / \mathrm{A}_{\mathrm{BUL}}$. However, in dry season, it showed strong negative linkage with $\mathrm{A}_{\mathrm{AGR}} / \mathrm{A}_{\mathrm{BUL}}$, and moderate positive linkage with $\mathrm{GWD} / \mathrm{L}_{\mathrm{c}}$.

Moderate to strong linkages among the response pi numbers were also apparent from the biplots. With similar type of orientation patterns, Chla/Chal ${ }_{\mathrm{o}}$ and $\mathrm{TP} / \mathrm{TP}_{0}$ showed strong mutual correspondence, suggesting TP as limiting nutrient. Moderate to strong negative linkages of $\mathrm{DO} / \mathrm{DO}_{\text {sat }}$ with $\mathrm{TN} / \mathrm{TN}_{0}, \mathrm{TP} / \mathrm{TP}_{0}$, and Chla/Chla 0 indicated, respectively, the deteriorating effect of TN, TP, and Chla on stream DO. Further, moderate linkage was found between $\mathrm{TN} / \mathrm{TN}_{0}$ and Chla/Chla 0 in wet season; which, however, had been weak in dry season. This might be because biodegradation of insoluble organic nitrogen to dissolved inorganic nitrogen (accessible to algae) was higher in relatively low salinity during wet season than that of dry season (see Table 3.1).

The PC scores on the biplots manifested important insights into the distribution of response and predictor pi numbers among the five canals. For example, C-11 canal was characterized by relatively high $\mathrm{A}_{\mathrm{AGR}} / \mathrm{A}_{\mathrm{BUL}}$ alongside high $\mathrm{TP} / \mathrm{TP}_{0}$ and Chla/Chla 0 — apparent from the closeness of the corresponding vectors to the $\mathrm{C}-11$ canal sites. $\mathrm{C}-13$ canal sites had both high and low $\mathrm{L}_{\mathrm{c}} / \mathrm{D}_{\mathrm{c}}, \mathrm{Sal} / \mathrm{Sal}_{0}$, and TN/TN $\mathrm{T}_{0}$ alongside relatively moderate to high $\mathrm{GWD} / \mathrm{L}_{\mathrm{c}}$, 
Similarly, for the other canals, the response and predictor pi numbers showed good distribution with relatively low to high values.

(a)

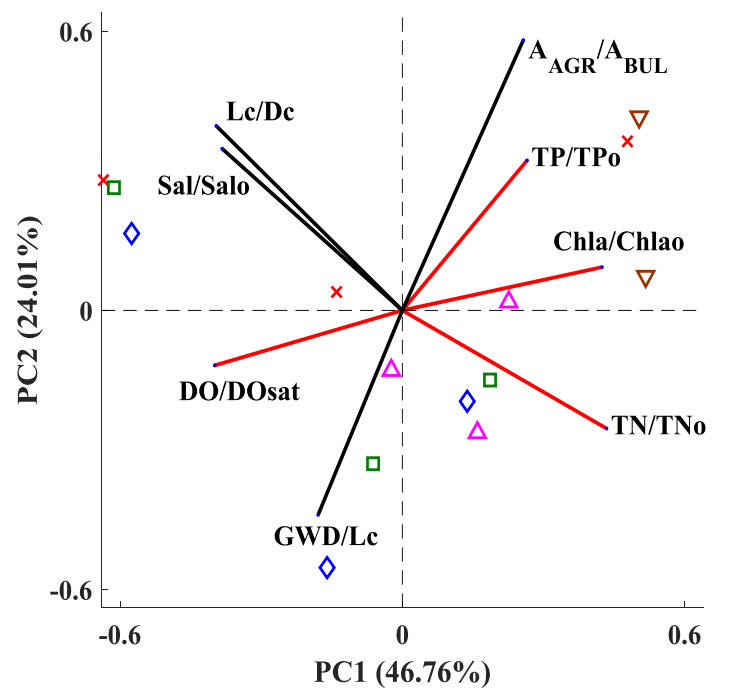

(b)

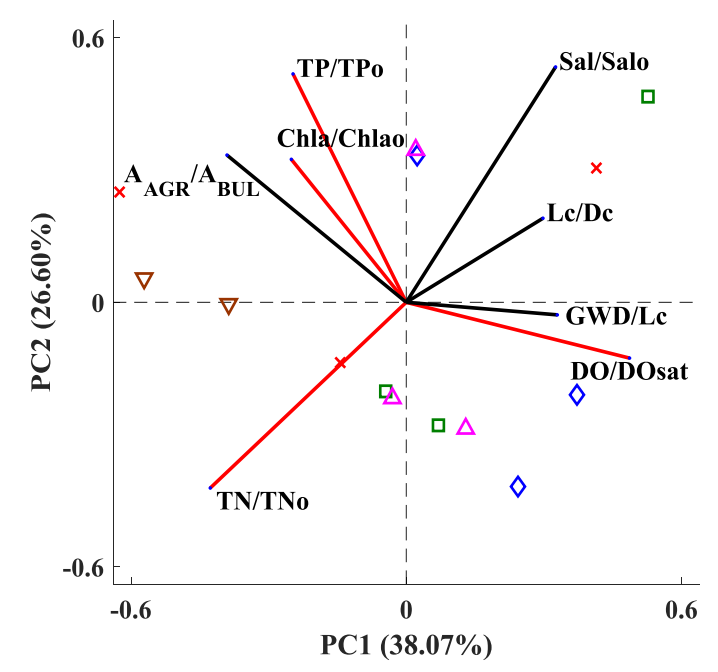

C-13 Canal $\Delta$ NNR Canal $\nabla$ C-11 Canal

Figure 3.2. Biplots from principal component analysis showing the interrelation patterns of the predictor pi numbers and response pi number in (a) wet and (b) dry seasons. Percent variance explained by each PC is shown in parenthesis.

\subsubsection{Interrelations among the pi numbers based on independent latent factors}

The eigenvalue $\geq 1$ criteria led to 3 independent factors that optimally explained the hidden patterns into the data matrices (Table 3.4). Variance explained by the first three factors ranged, respectively, from approximately $38 \%$ to $47 \%, 24 \%$ to $27 \%$, and $18 \%$ to $22 \%$ among the two seasons. 
Table 3.4. Major latent factors with their optimized loadings on the pi numbers.

\begin{tabular}{cccccccccc}
\hline & $\mathrm{F}$ & $\mathrm{TN}^{2} / \mathrm{TN}_{0}$ & $\mathrm{TP} / \mathrm{TP}_{0}$ & $\mathrm{Chla} / \mathrm{Chla} 0$ & $\mathrm{DO} / \mathrm{DO}_{\text {sat }}$ & $\mathrm{L}_{\mathrm{c}} / \mathrm{D}_{\mathrm{c}}$ & $\mathrm{GWD} / \mathrm{L}_{\mathrm{c}}$ & $\mathrm{A}_{\mathrm{AGR}} / \mathrm{A}_{\mathrm{BUL}}$ & $\mathrm{Sal} / \mathrm{Sal}_{0}$ \\
\hline \multirow{6}{*}{ Wet } & 1 & $\mathbf{- 0 . 7 4}$ & -0.08 & $\mathbf{- 0 . 5 6}$ & $\mathbf{0 . 5 1}$ & $\mathbf{0 . 9 9}$ & -0.08 & 0.17 & $\mathbf{0 . 7 6}$ \\
& 2 & 0.23 & $\mathbf{0 . 7 7}$ & $\mathbf{0 . 8 3}$ & -0.14 & -0.13 & -0.11 & $\mathbf{0 . 7 9}$ & 0.07 \\
& 3 & -0.19 & 0.00 & -0.01 & $\mathbf{0 . 7 8}$ & -0.05 & $\mathbf{0 . 9 2}$ & $\mathbf{- 0 . 5 0}$ & 0.23 \\
& 1 & $\mathbf{- 0 . 9 1}$ & 0.26 & 0.04 & 0.30 & $\mathbf{0 . 6 3}$ & 0.12 & 0.01 & $\mathbf{0 . 9 7}$ \\
& 2 & 0.18 & $\mathbf{0 . 5 7}$ & 0.13 & $\mathbf{- 0 . 9 5}$ & 0.12 & $\mathbf{- 0 . 5 6}$ & $\mathbf{0 . 7 7}$ & -0.12 \\
& 3 & 0.17 & $\mathbf{0 . 5 3}$ & $\mathbf{0 . 9 9}$ & -0.05 & $\mathbf{- 0 . 6 4}$ & 0.09 & 0.18 & 0.20 \\
\hline
\end{tabular}

Note: Bold values indicates variables having moderate to high loadings (correlations) on factors (F); F1-3 refer to three different factors, with F1 and F3 explaining the most and least variances, respectively.

$\mathrm{TN} / \mathrm{TN}_{0}$ in both seasons loaded most strongly on factor $1(-0.74$ to -0.91$)$, which had strong loadings of $\mathrm{L}_{\mathrm{c}} / \mathrm{D}_{\mathrm{c}}(0.63$ to 0.99$)$ and $\mathrm{Sal}_{\mathrm{Sal}}$ (0.76 to 0.97$)$; reiterating the strong control of 'hydrologic control number' and 'salinity number' on the dynamics of stream TN. However, both $\mathrm{TP} / \mathrm{TP}_{0}$ and Chla/Chla 0 loaded most strongly on factor $2(0.77$ to 0.83$)$ in wet season, along with the respective loading of $\mathrm{A}_{\mathrm{AGR}} / \mathrm{A}_{\mathrm{BUL}}(0.79)$; suggesting strong control of interacting land uses and reiterating TP as the limiting nutrient. In dry season, the TP and Chla numbers loaded moderate to strongly on factor 3 (0.53 to 0.99$)$ — which had high loading of $\mathrm{L}_{\mathrm{c}} / \mathrm{D}_{\mathrm{c}}(-0.64)$; implying strong control of 'hydrologic control number' in low flow period. Further, TP number loaded moderately on factor 2 (0.57) in dry season, which had high loading of $\mathrm{A}_{\mathrm{AGR}} / \mathrm{A}_{\mathrm{BUL}}(0.77)$ — indicating strong control of interacting land uses on TP dynamics. $\mathrm{DO} / \mathrm{DO}_{\text {sat }}$, in wet season, loaded most strongly on factor 3 (0.78), which had high loading of GWD/L $(0.92)$; indicating dominant control of interacting groundwater and surface water hydrology. However, in dry season, $\mathrm{DO} / \mathrm{DO}_{\text {sat }}$ loaded most strongly on factor $2(-0.95)$, which had high loading of $\mathrm{A}_{\mathrm{AGR}} / \mathrm{A}_{\mathrm{BUL}}(0.77)$ - suggesting strong control of the interacting land uses on DO. Further, both $\mathrm{DO} / \mathrm{DO}_{\text {sat }}$ and Chla/Chla 0 had moderate loadings on factor 1 (0.51 and -0.56 , respectively) in wet 
season, suggesting notable controls of 'salinity number' and 'hydrologic control number' on stream biomass and dissolved oxygen.

\subsubsection{Relative linkages between response and predictor pi numbers}

The synthesis of minimum AIC and acceptable NSE led to the inclusion of 2 PLS components achieving optimum PLSR models (Figure 3.3a, 3.3b). The model fitting efficiency (NSE $=0.57$ to 0.90 ), accuracy ( $R S R=0.31$ to 0.64 ), and observed vs. fitted data (Figure A3.1 in Appendix) indicated good performance of the optimal models. The power-law based PLSR models of Zscores were significant at the 95\% confidence level. The regression coefficients of PLSR models of Z-scores represented the estimated relative linkages between the response and predictor pi numbers (Table 3.5).

TN/TN 0 showed strong negative linkages $(\beta=-0.38$ to -0.64$)$ with $\mathrm{L}_{\mathrm{c}} / \mathrm{D}_{\mathrm{c}}$ and $\mathrm{Sal} / \mathrm{Sal} \mathrm{l}_{0}$ across wet and dry seasons — indicating dominant controls of 'hydrologic control number' and 'salinity number' on TN dynamics. Thus, the quantified relative linkages from PLSR model resolving the issue of mutual correlations between 'salinity number' and 'hydrologic control number' - implied that nitrogen dynamics had been primarily controlled by the interaction of external driver (e.g., upstream Everglades' contribution) and watershed hydrology alongside salinity. However, $\mathrm{TP} / \mathrm{TP}_{0}$ and $\mathrm{Chla} / \mathrm{Chla}_{0}$ showed moderate to strong positive linkages with $\mathrm{A}_{\mathrm{AGR}} / \mathrm{A}_{\mathrm{BUL}}(\beta=0.46$ to 0.88$)$ across two seasons — suggesting in-stream TP and Chla is strongly controlled by interactive control of land uses. Further, $L_{d} / D_{c}$ showed relatively moderate to strong negative linkages with $\mathrm{TP} / \mathrm{TP}_{0}(\beta=-0.24$ to -0.51$)$ and $\mathrm{Chla} / \mathrm{Chla}_{0}(\beta=-0.69$ to -0.93$)$ in both seasons; which implied that the 'hydrologic control number' has notable influence on instream TP and Chla. Unlike wet season, Sal/Sal0 showed relatively strong linkage ( $\beta=0.53$ to 0.65 ) with both $\mathrm{TP} / \mathrm{TP}_{0}$ and $\mathrm{Chla} / \mathrm{Chla}_{0}$ in dry season. $\mathrm{GWD} / \mathrm{L}_{\mathrm{c}}$ showed moderate positive 
linkages $(\beta=0.28$ to 0.41$)$ with $\mathrm{TP} / \mathrm{TP}_{0}$ and Chla/Chla 0 in wet season. $\mathrm{DO} / \mathrm{DO}_{\text {sat }}$ had the strongest linkage $(\beta=0.66)$ with $\mathrm{GWD} / \mathrm{L}_{\mathrm{c}}$ in wet season — suggesting dissolved oxygen is dominated by the interaction of groundwater and surface water. Further, wet season $\mathrm{DO} / \mathrm{DO}_{\text {sat }}$ had a notable positive linkage with $L_{d} / D_{c}(\beta=0.30)$, suggesting appreciable control of 'hydrologic control number'. However, in dry season, DO/DO sat showed strongest linkage with $\mathrm{A}_{\mathrm{AGR}} / \mathrm{A}_{\mathrm{BUL}}(\beta=-0.63)$, indicating strong control of interacting land uses on DO dynamics during the low flow period.

(a)

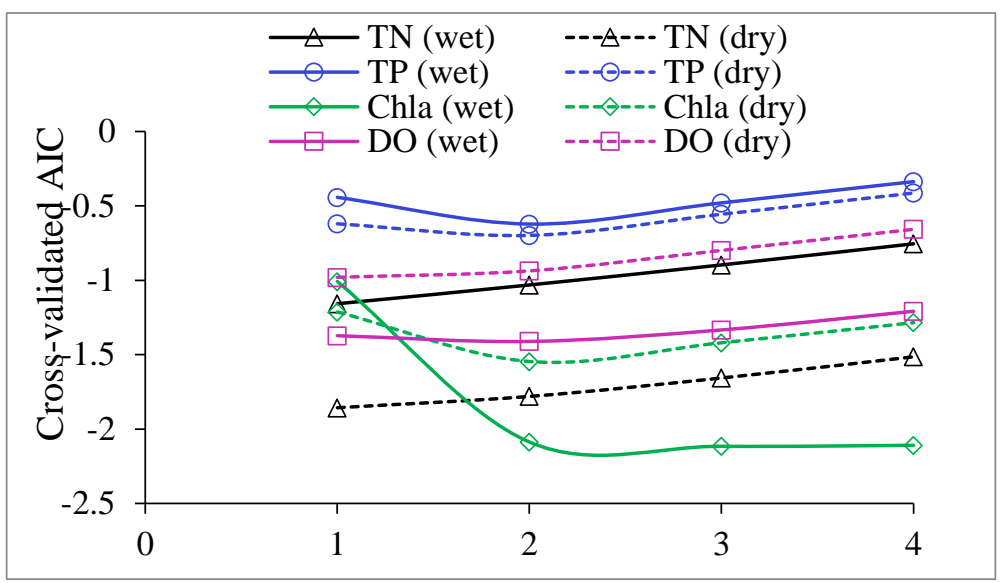

(b)

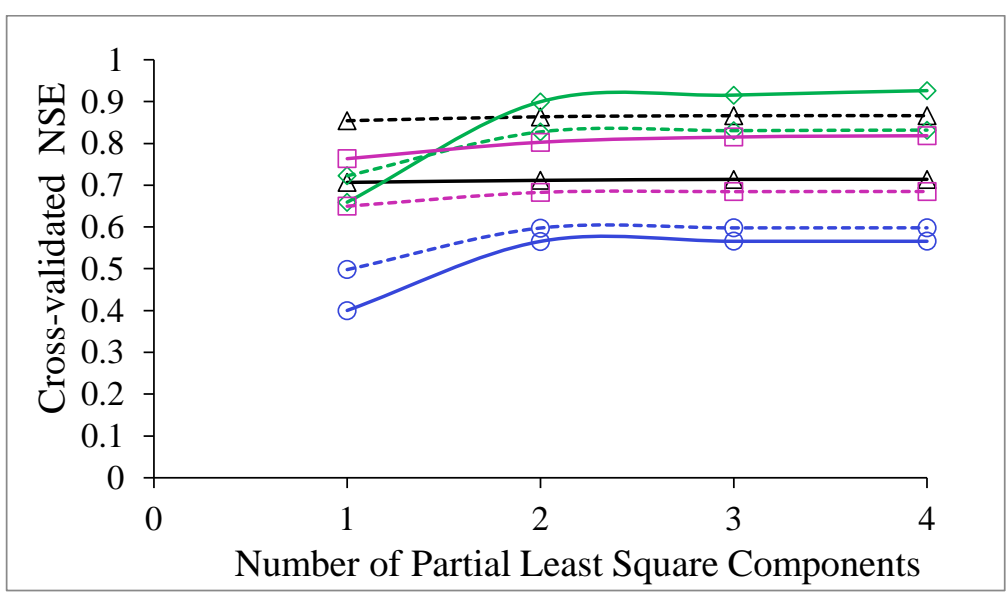

Figure 3.3. Plot of cross-validated (a) normalized AIC and (b) fitting efficiency (NSE) (for both wet and dry seasons) with the number of incorporated partial least squares components. 
Table 3.5. PLSR model coefficients $(\beta)$ of the standardized pi numbers in both wet and dry seasons.

\begin{tabular}{lrrrrrrrr}
\hline Response pi numbers & \multicolumn{2}{c}{$\mathrm{TN}^{2} \mathrm{TN}_{0}$} & \multicolumn{2}{c}{$\mathrm{TP} / \mathrm{TP}_{0}$} & \multicolumn{2}{c}{ Chla/Chla } & \multicolumn{2}{c}{ DO/DO $_{\text {sat }}$} \\
\hline Predictor pi numbers & \multicolumn{1}{c}{ Wet } & Dry & Wet & Dry & Wet & Dry & Wet & Dry \\
$\mathrm{L}_{\mathrm{c}} / \mathrm{D}_{\mathrm{c}}$ & -0.43 & -0.38 & -0.24 & -0.51 & -0.69 & -0.93 & 0.30 & 0.07 \\
$\mathrm{GWD}_{\mathrm{L}} \mathrm{c}$ & -0.06 & -0.20 & 0.41 & 0.22 & 0.28 & 0.09 & 0.66 & 0.14 \\
$\mathrm{~A}_{\mathrm{AGR}} / \mathrm{A}_{\mathrm{BUL}}$ & 0.16 & 0.03 & 0.87 & 0.68 & 0.88 & 0.46 & -0.14 & -0.63 \\
Sal/Sal & -0.46 & -0.64 & 0.05 & 0.53 & 0.11 & 0.65 & 0.26 & 0.32 \\
Model Statistics & & & & & & & & \\
PLS component & 2 & 2 & 2 & 2 & 2 & 2 & 2 & 2 \\
NSE & 0.71 & 0.86 & 0.57 & 0.60 & 0.90 & 0.83 & 0.80 & 0.68 \\
RSR & 0.52 & 0.36 & 0.64 & 0.61 & 0.31 & 0.40 & 0.43 & 0.54 \\
\hline
\end{tabular}

Notes: TN/TN $0, \mathrm{TP} / \mathrm{TP}_{0}, \mathrm{Chla} / \mathrm{Chla} 0$, and $\mathrm{Sal} / \mathrm{Sal}_{0}$, respectively, are the normalized concentrations of $\mathrm{TN}$, $\mathrm{TP}$, Chla, and Sal by their respective inlet concentrations. $\mathrm{DO} / \mathrm{DO}_{\text {sat }}$ is the normalized concentration of DO by its saturation concentration. $\mathrm{L}_{\mathrm{c}} / \mathrm{D}_{\mathrm{c}}, \mathrm{GWD} / \mathrm{L}_{\mathrm{c}}, \mathrm{A}_{\mathrm{AGR}} / \mathrm{A}_{\mathrm{BUL}}$, and Sal/Sal ${ }_{0}$, respectively, refer to 'hydrologic control number', 'hyporheic number', 'land use number', and 'salinity number'. $\mathrm{L}_{c}, \mathrm{D}_{\mathrm{c}}, \mathrm{GWD}, \mathrm{A}_{\mathrm{AGR}}$, and $\mathrm{A}_{\mathrm{BUL}}$, respectively, refer to sub-basin characteristic length, distance of sub-basin outlet from the coastline, groundwater depth from land surface, agricultural land area, and built-up land area.

\subsection{Discussion}

\subsubsection{Dominant pi numbers and their relative linkages}

The synthesis of the four layers of data analytics provided a comprehensive and confirmatory representation of the interrelations and the relative linkage patterns between the response and predicted pi numbers. The correlation analysis identified the multicollinear structure of the datasets alongside the background information on the correspondences among the pi numbers. PCA and FA presented the interrelation patterns among the pi numbers in orthogonal (independent) dimensions, and provided indirect measures of the dominant pi numbers. The orthogonal component-based PLSR modeling directly estimated the relative linkages of the predictor pi numbers with the response pi numbers by resolving multicollinearity. Overall, the 'hydrologic control number' and the 'salinity number' had been the most important pi numbers for $\mathrm{TN} / \mathrm{TN}_{0}$ across the wet and dry seasons. In contrast, the 'land use number' and the 
'hydrologic control number' dominated $\mathrm{TP} / \mathrm{TP}_{0}$ and $\mathrm{Chla} / \mathrm{Cha}_{0}$ in both seasons. However, $\mathrm{DO} / \mathrm{DO}_{\text {sat}}$, was dominated by 'hyporheic number' in the wet season and by 'land use number' in the dry season. The research reduced the 9 original variables into 5 meaningful dimensionless numbers to explain each water quality indicator-validating the hypothesis that coastal-urban stream water quality processes follow distinct 'biogeochemical-ecological' similitude (parametric reductions).

The strong negative linkage between TN number and 'hydrologic control number' (see Table 3.5) indicated that in-stream TN decreases with relatively higher $\mathrm{L}_{c}$ (i.e., larger watershed) and lower $D_{c}$ (i.e., less control from upstream Everglades' contribution). The contrasting role of watershed hydrology vs. external driver might be because Everglades contributes to in-stream nitrogen, while it is diluted by higher runoff generated from larger watersheds. Further, strong negative linkage between TN number and 'salinity number' suggested the adverse effect of salinity on in-stream nitrogen. Salinity adversely affects the metabolism of microbial community (Jackson and Vallaire, 2009) — reducing mineralization of insoluble organic nitrogen settled at the stream-bed, and therefore, reduces the inflow of nitrogen from benthic surface to the water column. Further, nitrogen fixation — that transfers atmospheric nitrogen to surface water (Brock, 2001; Gardner et al., 2006) — is reduced with increased salinity (Herbst, 1998; Palma et al., 2013). This suggests that relatively higher salinity might reduce in-stream TN by inhibiting the transfer of atmospheric nitrogen to surface water.

The strong mutual correlations between TP and Chla numbers alongside their corresponding relative linkages with the predictor pi number suggested TP as the limiting nutrient. The strong positive linkage of 'land use number' with TP and Chla numbers suggested that in-stream TP increases with relatively higher ratio of non-urban to urban land use - 
indicating contrasting role of two different types of land uses. This might be because non-urban land use contributed to in-stream TP through wash-off of fertilizers from agricultural land, while urban land use diluted it by higher runoff generation due to imperviousness. Substantial influences of land uses on coastal-urban stream nutrient is well documented in the literature (see references in Carey et al., 2013). Similar to $\mathrm{TN} / \mathrm{TN}_{0}$, the moderate to strong negative linkages of $\mathrm{L}_{\mathrm{c}} / \mathrm{D}_{\mathrm{c}}$ with TP and Chla numbers showed how the contrasting role of watershed hydrology vs. external driver controlled in-stream TP and biomass. Higher $\mathrm{L}_{\mathrm{c}} / \mathrm{D}_{\mathrm{c}}$ represented relatively larger watershed (i.e., higher $L_{c}$ ) — that might have diluted in-stream phosphorus by higher runoff generation (Kang et al., 2010). Further, the land uses in larger watersheds are more likely to be located relatively far from the stream, and thus, would have less influence on the stream water quality (Tran et al., 2010) — resulting in reduced TP. Apart from that, watershed with higher $\mathrm{L}_{\mathrm{c}} / \mathrm{D}_{\mathrm{c}}$ is relatively far from the Everglades (i.e., smaller $\mathrm{D}_{\mathrm{c}}$ ) leading to less nutrient loading manifested by its negative linkage with TP and Chla numbers. The stronger controls of 'hydrologic control number' on TP and Chla numbers in dry season compared to wet season indicated that watershed size is more important in dry period for the watershed transport of nutrients. This might be due to the fact that TP from the distant location of a large watershed might not reach the stream due to low rainfall-runoff in dry season.

'Salinity number' showed weak linkage with TP number in wet season, which, however, was relatively strong in dry season. This might be due to substantially higher value of 'salinity number' in dry season (average $\mathrm{Sal} / \mathrm{Sal}_{0}=121$ ) than that of wet season (average $\mathrm{Sal} / \mathrm{Sal}_{0}=13$ ). The positive linkage between $\mathrm{TP} / \mathrm{TP}_{0}$ and $\mathrm{Sal} / \mathrm{Sal}_{0}$ suggested that in-stream TP increases when the salinity is relatively higher. This might be due to the fact that salinity decreases the sorption capacity of sediments that binds phosphorus (Fox et al., 1986; Sundareshwar and Morris, 1999; 
Jordan et. al., 2008). Therefore, phosphorus is released in water column by desorption from sediments in highly saline water. In a relevant study (Zhang and Huang, 2011), substantial release of sediment phosphorus was also evident in highly saline water of Florida Bay. Increased amount of dissolved inorganic phosphorus released from the sediments in highly saline water during dry season might have increased phytoplankton production — that led to strong positive linkage between Chla/Chla 0 and 'salinity number'.

The strong linkage of $\mathrm{DO} / \mathrm{DO}_{\text {sat }}$ with $\mathrm{GWD} / \mathrm{L}_{\mathrm{c}}$ in wet season suggested that dissolved oxygen is dominated by the interaction of groundwater and surface water in wet period when groundwater table is elevated in the highly transmissive Biscayne aquifer (Lietz, 1999). Further, the positive linkage suggested that higher GWD/L $\mathrm{L}_{\mathfrak{c}}$ - that refers to less interaction of groundwater and surface water - increases stream dissolved oxygen. This might be due to the low DO in the groundwater of Biscayne aquifer (median $=0.15 \mathrm{mg} / \mathrm{L})($ Bradner et al., 2005) which reduces stream DO while interacting with stream water. However, strong negative linkage of $\mathrm{DO} / \mathrm{DO}_{\text {sat }}$ with 'land use number' in dry season suggested deteriorating effect of higher ratio of non-urban to urban land use in low flow period. Strong association of stream dissolved oxygen with land uses (e.g., urban, non-urban) in coastal environments were also evident by previous studies. For example, Dauer et al. (2000) found that the combined high level of agricultural and urban land use had been responsible for low dissolved oxygen in Chesapeake Bay, U.S.A. Further, Xiao et al. (2016) reported increased level of oxygen demanding material due to urban and agricultural land use in the coastal-urban streams of eastern China.

\subsubsection{Implications for management}

The knowledge of the dominant pi numbers and their relative linkages are expected to guide efficient management of land use, hydrologic, and coastal drivers to achieve healthy coastal- 
urban stream ecosystems. The sign (positive or negative) of the PLSR model coefficients suggested that in-stream nutrient and consequent algal bloom would be reduced in relatively higher 'hydrologic control number' and lower 'land use number' — which, in turn, would increase stream DO. The generalized scales offered by the dimensionless numbers can guide the water managers to identify the streams which are vulnerable to pollution to get management priority. For example, if two watersheds of differing sizes have similar distance from the Everglades, then the smaller watershed is more likely to have higher nitrogen pollution, given that they have identical land use, hyporheic, and salinity numbers. The differing dominant pi numbers in wet and dry seasons for $\mathrm{DO} / \mathrm{DO}_{\text {sat }}$ indicated the importance of dynamic management strategies for dissolved oxygen under changing seasons.

\subsection{Conclusions}

Similitude and dimensionless numbers were formulated to evaluate the contrasting hydrologic and land use controls of coastal-urban stream water quality, considering southeast Florida a prototype of growing/complex coastal-urban environments around the world. The research validated the hypothesis that coastal-urban stream water quality processes follow distinct 'biogeochemical-ecological' similitude (parametric reductions) — by reducing 9 original variables into 5 dimensionless numbers for each water quality indicator. Response dimensionless numbers $\mathrm{TN} / \mathrm{TN}_{0}, \mathrm{TP} / \mathrm{TP}_{0}$, and Chla/Chla 0 represented, respectively, the concentrations of $\mathrm{TN}$, $\mathrm{TP}$, and Chla normalized by their respective upstream reach concentrations. However, dimensionless concentration of dissolved oxygen (DO/DO $\left.\mathrm{Dat}_{\text {sa }}\right)$ was developed by normalizing with its saturated concentration $\left(\mathrm{DO}_{\text {sat }}\right)$, to avoid misleading scaling by upstream reach concentration due to the presence of DO sag phenomenon. The important predictor numbers included the 'hydrologic control number' (ratio of watershed characteristic length to the distance 
from coast), 'hyporheic (exchange) number' (ratio of groundwater depth from the land surface to watershed characteristic length), 'land use number' (ratio of nonurban to urban land area), and the 'salinity number' (ratio of downstream concentrations of salinity to that of immediate upstream). The four predictor numbers adequately represented the collective control from the interactions of a multitude of land use, hydrologic, and external (upstream Everglades and downstream coastal) drivers on coastal-urban stream water quality dynamics (NSE $=0.57$ to $0.90 ; \mathrm{RSR}=0.31$ to 0.64$)$.

A systematic data analytics framework showed that the 'hydrologic control number' and the 'salinity number' had been the most important dimensionless numbers for $\mathrm{TN} / \mathrm{TN}_{0}$ in both wet and dry seasons. In contrast, the 'land use number' and the 'hydrologic control number' dominated the $\mathrm{TP} / \mathrm{TP}_{0}$ and $\mathrm{Chla} / \mathrm{Cha}_{0}$ across the two seasons. However, $\mathrm{DO} / \mathrm{DO}_{\text {sat }}$, was dominated by the 'hyporheic (exchange) number' and 'land use number' in wet and dry seasons, respectively. The contrasting role of watershed hydrology vs. external driver suggested that instream nutrient — contributed from Everglades — had been diluted by higher runoff generated from the larger watersheds. The contrasting role of nonurban vs. urban land use indicated that nonurban land use contributed to TP through agricultural runoff, while urban land use diluted it by higher runoff from imperviousness. Relatively higher salinity reduced in-stream TN by inhibiting nitrogen fixation and reducing mineralization of insoluble organic nitrogen. However, relatively higher salinity increased in-stream TP and consequent algal bloom by increasing phosphorus release from sediment through decreasing its sorption capacity. The interaction of groundwater and surface water dominated stream DO in wet period when groundwater table is elevated in the highly transmissive Biscayne aquifer. However, unlike wet season, dry season DO was primarily controlled by the interactive role of urban vs. nonurban land use; suggesting 
urgency of dynamic management strategies under changing seasons. The knowledge and important insights of the dominant dimensionless numbers are expected to guide efficient water resources management to achieve healthy coastal-urban stream ecosystems.

\section{Acknowledgments}

The research was funded by the National Science Foundation (NSF) CAREER Award to Dr.

Omar I. Abdul-Aziz (NSF CBET Environmental Sustainability Award Number

1561942/1454435). We are thankful to Mr. Robert Bernhard of the Broward County, Florida for sharing study area map and reports. 


\section{Appendix 3}

Table A3.1. Mean and standard deviation (in parenthesis) of the stream water quality indicators and their drivers in the five major canals during 2009-13.

\begin{tabular}{|c|c|c|c|c|c|}
\hline Variables & Hillsboro & $\mathrm{C}-14$ & $\mathrm{C}-13$ & NNR & $\mathrm{C}-11$ \\
\hline $\mathrm{Lc}(\mathrm{km})$ & $15.37(2.84)$ & $11.16(2.45)$ & $9.73(2.76)$ & $9.02(2.87)$ & $14.45(21.31)$ \\
\hline $\mathrm{Dc}(\mathrm{km})$ & $7.80(6.06)$ & $7.65(5.62)$ & $9.51(5.84)$ & $10.53(4.75)$ & $15.79(7.37)$ \\
\hline $\mathrm{A}_{\mathrm{AGR}}\left(\mathrm{km}^{2}\right)$ & $10.98(12.01)$ & $2.00(1.11)$ & $0.33(0.36)$ & $0.37(0.11)$ & $18.75(15.02)$ \\
\hline \multirow[t]{2}{*}{$\mathrm{A}_{\mathrm{BUL}}\left(\mathrm{km}^{2}\right)$} & $53.95(24.66)$ & $44.83(21.97)$ & $19.86(13.07)$ & $13.27(8.99)$ & $56.39(4.01)$ \\
\hline & \multicolumn{5}{|c|}{ Wet Season (June-October) } \\
\hline $\mathrm{TN}(\mathrm{mg} / \mathrm{L})$ & $1.29(0.38)$ & $1.24(0.22)$ & $1.15(0.29)$ & $1.47(0.13)$ & $1.58(0.17)$ \\
\hline $\mathrm{TP}(\mathrm{mg} / \mathrm{L})$ & $0.08(0.04)$ & $0.03(0.01)$ & $0.03(0.01)$ & $0.03(0.01)$ & $0.03(0.02)$ \\
\hline Chla $(\mu \mathrm{g} / \mathrm{L})$ & $10.60(4.03)$ & $7.44(1.72)$ & $4.83(1.40)$ & $5.67(1.62)$ & $6.45(1.30)$ \\
\hline $\mathrm{DO}(\mathrm{mg} / \mathrm{L})$ & $4.22(0.60)$ & $4.78(0.19)$ & $4.46(0.85)$ & $3.37(1.31)$ & $3.03(0.39)$ \\
\hline $\mathrm{DO}_{\text {sat }}(\mathrm{mg} / \mathrm{L})$ & $7.56(0.45)$ & $7.44(0.33)$ & $7.46(0.38)$ & $7.40(0.20)$ & $7.80(0.02)$ \\
\hline Sal (ppt) & $4.06(7.74)$ & $3.31(6.27)$ & $5.31(9.40)$ & $1.74(2.18)$ & $0.22(0.10)$ \\
\hline \multirow[t]{2}{*}{ GWD (m) } & $2.03(0.35)$ & $2.69(0.37)$ & $2.42(0.78)$ & $1.33(0.26)$ & $1.02(0.33)$ \\
\hline & \multicolumn{5}{|c|}{ Dry Season (November-May) } \\
\hline $\mathrm{TN}(\mathrm{mg} / \mathrm{L})$ & $1.20(0.35)$ & $1.14(0.39)$ & $1.02(0.39)$ & $1.31(0.33)$ & $1.53(0.08)$ \\
\hline $\mathrm{TP}(\mathrm{mg} / \mathrm{L})$ & $0.06(0.03)$ & $0.03(0.01)$ & $0.03(0.02)$ & $0.03(0.01)$ & $0.03(0.01)$ \\
\hline Chla $(\mu \mathrm{g} / \mathrm{L})$ & $6.17(0.63)$ & $3.96(0.32)$ & $3.30(1.93)$ & $6.42(3.54)$ & $3.66(2.04)$ \\
\hline $\mathrm{DO}(\mathrm{mg} / \mathrm{L})$ & $5.50(0.65)$ & $6.38(0.29)$ & $6.34(0.53)$ & $5.75(1.40)$ & $4.82(1.32)$ \\
\hline $\mathrm{DO}_{\text {sat }}(\mathrm{mg} / \mathrm{L})$ & $8.27(0.64)$ & $8.11(0.67)$ & $8.07(0.50)$ & $7.81(0.67)$ & $8.50(0.06)$ \\
\hline Sal (ppt) & $5.50(10.91)$ & $5.87(11.62)$ & $7.74(11.31)$ & $7.65(8.80)$ & $0.07(0.02)$ \\
\hline GWD (m) & $2.14(0.26)$ & $2.85(0.37)$ & $2.65(0.86)$ & $1.51(0.23)$ & $1.06(0.41)$ \\
\hline
\end{tabular}

Notes: $\mathrm{L}_{\mathrm{c}}, \mathrm{D}_{\mathrm{c}}, \mathrm{GWD}, \mathrm{A}_{\mathrm{AGR}}$, and $\mathrm{A}_{\mathrm{BUL}}$, respectively, refer to subbasin characteristic length, distance of subbasin outlet from the coastline, groundwater depth from land surface, agricultural land area, and builtup land area. 
Table A3.2. Overall summary of the dimensionless numbers across all sites during 2009-13.

\begin{tabular}{|c|c|c|c|c|c|c|c|}
\hline $\begin{array}{l}\text { Dimensionless } \\
\text { Numbers }\end{array}$ & Mean & $\begin{array}{c}\text { Standard } \\
\text { Deviation }\end{array}$ & Minimum & $\begin{array}{c}25 \text { th } \\
\text { Percentile }\end{array}$ & $\begin{array}{c}\text { 50th } \\
\text { Percentile }\end{array}$ & $\begin{array}{c}\text { 75th } \\
\text { Percentile }\end{array}$ & Maximum \\
\hline $\mathrm{L}_{\mathrm{c}} / \mathrm{D}_{\mathrm{c}}$ & 2.08 & 2.03 & 0.56 & 0.79 & 1.15 & 2.90 & 6.91 \\
\hline $\mathrm{A}_{\mathrm{AGR}} / \mathrm{A}_{\mathrm{BUL}}$ & 0.12 & 0.16 & 0.002 & 0.02 & 0.05 & 0.12 & 0.50 \\
\hline \multicolumn{8}{|c|}{ Wet Season (June-October) } \\
\hline $\mathrm{TN} / \mathrm{TN}_{0}$ & 0.88 & 0.15 & 0.63 & 0.82 & 0.91 & 0.96 & 1.24 \\
\hline $\mathrm{TP} / \mathrm{TP}_{0}$ & 1.52 & 0.83 & 0.94 & 0.98 & 1.36 & 1.59 & 4.23 \\
\hline Chla/Chla 0 & 1.05 & 0.47 & 0.56 & 0.64 & 0.89 & 1.51 & 1.85 \\
\hline $\mathrm{DO} / \mathrm{DO}_{\text {sat }}$ & 0.58 & 0.11 & 0.35 & 0.49 & 0.61 & 0.63 & 0.74 \\
\hline $\mathrm{Sal} / \mathrm{Sal}_{0}$ & 13.20 & 26.24 & 0.53 & 0.91 & 2.09 & 9.84 & 89.60 \\
\hline $\operatorname{GWD} / \mathrm{L}_{\mathrm{c}}\left(10^{-4}\right)$ & 1.81 & 0.95 & 0.37 & 1.22 & 1.42 & 2.50 & 3.81 \\
\hline \multicolumn{8}{|c|}{ Dry Season (November-May) } \\
\hline $\mathrm{TN} / \mathrm{TN}_{0}$ & 0.82 & 0.17 & 0.49 & 0.68 & 0.88 & 0.93 & 1.09 \\
\hline $\mathrm{TP} / \mathrm{TP}_{0}$ & 1.50 & 0.61 & 0.93 & 1.06 & 1.27 & 1.85 & 3.09 \\
\hline Chla/Chlao & 1.28 & 0.76 & 0.34 & 0.83 & 1.01 & 1.46 & 2.83 \\
\hline $\mathrm{DO} / \mathrm{DO}_{\text {sat }}$ & 0.75 & 0.10 & 0.53 & 0.68 & 0.79 & 0.83 & 0.84 \\
\hline $\mathrm{Sal} / \mathrm{Sal}_{0}$ & 121.11 & 245.15 & 0.47 & 0.78 & 1.36 & 111.01 & 739.46 \\
\hline $\mathrm{GWD} / \mathrm{L}_{\mathrm{c}}\left(10^{-4}\right)$ & 1.96 & 1.04 & 0.36 & 1.32 & 1.60 & 2.67 & 4.19 \\
\hline
\end{tabular}

Notes: $\mathrm{TN} / \mathrm{TN}_{0}, \mathrm{TP} / \mathrm{TP}_{0}, \mathrm{Chla} / \mathrm{Chla}_{0}$, and $\mathrm{Sal} / \mathrm{Sal}_{0}$, respectively, are the normalized concentrations of $\mathrm{TN}$, $\mathrm{TP}$, Chla, and Sal by their respective inlet concentrations. $\mathrm{DO} / \mathrm{DO}_{\text {sat }}$ is the normalized concentration of DO by its saturation concentration. $\mathrm{L}_{\mathrm{c}} / \mathrm{D}_{\mathrm{c}}, \mathrm{GWD} / \mathrm{L}_{\mathrm{c}}, \mathrm{A}_{\mathrm{AGR}} / \mathrm{A}_{\mathrm{BUL}}$, and Sal/Salo, respectively, refer to 'hydrologic control number', 'hyporheic number', 'land use number', and 'salinity number'. $\mathrm{L}_{c}, \mathrm{D}_{\mathrm{c}}, \mathrm{GWD}, \mathrm{A}_{\mathrm{AGR}}$, and $\mathrm{A}_{\mathrm{BUL}}$, respectively, refer to sub-basin characteristic length, distance of sub-basin outlet from the coastline, groundwater depth from land surface, agricultural land area, and built-up land area. 
Table A3.3. Mean and standard deviation (in parenthesis) of the dimensionless numbers in the five major canals during 2009-13.

\begin{tabular}{|c|c|c|c|c|c|}
\hline $\begin{array}{l}\text { Dimensionless } \\
\text { Numbers }\end{array}$ & Hillsboro & $\mathrm{C}-14$ & $\mathrm{C}-13$ & NNR & $\mathrm{C}-11$ \\
\hline $\mathrm{L}_{\mathrm{c}} / \mathrm{D}_{\mathrm{c}}$ & $3.08(2.28)$ & $3.04(3.35)$ & $1.87(2.10)$ & $0.91(0.21)$ & $1.19(0.25)$ \\
\hline $\mathrm{A}_{\mathrm{AGR}} / \mathrm{A}_{\mathrm{BUL}}$ & $0.21(0.24)$ & $0.06(0.05)$ & $0.02(0.02)$ & $0.04(0.02)$ & $0.32(0.24)$ \\
\hline \multicolumn{6}{|c|}{ Wet Season (June-October) } \\
\hline $\mathrm{TN} / \mathrm{TN}_{0}$ & $0.79(0.14)$ & $0.87(0.14)$ & $0.82(0.15)$ & $0.93(0.03)$ & $1.08(0.22)$ \\
\hline $\mathrm{TP} / \mathrm{TP}_{0}$ & $2.06(1.88)$ & $1.27(0.27)$ & $1.40(0.38)$ & $1.26(0.30)$ & $1.64(0.25)$ \\
\hline Chla/Chla 0 & $1.02(0.67)$ & $0.94(0.47)$ & $0.93(0.57)$ & $1.21(0.56)$ & $1.23(0.07)$ \\
\hline $\mathrm{DO} / \mathrm{DO}_{\text {sat }}$ & $0.59(0.08)$ & $0.64(0.06)$ & $0.66(0.08)$ & $0.54(0.11)$ & $0.40(0.07)$ \\
\hline $\mathrm{Sal} / \mathrm{Sal}_{0}$ & $19.35(30.85)$ & $30.45(51.23)$ & $6.91(7.25)$ & $3.94(3.82)$ & $1.41(1.24)$ \\
\hline GWD/Lc $\left(10^{-4}\right)$ & $1.33(0.16)$ & $2.46(0.48)$ & $2.70(1.28)$ & $1.54(0.42)$ & $0.62(0.35)$ \\
\hline \multicolumn{6}{|c|}{ Dry Season (November-May) } \\
\hline $\mathrm{TN} / \mathrm{TN}_{0}$ & $0.80(0.22)$ & $0.76(0.24)$ & $0.74(0.13)$ & $0.84(0.10)$ & $1.00(0.12)$ \\
\hline $\mathrm{TP} / \mathrm{TP}_{0}$ & $1.78(1.13)$ & $1.36(0.43)$ & $1.46(0.78)$ & $1.39(0.45)$ & $1.49(0.10)$ \\
\hline Chla/Chla 0 & $0.99(0.17)$ & $0.95(0.12)$ & $1.32(1.30)$ & $1.59(1.08)$ & $1.70(0.69)$ \\
\hline $\mathrm{DO} / \mathrm{DO}_{\text {sat }}$ & $0.66(0.13)$ & $0.80(0.04)$ & $0.81(0.03)$ & $0.82(0.02)$ & $0.65(0.05)$ \\
\hline $\mathrm{Sal} / \mathrm{Sal}_{0}$ & $189.91(327.35)$ & $246.91(426.57)$ & $13.02(18.60)$ & $114.45(195.98)$ & $1.32(0.81)$ \\
\hline GWD/L $L_{c}\left(10^{-4}\right)$ & $1.41(0.20)$ & $2.61(0.51)$ & $2.97(1.41)$ & $1.75(0.47)$ & $0.65(0.41)$ \\
\hline
\end{tabular}

Notes: TN/TN $0, \mathrm{TP} / \mathrm{TP}_{0}, \mathrm{Chla} / \mathrm{Chla}_{0}$, and $\mathrm{Sal} / \mathrm{Sal}_{0}$, respectively, are the normalized concentrations of $\mathrm{TN}$, $\mathrm{TP}, \mathrm{Chla}$, and Sal by their respective inlet concentrations. DO/DO $\mathrm{Dat}_{\text {sat }}$ is the normalized concentration of DO by its saturation concentration. $\mathrm{L}_{\mathrm{c}} / \mathrm{D}_{\mathrm{c}}, \mathrm{GWD} / \mathrm{L}_{\mathrm{c}}, \mathrm{A}_{\mathrm{AGR}} / \mathrm{A}_{\mathrm{BUL}}$, and Sal/Salo, respectively, refer to 'hydrologic control number', 'hyporheic number', 'land use number', and 'salinity number'. $\mathrm{L}_{\mathrm{c}}, \mathrm{D}_{\mathrm{c}}, \mathrm{GWD}, \mathrm{A}_{\mathrm{AGR}}$, and $\mathrm{A}_{\mathrm{BUL}}$, respectively, refer to sub-basin characteristic length, distance of sub-basin outlet from the coastline, groundwater depth from land surface, agricultural land area, and built-up land area. 
Table A3.4. Correlation matrix of the response and predictor pi numbers in wet season (June-

October).

\begin{tabular}{|c|c|c|c|c|c|c|c|c|}
\hline & $\mathrm{TN} / \mathrm{TN}_{0}$ & $\mathrm{TP} / \mathrm{TP}_{0}$ & Chla/Chla0 & $\mathrm{DO} / \mathrm{DO}_{\text {sat }}$ & $\mathrm{L}_{\mathrm{c}} / \mathrm{D}_{\mathrm{c}}$ & $\mathrm{GWD} / \mathrm{L}_{\mathrm{c}}$ & $\mathrm{A}_{\mathrm{AGR}} / \mathrm{A}_{\mathrm{BUL}}$ & $\mathrm{Sal} / \mathrm{Sal}_{0}$ \\
\hline $\mathrm{TN} / \mathrm{TN}_{0}$ & 1.00 & 0.21 & 0.60 & -0.56 & -0.75 & -0.11 & 0.16 & -0.78 \\
\hline $\mathrm{TP} / \mathrm{TP}_{0}$ & 0.21 & 1.00 & 0.68 & -0.17 & -0.18 & -0.03 & 0.62 & -0.10 \\
\hline Chla/Chla0 & 0.60 & 0.68 & 1.00 & -0.41 & -0.66 & -0.06 & 0.57 & -0.37 \\
\hline $\mathrm{DO} / \mathrm{DO}_{\text {sat }}$ & -0.56 & -0.17 & -0.41 & 1.00 & 0.48 & 0.70 & -0.40 & 0.55 \\
\hline $\mathrm{L}_{\mathrm{c}} / \mathrm{D}_{\mathrm{c}}$ & -0.75 & -0.18 & -0.66 & 0.48 & 1.00 & -0.11 & 0.08 & 0.74 \\
\hline $\mathrm{GWD} / \mathrm{L}_{\mathrm{c}}$ & -0.11 & -0.03 & -0.06 & 0.70 & -0.11 & 1.00 & -0.55 & 0.09 \\
\hline $\mathrm{A}_{\mathrm{AGR}} / \mathrm{A}_{\mathrm{BUL}}$ & 0.16 & 0.62 & 0.57 & -0.40 & 0.08 & -0.55 & 1.00 & 0.00 \\
\hline $\mathrm{Sal} / \mathrm{Sal}_{0}$ & -0.78 & -0.10 & -0.37 & 0.55 & 0.74 & 0.09 & 0.00 & 1.00 \\
\hline
\end{tabular}

Notes: (1) Data for all variables were $\log _{10}$ transformed to incorporate any non-linear correspondences;

(2) the correlations in bold are significant at $95 \%$ level of confidence ( $p$-values $<0.05$ ).

Table A3.5. Correlation matrix of the response and predictor pi numbers in dry season (November-May).

\begin{tabular}{|c|c|c|c|c|c|c|c|c|}
\hline & $\mathrm{TN} / \mathrm{TN}_{0}$ & $\mathrm{TP} / \mathrm{TP}_{0}$ & Chla/Chlao & $\mathrm{DO} / \mathrm{DO}_{\text {sat }}$ & $\mathrm{L}_{\mathrm{c}} / \mathrm{D}_{\mathrm{c}}$ & $\mathrm{GWD} / \mathrm{L}_{\mathrm{c}}$ & $\mathrm{A}_{\mathrm{AGR}} / \mathrm{A}_{\mathrm{BUL}}$ & $\mathrm{Sal} / \mathrm{Sal}_{0}$ \\
\hline $\mathrm{TN} / \mathrm{TN}_{0}$ & 1.00 & -0.13 & 0.16 & -0.46 & -0.62 & -0.34 & 0.16 & -0.87 \\
\hline $\mathrm{TP} / \mathrm{TP}_{0}$ & -0.13 & 1.00 & 0.61 & -0.49 & -0.23 & 0.00 & 0.49 & 0.28 \\
\hline Chla/Chla0 & 0.16 & 0.61 & 1.00 & -0.16 & -0.60 & 0.01 & 0.29 & 0.22 \\
\hline $\mathrm{DO} / \mathrm{DO}_{\text {sat }}$ & -0.46 & -0.49 & -0.16 & 1.00 & 0.11 & 0.57 & -0.74 & 0.40 \\
\hline $\mathrm{L}_{\mathrm{c}} / \mathrm{D}_{\mathrm{c}}$ & -0.62 & -0.23 & -0.60 & 0.11 & 1.00 & -0.11 & 0.08 & 0.47 \\
\hline $\mathrm{GWD} / \mathrm{L}_{\mathrm{c}}$ & -0.34 & 0.00 & 0.01 & 0.57 & -0.11 & 1.00 & -0.57 & 0.20 \\
\hline $\mathrm{A}_{\mathrm{AGR}} / \mathrm{A}_{\mathrm{BUL}}$ & 0.16 & 0.49 & 0.29 & -0.74 & 0.08 & -0.57 & 1.00 & -0.05 \\
\hline $\mathrm{Sal} / \mathrm{Sal}_{0}$ & -0.87 & 0.28 & 0.22 & 0.40 & 0.47 & 0.20 & -0.05 & 1.00 \\
\hline
\end{tabular}

Notes: (1) Data for all variables were $\log _{10}$ transformed to incorporate any non-linear correspondences;

(2) the correlations in bold are significant at $95 \%$ level of confidence (p-values < 0.05 ). 
Table A3.6: Percent variance explained by each principal component (PC) in wet and dry seasons.

\begin{tabular}{ccc}
\hline Principal Component & Wet & Dry \\
\hline PC 1 & 46.76 & 38.07 \\
PC 2 & 24.01 & 26.60 \\
PC 3 & 17.82 & 22.05 \\
PC 4 & 4.35 & 7.33 \\
PC 5 & 3.62 & 3.25 \\
PC 6 & 1.99 & 1.71 \\
PC 7 & 1.18 & 0.78 \\
PC 8 & 0.29 & 0.21 \\
\hline
\end{tabular}


$\mathbf{T N} / \mathbf{T N}_{0}$

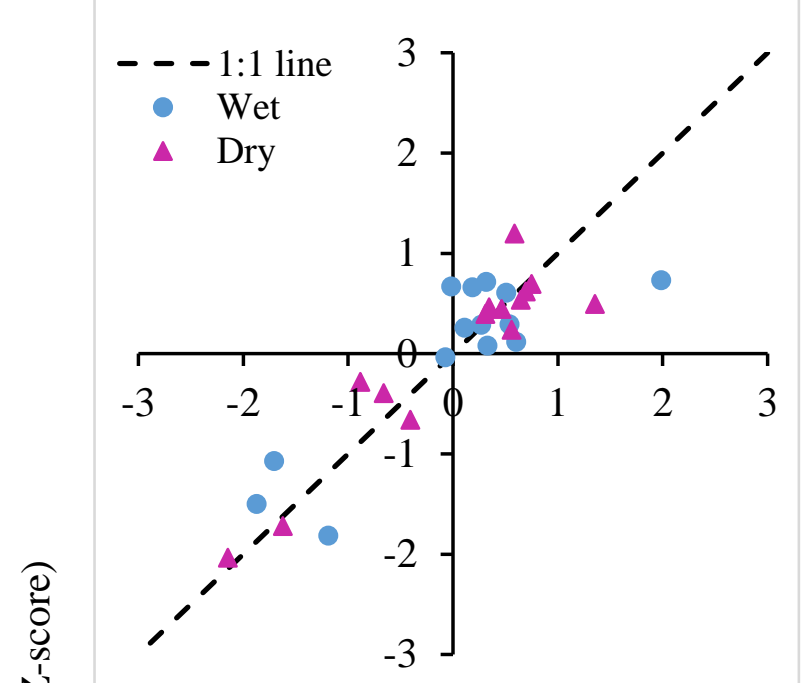

Chla/Chla 0

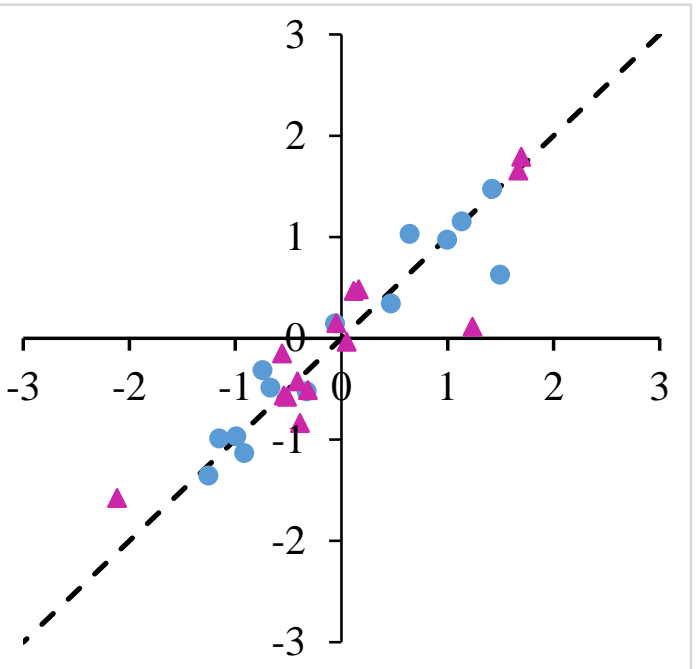

$\mathbf{T P} / \mathbf{T P}_{0}$

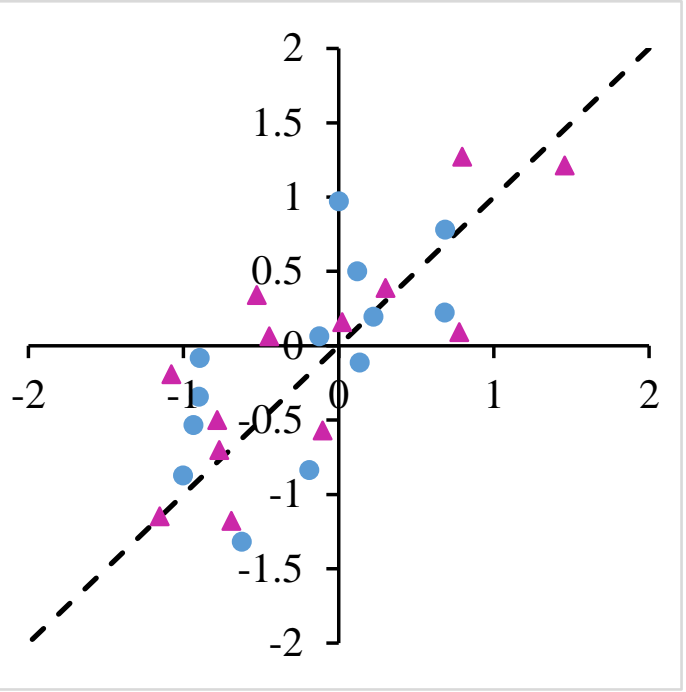

\section{DO/DO sat}

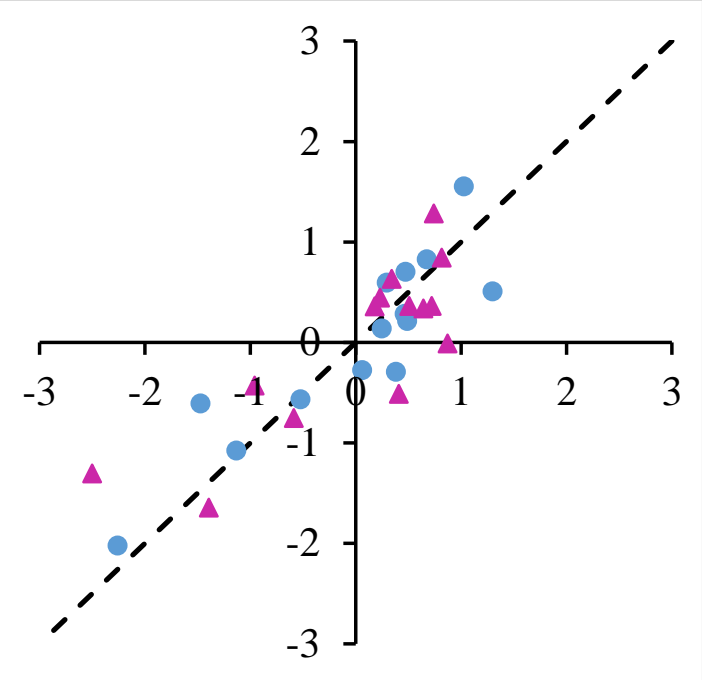

Observed Value (Z-score)

Figure A3.1. Observed vs. predicted Z-scores of TN/TN $0, T P / \mathrm{TP}_{0}, \mathrm{Chla}_{\mathrm{C}} / \mathrm{Chla} 0$, and DO/DO sat in wet (June-October) and dry (November-May) seasons. 


\title{
Chapter 4: Relative controls of land use, hydro-climatic, and biogeochemical drivers on stream dissolved oxygen across the East Coast of U.S.A.
}

\begin{abstract}
The relative controls of land use, hydro-climatic, and biogeochemical drivers on stream dissolved oxygen (DO) were investigated incorporating 50 stream water quality monitoring sites across the East Coast of U.S.A. A systematic data analytics framework - incorporating correlation analysis, principal component analysis, factor analysis, and partial least squares regression model — was employed to quantify the relative linkages resolving multicollinearity. The data analytics implied strong controls of redox drivers $(\mathrm{pH}$, specific conductance) on stream DO in wet season - suggesting domination of metabolic activity (e.g., microbial decomposition) and salinity. However, in dry season, reduced linkage of DO with the redox drivers suggested decreased metabolic control due to lower temperature. Strong negative linkage of DO with stream temperature across the seasons suggested dominant climatic controls. Builtup land was found to have strong positive influence on stream DO by dilution of pollutants with higher runoff generation. Agricultural land showed negative impact on stream DO only in wet season, suggesting a potential source of nutrient enrichment by agricultural runoff. The aggregated linkages showed strongest controls of 'redox' and 'climatic' components, respectively, in wet and dry seasons - approximately 2 to 3 times stronger than the other environmental components. The quantified relative linkages of DO with the land use, hydroclimatic, and biogeochemical drivers across the large spatial scale would guide to develop effective management strategies ensuring healthy coastal streams and ecosystems.
\end{abstract}




\subsection{Introduction}

The protection and management of coastal stream water quality has been a worldwide phenomenon, since it is closely associated with human health and aquatic ecosystem. The interacting effect of land uses, fluctuations in temperature, salinity, nutrient enrichment, and biogeochemical processes make the coastal water highly vulnerable to pollution (Gao and Zheng, 2010; Cai et al., 2011; Badruzzaman et al., 2012). A key indicator of stream water quality is dissolved oxygen (DO) — which has changed drastically over a very short period of time in the coastal environments (Diaz and Rosenberg, 2008) and become a world-wide phenomenon (Zhang et al., 2010). The number of DO depleted sites around the world reported in the literatures has increased an order of magnitude from 1960s to present (Diaz and Rosenberg, 2008) - indicating the urgency for protection and management of coastal stream water quality. Effective management interventions require identification of the dominant coastal stream water quality drivers - which, however, is yet to be achieved across a large spatial scale. The study of the interrelationships among the land uses, hydro-climatic, and biogeochemical drivers, and their quantified relative controls could provide profound knowledge to aid effective management of coastal stream water quality and ecosystem health.

Reduced DO phenomena in coastal water by organic matter alongside nutrient (e.g., TN, TP) enrichment have been reported to adversely affect the surface water quality (Dodds, 2006; Pena et al., 2010; King et al., 2015). Wan et al. (2014b) reported that the nutrient input in secondary and tertiary canals from agricultural land is the potential cause of low DO in the southern Indian River Lagoon watershed located in southeast coast of Florida. Carstens and Amer (2017) found the decrease of DO were consistent with the increase of urban land in Pontchartrain Basin, Louisiana. Tufford et al. (2003) reported potential linkage of higher 
concentration of nitrate-nitrogen and total phosphorus with urban land uses in the coastal streams of South Carolina. Sanger et al. (2015) studied the tidal creek data for the period of 2005-2006 in southern North Carolina to southern Georgia, and reported relationships between coastal development and land uses with increased pollutants (e.g., nitrate/nitrite, increased pathogens). Xiao et al. (2016) studied 34 sampling sites in Tiaoxi River, eastern coastal China, during the period from 2001 to 2007, and found that the concentration of nutrients (e.g., $\mathrm{NH}_{3}-\mathrm{N}$ ) and organic matter (e.g., biochemical oxygen demand) increase with increased composition of builtup land. Dauer et al. (2000) found linkage of low DO with urban land uses in Chesapeake Bay, U.S.A. Rabalais et al. (2007) reported that alteration of land uses (e.g., deforestation, expansion of artificial agricultural drainage) have influenced the input of nutrients and sediments in Mississippi River basin affecting the coastal ecosystem. Zhou et al. (2016) found the influence of land uses (e.g., agricultural, urban) on coastal stream water quality in Minjiang River Watershed, southeast China. Huang et al. (2015) reported built-up land as a source of pollutant (e.g., ammonium nitrogen, nitrate nitrogen, oxygen demanding waste, soluble reactive phosphate) in the coastal stream water quality in eastern coastal area of China. However, they reported forest land to have negative linkage with pollution suggesting their contribution to improve the stream water quality.

The hydro-climatic and coastal drivers have been reported to strongly influence the stream water quality in many regions. Strong negative linkage of DO was found with water temperature (Schaefer and Hollibaugh, 2017) alongside salinity (Prasad et al., 2011) in Chesapeake Bay, U.S.A. Dyar and Alhadeff (2005) studied 31 stream water quality monitoring stations in Georgia, and found direct control of stream temperature on DO characteristics. Wood and Kaushal (2017) reported that total dissolved nitrogen decreases with increasing water 
temperature due to potential biological uptake in the streams located in Anacostia watershed, Washington D.C. Yu et al. (2016) reported strong influence of watershed slope on stream water quality in Wei River basin, China. Cai et al. (2011) found relationship between DO with pH in the northern Gulf of Mexico. Menció and Mas-Pla (2008) reported direct linkage of the surface water quality with the interaction of groundwater and surface water in the urbanized Mediterranean streams. Kang et al. (2010) found important linkage of stream water quality with watershed size, slope, and permeability in Yeongsan river basin, South Korea. Furthermore, salinity, temperature, and water circulation patterns in coastal waters have also been reported to affect stream water quality (see references in Garcia et al. (2003)).

The effect of the land uses, hydro-climatic, and biogeochemical variables on stream water quality was found to vary seasonally. Nelson et al. (2017) reported that the control of hydrologic variables on DO were relatively higher in early winter months than the warmer season in a tidal creek of a Chesapeake Bay marsh (Maryland, U.S.A). Bu et al. (2014) reported the stream water quality in Taizi River basin, China, was primarily governed by built-up land in dry season, which, however, was strongly controlled by both agricultural and built-up land in wet season, suggesting mixed pollution. Chen et al. (2010) found the pollution of ChangLe River, China, from agricultural land use was higher in wet season than that of dry season. Yu et al. (2016) found the linkage of stream water quality variables with various land uses were stronger in dry season than that of wet season in Wei River basin, China.

Majority of the studies on coastal stream water quality do not incorporate large spatial scale having gradient of land uses alongside hydro-climatic and biogeochemical drivers. The coastal stream water quality in a large spatial scale could provide profound knowledge on the interactions of the water quality drivers under diverse environmental condition of rapidly 
changing coastal environment. However, the multitude of land use, hydro-climatic, and biogeochemical drives of stream water quality interact with each other, and therefore, are highly multicollinear - that can lead to biased result. The issue of multicollinearity can be resolved by employing partial least squares regression (PLSR)—which performs the model-fitting on the transformed orthogonal planes (Abdul-Aziz and Ahmed, 2017). Abdul-Aziz and Ahmed (2017) successfully employed PLSR model to quantify the relative linkages of stream water quality with the relevant drivers in the coastal-urban watersheds of southeast Florida.

This study attempts to investigate the complex interactions of coastal stream water quality with the land use, hydro-climatic, and biogeochemical drivers, and quantify their relative linkages incorporating wide range of environmental drivers across the East Coast of U.S.A. The complex interactions and the linkage patterns were investigated by employing a systematic utilization of multivariate pattern recognition techniques of correlation analysis, principal component analysis, and factor analysis. The relative controls of the drivers on stream water quality was estimated resolving multicollinearity among the predictors by employing PLSR model. The knowledge of the dominant land uses and environmental drivers alongside their complex interactions across a large spatial scale would guide to develop effective management strategies ensuring healthy coastal streams and ecosystems.

\subsection{Materials and methods}

\subsubsection{Study sites and data sets}

The study area incorporates a large spatial scale having 50 stream water quality monitoring stations across the East Coast of U.S.A (Figure 4.1) - located in the coastal watersheds defined by National Oceanic and Atmospheric Administration (NOAA) (Percy Pacheco, personal 
communications, 2016). With eight different U.S. states across the East Coast, the study area represents diverse ecoregions starting from "northeastern coastal zone" in the northern part and "southern coastal plain" in the southern part (Omernik and Griffith, 2014). The eight different U.S. states are: (i) Connecticut; (ii) New Jersey; (iii) Maryland; (iv) Virginia; (v) North Carolina; (vi) South Carolina; (vii) Georgia; and (viii) Florida.

Grab sample stream water quality (Table 4.1) of USGS and EPA STORET were collected from National Water Quality Monitoring Council (NWQMC) databases (NWQMC, 2017). The temporal data (1998-2015) across the year were mostly measured at quarterly time interval. DO represented the indicator of stream water quality, while the climatic and instream control on DO was represented by temperature of water (TW), specific conductance (SC), $\mathrm{pH}$, and total solar radiation (SR) and atmospheric pressure (AP). The SR and AP data were collected from 4 x $4 \mathrm{~km}$ grid cells of National Solar Radiation Data Base (NSRDB) (NSRDB, 2017). We removed the extreme values (outliers) in the data by employing the interquartile range (IQR, the distance between the 25th and 75th sample percentiles) as $P_{25}-2 \times I Q R$ and $P_{75}+2 \times I Q R$, where, $P_{25}$ and $P_{75}$ are, respectively, $25^{\text {th }}$ and $75^{\text {th }}$ percentiles. To account for the seasonal effect, separate and comparative analyses were performed for wet (May-October) and dry (November-April) seasons (North American Monsoon Experiment (NAME), 2018). Temporal data set for each season were averaged to represent the corresponding stream water quality in each site. 


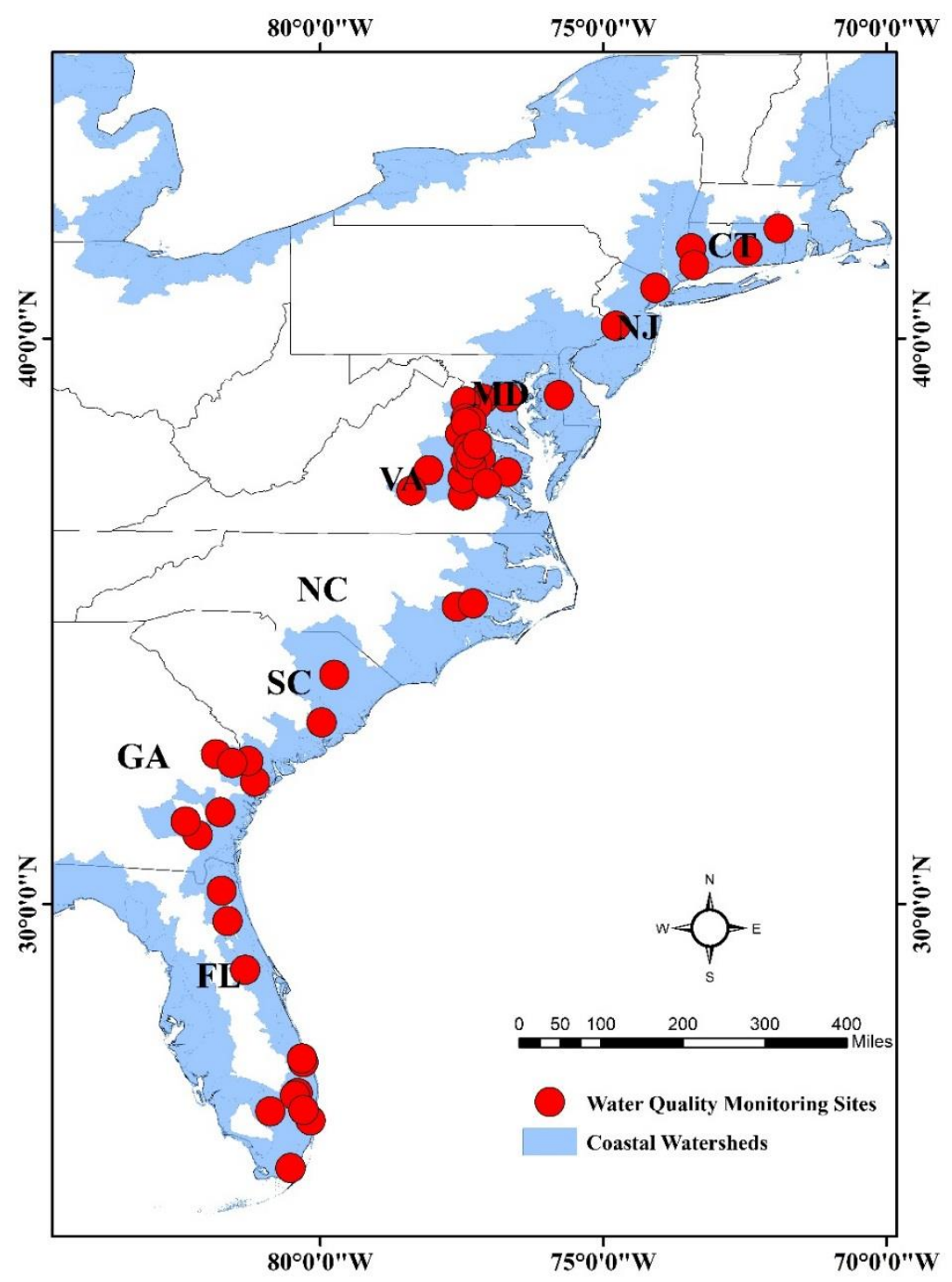

Figure 4.1. Locations of the coastal stream water quality monitoring stations across the East Coast of U.S.A. 
Table 4.1. Summary of the stream dissolved oxygen, land use, hydro-climatic, and biogeochemical drivers across all the stream water quality monitoring sites.

\begin{tabular}{|c|c|c|c|c|c|c|c|}
\hline Variables & Mean & $\begin{array}{l}\text { Standard } \\
\text { Deviation }\end{array}$ & Minimum & $\begin{array}{l}\text { 25th } \\
\text { Percentile }\end{array}$ & $\begin{array}{l}\text { 50th } \\
\text { Percentile }\end{array}$ & $\begin{array}{l}\text { 75th } \\
\text { Percentile }\end{array}$ & Maximum \\
\hline $\mathrm{A}\left(\mathrm{km}^{2}\right)$ & 4955.25 & 8683.55 & 1.09 & 80.48 & 753.66 & 4543.49 & 35211.29 \\
\hline $\mathrm{S}(\%)$ & 6.52 & 5.51 & 0.04 & 1.60 & 5.57 & 9.64 & 23.05 \\
\hline $\mathrm{I}(\%)$ & 4.05 & 6.94 & 0.00 & 0.69 & 1.11 & 3.23 & 33.55 \\
\hline $\mathrm{D}_{\mathrm{c}}(\mathrm{km})$ & 80.07 & 59.06 & 3.45 & 25.26 & 69.18 & 113.76 & 213.25 \\
\hline WAT (\%) & 3.28 & 9.50 & 0.00 & 0.30 & 0.71 & 2.11 & 63.90 \\
\hline BUL (\%) & 17.03 & 22.43 & 0.00 & 5.01 & 7.73 & 16.02 & 87.82 \\
\hline OPN (\%) & 0.18 & 0.19 & 0.00 & 0.00 & 0.17 & 0.28 & 0.85 \\
\hline VEG (\%) & 43.86 & 27.35 & 0.08 & 14.03 & 51.92 & 66.70 & 83.49 \\
\hline $\operatorname{AGR}(\%)$ & 17.34 & 17.46 & 0.00 & 5.51 & 14.00 & 23.07 & 93.86 \\
\hline WTL (\%) & 18.31 & 21.36 & 0.22 & 5.41 & 11.14 & 20.92 & 91.55 \\
\hline \multicolumn{8}{|c|}{ Wet Season (May-October) } \\
\hline $\mathrm{TW}\left({ }^{\circ} \mathrm{C}\right)$ & 23.43 & 3.64 & 17.18 & 20.01 & 23.53 & 26.42 & 29.79 \\
\hline $\mathrm{SC}(\mathrm{uS} / \mathrm{cm})$ & 518.41 & 896.62 & 40.38 & 101.61 & 191.78 & 549.27 & 3989.68 \\
\hline $\mathrm{pH}$ & 7.20 & 0.54 & 5.68 & 6.86 & 7.23 & 7.57 & 8.30 \\
\hline $\mathrm{SR}\left(\mathrm{W} / \mathrm{m}^{2}\right)$ & 564.69 & 119.66 & 117.63 & 510.47 & 574.82 & 633.88 & 776.23 \\
\hline $\mathrm{AP}(\mathrm{mbar})$ & 1010.57 & 5.80 & 991.30 & 1008.98 & 1011.86 & 1014.71 & 1016.95 \\
\hline GWD (m) & 13.70 & 15.57 & 0.42 & 2.52 & 7.44 & 20.47 & 63.44 \\
\hline $\mathrm{DO}(\mathrm{mg} / \mathrm{L})$ & 6.72 & 1.90 & 1.97 & 5.39 & 7.03 & 8.11 & 9.92 \\
\hline \multicolumn{8}{|c|}{ Dry Season (November-April) } \\
\hline $\mathrm{TW}\left({ }^{\circ} \mathrm{C}\right)$ & 12.10 & 5.82 & 4.36 & 7.66 & 9.37 & 15.24 & 23.30 \\
\hline $\mathrm{SC}(\mathrm{uS} / \mathrm{cm})$ & 803.94 & 2554.67 & 48.75 & 100.34 & 173.80 & 547.32 & 17477.42 \\
\hline $\mathrm{pH}$ & 7.17 & 0.57 & 5.70 & 6.73 & 7.18 & 7.71 & 8.11 \\
\hline $\mathrm{SR}\left(\mathrm{W} / \mathrm{m}^{2}\right)$ & 400.75 & 114.76 & 138.38 & 335.27 & 397.29 & 455.70 & 622.59 \\
\hline $\mathrm{AP}$ (mbar) & 1013.06 & 6.37 & 993.54 & 1011.24 & 1015.06 & 1017.72 & 1020.23 \\
\hline GWD (m) & 13.50 & 15.47 & 0.55 & 2.35 & 7.44 & 20.02 & 63.31 \\
\hline $\mathrm{DO}(\mathrm{mg} / \mathrm{L})$ & 9.62 & 2.35 & 4.16 & 8.12 & 9.96 & 11.36 & 13.49 \\
\hline
\end{tabular}

Notes: A, S, I, D , WAT, BUL, OPN, VEG, AGR, WTL, TW, SC, SR, AP, GWD respectively, refer to watershed area, slope, imperviousness, distance from coast, waterbody, built-up land, open land, vegetated land, agricultural land, wetland, temperature of water, specific conductance, solar radiation, atmospheric pressure, and groundwater depth.

Watershed (drainage area) for each stream water quality site was generated using ESRI ArcGIS 10.2 based on 10 m digital elevation model (United States Geological Survey (USGS), 
2017a). Watershed areas (A), mean slope (S), and mean percent imperviousness (I) were estimated using ESRI ArcGIS 10.2 to represent watershed hydrology. The mean percentage of various land uses and imperviousness for the corresponding time period of temporal data were estimated from the $30 \mathrm{~m}$ data of National Land Cover Database (NLCD) for 2001, 2006, and 2011 (NLCD, 2017). Following the guidelines of NLCD (2017), land use types were classified into six broad categories as follows: (1) built-up land (BUL), representing developed areas; (2) agricultural land (AGR), representing land uses for agriculture and grazing; (3) waterbody (WAT), representing open water; (4) vegetated land (VEG), representing forest and other nonagricultural vegetated lands; (5) open land (OPN), representing barren lands; (6) wetland (WET), representing wetland. The data summary (Table 4.1) showed a wide range of stream water quality, land use, hydro-climatic, and biogeochemical variables representing diverse stream water quality processes.

\subsubsection{Data analytics of stream DO and pertinent environmental drivers}

The interactions among the drivers of stream water quality and their relative controls were studied by employing a systematic data analytics framework (Figure 4.2) (Ishtiaq and AbdulAziz, 2015; Abdul-Aziz and Ahmed, 2017). The framework incorporated systematic utilization of four layers of data analytics techniques as follows: (i) Pearson correlation matrix, (ii) principal component analysis (PCA), (iii) factor analysis (FA), and (iv) partial least squares regression

(PLSR). The multilayer data analytics framework was preferred over any single technique to ensure the detailed and confirmatory results by synthesizing the overall outcome. The data analytics framework was applied on, first, logarithmically $\left(\log _{10}\right)$ transformed, and then standardized (dimensionless Z-score) data-respectively, to account for the non-linear interactions and bring the participatory variables in a similar comparable reference scale. We 
calculated the Z-scores as follows: $Z=(X-\bar{X}) / s_{X}$, where $X=\log _{10}$-transformed value of a variable, $\bar{X}=$ mean of $X$, and $s_{X}=$ standard deviation of $X$. The data analytics framework was applied in MATLAB R2016a platform.

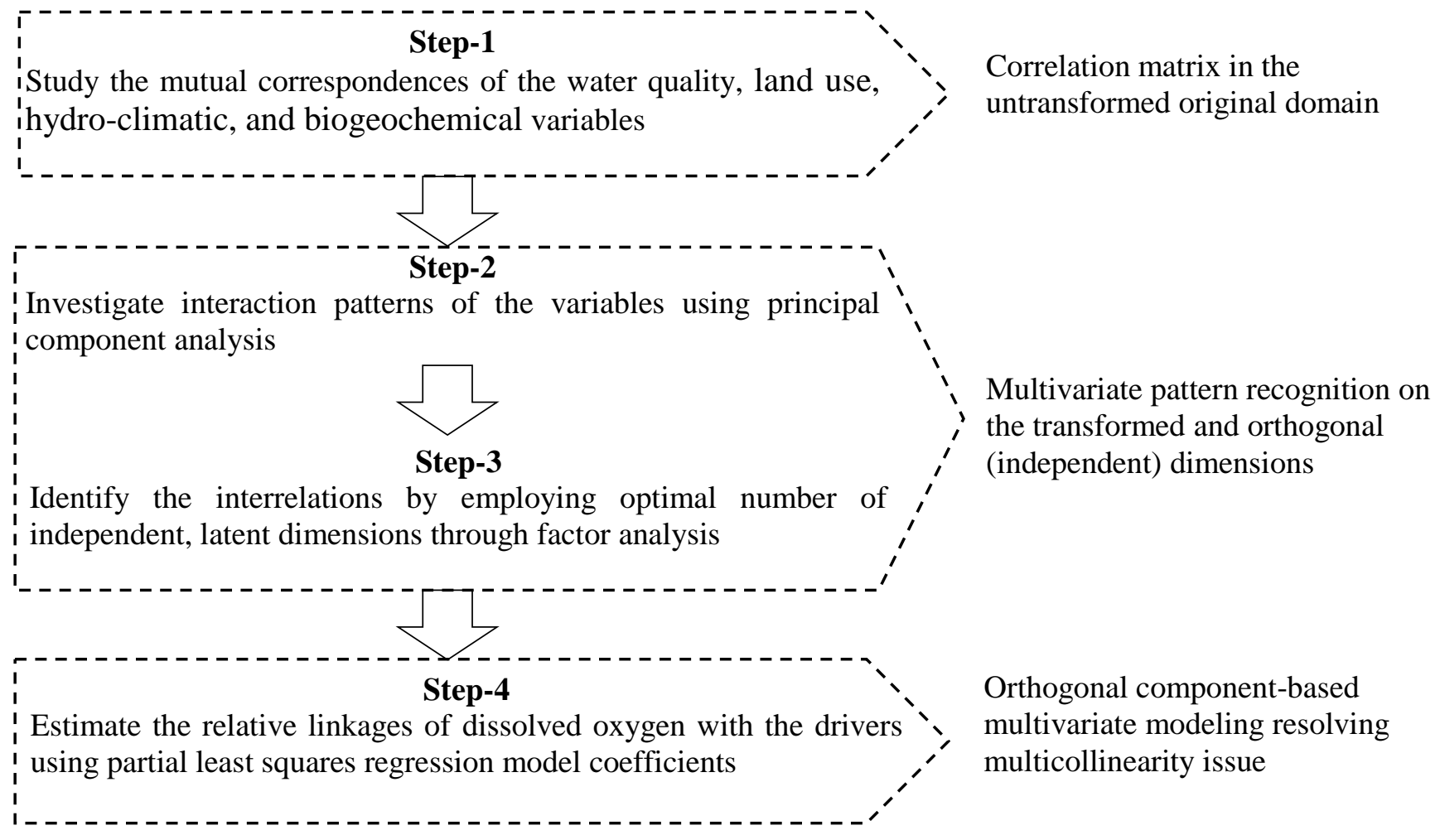

Figure 4.2. The data analytics framework to investigate the interrelations and quantify the relative linkages of dissolved oxygen with the land use, hydro-climatic, and biogeochemical drivers.

At the preliminary step of the data analytic framework, we employed Pearson correlation matrix to get background information on the mutual interrelations among the stream water quality, land use, hyro-climatic, and biogeochemical drivers. Thereafter, the relative controls of the drivers on stream DO and their mutual interactions were investigated by employing PCA and FA resolving multicollinearity in the orthogonal domain (Jolliffe, 2002). While PCA derives the orthogonal entities (principal components (PCs)) as a linear combination of all variables, FA 
decomposes the original variables into a reduced set of latent entities (factors). The factors redistribute the variance of each variable to maximize the total data variance-by optimizing the factors using a method called "varimax" orthogonal rotation. The optimal number of factorsexplaining most of the data variances - were determined using an eigenvalue criteria: eigenvalue $\geq 1$.

Finally, we estimated the relative linkages of DO with stream water quality drivers by employing PLSR model— that simultaneously determines the orthogonal partial least squares (PLS) components of predictors and fits them with the response by decomposing all the participatory variable (Schumann et al., 2013). PLSR model—after appropriate optimizationresolves the multicollinearity that prevails among the predictors through the transformed orthogonal planes (Kuhn and Johnson, 2013). We optimized the PLSR models by a synthesis of the maximum Nash-Sutcliffe efficiency (NSE) and minimum Akaike Information Criterion (AIC) and (Nash and Sutcliffe, 1970; Ishtiaq and Abdul-Aziz, 2015). The Z-score based optimized PLSR models were developed using SIMPLS algorithm (de Jong, 1993; Hubert and Branden, 2003) and a 10-fold cross validation method (Kuhn and Johnson, 2013). The final model efficiency was determined using NSE criteria. The NSE value of 1.0 indicates a perfect model, while NSE value of less than zero indicates a worse model than that of the model developed based on the mean observations (Moriasi et al., 2007). The accuracy of the model was determined using the ratio of root-mean-square error to the standard deviation of the observations (RSR). Moriasi et al. (2007) defined the RSR values of 0-0.5, 0.5-0.6, 0.6-0.7, and $>0.70$ respectively, as indicating "very good", "good", "satisfactory", and "unsatisfactory" models. 
The Z-score based model coefficients $(\beta)$ represented the quantified relative linkages of DO with the land use, hydro-climatic, and biogeochemical drivers. The absolute value of $\beta$ indicated the strength of the relative linkage. The positive/negative sign of $\beta$ indicated the direction of the relationships (i.e., increasing or decreasing) between the DO and the drivers, which, however, was more meaningful for the important drivers (i.e., higher $\beta$ ) than that of the weak drivers. The controls of the different stream water quality process components were determined by aggregating the relative linkages $(\beta)$. The aggregated relative linkages of 'land use $\left(\beta_{\mathrm{LU}}\right)$, 'climate' $\left(\beta_{\mathrm{C}}\right)$, 'hydrologic' $\left(\beta_{\mathrm{H}}\right)$, and 'redox' $\left(\beta_{\mathrm{R}}\right)$ components were estimated following the method of vector summation as follows:

$\beta_{L U}=\sqrt{\beta_{B U L}^{2}+\beta_{A G R}^{2}+\beta_{W A T}^{2}+\beta_{O P N}^{2}+\beta_{V E G}^{2}+\beta_{W T L}^{2}}$

$\beta_{C}=\sqrt{\beta_{T W}^{2}+\beta_{S R}^{2}+\beta_{A P}^{2}}$

$\beta_{H}=\sqrt{\beta_{A}^{2}+\beta_{S}^{2}+\beta_{I}^{2}+\beta_{G W D}^{2}}$

$\beta_{R}=\sqrt{\beta_{p H}^{2}+\beta_{S C}^{2}}$

\subsection{Results}

\subsubsection{Background information on mutual correlations}

The background information on the nonlinear mutual correspondences of stream water quality and the drivers were examined by estimating correlation coefficients ( $r$ ) for both wet and dry seasons (Table 4.2). In both seasons, strong negative correlations of DO were found with TW (r $=-0.65$ to -0.87 ), suggesting strong climatic control. Further, moderate negative correlations of DO with SC ( $r=-0.55$ to -0.56$)$ across the seasons indicated substantial control of redox process 
on stream water quality. Moderate to strong positive correlations of slope $(r=0.73$ to 0.79$)$ and imperviousness ( $r=0.47$ to 0.57 ) with DO suggested positive influence of hydrologic controls on steam water quality. Among the land use variables, moderate to strong positive correlations of DO were found with built-up land $(r=0.55$ to 0.65$)$ and vegetated land $(r=0.63$ to 0.69$)$.

However, wetland showed strong negative correlation $(r=-0.63)$ with DO—suggesting a potential source of nutrient enrichment.

Table 4.2. Pearson correlation coefficients (r) of DO with land use, hydro-climatic, and biogeochemical drivers.

\begin{tabular}{|c|c|c|c|c|c|c|c|c|c|c|c|c|c|c|c|c|}
\hline & $\mathrm{A}$ & $\mathrm{S}$ & I & WAT & BUL & OPN & VEG & AGR & WTL & TW & $\mathrm{SC}$ & $\mathrm{pH}$ & $\overline{S R}$ & $\mathrm{AP}$ & GWD & $\mathrm{D}_{\mathrm{c}}$ \\
\hline Wet & 0.37 & 0.73 & 0.57 & -0.16 & 0.65 & 0.36 & 0.63 & 0.15 & -0.63 & -0.65 & -0.55 & 0.10 & -0.14 & -0.49 & 0.46 & 0.12 \\
\hline Dry & 0.38 & 0.79 & 0.47 & -0.08 & 0.55 & 0.4 & 0.69 & 0.22 & -0.63 & -0.87 & -0.56 & -0.17 & -0.37 & -0.55 & 0.49 & 0.19 \\
\hline
\end{tabular}

Note: (1) Data for all pi numbers were $\log _{10}$ transformed to incorporate any nonlinear correspondences. (2) Correlations in bold are significant at the $95 \%$ level of confidence from a two-tailed test. (3) A, S, I, Dc, WAT, BUL, OPN, VEG, AGR, WTL, TW, SC, SR, AP, GWD respectively, refer to watershed area, slope, imperviousness, distance from coast, waterbody, built-up land, open land, vegetated land, agricultural land, wetland, temperature of water, specific conductance, solar radiation, atmospheric pressure, and groundwater depth.

The mutual correspondences among the land use, hydrologic, and biogeochemical drivers were also apparent from the correlation matrices (Tables A4.1 and A4.2 in Appendix 4) indicating presence of multicollinearity in the data matrix. For example, built-up land and imperviousness showed strong correlation $(r=0.98)$, indicating that imperviousness increases with increasing built-up land. The strong negative correlations ( $r=-0.60$ to -0.79$)$ of $\mathrm{TW}$ and vegetated land in both seasons might suggest that stream temperature is reduced with higher vegetation due to shading effect. The strong negative correlations ( $r=-0.63$ to -0.83$)$ of TW and slope might be due to the fact that the watershed slope decreases and temperature increases from north to the south (temperate to tropical) across the East Coast. 


\subsubsection{Interrelations among the spatiotemporal drivers to control stream DO}

\subsubsection{Based on PCA}

The nonlinear loadings of all the participatory variables on the first two PCs are shown using biplots in wet (Figure 4.3a) and dry (Figure 4.3b) seasons. The first two PCs explained, respectively, $53.4 \%$ and $56.8 \%$ of the total data variances in wet and dry seasons (see Table A4.3 in Appendix 4). The interrelations among the variables were described based on the relative orientations and length of the vectors. In both seasons, the nonlinear and opposite orientations of TW and SC with DO reiterated their strong negative controls on stream DO. The negative linkage of wetland with DO reiterated the nutrient input to increase DO consumption. However, built-up land and imperviousness formed a cluster to show strong positive linkage with DO. Further, positive linkages with DO were also manifested by slope and vegetated land. However, with similar types of orientations, $\mathrm{D}_{\mathrm{c}}$, agricultural land, and open land grouped together to show weak linkages with DO in both seasons. Further, moderate to weak linkages of DO was also found with GWD across the seasons.

The clusters/groups among the stream water quality drivers indicated their mutual correspondences. The positive interrelations among $\mathrm{D}_{\mathrm{c}}$, agricultural land, and open land suggested that the agricultural land and open land increases away from the coast. The moderate positive linkage of TW and SR suggested that water temperature increases with increasing solar radiation. The strong positive linkage between built-up land and imperviousness reiterated that imperviousness increases with built-up land. The positive linkage between slope and vegetated land might be due to the fact that steeper/hilly watersheds are more likely to be natural (Chang, 2008), and thus, would have higher vegetation. 
(a)

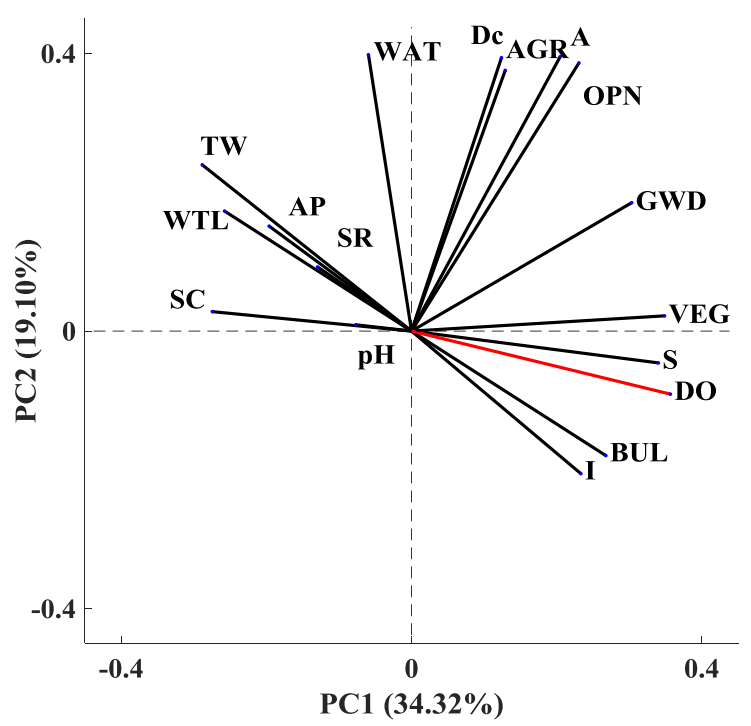

(b)

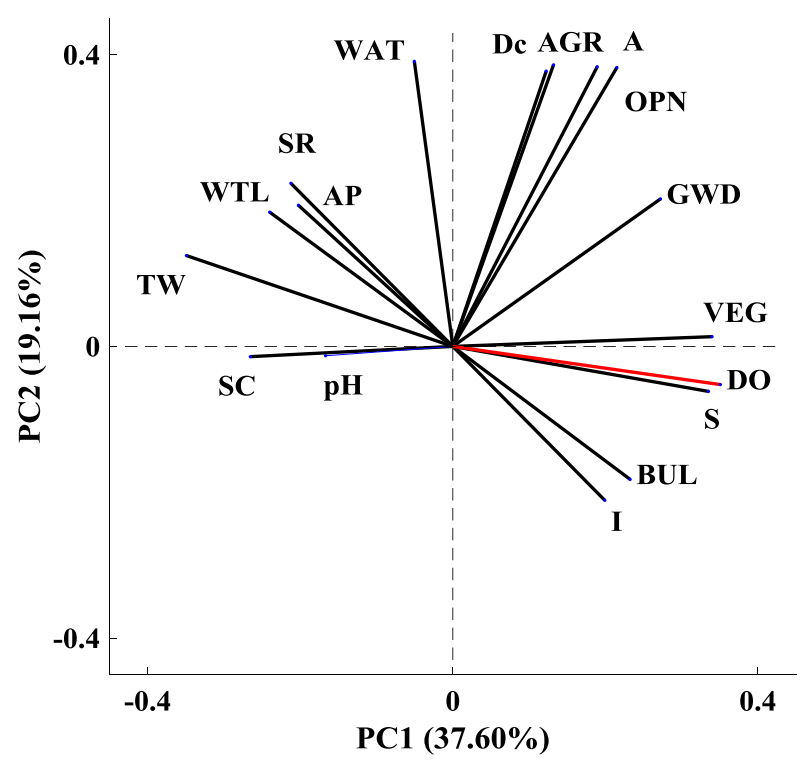

Figure 4.3. Biplots from principal component analysis manifesting the interrelation patterns of the stream water quality with the drivers in (a) wet and (b) dry seasons. Percent variance explained by each PC is shown in parenthesis.

\subsubsection{Based on FA}

Four independent factors were determined using the eigenvalue $\geq 1$ criteria to explain the hidden patterns into the data matrices (Table 4.3) across the seasons. Variance explained by the first four 
factors ranged, respectively, from approximately $34 \%$ to $38 \%, 19 \%, 11 \%$ to $12 \%$, and $9 \%$ to $10 \%$ across the wet and dry seasons.

In wet season, DO loaded most strongly on factor $1(0.64)$, which also had high loadings of slope (0.97), vegetated land (0.74), wetland (-0.67), and TW (-0.63)—suggesting their strong controls on stream water quality. Further, the moderate loading of SC (-0.43) on factor 1 suggested notable control on stream DO. The strong mutual interrelation of imperviousness and built-up land was apparent from their strong loading on factor 3 (0.97 to 0.98 ), which also had moderate loading of DO (0.49) — suggesting substantial control of the corresponding drivers on stream DO. Similar to wet season, dry season DO loaded most strongly on factor 1 (0.83), which had concurrent high loading of slope (0.88), vegetated land (0.72), wetland (-0.62), TW (-0.92), SC (-0.55), and AP (-0.67) — indicating the strong controls of the corresponding drivers on stream DO. Dry season factor 3 had strong loadings of imperviousness (0.97) and built-up land (0.96), which, however, had relatively weaker loading (0.33) on DO than that of wet seasonsuggesting their reduced control during low flow period in dry season. 
Table 4.3. Major latent factors with their optimized loadings on the participatory variables in wet and dry seasons.

\begin{tabular}{|c|c|c|c|c|c|c|c|c|c|c|c|c|c|c|c|c|c|c|}
\hline & & A & $S$ & I & WAT & BUL & OPN & VEG & AGR & WTL & TW & SC & $\mathrm{pH}$ & SR & AP & GWD & Dc & DO \\
\hline \multirow[t]{4}{*}{ Wet } & F1 & 0.17 & 0.97 & 0.17 & -0.05 & 0.19 & 0.12 & 0.74 & -0.05 & -0.67 & -0.63 & -0.43 & 0.10 & -0.18 & -0.54 & 0.41 & 0.14 & 0.64 \\
\hline & $\mathrm{F} 2$ & 0.93 & 0.17 & 0.02 & 0.46 & 0.11 & 0.86 & 0.29 & 0.75 & -0.01 & 0.19 & -0.16 & 0.00 & 0.01 & 0.13 & 0.52 & 0.61 & 0.23 \\
\hline & F3 & 0.16 & 0.12 & 0.98 & -0.35 & 0.97 & 0.15 & 0.17 & -0.09 & -0.33 & -0.24 & -0.02 & -0.08 & -0.11 & -0.13 & 0.25 & -0.29 & 0.49 \\
\hline & $\mathrm{F} 4$ & 0.18 & -0.04 & 0.01 & 0.40 & -0.11 & -0.14 & -0.33 & -0.19 & -0.10 & 0.51 & 0.76 & 0.66 & 0.36 & 0.05 & -0.31 & -0.17 & -0.21 \\
\hline \multirow[t]{2}{*}{ Dry } & $\mathrm{F} 1$ & 0.14 & 0.88 & 0.18 & -0.10 & 0.23 & 0.16 & 0.72 & 0.05 & -0.62 & -0.92 & -0.55 & -0.11 & -0.46 & -0.67 & 0.36 & 0.14 & 0.83 \\
\hline & $\mathrm{F} 2$ & 0.94 & 0.20 & 0.03 & 0.50 & 0.10 & 0.85 & 0.28 & 0.71 & -0.03 & -0.03 & -0.15 & -0.05 & 0.16 & 0.17 & 0.52 & 0.60 & 0.24 \\
\hline
\end{tabular}

Note: (1) Bold values indicates variables having moderate to high loadings (correlations) on factors (F); F1-4 refer to four different factors, with F1 and F4 explaining the most and least variances, respectively. (2) A, S, I, Dc, WAT, BUL, OPN, VEG, AGR, WTL, TW, SC, SR, AP, GWD respectively, refer to watershed area, slope, imperviousness, distance from coast, waterbody, built-up land, open land, vegetated land, agricultural land, wetland, temperature of water, specific conductance, solar radiation, atmospheric pressure, and groundwater depth. 


\subsubsection{Identification of the dominant drivers by estimating the relative linkages}

Based on the synthesis of maximum NSE and minimum AIC criteria, five PLS components were determined to achieve optimum PLSR models in both wet and dry seasons (Figure 4.4). The NSE (0.88) and RSR (0.34) of the optimal models suggested good predictions in both seasons (Table 4.4, and Figure A4.1 in Appendix 4). The power law-based PLSR models were significant at $95 \%$ confidence level.

(a)

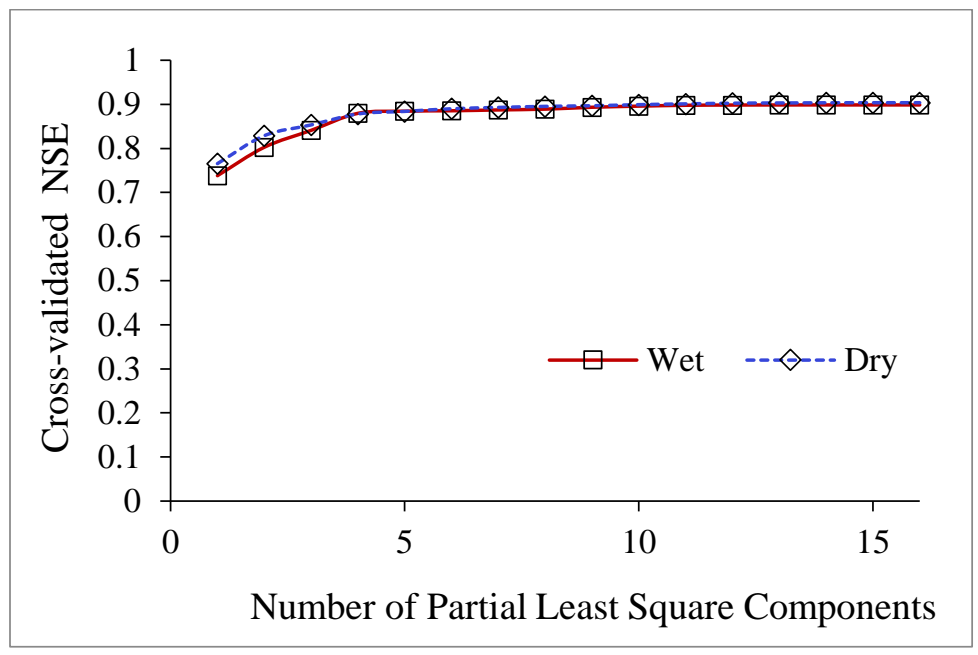

(b)

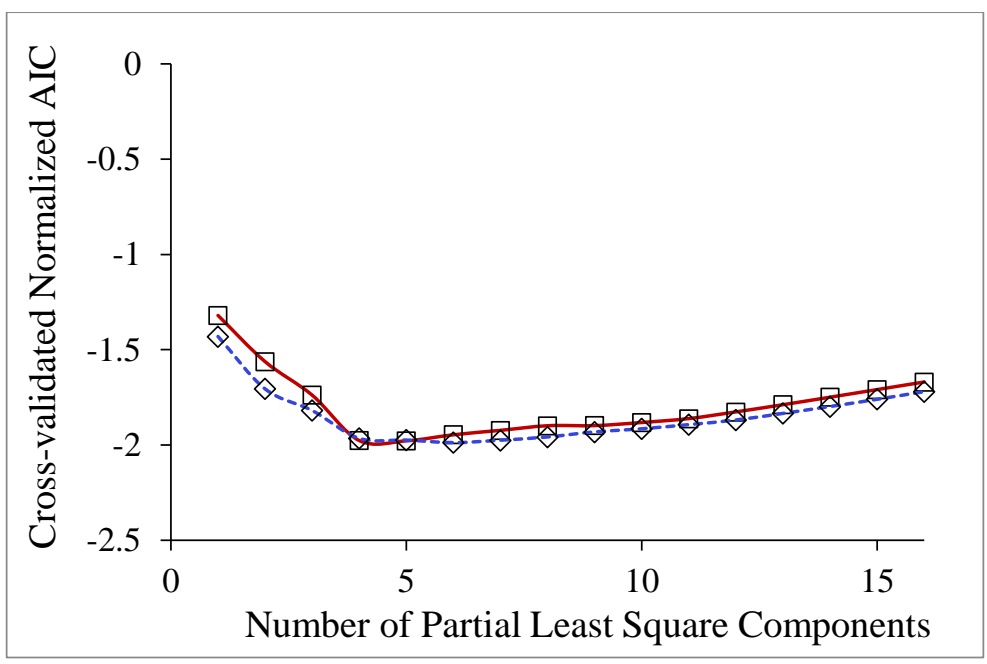

Figure 4.4. Plot of cross-validated (a) fitting efficiency (NSE) and (b) normalized AIC (for both wet and dry seasons) with the number of incorporated partial least squares components. 
Table 4.4. PLSR model coefficients $(\beta)$ of the drivers in both wet and dry seasons.

\begin{tabular}{|c|c|c|}
\hline Predictors & Wet & Dry \\
\hline A & 0.12 & 0.02 \\
\hline$S$ & 0.14 & 0.15 \\
\hline $\mathrm{I}$ & 0.17 & 0.10 \\
\hline WAT & 0.03 & 0.06 \\
\hline BUL & 0.31 & 0.22 \\
\hline OPN & 0.08 & 0.07 \\
\hline VEG & -0.03 & -0.07 \\
\hline AGR & -0.08 & 0.04 \\
\hline WTL & -0.06 & -0.10 \\
\hline TW & -0.27 & -0.48 \\
\hline $\mathrm{SC}$ & -0.48 & -0.29 \\
\hline $\mathrm{pH}$ & 0.36 & 0.17 \\
\hline SR & 0.11 & 0.17 \\
\hline $\mathrm{AP}$ & 0.04 & -0.09 \\
\hline GWD & -0.10 & 0.01 \\
\hline$D_{c}$ & 0.09 & 0.00 \\
\hline \multicolumn{3}{|c|}{ Model Statistics } \\
\hline PLS components & 5.00 & 5.00 \\
\hline NSE & 0.88 & 0.88 \\
\hline RSR & 0.34 & 0.34 \\
\hline \multicolumn{3}{|c|}{ Aggregated Linkages } \\
\hline$\beta_{\mathrm{LU}}$ & 0.34 & 0.27 \\
\hline$\beta_{\mathrm{C}}$ & 0.29 & 0.52 \\
\hline$\beta_{\mathrm{H}}$ & 0.27 & 0.18 \\
\hline$\beta_{R}$ & 0.60 & 0.33 \\
\hline
\end{tabular}

Notes: A, S, I, D , WAT, BUL, OPN, VEG, AGR, WTL, TW, SC, SR, AP, GWD respectively, refer to watershed area, slope, imperviousness, distance from coast, waterbody, built-up land, open land, vegetated land, agricultural land, wetland, temperature of water, specific conductance, solar radiation, atmospheric pressure, and groundwater depth.

In wet season, the strong linkages of $\mathrm{DO}$ was found with $\mathrm{SC}(\beta=-0.48)$ and $\mathrm{pH}(\beta=$ 0.36) (Table 4.4), indicating domination of redox processes in this season. Strong negative linkage of DO with TW ( $\beta=-0.27)$ suggested adverse effect of temperature. The moderate to 
strong linkage of DO with $S(\beta=0.14)$, imperviousness $(\beta=0.17)$, and built-up land $(\beta=0.31)$ also suggested their dominant control on DO. Moderate negative linkage $(\beta=-0.08)$ of DO with agricultural land indicated its adverse effect on stream DO by nutrient enrichment. Based on the aggregated linkages, the 'redox' component showed strongest linkage with DO-having approximately 2.0 times stronger control than the 'climatic' $\left(\beta_{\mathrm{c}}\right)$, 'land use' $\left(\beta_{\mathrm{LU}}\right)$, and 'hydrologic' $\left(\beta_{\mathrm{H}}\right)$ components.

Unlike wet season, dry season DO showed strongest linkage $(\beta=-0.48)$ with TW, suggesting dominant climatic control. Further, moderate to strong linkage of DO was also found with SC $(\beta=-0.29)$ and $\mathrm{pH}(\beta=0.17)$, which, however, was relatively lower than the wet season-suggesting their reduced controls in dry season. Moderate positive linkage of DO with S $(\beta=0.15)$, built-up land $(\beta=0.22)$, imperviousness $(\beta=0.10)$, and $\operatorname{SR}(\beta=0.15)$ suggested their positive controls on stream water quality. However, the positive linkages of DO with built-up land and imperviousness was relatively lower in dry season than that of wet season, suggesting their reduced controls. The aggregated linkages showed strongest control of 'climatic' component on DO, which is approximately 2 to 3 times stronger than 'redox' $\left(\beta_{R}\right)$, 'land use' $\left(\beta_{\mathrm{LU}}\right)$, and 'hydrologic' $\left(\beta_{\mathrm{H}}\right)$ components.

Overall, the results suggested domination of 'redox' and 'climatic' processes on stream DO, respectively, in wet and dry seasons. The moderate to strong controls of redox and climatic drivers on stream DO across the seasons were also apparent in the annual scale analysis (see Table A4.4 in Appendix 4). Among the land uses, built-up land and agricultural land showed, respectively, positive and negative controls on stream DO. Further, watershed slope showed substantial positive influence on stream water quality. The relative controls of the dominant 
drivers on stream DO were found to vary across the seasons—-suggesting seasonal effect on stream water quality processes.

\subsection{Discussion}

The differing relative linkages of DO with the drivers in wet and dry seasons suggested that the seasonal changes of hydro-climatic conditions influence the major stream water quality processes. In wet season, DO had the strong linkages with both $\mathrm{pH}$ and $\mathrm{SC}$, suggesting the domination of redox process. The negative linkage of SC with DO indicated reduced solubility of oxygen with increasing salinity. Further, salinity can reduce DO through inhibiting algal photosynthesis by imposing biological stress (Satoh et al., 1983). The adverse effect of salinity on DO was relatively higher in wet season than that of dry season. This might be due to the fact that salinity retards more photosynthesis in wet season since photosynthetic activity is higher during wet season temperature (see Table 4.1), which is close the optimum temperature (20 to $30^{\circ} \mathrm{C}$ ) for algal photosynthesis (Mosser and Brock, 1976; Konopka and Brock, 1978). The substantial linkage between $\mathrm{pH}$ and DO indicated the control from metabolic activity (i.e., microbial decomposition) on stream DO. The positive linkage suggested the concurrent decrease of DO and $\mathrm{pH}$ with increased microbial decomposition, respectively, by consumption of DO and production of carbon dioxide (Cai et al., 2011). Further, increased algal photosynthesis contributes to DO and consumes carbon dioxide that increases pH (Zang et al., 2011; Frieder et al., 2012) - leading to their positive linkage. The reduced linkage of $\mathrm{pH}$ and $\mathrm{DO}$ in the dry season than the wet season might be due to reduced metabolic activity in low temperature during dry season. 
In dry season, the strongest linkage of DO was found with TW—suggesting dominant climatic control when metabolic activity is relatively low (Wetz et al., 2016) due to reduced temperature in dry period (see Table 4.1). The strong negative linkage of TW suggested decreasing solubility of DO with increasing TW (Caccia and Boyer, 2005; Shrestha and Kazama, 2007) - representing the thermodynamic control on DO. Further, increasing temperature can adversely affect stream water quality by increasing metabolic consumption of DO (Schaefer and Hollibaugh, 2017). Previous literatures reported the negative control of TW on DO in various coastal watersheds. For example, strong adverse control of TW on DO was reported in Rhode River of Maryland by Nelson et al. (2017) and in the coastal bays of Maryland and Virginia by Jacobs et al. (2009). In our study, the wet season DO was lower than that of dry season (see Table 4.1) - suggesting higher metabolic consumption of DO and low solubility due to higher temperature in wet season. Graves et al. (2004) also reported that low DO in summer/wet season was partly caused by the higher temperature of wet season in the southeast coast of Florida.

The positive linkage between watershed slope and DO might be attributed to higher reaeration from faster runoff - generated by steeper slope (Chang, 2008). Further, land uses (e.g., agricultural land) with steeper slope has lower potential to contribute for nutrients (Wan et al., 2014a) due to less contact time with surface runoff-leading to improvement of stream DO. The positive linkage of imperviousness and built-up land with DO suggested that higher imperviousness generated higher watershed runoff that diluted in-stream pollutant and contributed to aeration-leading to increased DO. Similarly, the positive linkage between watershed size and DO in wet season indicated higher reaeration with increased watershed runoff from bigger watershed. Further, the pollutant sources in larger watersheds are more likely to be located far from the stream - contributing to improved stream DO (Tran et al., 2010). The result 
corroborates the findings of Kang et al. (2010) — reporting that the land use contributions of various water quality parameters decreased with increasing size of watershed in the Yeongsan Basin, South Korea.

The controls of built-up land, imperviousness, and watershed size were reduced in dry season, which might be due to low rainfall runoff during dry season. The intriguing positive linkage of built-up land with DO might be due to treatment of the urban runoff in wastewater treatment plant prior to the discharge in surface water. The positive linkage of DO with urban land was also reported by Wan et al. (2014b) in the Indian River Lagoon watersheds of Florida. The moderate negative linkage of agricultural land with DO in wet season suggested the nutrient input from agricultural runoff (Bu et al., 2014, Wan et al., 2014b) that increased microbial consumption of stream DO. However, the weak linkage of dry season DO with agricultural land might be due to the combined effect of low rainfall runoff and no/negligible use of fertilizer in dry season (non-growing). This is consistent with the findings of Chen et al. (2010) in ChangLe River, China - reporting that stream water pollution from agricultural land use was higher in wet season than that of dry season. The positive linkage of solar radiation might suggest contribution to stream DO by increasing photosynthesis.

The quantification of the relative linkages of stream DO with the land use, hydrologic, and biogeochemical drivers would advance the knowledge of coastal stream water quality and guide developing effective management policies. The seasonal changes of the controls of DO from land use, hydro-climatic, and biological drivers suggested urgency of separate management strategies for wet and dry seasons. The higher aggregated linkages of land use, hydrologic, and redox components in wet season suggested that stream DO could be relatively better controlled in wet season by managing those environmental components. Relatively higher aggregated 
linkage of redox component in wet season suggested that nutrient input in wet season would have relatively higher deleterious effect on DO due to greater potential of microbial decomposition. Since salinity had strong adverse effect of stream DO, proper management strategy (e.g., salinity control structure) should be taken to control salinity intrusion into the coastal streams across the East Coast. Further, management priority should also be given to control thermal pollution from industrial discharge. Riparian vegetation can also be introduced to reduce the urban heat island effect. The study further suggested that stream DO could be improved by controlling the nutrient input into coastal streams from watershed land uses (e.g., agricultural land) (Diaz and Rosenberg, 2008; Cai et al., 2011).

\subsection{Conclusions}

The study identified the dominant controls of coastal stream DO by quantifying the relative linkages of land use, hydro-climatic, and biogeochemical drivers across a large spatial scale of the East Coast of U.S.A. A systematic data analytics technique was employed incorporating correlation analysis, principal component analysis, factor analysis, and partial least squares regression models to quantify the relative linkages resolving multicollinearity. The seasonal effect was taken into account by performing separate and comparative analyses for wet and dry seasons. The relative linkage patterns of the land use, hydro-climatic, and biogeochemical drivers were found to be influenced by seasonal effect. The data analytics showed strong controls of redox variables $(\mathrm{pH}$, specific conductance) on stream DO in wet season- suggesting domination of metabolic activity (e.g., microbial decomposition) and salinity. However, in dry season, reduced linkage of DO was found with the redox drivers, which might be due to the fact that metabolic control decreased in lower temperature during dry season. Strong negative control of stream temperature on DO across the seasons suggested dominant climatic controls. Higher 
stream temperature reduced oxygen solubility and increased metabolic consumption to adversely affect stream DO.

Among the land uses, built-up land was found to have strong positive influence on stream DO by dilution of pollutants with higher runoff generation. Agricultural land showed negative impact on stream DO only in wet season, suggesting potential source for nutrient enrichment from agricultural runoff. The aggregated linkages showed strongest controls of 'redox' and 'climatic' components, respectively, in wet and dry seasons - approximately 2 to 3 times stronger than the other environmental components. The knowledge of the quantified relative linkages of DO with the land use, hydro-climatic, and biogeochemical drivers across the large spatial scale would guide to develop effective management interventions ensuring healthy coastal streams and ecosystems across the East Coast of U.SA.

\section{Acknowledgments}

The research was funded by the National Science Foundation (NSF) CAREER Award to Dr. Omar I. Abdul-Aziz (NSF CBET Environmental Sustainability Award Number 1561942/1454435). 


\section{Appendix 4}

Table A4.1. Correlation matrix of DO with land use, hydro-climatic, and biogeochemical drivers in wet season (May-October).

\begin{tabular}{|c|c|c|c|c|c|c|c|c|c|c|c|c|c|c|c|c|c|}
\hline & $\mathrm{A}$ & $S$ & I & WAT & BUL & OPN & VEG & AGR & WTL & TW & SC & $\mathrm{pH}$ & SR & AP & GWD & $\mathrm{D}_{\mathrm{c}}$ & DO \\
\hline A & 1.00 & .34 & 0.21 & 0.41 & 0.27 & 0.81 & 0.35 & 0.66 & -0.21 & 0.13 & 0.10 & 0.13 & 0.01 & 0.02 & 0.52 & 0.51 & 0.37 \\
\hline 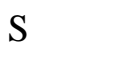 & 0.34 & 1.00 & 0.29 & -0.03 & 0.32 & 0.29 & 0.80 & 0.07 & -0.69 & -0.63 & 0.48 & 0.06 & 0.20 & -0.52 & 0.53 & 0.21 & 0.73 \\
\hline I & .21 & 0.29 & 1.00 & $-\mathbf{0 . 3 0}$ & 0.98 & 0.19 & 0.31 & -0.09 & -0.42 & -0.32 & -0.08 & -0.08 & -0.15 & -0.22 & 0.33 & -0.23 & 0.57 \\
\hline$w$ & 0.41 & -0.03 & .30 & 1.00 & -0.35 & 0.40 & -0.06 & 0.21 & 0.25 & 0.38 & 0.30 & 0.28 & 0.28 & 0.02 & 0.07 & 0.44 & -0.16 \\
\hline BUL & 0.27 & 32 & 0.98 & -0.35 & 1.00 & 0.28 & 0.37 & 0.01 & -0.44 & -0.38 & -0.20 & -0.13 & -0.18 & -0.22 & 0.41 & -0.18 & 0.65 \\
\hline & 0.81 & 29 & 19 & 0.40 & 0.28 & 1.00 & 0.47 & 0.66 & -0.07 & -0.06 & -0.27 & -0.12 & -0.07 & .03 & .63 & 0.48 & 0.36 \\
\hline VEG & 0.35 & 0.80 & 0.31 & -0.06 & 0.37 & 0.47 & 1.00 & 0.17 & -0.43 & -0.60 & -0.60 & -0.22 & -0.30 & -0.39 & 0.63 & 0.30 & 0.63 \\
\hline GR & 0.66 & 07 & .09 & 0.21 & 0.01 & 0.66 & 0.17 & 1.00 & -0.02 & -0.01 & -0.23 & -0.08 & 0.01 & 0.03 & 0.34 & 0.48 & 0.15 \\
\hline TL & 0.21 & -0.69 & 0.42 & 0.25 & -0.44 & -0.07 & -0.43 & -0.02 & 1.00 & 0.43 & 0.25 & -0.20 & 0.10 & 0.39 & -0.28 & 0.08 & -0.63 \\
\hline TW & 0.13 & -0.63 & -0.32 & 0.38 & -0.38 & -0.06 & -0.60 & -0.01 & 0.43 & 1.00 & 0.61 & 0.23 & 0.25 & 0.59 & -0.34 & 0.03 & -0.65 \\
\hline 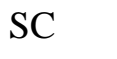 & 10 & & 8 & 0.30 & -0.20 & -0.27 & -0.60 & -0.23 & 0.25 & 0.61 & 1.00 & 19 & 0.40 & 24 & .46 & -0.30 & -0.55 \\
\hline $\mathrm{p}$ & 13 & & -0.08 & 0.28 & -0.13 & -0.12 & -0.22 & -0.08 & -0.20 & 0.23 & 0.49 & 1.00 & 0.29 & -0.16 & -0.32 & -0.16 & 0.10 \\
\hline SR & 0.01 & -0.20 & -0.15 & 0.28 & -0.18 & -0.07 & -0.30 & 0.01 & 0.10 & 0.25 & 0.40 & 0.29 & 1.00 & -0.01 & -0.19 & -0.04 & -0.14 \\
\hline AP & 0.02 & -0.52 & -0.22 & 0.02 & -0.22 & 0.03 & -0.39 & 0.03 & 0.39 & 0.59 & 0.24 & -0.16 & -0.01 & 1.00 & -0.09 & -0.10 & -0.49 \\
\hline GWD & 0.52 & 0.53 & 0.33 & 0.07 & 0.41 & 0.63 & 0.63 & 0.34 & -0.28 & -0.34 & -0.46 & -0.32 & -0.19 & -0.09 & 1.00 & 0.46 & 0.46 \\
\hline $\mathrm{D}_{\mathrm{c}}$ & 0.51 & 0.21 & -0.23 & 0.44 & -0.18 & 0.48 & 0.30 & 0.48 & 0.08 & 0.03 & -0.30 & -0.16 & -0.04 & -0.10 & 0.46 & 1.00 & 0.12 \\
\hline DO & 0.37 & 0.73 & 0.57 & -0.16 & 0.65 & 0.36 & 0.63 & 0.15 & -0.63 & -0.65 & -0.55 & 0.10 & -0.14 & -0.49 & 0.46 & 0.12 & 1.00 \\
\hline
\end{tabular}

Notes: (1) Data for all variables were $\log _{10}$ transformed to incorporate any non-linear correspondences; (2) the correlations in bold are significant at $95 \%$ level of confidence ( $\mathrm{p}$-values < 0.05$)$. 
Table A4.2. Correlation matrix of DO with land use, hydro-climatic, and biogeochemical drivers in dry season (November-April).

\begin{tabular}{|c|c|c|c|c|c|c|c|c|c|c|c|c|c|c|c|c|c|}
\hline & $\mathrm{A}$ & $S$ & I & $\overline{\mathrm{VAT}}$ & BUL & $\overline{\mathrm{OPN}}$ & VEG & AGR & WTL & TW & $\mathrm{SC}$ & $\mathrm{pH}$ & SR & AP & GWD & $\mathrm{D}_{\mathrm{c}}$ & DO \\
\hline A & 1.00 & 0.34 & 0.21 & 0.41 & 0.27 & 0.81 & 0.35 & 0.66 & -0.21 & -0.15 & 0.15 & 0.03 & 0.09 & 0.05 & 0.51 & 0.51 & 0.38 \\
\hline S & 0.34 & 1.0 & 0.29 & -0.03 & 0.32 & 0.29 & 0.80 & 0.07 & -0.69 & -0.83 & -0.49 & -0.18 & -0.45 & -0.54 & .49 & 0.21 & 0.79 \\
\hline I & 21 & 0.29 & 1.00 & -0.30 & 0.98 & 0.19 & 0.31 & -0.09 & -0.42 & -0.33 & -0.02 & -0.12 & -0.28 & -0.24 & 0.27 & -0.23 & 0.47 \\
\hline & 0.41 & -0.03 & -0.30 & 1.00 & -0.35 & 0.40 & -0.06 & 0.21 & 0.25 & 0.23 & 0.23 & 0.28 & 0.39 & 0.08 & 0.10 & 0.44 & -0.08 \\
\hline BUL & 0.27 & 0.32 & 8 & -0.35 & 1.00 & 0.28 & 0.37 & 0.01 & -0.44 & -0.41 & -0.14 & -0.19 & -0.31 & -0.24 & 35 & -0.18 & 0.55 \\
\hline OPN & 0.81 & 0.29 & 0.19 & 0.40 & 0.28 & 1.00 & 0.47 & 0.66 & -0.07 & -0.27 & -0.27 & -0.20 & -0.03 & 0.05 & 0.62 & 0.48 & 0.40 \\
\hline VEG & 0.35 & .80 & 31 & -0.06 & 0.37 & 0.47 & 1.00 & 0.17 & -0.43 & -0.79 & -0.60 & -0.42 & -0.45 & -0.40 & 0.58 & 0.30 & 0.69 \\
\hline 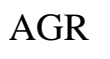 & & & & & & & & & & -0 & -0 & & 9 & & & 48 & 22 \\
\hline WTL & -0.21 & -0.69 & -0.42 & 0.25 & -0.44 & -0.07 & -0.43 & -0.02 & 1.00 & 0.54 & 0.22 & -0.04 & 0.29 & 0.40 & -0.25 & 0.08 & -0.63 \\
\hline TW & -0.15 & -0.83 & -0.33 & 0.23 & -0.41 & -0.27 & -0.79 & -0.13 & 0.54 & 1.00 & 0.68 & 0.35 & 0.54 & 0.62 & -0.48 & -0.15 & -0.87 \\
\hline q & -0.15 & 49 & -0.02 & 0.23 & -0.14 & -0.27 & -0.60 & -0.23 & 0.22 & 0.68 & 1.00 & 0.62 & 0.46 & 0.25 & -0.42 & -0.35 & -0.56 \\
\hline $\mathrm{pH}$ & 0.03 & -0.18 & -0.12 & 0.28 & -0.19 & -0.20 & -0.42 & -0.12 & -0.04 & 0.35 & 0.62 & 1.00 & 0.32 & -0.01 & -0.44 & -0.29 & -0.17 \\
\hline SR & 0.09 & -0 & -0.28 & 0.39 & -0.31 & -0.03 & -0.45 & 0.09 & 0.29 & 0.54 & 0.46 & 32 & 1.00 & 0.44 & -0.22 & -0.03 & -0.37 \\
\hline AP & 0.05 & -0.54 & -0.24 & 0.08 & -0.24 & 0.05 & -0.40 & 0.03 & 0.40 & 0.62 & 0.25 & -0.01 & 0.44 & 1.00 & -0.05 & -0.09 & -0.55 \\
\hline GW & 0.51 & 0.49 & 0.27 & 0.10 & 0.35 & 0.62 & 0.58 & 0.33 & -0.25 & -0.48 & -0.42 & -0.44 & -0.22 & -0.05 & 1.00 & 0.47 & 0.49 \\
\hline $\mathrm{D}_{\mathrm{c}}$ & 0.51 & 0.21 & -0.23 & 0.44 & -0.18 & 0.48 & 0.30 & 0.48 & 0.08 & -0.15 & -0.35 & -0.29 & -0.03 & -0.09 & 0.47 & 1.00 & 0.19 \\
\hline DO & 0.38 & 0.79 & 0.47 & -0.08 & 0.55 & 0.40 & 0.69 & 0.22 & -0.63 & -0.87 & -0.56 & -0.17 & -0.37 & -0.55 & 0.49 & 0.19 & 1.00 \\
\hline
\end{tabular}

Notes: (1) Data for all variables were $\log _{10}$ transformed to incorporate any non-linear correspondences; (2) the correlations in bold are significant at $95 \%$ level of confidence ( $\mathrm{p}$-values $<0.05)$. 
Table A4.3. Percent variance explained by each principal component (PC) in wet and dry seasons.

\begin{tabular}{lrr}
\hline Principal Component & Wet & Dry \\
\hline PC 1 & 34.32 & 37.60 \\
PC 2 & 19.10 & 19.16 \\
PC 3 & 11.79 & 11.33 \\
PC 4 & 9.98 & 9.11 \\
PC 5 & 4.84 & 4.53 \\
PC 6 & 4.58 & 4.25 \\
PC 7 & 3.74 & 3.09 \\
PC 8 & 2.72 & 2.77 \\
PC 9 & 2.32 & 1.98 \\
PC 10 & 1.73 & 1.79 \\
PC 11 & 1.57 & 1.44 \\
PC 12 & 1.14 & 0.89 \\
PC 13 & 0.78 & 0.79 \\
PC 14 & 0.68 & 0.67 \\
PC 15 & 0.38 & 0.33 \\
PC 16 & 0.30 & 0.22 \\
PC 17 & 0.04 & 0.04 \\
\hline
\end{tabular}


Table A4.4. PLSR model coefficients ( $\beta$ ) of the drivers across the seasons and year.

\begin{tabular}{lrrr}
\hline Predictors & Wet & Dry & Annual \\
\hline $\mathrm{A}$ & 0.12 & 0.02 & 0.07 \\
$\mathrm{~S}$ & 0.14 & 0.15 & 0.15 \\
$\mathrm{I}$ & 0.17 & 0.10 & 0.10 \\
$\mathrm{WAT}$ & 0.03 & 0.06 & 0.05 \\
$\mathrm{BUL}$ & 0.31 & 0.22 & 0.22 \\
$\mathrm{OPN}$ & 0.08 & 0.07 & 0.10 \\
$\mathrm{VEG}$ & -0.03 & -0.07 & 0.00 \\
$\mathrm{AGR}$ & -0.08 & 0.04 & -0.03 \\
$\mathrm{WTL}$ & -0.06 & -0.10 & -0.09 \\
$\mathrm{TW}$ & -0.27 & -0.48 & -0.41 \\
$\mathrm{SC}$ & -0.48 & -0.29 & -0.37 \\
$\mathrm{pH}$ & 0.36 & 0.17 & 0.28 \\
$\mathrm{SR}$ & 0.11 & 0.17 & 0.08 \\
$\mathrm{AP}$ & 0.04 & -0.09 & -0.01 \\
$\mathrm{GWD}$ & -0.10 & 0.01 & -0.06 \\
$\mathrm{D}_{\mathrm{c}}$ & 0.09 & 0.00 & 0.03 \\
& & & \\
$\mathrm{PLS}$ components & Model Statistics & & \\
$\mathrm{NSE}$ & 5.00 & 5.00 & 5.00 \\
$\mathrm{RSR}$ & 0.88 & 0.88 & 0.89 \\
& 0.34 & 0.34 & 0.32 \\
$\beta_{\mathrm{LU}}$ & Aggregated Linkage & & \\
$\beta_{\mathrm{C}}$ & 0.34 & 0.27 & 0.26 \\
$\beta_{\mathrm{H}}$ & 0.29 & 0.52 & 0.42 \\
$\beta_{\mathrm{R}}$ & 0.27 & 0.18 & 0.20 \\
\hline & 0.60 & 0.33 & 0.46 \\
\hline & & &
\end{tabular}

Notes: A, S, I, D , WAT, BUL, OPN, VEG, AGR, WTL, TW, SC, SR, AP, GWD respectively, refer to watershed area, slope, imperviousness, distance from coast, waterbody, built-up land, open land, vegetated land, agricultural land, wetland, temperature of water, specific conductance, solar radiation, atmospheric pressure, and groundwater depth. 


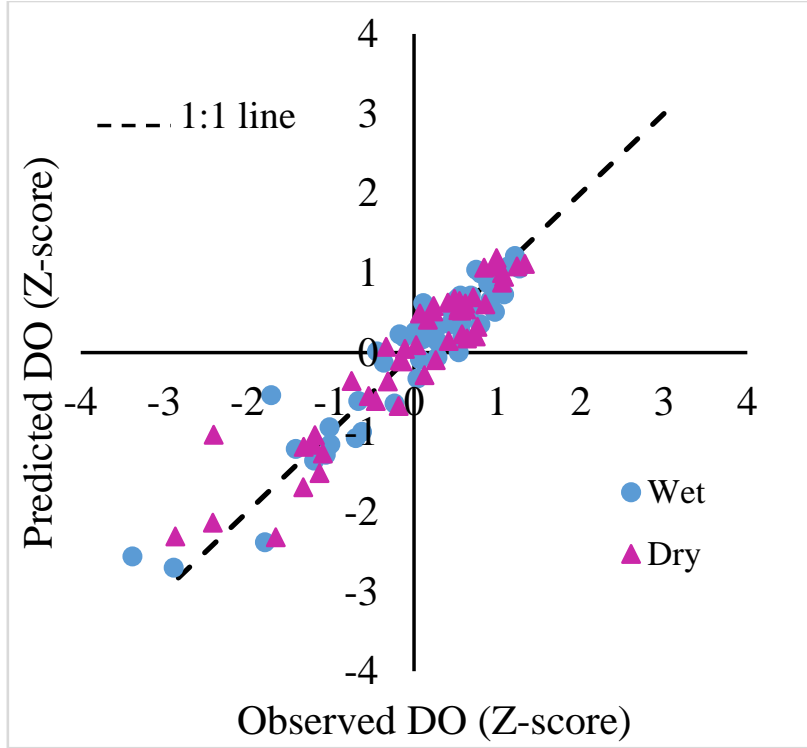

Figure A4.1. Observed vs. predicted Z-scores from PLSR models in wet (May-October) and dry (November-April) seasons. 


\title{
Chapter 5: Dimensional analysis and similitude to analyze the interactive controls of land use, hydro-climatic, and biogeochemical drivers on stream dissolved oxygen across the East \\ Coast of U.S.A.
}

\begin{abstract}
The interactive controls of land use, hydro-climatic, and biogeochemical drivers on coastal stream dissolved oxygen (DO) were investigated across the East Coast of U.S.A by employing similitude and dimensional analysis. The concentration of DO was normalized by its saturated concentration $\left(\mathrm{DO}_{\text {sat }}\right)$ to formulate the response dimensionless number $\left(\mathrm{DO} / \mathrm{DO}_{\text {sat }}\right)$, which generalized stream DO of diverse environments in a similar comparable scale with respect to the solubility of oxygen in water. The predictor dimensionless numbers represented the interactive controls of different land use, hydro-climatic, and biogeochemical drivers on stream water quality. The 'metabolic number' and 'salinity number' represented the interactive controls of climatic drivers (e.g., temperature, atmospheric pressure), respectively, with stream metabolism and salinity. Further, the 'land use number' showed the contrasting controls from agricultural vs. built-up land uses, and the 'slope number' represented the control from watershed hydrology. The research validated the hypothesis that coastal stream water quality processes follow distinct similitude (parametric reductions) — by reducing 11 original variables of stream water quality to a smaller set of 5 meaningful dimensionless numbers. A systematic data analytics implied strong controls of 'metabolic number' and 'salinity number' on stream DO suggesting that the stream water quality was primarily driven by the interactive controls of stream metabolism, salinity, and climatic drivers. The significant linkage of 'slope number' with normalized DO suggested the important role of watershed hydrology to control stream DO by aeration. Further, substantial
\end{abstract}


control of 'land use number' on normalized DO indicated in-stream nutrient enrichment by agricultural land, while dilution of the nutrient by runoff from built-up land. The knowledge of the dominant interactive controls of the environmental drivers found from similitude and dimensionless numbers would advance the generalized understanding of coastal stream water quality to guide effective management of coastal ecosystems across the East Coast of U.S.A.

\subsection{Introduction}

Increasing pressure of development and changing climate pose a major threat to degrade stream water quality, particularly in the coastal environments. Dissolved oxygen (DO)—a key indicator to assess the stream water quality—has drastically changed over a short period of time in the coastal environments (Diaz and Rosenberg, 2008) demanding urgent protection and management of coastal water resources. However, multitude of interacting watershed land use, hydro-climatic, and biogeochemical drivers (Tran et al., 2010; Badruzzaman et al., 2012) makes it challenging to develop a generalizable process understanding of stream water quality. It is important to know how the drivers mutually and comparatively interact to control stream water quality under diverse environments for effective management of water resources. Further, an important research question is whether the numerous stream water quality drivers can be reduced to a smaller set of combined entities representing interactions of different environmental process components controlling stream water quality. Similitude and scaling can be leveraged in this regard to combine the interactions of different hydro-climatic, biogeochemical, and land use drivers into a reduced set of dimensionless numbers leading to generalizable process understanding of coastal stream water quality dynamics. 
Watershed land uses (e.g, urban, nonurban) have been important drivers of coastal stream water quality by contributing nutrient induced eutrophication and subsequent microbiological decomposition resulting from high concentration of development near coastal regions (Diaz and Rosenberg, 2008; Xiao et al., 2016). Zhou et al. (2016) reported in-stream nitrogen enrichment by non-point source pollution from high proportion of agricultural land alongside point source pollution from urban areas in Minjiang River Watershed, southeast China. Wan et al. (2014b) reported agricultural land as a strong source of nutrients (e.g., $\mathrm{PO}_{4}-\mathrm{P}, \mathrm{NH}_{4}-\mathrm{PN}$ ) which adversely affected the stream DO in the Indian River Lagoon Watershed, Florida. Fan and Shibata (2015) reported that agricultural land is a strong source of nitrogen and phosphorus loads in Teshio River catchment in northern Hokkaido of North Japan. Further, they showed positive effect of riparian zones by reducing the nutrient load from land uses. Bu et al. (2014) reported strong effect of both agricultural and built-up land on stream DO by contributing to oxygen demanding waste in Taizi River basin, China.

Climate (e.g., temperature) has been reported a strong driver of stream DO since the metabolic and biogeochemical processes of stream water quality is temperature-dependent (Sinsabaugh, 1997; Uehlinger et al., 2000). Further, the solubility of DO in water is strongly affected by temperature (Chapra, 1997). Fan and Shibata (2015) reported strong effect of temperature to control stream water quality in Teshio River of North Japan. Dyar and Alhadeff (2005) found strong control of temperature on stream DO in their study of 31 stream water quality monitoring stations in Georgia. Correa-González et al. (2014) found that temperature strongly influenced the DO in Río Chiquito stream, México. Schaefer and Hollibaugh (2017) reported strong negative effect of temperature on stream DO in the coastal water of Georgia. Apart from climate, hydrologic drivers (e.g., watershed slope, stream flow) also affect stream 
DO by aeration through turbulence and pollutant transport. Salinity intrusion in coastal water can reduce DO by decreasing its solubility in water. Prasad et al. (2011) reported strong effect of salinity on stream DO in Chesapeake Bay, U.S.A. Further, stream biogeochemical processes (e.g., microbial decomposition, photosynthesis) have also been reported to play important role in the dynamics of coastal stream DO (Cai et al., 2011).

The goal of the study is to investigate interactive controls of various environmental drivers on coastal stream DO by employing dimensional analysis and similitude. The research tests the hypothesis that coastal stream water quality follows distinct biogeochemical-ecological similitude incorporating a large spatial scale across East Coast of U.S.A. Dimensionless numbers - representing the interactive and collective controls of environmental drivers-were formulated employing dimensional analysis. The dominant dimensionless numbers were identified by employing a systematic data analytics technique (Ishtiaq and Abdul-Aziz, 2015). The knowledge of the similitude and dominant drivers is expected to guide effective management of coastal stream water quality to maintain healthy aquatic ecosystems.

\subsection{Materials and methods}

\subsubsection{Study area and data sets}

The study area includes 40 stream water quality sites of NOAA's coastal watersheds (Percy Pacheco, personal communications, 2016) across the East Coast of U.S.A (Figure 5.1). The stream water quality sites are located in eight different U.S. states: (i) Connecticut; (ii) New Jersey; (iii) Maryland; (iv) Virginia; (v) North Carolina; (vi) South Carolina; (vii) Georgia; and (viii) Florida. With a wide range of vegetation, geology, and land uses, the study area 
incorporated diverse ecoregions starting from "eastern temperate forests" in the northern part and "tropical wet forests" in the southern part (Omernik and Griffith, 2014).

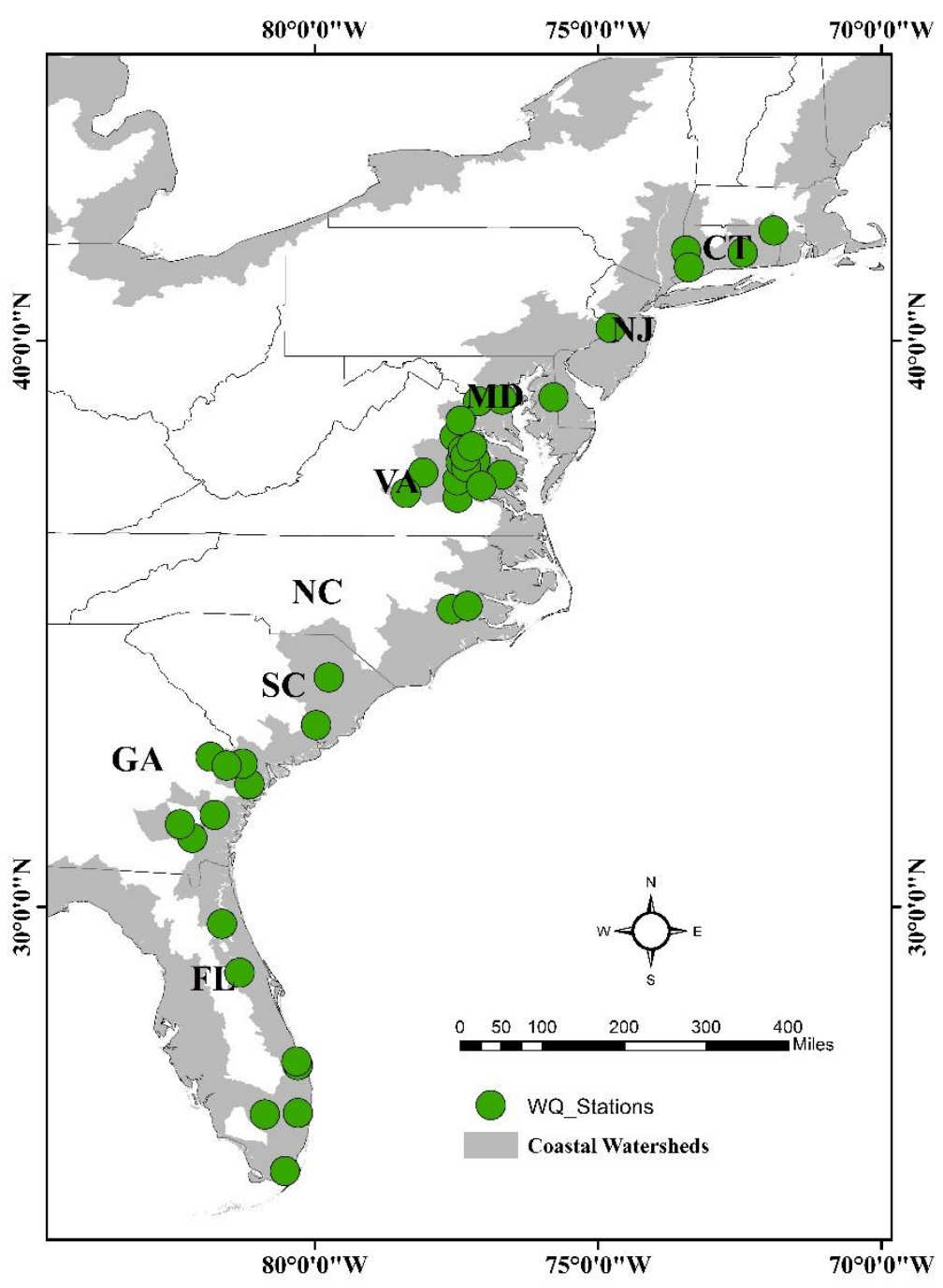

Figure 5.1. Locations of the coastal stream water quality monitoring sites across the East Coast of U.S.A.

Temporal data (1998-2015) of grab sample stream water quality collected mostly at quarterly time interval were used. Stream water quality data of USGS NWIS and EPA STORET 
were gathered from National Water Quality Monitoring Council (NWQMC) databases

(NWQMC, 2017). Selected stream water quality variables were DO, temperature of water (TW), salinity (Sal), and $\mathrm{pH}$. Salinity was estimated from the observed data of specific conductance following Schemel (2001). DO represented the indicator of stream water quality, while salinity (Sal) and pH represented, respectively, the saltwater intrusion and metabolic (e.g., microbial decomposition) controls. Data of atmospheric pressure (AP)—representing controls from atmospheric gas exchange-were collected from 4 x 4 km grid cells of National Solar Radiation Data Base (NSRDB) (NSRDB, 2017). Dissolved oxygen saturation ( $\mathrm{DO}_{\text {sat }}$ ) was estimated as a function of TW, Sal, and AP following Chapra (2008). The outliers in the data were removed using the criteria of interquartile range (IQR) as $P_{25}-2 \times I Q R$ and $P_{75}+2 \times I Q R$; where, $P_{25}, P_{75}$, are, respectively, $25^{\text {th }}$ percentile and $75^{\text {th }}$ percentile. Separate analyses were performed for wet (May-October) and dry (November-April) seasons (NAME, 2018) with seasonal averaged data to account for the seasonal effect.

Drainage area for each stream water quality site was generated in ESRI ArcGIS 10.2 platform using 10 m digital elevation model (United States Geological Survey (USGS), 2017a). Watershed characteristic length $\left(\mathrm{L}_{c}\right.$; calculated as the longest flow path to the watershed outlet) and characteristic relief $\left(\mathrm{Z}_{\mathrm{c}}\right.$; calculated as the elevation difference between the watershed outlet and inlet) were used to represent control from the watershed surface hydrology. The mean area of watershed land uses for the respective time period of temporal data were estimated from the 30 m data of National Land Cover Database (NLCD) for 2001, 2006, and 2011 (NLCD, 2017). Area of built-up land ( $\left.\mathrm{A}_{\mathrm{BUL}}\right)$ and agricultural land $\left(\mathrm{A}_{\mathrm{AGR}}\right)$ were used to represent the controls of watershed land uses. The data summary (Table 5.1) represented wide ranges of diverse land use, hydro-climatic, and biogeochemical drivers to control the stream water quality dynamics. 
Table 5.1. Summary of the stream dissolved oxygen, land use, hydro-climatic, and biogeochemical drivers across all the stream water quality monitoring sites.

\begin{tabular}{|c|c|c|c|c|c|c|c|}
\hline \multirow[t]{2}{*}{ Variables } & \multirow[t]{2}{*}{ Mean } & Standard & Minimum & \multirow{2}{*}{$\begin{array}{r}\text { 25th } \\
\text { Percentile }\end{array}$} & \multirow{2}{*}{$\begin{array}{r}\text { 50th } \\
\text { Percentile }\end{array}$} & \multirow{2}{*}{$\begin{array}{r}\text { 75th } \\
\text { Percentile }\end{array}$} & \multirow[t]{2}{*}{ Maximum } \\
\hline & & Deviation & & & & & \\
\hline $\mathrm{L}_{\mathrm{c}}(\mathrm{km})$ & 203.60 & 189.37 & 9.86 & 51.72 & 130.34 & 328.98 & 621.69 \\
\hline $\mathrm{Z}_{\mathrm{c}}(\mathrm{m})$ & 284.74 & 321.69 & 0.42 & 50.85 & 191.10 & 331.26 & 1054.37 \\
\hline $\mathrm{A}_{\mathrm{AGR}}\left(\mathrm{km}^{2}\right)$ & 1153.98 & 1800.74 & 0.18 & 95.20 & 357.09 & 1569.32 & 8812.52 \\
\hline $\mathrm{A}_{\mathrm{BUL}}\left(\mathrm{km}^{2}\right)$ & 625.43 & 984.61 & 1.02 & 26.52 & 154.40 & 961.20 & 3961.37 \\
\hline \multicolumn{8}{|c|}{ Wet Season (May-October) } \\
\hline $\mathrm{DO}(\mathrm{mg} / \mathrm{L})$ & 7.00 & 1.58 & 3.90 & 5.95 & 7.04 & 8.12 & 9.92 \\
\hline $\mathrm{DO}_{\text {sat }}(\mathrm{mg} / \mathrm{L})$ & 8.55 & 0.55 & 7.58 & 8.16 & 8.49 & 9.07 & 9.66 \\
\hline Sal (ppt) & 0.22 & 0.47 & 0.03 & 0.05 & 0.08 & 0.14 & 2.26 \\
\hline $\mathrm{pH}$ & 7.18 & 0.58 & 5.68 & 6.82 & 7.14 & 7.55 & 8.30 \\
\hline $\mathrm{TW}\left({ }^{\circ} \mathrm{C}\right)$ & 23.38 & 3.42 & 17.18 & 20.09 & 23.53 & 25.89 & 29.22 \\
\hline AP (mbar) & 1010.47 & 5.97 & 991.30 & 1009.11 & 1011.75 & 1014.64 & 1016.95 \\
\hline \multicolumn{8}{|c|}{ Dry Season (November-April) } \\
\hline DO (mg/L) & 10.03 & 1.99 & 6.40 & 8.67 & 10.20 & 11.63 & 13.49 \\
\hline $\mathrm{DO}_{\text {sat }}(\mathrm{mg} / \mathrm{L})$ & 11.08 & 1.29 & 8.25 & 10.30 & 11.66 & 12.08 & 12.70 \\
\hline Sal (ppt) & 0.44 & 1.69 & 0.03 & 0.05 & 0.06 & 0.14 & 10.57 \\
\hline $\mathrm{pH}$ & 7.12 & 0.59 & 5.70 & 6.69 & 7.12 & 7.71 & 8.11 \\
\hline $\mathrm{TW}\left({ }^{\circ} \mathrm{C}\right)$ & 11.56 & 5.45 & 5.06 & 7.62 & 8.95 & 14.52 & 23.26 \\
\hline AP (mbar) & 1013.11 & 6.53 & 993.54 & 1011.68 & 1015.06 & 1017.57 & 1020.23 \\
\hline
\end{tabular}

\subsubsection{Formulation of the dimensionless numbers}

Dimensionless numbers were formulated employing Buckingham's pi theorem (Finnemore and Franzini 2002; Kundu and Cohen, 2002), which states that 'n' dimensional variables can be combined to form (n-r) dimensionless (pi or $\Pi$ ) numbers, where $r$ is the number of relevant fundamental dimensions. The pi theorem was employed by incorporating the important stream water quality variables and drivers - selected based on the process-based knowledge of stream water quality and preliminary analysis. Specific heat of water $\left(c_{p}=4184 \mathrm{~J} \mathrm{~kg}^{-1}{ }^{\circ} \mathrm{C}^{-1}\right)$ was 
incorporated to conform with the unit of TW. The concentration of hydrogen ion $(\mathrm{H})$ was directly estimated from $\mathrm{pH}$. A functional relationship of the stream DO with the relevant drivers can be expressed as follows:

$$
f\left(D O, D O_{s a t}, H, S a l, T W, A P, c_{p}, L_{c}, Z_{c}, A_{A G R}, A_{B U L}\right)=0
$$

The equation has total number of variables, $\mathrm{n}=11$; number of relevant fundamental dimensions, $\mathrm{r}=4$ (mass: $\mathrm{M}$; length: L; Time: T; temperature: K) (see Table 5.2). Therefore, the number of dimensionless numbers can be formed from the set is seven $(n-r=7)$. This seven dimensionless numbers can be used to reform the Eq. (1) as follows:

$\varphi\left(\Pi_{1}, \Pi_{2}, \Pi_{3}, \Pi_{4}, \Pi_{5}, \Pi_{6}, \Pi_{7}\right)=0$

Table 5.2. List of variables and their dimensions

\begin{tabular}{lll}
\hline Variables & Units & Dimensions \\
\hline Dissolved oxygen $(\mathrm{DO})$ & $\mathrm{kg} \mathrm{m}^{-3}$ & {$\left[\mathrm{ML}^{-3}\right]$} \\
Saturated concentration of dissolved oxygen $\left(\mathrm{DO}_{\mathrm{sat}}\right)$ & $\mathrm{kg} \mathrm{m}^{-3}$ & {$\left[\mathrm{ML}^{-3}\right]$} \\
Concentration of hydrogen ion $(\mathrm{H})$ & $\mathrm{kg} \mathrm{m}^{-3}$ & {$\left[\mathrm{ML}^{-3}\right]$} \\
Salinity (Sal) & $\mathrm{kg} \mathrm{m}^{-3}$ & {$\left[\mathrm{ML}^{-3}\right]$} \\
Stream water temperature $(\mathrm{TW})$ & ${ }^{\circ} \mathrm{C}$ & {$\left[\mathrm{K}^{\circ}\right]$} \\
Atmospheric pressure $(\mathrm{AP})$ & $\mathrm{Kg} \mathrm{m}^{-1} \mathrm{~s}^{-2}$ & {$\left[\mathrm{ML}^{-1} \mathrm{~T}^{-2}\right]$} \\
Specific heat of water $\left(\mathrm{c}_{\mathrm{p}}\right)$ & $\mathrm{J} \mathrm{kg}^{-1} \mathrm{C}^{-1}$ & {$\left[\mathrm{~L}^{2} \mathrm{~T}^{-2} \mathrm{~K}^{-1}\right]$} \\
Characteristic length of watershed $\left(\mathrm{L}_{\mathrm{c}}\right)$ & $\mathrm{m}$ & {$\left[\mathrm{L}^{-1}\right]$} \\
Characteristic relief of watershed $\left(\mathrm{Z}_{\mathrm{c}}\right)$ & $\mathrm{m}$ & {$\left[\mathrm{L}^{-}\right]$} \\
Agricultural land $\left(\mathrm{A}_{\mathrm{AGR}}\right)$ & $\mathrm{m}^{2}$ & {$\left[\mathrm{~L}^{2}\right]$} \\
Built-up land $\left(\mathrm{A}_{\mathrm{BUL}}\right)$ & $\mathrm{m}^{2}$ & {$\left[\mathrm{~L}^{2}\right]$} \\
\hline
\end{tabular}

A set of four $(\mathrm{r}=4)$ 'repeating variables' were selected ensuring that they contain all the fundamental dimensions and do not form dimensionless numbers among themselves. The set of repeating variables alongside one of the remaining variables were used in each iteration to 
develop the dimensionless number. If we select the repeating variables as $\mathrm{TW}, \mathrm{c}_{\mathrm{p}}, \mathrm{H}$, and $\mathrm{A}_{\mathrm{BUL}}$ with AP as the remaining variable, then the first dimensionless number can be formulated as:

$$
\Pi_{1}=T W^{a} c_{p}^{b} H^{c} A_{B U L}^{d} A P
$$

Based on the principle of dimensional homogeneity:

$$
M^{0} L^{0} T^{0} K^{0}=(K)^{a}\left(L^{2} T^{-2} K^{-1}\right)^{b}\left(M L^{-3}\right)^{c}\left(L^{2}\right)^{d}\left(M L^{-1} T^{-2}\right)
$$

Equating the exponents on both sides, we get $\mathrm{a}=-1, \mathrm{~b}=-1 ; \mathrm{c}=-1 ; \mathrm{d}=0$; therefore,

$$
\Pi_{1}=T W^{-1} c_{p}^{-1} H^{-1} A_{B U L}{ }^{0} A P^{1}=\left(\frac{A P}{c_{p} \cdot T W \cdot H}\right)
$$

Similarly, the other pi numbers $\left(\Pi_{2}\right.$ to $\left.\Pi_{7}\right)$ were formulated as follows:

$$
\Pi_{2}=\left(\frac{A P}{c_{p} \cdot T W \cdot S a l}\right), \Pi_{3}=\left(\frac{A P}{c_{p} \cdot T W \cdot D O}\right), \Pi_{4}=\left(\frac{A P}{c_{p} \cdot T W \cdot D O_{s a t}}\right), \Pi_{5}=\left(\frac{A_{A G R}}{A_{B U L}}\right), \Pi_{6}=\left(\frac{L_{c}}{A_{B U L}^{0.5}}\right), \Pi_{7}=\left(\frac{Z_{c}}{A_{B U L}^{0.5}}\right)
$$

The functional relationship among the dimensionless numbers can be written as:

$\phi\left(\frac{A P}{c_{p} \cdot T W \cdot H}, \frac{A P}{c_{p} \cdot T W \cdot S a l}, \frac{A P}{c_{p} \cdot T W \cdot D O}, \frac{A P}{c_{p} \cdot T W \cdot D O_{s a t}}, \frac{A_{A G R}}{A_{B U L}}, \frac{L_{c}}{A_{B U L}^{0.5}}, \frac{Z_{c}}{A_{B U L}^{0.5}}\right)=0$

Following the Buckingham's pi theorem, numerous iterations were performed to obtain other possible pi numbers. The relevant pi number were combined to formulate new pi numbers (e.g., DO/DO $\mathrm{Dat}_{\mathrm{s}}, \mathrm{Z}_{\mathrm{c}} / \mathrm{L}_{\mathrm{c}}$ ). Finally, based on the process-based knowledge of stream water quality, we selected meaningful set of 5 pi numbers (Eqn. 3) to represent stream water quality process. The pi theorem allows to express the response pi number as a function of the predictor pi numbers as follows:

$$
\frac{D O}{D O_{s a t}}=\varphi\left[\left(\frac{Z_{c}}{L_{c}}\right)\left(\frac{A_{A G R}}{A_{B U L}}\right)\left(\frac{A P}{c_{p} \cdot T W \cdot H}\right)\left(\frac{A P}{c_{p} \cdot T W \cdot S a l}\right)\right]
$$


$\mathrm{DO} / \mathrm{DO}_{\text {sat }}$ represented the concentration of DO normalized by its saturation point to bring DO of different streams in a similar comparable scale in terms of its solubility in water. The predictor pi numbers represented the interactive and collective controls from diverse environmental drivers. For example, $Z_{c} / L_{c}$ is the ratio of characteristic relief to the longest flow path of watershed, and thus, can be termed as 'slope number'-representing watershed hydrology. $\mathrm{A}_{\mathrm{AGR}} / \mathrm{A}_{\mathrm{BUL}}$ represented the contrasting control of agricultural vs. built-up land, and was termed as the 'land use number'. $\mathrm{AP} /\left(\mathrm{c}_{\mathrm{p}} \cdot \mathrm{TW} \cdot \mathrm{H}\right)$ represented the interactive controls of stream metabolic driver (i.e., $\mathrm{pH}$ ) with TW and AP, and was termed as 'metabolic number'. Further, AP/( $\left.c_{p} \cdot T W \cdot S a l\right)$ showed the interactive controls of salinity with TW and AP, and therefore, was termed as 'salinity number'.

The parametric reduction of the dimensional analysis - by reducing the 11 original variables to a smaller set of 5 meaningful pi numbers—can be termed as 'stream biogeochemical-ecological similitude' in this research. The quantification of the relative linkages of the response pi number with the predictor pi number would indicate the dominant interactive and collective controls of the environmental drivers to control stream water quality. The functional relationship of the response pi number with the predictor pi numbers can be expressed as a power-law equation as follows: $\Pi_{1}=k \prod_{2}^{a} \Pi_{3}^{b} \Pi_{4}^{c} \Pi_{5}^{d}$, where the coefficient $(k)$ and exponents $(a, b, c, d)$ need to be estimated by fitting with observational data.

\subsubsection{Quantifying the relative controls of the pi numbers}

The relative controls of the predictor pi numbers on the response pi number were quantified by employing a systematic data analytics framework (Ishtiaq and Abdul-Aziz, 2015). The data analytics involved a systematic utilization of four multivariate pattern recognition techniques: (i) Pearson correlation matrix, (ii) principal component analysis (PCA), (iii) factor analysis (FA), 
and (iv) partial least squares regression (PLSR). The data were transformed logarithmically $\left(\log _{10}\right)$ to account for the non-linear interactions among the stream water quality processes. Further, the $\log _{10}$-transformed data were then standardized (dimensionless Z-score) to bring various pi numbers in a similar comparable reference scale. The Z-scores were calculated as follows: $Z=(X-\bar{X}) / s_{X}$; where $X=\log _{10}$-transformed variable, $\bar{X}=$ mean of $X$, and $s_{X}=$ standard deviation of $X$. The data analytics was performed using MATLAB.

The Pearson correlation matrix provided initial knowledge on the mutual correspondences among the pi numbers. Then we applied PCA and FA to get deeper insights into the interrelationships among the pi numbers by resolving multicollinearity in the orthogonal (independent) domain (Jolliffe, 2002). In factor analysis, the number of optimal factors was determined by using an eigenvalue criterion of eigenvalue $\geq 1$. Finally, we employed PLSR model to quantify the relative linkages between the response and predictor pi numbers. PLSRupon appropriate optimization-resolves the model instability and error caused by multicollinearity through transformed orthogonal planes. The PLSR model optimization was achieved by using a synthesis of the minimum Akaike Information Criterion (AIC) and the maximum Nash-Sutcliffe efficiency (NSE) criteria (Nash and Sutcliffe, 1970; Ishtiaq and AbdulAziz, 2015). The PLSR models were developed using SIMPLS algorithm (de Jong, 1993; Hubert and Branden, 2003) and a 10-fold cross validation method (Kuhn and Johnson, 2013). More details into the data analytics can be found in Ishtiaq and Abdul-Aziz (2015). The estimated relative controls/linkages between the response and predictor pi numbers were represented by the PLSR model coefficients (BETA). The model efficiency and accuracy were measured, respectively, by NSE and the ratio of root-mean-square error to the standard deviation of the observations (RSR). The model RSR values of $0-0.5,0.5-0.6,0.6-0.7$, and $>0.70$ indicate 
respectively, "very good", "good”, "satisfactory", and "unsatisfactory" models (Moriasi et al., 2007).

\subsection{Results}

\subsubsection{Mutual relationships among the pi numbers}

The mutual relationships among the pi numbers were represented by correlation coefficients (r) in both wet and dry seasons. (Table 5.3). Results showed moderate to strong positive linkages of $\mathrm{DO} / \mathrm{DO}_{\text {sat }}$ with 'slope number', 'metabolic number' and 'salinity number' across wet ( $\mathrm{r}=0.41$ to $0.61)$ and dry ( $r=0.42$ to 0.56$)$ seasons — suggesting their dominant controls. The positive linkages of 'salinity number' and 'metabolic number' might be the result of interactive effects of the sources (i.e., contribution from atmosphere) and sinks (i.e., microbial consumption, reduced solubility) of DO. Further, the positive linkage of 'slope number' with normalized DO might have suggested that steeper slope contributed to stream DO by increased aeration. The linkage of 'slope number' was relatively low in dry season than the wet season, suggesting relatively

reduced hydrologic control due to lower runoff in dry period. The notable negative linkages $(\mathrm{r}=$ -0.37 to -0.44 ) of $\mathrm{A}_{\mathrm{AGR}} / \mathrm{A}_{\mathrm{BUL}}$ with $\mathrm{DO} / \mathrm{DO}_{\text {sat }}$ across the seasons indicated substantial control of interacting land uses. The mutual relationships among some of the predictor pi numbers were also apparent from the correlation matrices (Table A5.1 and A5.2 in Appendix 5). For example, strong positive linkage $(r=0.57$ to 0.63$)$ of $\mathrm{Z}_{\mathrm{c}} / \mathrm{L}_{\mathrm{c}}$ with $\mathrm{AP} /\left(\mathrm{c}_{\mathrm{p}} \cdot \mathrm{TW} \cdot \mathrm{Sal}\right)$ across the seasons suggested that steeper slope leads to higher runoff which reduced the downstream salinity at the watershed outlet (Xie et al., 2017). Further, the negative linkage of 'slope number' with 'land use number' indicated that the ratio of agricultural to built-up land decreases with increasing slope across the US East Coast. 
Table 5.3. Pearson correlation coefficients $(\mathrm{r})$ of $\mathrm{DO} / \mathrm{DO}_{\text {sat }}$ with the predictor pi numbers.

\begin{tabular}{lrrrr}
\hline & $\mathrm{Z}_{\mathrm{c}} / \mathrm{L}_{\mathrm{c}}$ & $\mathrm{A}_{\mathrm{AGR}} / \mathrm{A}_{\mathrm{BUL}}$ & $\mathrm{AP} /\left(\mathrm{c}_{\mathrm{p}} \cdot \mathrm{TW} \cdot \mathrm{Sal}\right)$ & $\mathrm{AP} /\left(\mathrm{c}_{\mathrm{p}} \cdot \mathrm{TW} \cdot \mathrm{H}\right)$ \\
\hline Wet & 0.61 & -0.37 & 0.41 & 0.51 \\
Dry & 0.56 & -0.44 & 0.42 & 0.53 \\
\hline
\end{tabular}

Note: (1) Data for all pi numbers were $\log _{10}$ transformed to incorporate any nonlinear correspondences. (2) All correlations are significant at the $95 \%$ level of confidence from a two-tailed test.

\subsubsection{Interrelationships based on the PCA}

The nonlinear relationships of the pi numbers were represented by the first two PCs through biplots in wet (Figure 5.2a) and dry (Figure 5.2b) seasons. The first two PCs explained approximately $74.48 \%$ to $75.97 \%$ of the total data variances across the two seasons (see Table A5.3 in Appendix 5). The relative orientations and lengths of the vectors suggested moderate to strong positive linkages of $\mathrm{DO} / \mathrm{DO}_{\text {sat }}$ with $\mathrm{AP} /\left(\mathrm{c}_{\mathrm{p}} \cdot \mathrm{TW} \cdot \mathrm{H}\right)$ and $\mathrm{AP} /\left(\mathrm{c}_{\mathrm{p}} \cdot \mathrm{TW} \cdot \mathrm{Sal}\right)$ across the seasons - reiterating dominant controls from interactive climate, stream metabolism, and salinity. Further, strong positive linkage of normalized DO with 'slope number' indicated contribution of watershed hydrology to stream DO by aeration. With non-orthogonal and opposite orientations of the vectors, $\mathrm{A}_{\mathrm{AGR}} / \mathrm{A}_{\mathrm{BUL}}$ showed moderate negative linkages with $\mathrm{DO} / \mathrm{DO}_{\text {sat }}$ across the seasons - indicating that relatively higher ratio of agricultural to built-up land adversely affected stream DO. The non-orthogonal orientations of 'slope number' and 'salinity number' reiterated their moderate to strong mutual correlations across the seasons. Further, the opposite orientations of 'slope number' and 'land use' number indicated their negative linkages. 
(a)

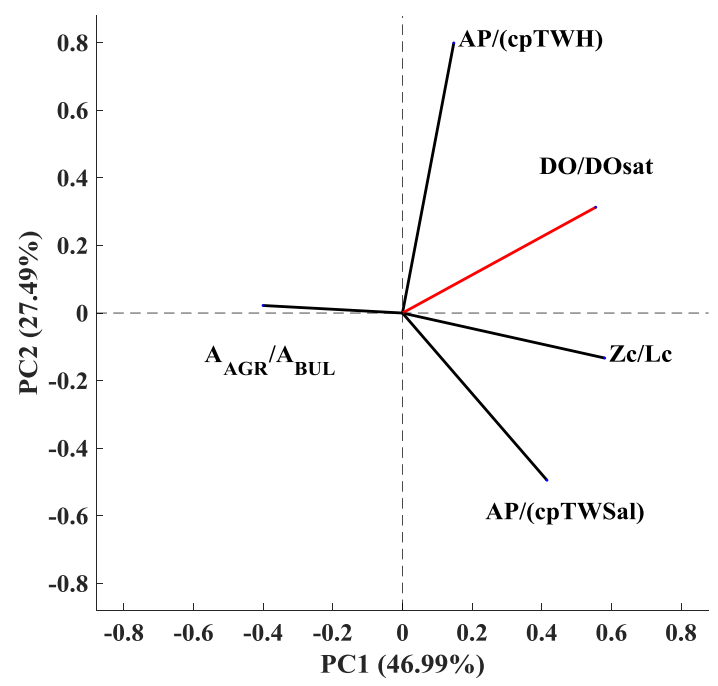

(b)

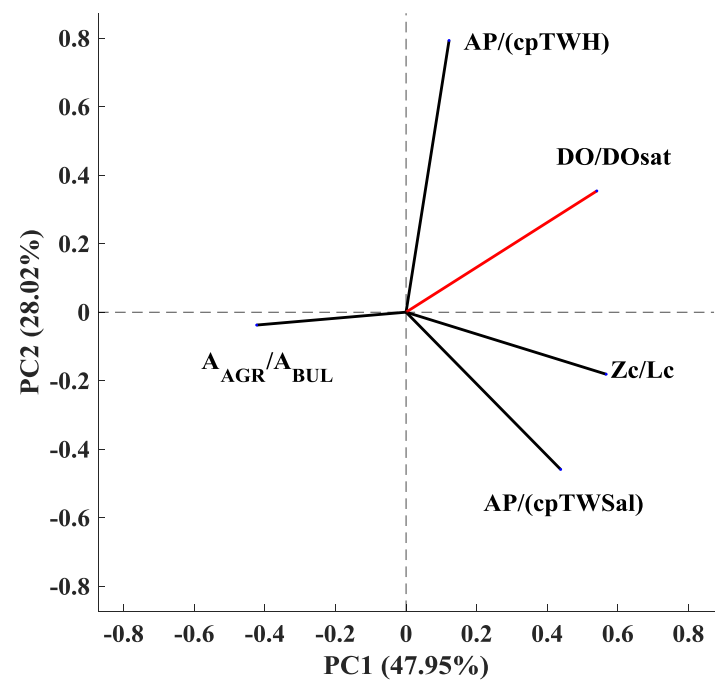

Figure 5.2. PCA Biplots showing the interrelationship patterns among the predictor and response pi numbers in (a) wet and (b) dry seasons. Percent variance explained by each PC is shown in parenthesis.

\subsubsection{Interrelationships based on the FA}

Based on the eigenvalue $\geq 1$ criteria, two independent factors were determined to optimally explain the hidden patterns into the data matrices (Table 5.4). Variances explained by the first two factors ranged, respectively, from approximately $46.99 \%$ to $47.95 \%$ and $27.49 \%$ to $28.02 \%$ across the two seasons.

Table 5.4. Major latent factors with their optimized loadings on the pi numbers.

\begin{tabular}{clrrrrr}
\hline & Factors & $\mathrm{Z}_{\mathrm{c}} / \mathrm{L}_{\mathrm{c}}$ & $\mathrm{A}_{\mathrm{AGR}} / \mathrm{A}_{\mathrm{BUL}}$ & $\mathrm{AP} /\left(\mathrm{c}_{\mathrm{p}} \cdot \mathrm{TW} \cdot \mathrm{Sal}\right)$ & $\mathrm{AP} /\left(\mathrm{c}_{\mathrm{p}} \cdot \mathrm{TW} \cdot \mathrm{H}\right)$ & $\mathrm{DO} / \mathrm{DOsat}$ \\
\hline \multirow{2}{*}{ Wet } & F1 & $\mathbf{0 . 7 9}$ & $\mathbf{- 0 . 4 6}$ & $\mathbf{0 . 7 1}$ & 0.04 & $\mathbf{0 . 7 8}$ \\
& F2 & 0.04 & 0.02 & -0.32 & $\mathbf{1 . 0 0}$ & $\mathbf{0 . 4 9}$ \\
& F1 & $\mathbf{0 . 8 0}$ & $\mathbf{- 0 . 5 1}$ & $\mathbf{0 . 7 5}$ & -0.02 & $\mathbf{0 . 7 4}$ \\
& F2 & 0.01 & -0.03 & -0.27 & $\mathbf{1 . 0 0}$ & $\mathbf{0 . 5 4}$ \\
\hline
\end{tabular}

Note: Bold values indicate variables having moderate to high loadings (correlations) on factors (F); F1-2 refer to two different factors. 
$\mathrm{DO} / \mathrm{DO}_{\text {sat }}$ loaded strongly on factor $1(0.78)$ in wet season, which had high loadings of $\mathrm{Zc} / \mathrm{Lc}(0.79)$ and $\mathrm{AP} /\left(\mathrm{c}_{\mathrm{p}} \cdot \mathrm{TW} \cdot \mathrm{Sal}\right)(0.71)$, while moderate loading of $\mathrm{A}_{\mathrm{AGR}} / \mathrm{A}_{\mathrm{BUL}}(-0.46)-$ suggesting moderate to strong controls of interacting hydro-climatic, salinity, and land use drivers. Further, DO/DO sat loaded strongly on factor 2 (0.49) which had very high loading (1.0) of $\mathrm{AP} /\left(\mathrm{c}_{\mathrm{p}} \cdot \mathrm{TW} \cdot \mathrm{H}\right)$ - reiterating strong control of 'stream metabolism' on stream DO. Similar to wet season, dry season DO/DO sat loaded strongly on factor $1(0.74)$, which had moderate to high loadings of $\mathrm{Zc} / \mathrm{Lc}(0.80), \mathrm{AP} /\left(\mathrm{c}_{\mathrm{p}} \cdot \mathrm{TW} \cdot \mathrm{Sal}\right)(0.75)$, and $\mathrm{A}_{\mathrm{AGR}} / \mathrm{A}_{\mathrm{BUL}}(-0.51)$-indicating their substantial controls on stream DO. Further, high loadings (0.54 to 1.0) of both DO/DOsat and $\mathrm{AP} /\left(\mathrm{c}_{\mathrm{p}} \cdot \mathrm{TW} \cdot \mathrm{H}\right)$ on factor 2 indicated strong control of stream metabolism on DO. The moderate to strong loadings of 'slope number', 'salinity number, and 'land use number' in factor 1 across the seasons reiterated their mutual interrelationships.

\subsubsection{Quantification of the relative controls by PLSR}

The model optimization required inclusion of 3 PLS components based on the synthesis of minimum AIC and acceptable NSE across the seasons (Figure 5.3). Good performance of the optimized models was manifested by the model fitting efficiency (NSE $=0.72$ to 0.74 ), accuracy $(\mathrm{RSR}=0.50$ to 0.52), and observed vs. fitted data (Figure A5.1 in Appendix 5). The PLSR models were significant at the $95 \%$ confidence level. The quantified relative controls of the predictor pi numbers on the response pi number were represented by the regression coefficients of PLSR models of Z-scores (Table 5.5). 
(a)

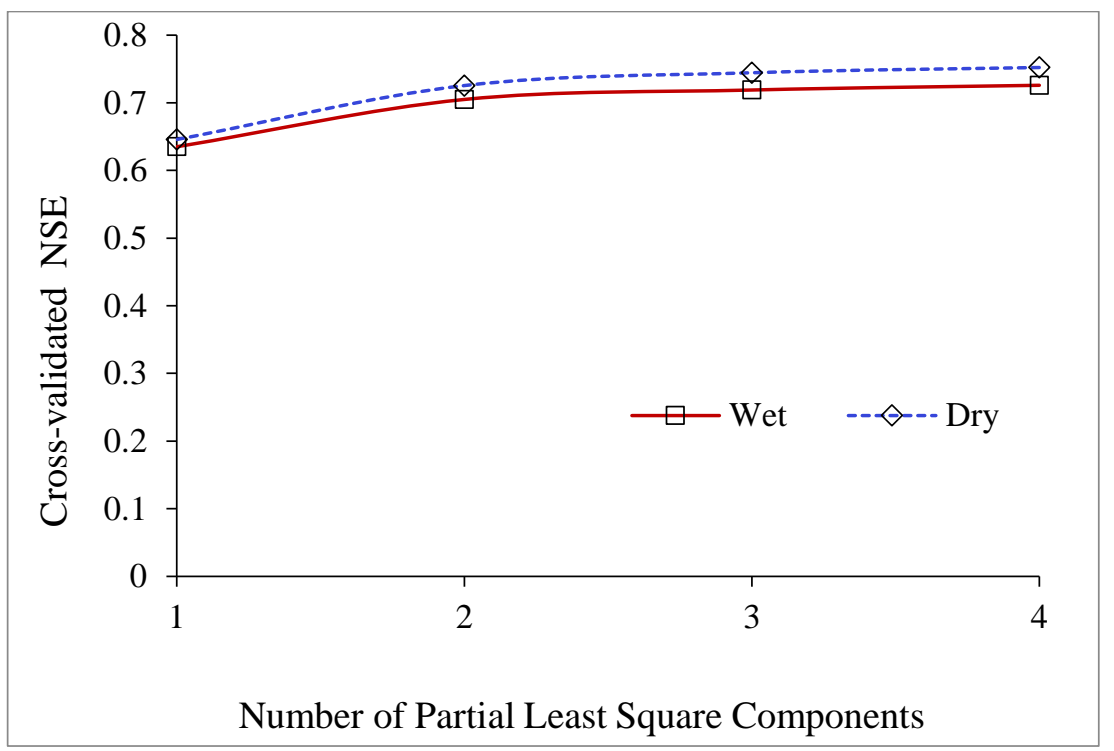

(b)

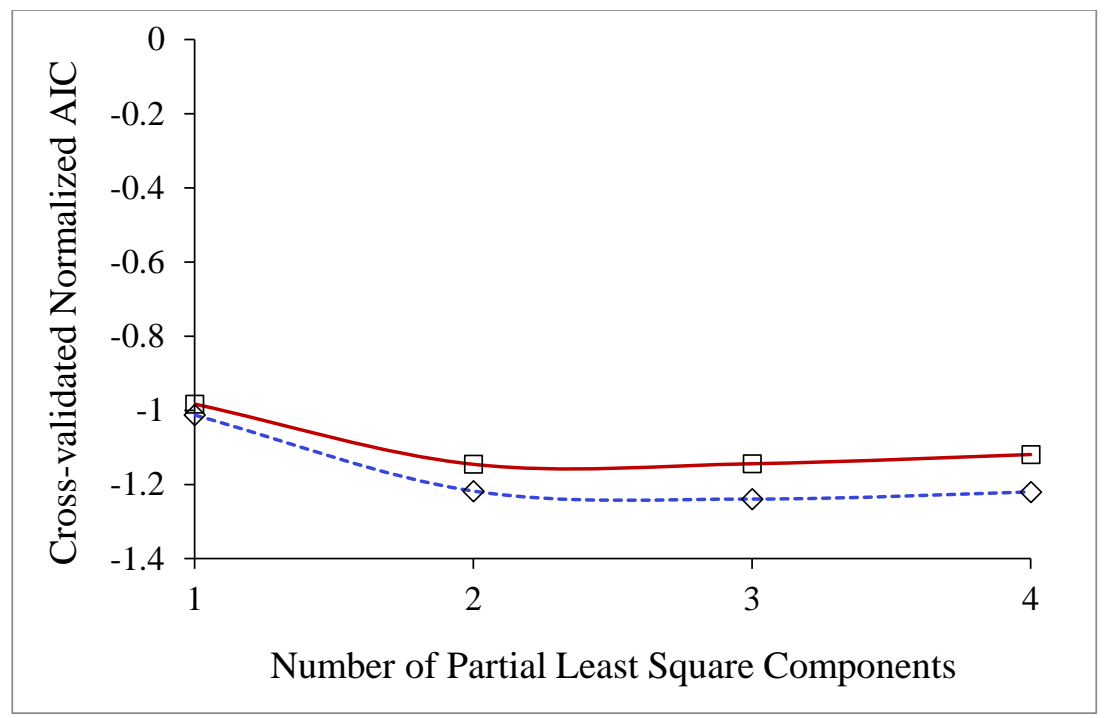

Figure 5.3. Plots of cross-validated (a) fitting efficiency (NSE) and (b) normalized AIC with the number of incorporated partial least squares components.

$\mathrm{DO} / \mathrm{DO}_{\text {sat }}$ had strong positive linkages $(\beta=0.43$ to 0.65$)$ with $\mathrm{AP} /\left(\mathrm{c}_{\mathrm{p}} \cdot \mathrm{TW} \cdot \mathrm{H}\right)$ and $\mathrm{AP} /\left(\mathrm{c}_{\mathrm{p}} \cdot \mathrm{TW} \cdot \mathrm{Sal}\right)$ across wet and dry seasons, which implied the dominant controls of interactive climate, stream metabolism, and salinity on stream water quality. The moderate positive linkages $(\beta=0.21$ to 0.28$)$ of $\mathrm{Z}_{\mathrm{c}} / \mathrm{L}_{\mathrm{c}}$ with $\mathrm{DO} / \mathrm{DO}_{\text {sat }}$ across the seasons indicated significant contribution to 
stream DO from watershed hydrology. However, the linkage of $\mathrm{DO} / \mathrm{DO}_{\text {sat }}$ with $\mathrm{Z}_{\mathrm{c}} / \mathrm{L}_{\mathrm{c}}$ was relatively reduced in dry season than wet season — suggesting relatively less strong control of watershed hydrology due to low flow period. The moderate negative linkages $(\beta=-0.14$ to -0.21$)$ of $\mathrm{A}_{\mathrm{AGR}} / \mathrm{A}_{\mathrm{BUL}}$ with $\mathrm{DO} / \mathrm{DO}_{\text {sat }}$ across the seasons indicated increased pollution of stream water with increasing ratio of agricultural to built-up land. Further, comparatively higher linkage of $\mathrm{DO} / \mathrm{DO}_{\text {sat }}$ with $\mathrm{A}_{\mathrm{AGR}} / \mathrm{A}_{\mathrm{BUL}}$ in dry season suggested increased agricultural pollution due to less dilution from built-up land in low flow period.

Table 5.5. PLSR model coefficients $(\beta)$ of the standardized pi numbers across wet and dry seasons.

\begin{tabular}{lrr}
\hline $\begin{array}{l}\text { Predictor pi } \\
\text { numbers }\end{array}$ & Wet & Dry \\
\hline $\mathrm{Z}_{\mathrm{c}} / \mathrm{L}_{\mathrm{c}}$ & 0.28 & 0.21 \\
$\mathrm{~A}_{\mathrm{AGR}} / \mathrm{A}_{\mathrm{BUL}}$ & -0.14 & -0.21 \\
$\mathrm{AP} /\left(\mathrm{c}_{\mathrm{p}} \cdot \mathrm{TW} \cdot \mathrm{Sal}\right)$ & 0.43 & 0.45 \\
$\mathrm{AP} /\left(\mathrm{c}_{\mathrm{p}} \cdot \mathrm{TW} \cdot \mathrm{H}\right)$ & 0.62 & 0.65 \\
\multicolumn{4}{r}{ Model Statistics } \\
PLS components & 3 & 3 \\
$\mathrm{NSE}$ & 0.72 & 0.74 \\
$\mathrm{RSR}$ & 0.52 & 0.50 \\
\hline
\end{tabular}

\subsection{Discussion}

The data analytics provided a comprehensive and confirmatory understanding of the dominant controls of interacting stream water quality processes leveraging the dimensionless numbers. While the synthesis of the correlation analysis, PCA, and FA manifested the interrelations among the dimensionless numbers, PLSR provided direct quantification of the relative controls of the 
predictor dimensionless numbers on the response dimensionless number. The dimensional analysis reduced a set of 11 original variables to a set of 5 meaningful dimensionless numbers to appropriately explain (PLSR model NSE $=0.72$ to 0.74 ) coastal stream water quality processes. Such parametric reduction of model parameters validated the hypothesis that stream water quality processes follow distinct 'biogeochemical-ecological' similitude across the US East Coast.

The 'metabolic number' and 'salinity number' represented how the interactions of atmospheric gas exchange and temperature, respectively, with stream metabolism and salinity collectively controlled stream DO. Both of the 'metabolic number' and 'salinity number' have the source (i.e, AP) in numerator and sinks (i.e., TW, H, Sal) in denominator-leading to their positive linkages with $\mathrm{DO} / \mathrm{DO}_{\text {sat. }}$ Therefore, the 'metabolic number' and 'salinity number' showed the contrasting and interactive controls of the source and sinks on stream water quality. The strong linkages of 'metabolic number' and 'salinity number' suggested that stream DO is primarily governed by the interactive controls of climate, stream metabolism, and salinity. Stream metabolic activity (e.g., microbial decomposition) is a sink of DO which is represented by the hydrogen ion concentration $(\mathrm{H})$. The microbial community releases carbon dioxide (i.e., increases $\mathrm{H}$ ) and consumes oxygen during biodegradation-leading to the negative between DO and $\mathrm{H}$. This corroborated the findings of Cai et al. (2011), who reported strong negative linkage between DO and H in northern Gulf of Mexico. Stream temperature — another sink of DOadversely affects stream water quality by reducing oxygen solubility with increasing temperature (Caccia and Boyer, 2005; Shrestha and Kazama, 2007). Further, the microbial consumption of DO increases with higher temperature (Schaefer and Hollibaugh, 2017)—reducing oxygen availability. The adverse controls of temperature on stream DO are well documented in 
literature. For example, the reduced solubility of DO with increasing temperature was reported to cause their strong negative linkage in Fuji River, Japan, by Shrestha and Kazama (2007). Further, Nelson et al. (2017) reported adverse effect of increasing temperature on stream DO in the Rhode River located in Maryland, U.S.A. Similar to temperature, higher salinity acts as a sink of stream DO by reducing oxygen solubility in water (Chapra, 1997). Further, salinity imposes biological stress which reduces the algal photosynthesis (Satoh et al., 1983; Cloern, 1987)—leading to reduced stream DO.

The negative linkages of $\mathrm{A}_{\mathrm{AGR}} / \mathrm{A}_{\mathrm{BUL}}$ with normalized $\mathrm{DO}$ across the seasons indicated that the increasing ratio of agricultural to built-up land adversely affected stream water quality. This suggested that agricultural land degraded stream DO by contributing to in-stream nutrients through agricultural runoff that led to subsequent eutrophication. However, built-up land might have contributed to stream DO by higher runoff generation from imperviousness that increased aeration and diluted in-stream nutrient. The opposite controls of agricultural and built-up land on stream DO were also reported by Wan et al. (2014b) in the Indian River Lagoon Watershed, located at east coast of Florida. In their study, while agricultural (i.e., pasture) land showed negative linkage with stream DO by contributing to in-stream nutrient, built-up land (i.e., urban) was found to have positive linkage with stream DO. In our study, comparatively higher linkage of $\mathrm{DO} / \mathrm{DO}$ sat with $\mathrm{A}_{\mathrm{AGR}} / \mathrm{A}_{\mathrm{BUL}}$ in dry season than the wet season might have suggested increased pollution from agricultural runoff due to less dilution from built-up land in low flow period.

The positive linkage of normalized DO with 'slope number' suggested that stream DO increases with steeper slope due to higher reaeration from faster runoff (Chang, 2008). Further, the contact time of pollutants with watershed runoff decreases due to faster runoff generated from steeper slope, which reduces the pollution potential from land uses (e.g., agricultural)— 
improving stream DO. This corroborated the findings of Wan et al. (2014a) in Xitiaoxi River watershed, China, reporting that agricultural field with flatter slope had higher potential for nutrient (e.g., total nitrogen, total phosphorus) pollution. The control of 'slope number' on normalized DO in dry season was lower than the wet season, which might be due to lower rainfall runoff in dry period.

The collective environmental controls from the dimensionless numbers and their relative linkages can guide to identify the management targets and priorities to achieve healthy coastal ecosystems across the US East Coast. The generalized entity offered by the dimensionless numbers is advantageous to investigate the health of different coastal streams under diverse environments in a similar comparable scale. For example, the 'metabolic number' and 'salinity number' showed, respectively, the controls of stream metabolism and salinity with respect to the climate (e.g., temperature, atmospheric pressure). Therefore, watersheds located at various climatic zones can be brought in a similar comparable scale to determine their pollution potentials from stream metabolism and salinity by estimating their respective 'metabolic number' and 'salinity number' (e.g., higher number would indicate lower pollution potential and vice versa). This would give the water managers more flexibility to choose the best engineering solution from multiple alternatives for efficient ecological managements. Further, if two watersheds have similar 'land use number' and climate, then the watershed with flatter slope would be more vulnerable to pollution from agricultural runoff to get management priority.

\subsection{Conclusions}

The study investigated the interactive controls of the land use, hydro-climatic, and biogeochemical drivers on coastal stream water quality across the East Coast of U.S.A by 
employing similitude and dimensional analysis. The response pi number $\left(\mathrm{DO} / \mathrm{DO}_{\text {sat }}\right)$ represented the concentration of DO normalized by its saturation concentration to bring stream DO of diverse environments in a similar comparable scale in relation to the oxygen solubility in water. The predictor pi numbers represented collective controls of land use, hydro-climatic, and biogeochemical drivers by appropriately combining their interactions. The 'land use number' showed the contrasting controls from agricultural vs. built-up land uses, and the 'slope number' represented the controls from watershed hydrology. Further, the 'metabolic number' and 'salinity number' showed the interactive controls of climatic drivers (e.g., temperature, atmospheric pressure) with, respectively, stream metabolism and salinity. The research reduced 11 original variables of stream water quality to a smaller set of 5 meaningful dimensionless numbersvalidating the hypothesis that coastal stream water quality processes follow biogeochemicalecological similitude (parametric reductions).

The important predictor dimensionless numbers were identified by quantifying their relative linkages with the normalized DO employing a systematic data analytics framework. Results showed strong controls of 'metabolic number' and 'salinity number' on stream DO implying that the stream DO was primarily driven by the interactive controls of stream metabolism, salinity, and climatic drivers. The 'slope number' was found to have substantial positive influence on stream DO suggesting contribution from aeration. Further, notable control of 'land use number' on normalized DO indicated the contrasting controls of agricultural and built-up runoff, respectively, by contributing and diluting in-stream nutrient. The dimensionless numbers offered a generalized entity to investigate the health of different coastal streams under diverse environments in a similar comparable scale. The knowledge of the dominant interactive controls of the environmental drivers from similitude and dimensionless numbers would enrich 
the understanding of coastal stream water quality processes to guide effective management of coastal ecosystems across the East Coast of U.S.A.

\section{Acknowledgments}

The research was funded by the National Science Foundation (NSF) CAREER Award to Dr.

Omar I. Abdul-Aziz (NSF CBET Environmental Sustainability Award Number $1561942 / 1454435)$. 


\section{Appendix 5}

Table A5.1. Correlation matrix of the response and predictor pi numbers in wet season (MayOctober).

\begin{tabular}{lrrrrr}
\hline & $\mathrm{Z}_{\mathrm{c}} / \mathrm{L}_{\mathrm{c}}$ & $\mathrm{A}_{\mathrm{AGR}} / \mathrm{A}_{\mathrm{BUL}}$ & $\mathrm{AP} /\left(\mathrm{c}_{\mathrm{p}} \cdot \mathrm{TW} \cdot \mathrm{Sal}\right)$ & $\mathrm{AP} /\left(\mathrm{c}_{\mathrm{p}} \cdot \mathrm{TW} \cdot \mathrm{H}\right)$ & $\mathrm{DO} / \mathrm{DOsat}$ \\
\hline $\mathrm{Z}_{\mathrm{c}} / \mathrm{L}_{\mathrm{c}}$ & 1.00 & $\mathbf{- 0 . 5 0}$ & $\mathbf{0 . 5 7}$ & 0.07 & $\mathbf{0 . 6 1}$ \\
$\mathrm{A}_{\mathrm{AGR}} / \mathrm{A}_{\mathrm{BUL}}$ & $\mathbf{- 0 . 5 0}$ & 1.00 & -0.11 & 0.01 & $\mathbf{- 0 . 3 7}$ \\
$\mathrm{AP} /\left(\mathrm{c}_{\mathrm{p}} \cdot \mathrm{TW} \cdot \mathrm{Sal}\right)$ & $\mathbf{0 . 5 7}$ & -0.11 & 1.00 & -0.30 & $\mathbf{0 . 4 1}$ \\
$\mathrm{AP} /\left(\mathrm{c}_{\mathrm{p}} \cdot \mathrm{TW} \cdot \mathrm{H}\right)$ & 0.07 & 0.01 & -0.30 & 1.00 & $\mathbf{0 . 5 1}$ \\
$\mathrm{DO} / \mathrm{DOsat}$ & $\mathbf{0 . 6 1}$ & $\mathbf{- 0 . 3 7}$ & $\mathbf{0 . 4 1}$ & $\mathbf{0 . 5 1}$ & 1.00 \\
\hline
\end{tabular}

Notes: (1) Data for all variables were $\log _{10}$ transformed to incorporate any non-linear correspondences;

(2) the correlations in bold are significant at $95 \%$ level of confidence ( $p$-values $<0.05$ ).

Table A5.2. Correlation matrix of the response and predictor pi numbers in dry season (November-April).

\begin{tabular}{lrrrrr}
\hline & $\mathrm{Z}_{\mathrm{c}} / \mathrm{L}_{\mathrm{c}}$ & $\mathrm{A}_{\mathrm{AGR}} / \mathrm{A}_{\mathrm{BUL}}$ & $\mathrm{AP} /\left(\mathrm{c}_{\mathrm{p}} \cdot \mathrm{TW} \cdot \mathrm{Sal}\right)$ & $\mathrm{AP} /\left(\mathrm{c}_{\mathrm{p}} \cdot \mathrm{TW} \cdot \mathrm{H}\right)$ & $\mathrm{DO} / \mathrm{DOsat}$ \\
\hline $\mathrm{Z}_{\mathrm{c}} / \mathrm{L}_{\mathrm{c}}$ & 1.00 & $\mathbf{- 0 . 5 0}$ & $\mathbf{0 . 6 3}$ & 0.00 & $\mathbf{0 . 5 6}$ \\
$\mathrm{A}_{\mathrm{AGR}} / \mathrm{A}_{\mathrm{BUL}}$ & $\mathbf{- 0 . 5 0}$ & 1.00 & -0.15 & -0.02 & $\mathbf{- 0 . 4 4}$ \\
$\mathrm{AP} /\left(\mathrm{c}_{\mathrm{p}} \cdot \mathrm{TW} \cdot \mathrm{Sal}\right)$ & $\mathbf{0 . 6 3}$ & -0.15 & 1.00 & -0.28 & $\mathbf{0 . 4 2}$ \\
$\mathrm{AP} /\left(\mathrm{c}_{\mathrm{p}} \cdot \mathrm{TW} \cdot \mathrm{H}\right)$ & 0.00 & -0.02 & -0.28 & 1.00 & $\mathbf{0 . 5 3}$ \\
$\mathrm{DO} / \mathrm{DO}$ Sat & $\mathbf{0 . 5 6}$ & $\mathbf{- 0 . 4 4}$ & $\mathbf{0 . 4 2}$ & $\mathbf{0 . 5 3}$ & 1.00 \\
\hline
\end{tabular}

Notes: (1) Data for all variables were $\log _{10}$ transformed to incorporate any non-linear correspondences;

(2) the correlations in bold are significant at $95 \%$ level of confidence ( $p$-values $<0.05$ ). 
Table A5.3. Percent variance explained by each principal component (PC) in wet and dry seasons.

\begin{tabular}{lrr}
\hline Principal Component & Wet & Dry \\
\hline PC 1 & 46.99 & 47.95 \\
PC 2 & 27.49 & 28.02 \\
PC 3 & 17.16 & 15.93 \\
PC 4 & 5.70 & 5.75 \\
PC 5 & 2.67 & 2.36 \\
\hline
\end{tabular}

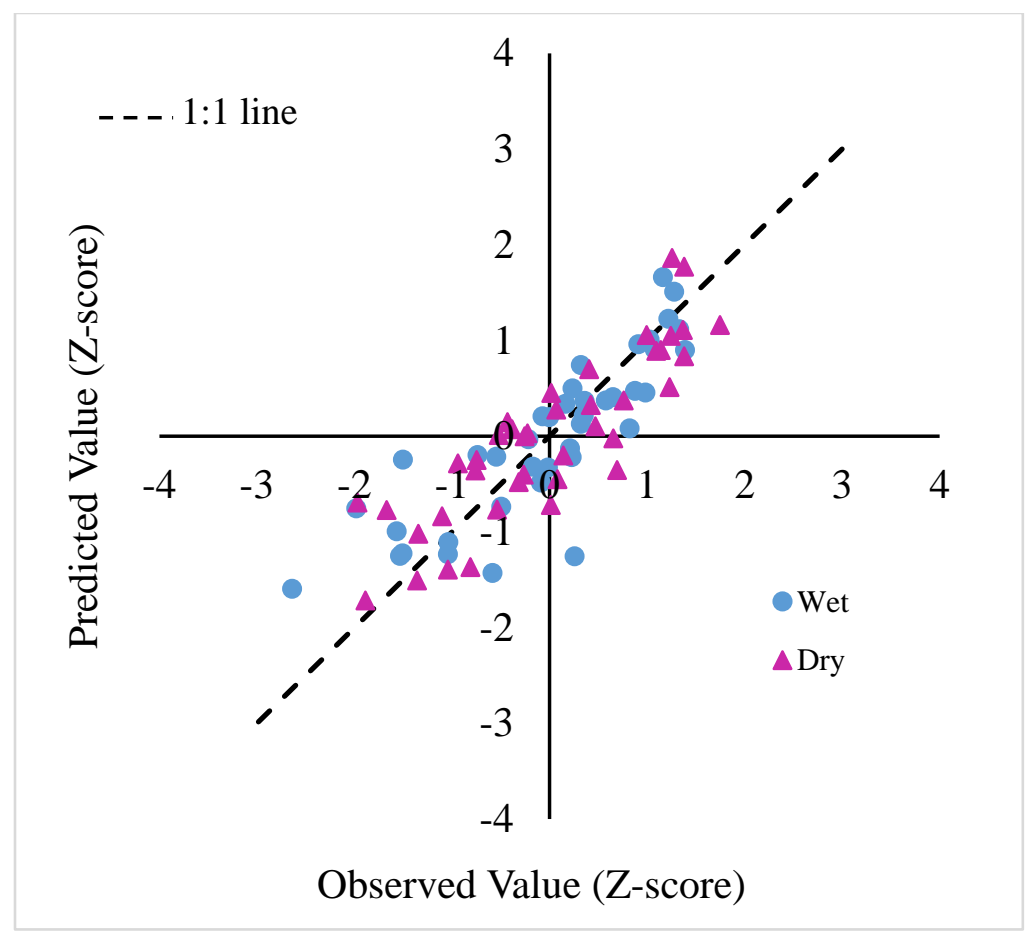

Figure A5.1. Observed vs. predicted Z-score values from PLSR models in wet (May-October) and dry (November-April) seasons. 


\title{
Chapter 6: Dynamic controls of stream dissolved oxygen across the East Coast of U.S.A.
}

\author{
Abstract \\ The dynamic hydro-climatic and biogeochemical controls of stream dissolved oxygen (DO) in \\ diverse environments were investigated incorporating temporal data of 51 stream water quality \\ monitoring sites across the U.S. East Coast. Multivariate pattern recognition techniques were \\ employed to identify the interrelationships among the environmental drivers. The relative \\ controls of the drivers on stream DO were reliably estimated resolving multicollinearity by \\ developing power-law based partial least squares regression models with a bootstrap Monte- \\ Carlo procedure (1000 iterations). Based on the dominant drivers of DO, the data analytics \\ categorized the streams into three distinct environmental regimes following the climatic gradient \\ (temperate to tropical) across the East Coast. Streams in the northern part of the temperate \\ latitude (e.g., northeast coast) showed strongest linkage of DO with water temperature; \\ indicating an environmental regime dominated by climatic control. However, majority of the \\ streams in the tropical zone (e.g., southeast Florida) showed strongest linkage of DO with pH; \\ suggesting an environmental regime likely driven by redox process. Further, a transitional \\ regime was found between the temperate and tropical zones-dominated by both water \\ temperature and $\mathrm{pH}$. The three environmental regimes in distinct climate zones indicated a strong \\ effect of climatic gradient (temperate to tropical) on stream DO dynamics across the East Coast. \\ Further, notable linkages of DO were found with total phosphorus and stream flow, while weak \\ controls were found from solar radiation, specific conductance, and atmospheric pressure in \\ majority of the streams. The identified environmental regimes and the regime-specific relative
}


linkages would guide efficient planning and management of coastal stream water quality and ecosystem health across the U.S. East Coast under a changing climate and environment.

\subsection{Introduction}

Good stream water quality is vital for the public health and environmental sustainability of a nation. One of the key components to assess the stream water quality and health of aquatic ecosystem is dissolved oxygen (DO) (Hondzo et al., 2005; O'Connor and Hondzo, 2008; Markfort and Hondzo, 2009). With reduced concentration of DO, aquatic lives are forced to alter their breathing pattern or lower their metabolism (Cox, 2003)_-jeopardizing the health of aquatic ecosystem. Depletion of DO in coastal water - a widespread and growing phenomenon (Diaz and Rosenberg, 2008; Prasad et al., 2011) — is often attributed to a multitude of climatic, hydrologic, and biogeochemical processes (see references in Best et al., 2007) that rapidly changes in the highly variable system of coastal environment (Frieder et al., 2012). Therefore, it is crucial to investigate how the dynamics of coastal stream DO is controlled by various hydroclimatic and biogeochemical drivers that can provide important insights into the dominant stream water quality processes. Although numerous studies investigated the controls of the drivers on DO, it is yet to quantify their relative linkages/controls and investigate their complex interactions in highly dynamic coastal environment across a large spatial scale.

DO is typically added to stream by photosynthesis and reaeration (O'Connor and Hondzo, 2008, Dick et al., 2016), while it can be consumed by respiration and degradation of organic matter (Cai et al., 2011; Xu and Xu, 2016). Stream temperature might have substantial influence in driving DO since many biological, chemical, and physical processes in water are temperaturedependent (see references in Murdoch et al. (2000)). For example, the solubility of compounds 
in water, metabolic rates of aquatic organisms, rates of chemical reactions, and density of water are affected by water temperature (Chapra, 1997; Schaefer and Hollibaugh, 2017). Further, salinity and atmospheric pressure is also important drivers that affect the solubility of DO in water (Chapra, 1997). In addition, depletion of dissolved oxygen may occur from eutrophication —resulting from nutrient (e.g., nitrogen, phosphorus) enrichment in water (Hondzo and Wang, 2002; Diaz and Rosenberg, 2008). Stream discharge (flow rate) can contribute to stream DO by aeration through turbulence and minimize the DO consumption by diluting the nutrient. However, stream discharge can also negatively affect stream DO by bringing allochthonous nutrients causing eutrophication.

Much research specifically investigated the dynamics of DO in coastal waters and estuaries. For example, Todd et al. (2009) reported high consumption of DO by the organic matter deposited at river bed in Little River of Georgia Coastal Plain. Cai et al. (2011) found riverine nutrients as primary drivers for elevated level of algae production and subsequent reduction of DO in Gulf of Mexico and the East China Sea. Schaefer and Hollibaugh (2017) reported strong negative relationship between water temperature and DO in Chesapeake Bay, the largest estuary in U.S.A. Further, DO in Chesapeake Bay has also been linked with dissolved nutrient and salinity alongside temperature by Prasad et al. (2011). In addition, many estuaries have been reported (see references in Best et al. (2007)) to experience substantial DO consumption due to degradation of organic matter within the water column. Overall, most of the previous studies on coastal stream DO focused on identification of the source/sink and understanding the DO dynamics in site-specific scale. However, a quantitative assessment of the relative linkages of various hydro-climatic and biogeochemical drivers with coastal stream DO across diverse environmental conditions is yet to achieve in large spatial scale. Quantification of 
the relative linkages would help understanding the nature of the drivers to control DO dynamics in coastal environment - providing profound knowledge on the coastal stream water quality processes.

Increasing acquisition of water quality data and the associated drivers has resulted in large database that can collectively be used to achieve crucial insights into stream water quality processes across large spatial gradient using data analytics techniques. However, assessment of stream water quality often involves multicollinear data sets since it is shaped by a multitude of hydro-climatic and biogeochemical drivers that are mutually interconnected (i.e., multicollinearity). The multicollinearity can lead to biased results while using multivariate techniques and traditional regression modeling - employed by most of the previous studies. Multicollinearity may be reduced by the process of backward elimination (or forward addition) of predictors based on statistical significance — which, however, can exclude mechanistically meaningful variables by the step-wise selection. This problem can be solved by partial least squares regression (PLSR) which resolves multicollinearity by performing the model-fitting on the transformed orthogonal planes (Abdul-Aziz and Ahmed, 2017). The estimated PLSR model in orthogonal planes is then transformed back to the original variable domain to compute regression coefficients of the individual predictors.

This paper aims to investigate the complex interactions of stream DO with the hydroclimatic and biogeochemical drivers across a large spatial scale of the East Coast of U.S.A. Multivariate pattern recognition techniques of correlation analysis, principal component analysis, and factor analysis were employed with standardized data to investigate the interrelations and relative linkage patterns of the water quality variables. PLSR models were then developed with the standardized data to quantify the relative linkages of the drivers with stream DO. The relative 
linkage patterns in different stream locations across the East Coast were compared to investigate potential environmental regimes - based on the dominant stream water quality processes. The quantified relative linkages of stream DO with its drivers across the large spatial scale will provide crucial knowledge on stream water quality dynamics under highly variable coastal environment that would guide developing management strategy to achieve healthy coastal stream ecosystems.

\subsection{Materials and methods}

\subsubsection{Study area}

The study area includes 51 stream water quality monitoring sites of coastal watersheds across the East Coast of U.S.A. with good spatial distribution (Figure 6.1). The coastal watersheds were identified by the ArcGIS shape file of NOAA's coastal watersheds (Percy Pacheco, personal communications, 2016). The study area incorporated a good climatic gradient (temperate to tropical) with large geographical range encompassing eight different U.S. states: (i) Connecticut; (ii) New Jersey; (iii) Maryland; (iv) Virginia; (v) North Carolina; (vi) South Carolina; (vii) Georgia; and (viii) Florida. The study area included diverse ecoregions starting from "eastern temperate forests" in the northern part and "tropical wet forests" in the southern part (Omernik and Griffith, 2014), representing a wide range of vegetation, geology, and land uses. Majority of the study sites correspond to temperate climate zone (Table 6.1) located in the northern part, while the rest of the sites are characterized by tropical climate located in the southern part. In temperate climate zone, spring or summer have an average monthly high temperature of $10^{\circ} \mathrm{C}$, and fall or winter have an average monthly low temperature greater than $-3^{\circ} \mathrm{C}(\mathrm{KCC}, 2017)$. However, tropical climate zone is characterized by constant high temperatures (year-round average of $18^{\circ} \mathrm{C}$ or higher) at sea level and low elevations (KCC, 2017). 


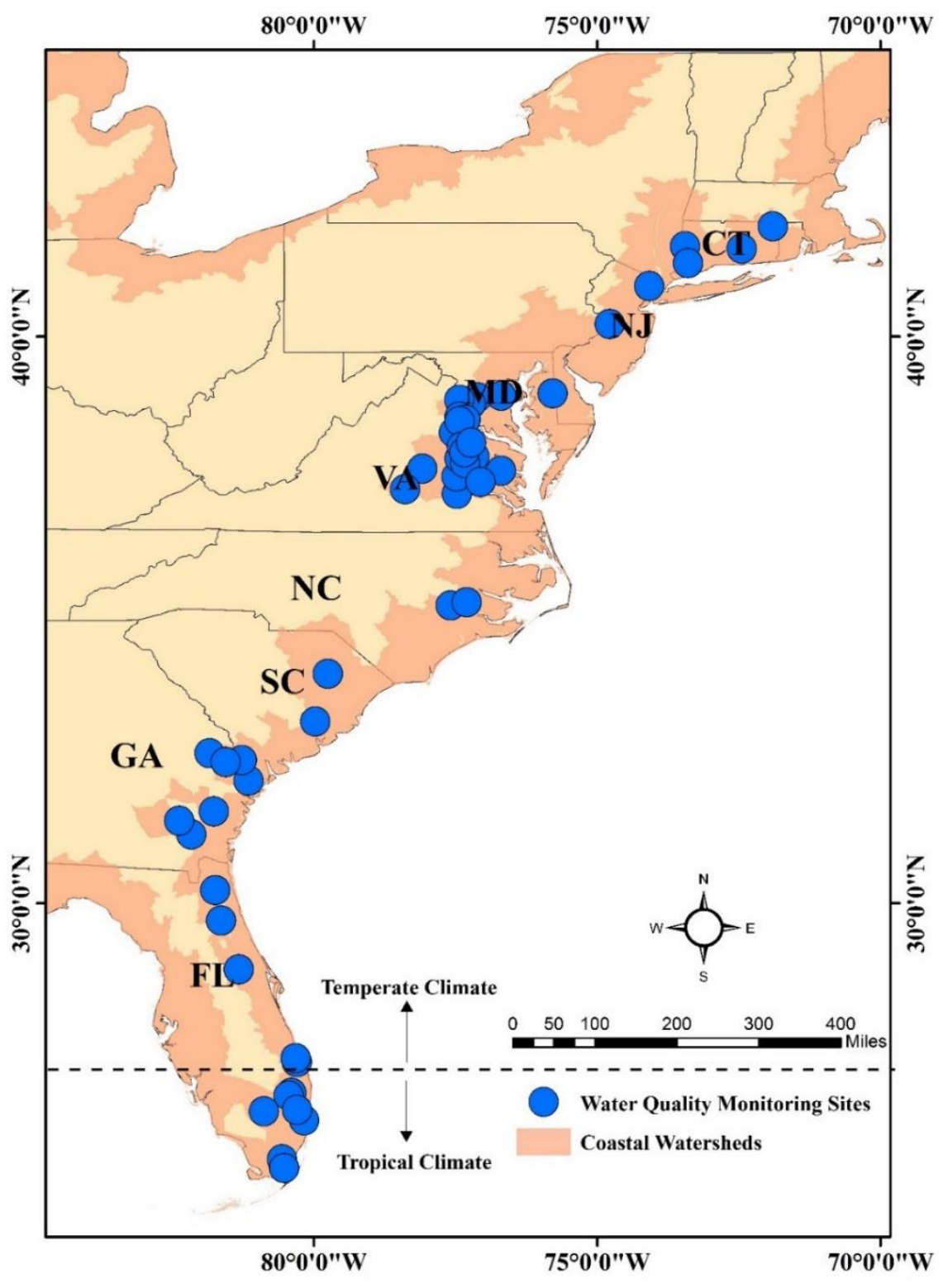

Figure 6.1. Locations of the coastal stream water quality monitoring stations across the U.S. East Coast. 
Table 6.1. Data summary with mean and standard deviation (in parentheses) of stream water quality, hydro-climatic, and biogeochemical variables of the 51 stream water quality monitoring sites across the U.S. East Coast representing diverse environmental conditions.

\begin{tabular}{|c|c|c|c|c|c|c|c|c|c|c|c|c|c|}
\hline Site ID & State & Period & $\mathrm{n}$ & $\mathrm{KC}$ & $\mathrm{TN}(\mathrm{mg} / \mathrm{L})$ & $\mathrm{TP}(\mathrm{mg} / \mathrm{L})$ & $\mathrm{TW}\left({ }^{\circ} \mathrm{C}\right)$ & $\mathrm{SC}(\mathrm{uS} / \mathrm{cm})$ & $\mathrm{pH}$ & $\mathrm{Q}\left(\mathrm{m}^{3} / \mathrm{s}\right)$ & $\mathrm{SR}\left(\mathrm{W} / \mathrm{m}^{2}\right)$ & AP (mbar) & $\mathrm{DO}(\mathrm{mg} / \mathrm{L})$ \\
\hline USGS-0 & $\mathrm{CT}$ & $00-2$ & 44 & $\mathrm{e}$ & & & $20<0$ & $38.3(32.13)$ & 9) & $6.41(5.48)$ & 2251 (2502 & & \\
\hline & & & & No & & & & & & & & & \\
\hline & $\mathrm{C}^{\prime}$ & & 92 & $\mathrm{Te}$ & & & & & & & & & \\
\hline 90 & $\mathrm{CT}$ & & 100 & $\mathrm{Te}$ & & & & & & & & 2) & 02) \\
\hline USGS-01391500 & $\mathrm{NJ}$ & 98-2014 & 62 & $\mathrm{Te}$ & 78) & 8) & 9) & 821. & & & & & 4) \\
\hline & $\mathrm{NJ}$ & & & $\mathrm{Te}$ & & & & & & & & & \\
\hline & & & & $\mathrm{Te}$ & & & & & & & & & \\
\hline USG & MD & & 245 & $\mathrm{Te}$ & & & & & & & & & \\
\hline & VA & & 01 & $\mathrm{Te}$ & & & & & & 13.3) & 30) & & $2.51)$ \\
\hline & VA & & 1 & $\mathrm{Te}$ & & & & & & & & & \\
\hline & VA & & 63 & $\mathrm{Te}$ & & & & & & & & & \\
\hline 00 & VA & 15 & 114 & $\mathrm{Te}$ & & & 1) & 70 & & & & & 5) \\
\hline & & & 25 & $\mathrm{Te}$ & & & & & & & & & \\
\hline & & & 16 & $\mathrm{Te}$ & & & & & & & & & \\
\hline 000 & VA & 5 & 68 & $\mathrm{Te}$ & & & 4) & & & & 72) & & \\
\hline USC & VA & 15 & 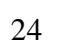 & $\mathrm{Te}$ & 8) & 4) & $35)$ & 51 & & 0. & 04.09) & 9) & 10.2 \\
\hline 000 & VA & & 19 & $\mathrm{Te}$ & & & & & & & & & \\
\hline & VA & & 53 & $\mathrm{Te}$ & & & & & & & & & \\
\hline & VA & & 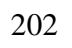 & $\mathrm{Te}$ & & & & & & & & 1012.03 & $9.28(2.19)$ \\
\hline & VA & & & $\mathrm{Te}$ & & & ) & & & & & & \\
\hline & VA & & & $\mathrm{Te}$ & & & & & & 56) & 467. & 7.29) & 9.51 \\
\hline & VA & & 188 & $\mathrm{Te}$ & & & $14.93(8.75)$ & $200.49(69.06)$ & & $210.55(185.84$ & & $1006.59(6.29)$ & $10.17(2.2)$ \\
\hline & VA & & 77 & $\mathrm{Te}$ & & & $13.27(7.42)$ & & & & $527.13(254.24)$ & $1016.42(7.05)$ & $7.69(2.71)$ \\
\hline 518 & VA & 2011-2015 & 67 & $\mathrm{Te}$ & 7) & 0.0 & $7(9.41)$ & $(60.11)$ & $.36)$ & $228.8(205.15)$ & $530.43(247.14)$ & $1014.02(6.57)$ & $10.77(2.17)$ \\
\hline & VA & 2007-2015 & 152 & $\mathrm{Te}$ & & & & & & & & & \\
\hline & VA & $2012-2015$ & 21 & $\mathrm{Te}$ & & & $9.93(6.46)$ & & & & $309.93(253.14)$ & $993.11(8.51)$ & $10.09(1.86)$ \\
\hline USGS-02041650 & VA & $2005-2015$ & 165 & $\mathrm{Te}$ & $0.6(0.16)$ & $0.05(0.02)$ & $15.70(8.09)$ & $90.83(13.32)$ & $7.38(0.31)$ & $30.74(32.64)$ & $477.13(250.08)$ & $1013.99(6.42)$ & $10.17(2.19)$ \\
\hline
\end{tabular}


Table 6.1 continued

\begin{tabular}{|c|c|c|c|c|c|c|c|c|c|c|c|c|c|}
\hline Site ID & State & Period & $\mathrm{n}$ & $\mathrm{KC}$ & $\mathrm{TN}(\mathrm{mg} / \mathrm{L})$ & $\mathrm{TP}(\mathrm{mg} / \mathrm{L})$ & $\mathrm{TW}\left({ }^{\circ} \mathrm{C}\right)$ & $\mathrm{SC}(\mathrm{uS} / \mathrm{cm})$ & $\mathrm{pH}$ & $\mathrm{Q}\left(\mathrm{m}^{3} / \mathrm{s}\right)$ & $\mathrm{SR}\left(\mathrm{W} / \mathrm{m}^{2}\right)$ & AP (mbar) & $\mathrm{DO}(\mathrm{mg} / \mathrm{L})$ \\
\hline USGS-02091814 & $\mathrm{NC}$ & $1999-2002$ & 22 & $\mathrm{Te}$ & .22) & $.04)$ & $9.88(7.57)$ & 1.52) & $68(0.40)$ & $76.42(71.42)$ & $476.70(238.45)$ & $(4.68)$ & $7.60(1.79)$ \\
\hline USGS-02089500 & $\mathrm{NC}$ & $1998-2015$ & 130 & 10 & $.11(0.23)$ & $.11(0.03)$ & $8.73(7.76)$ & $125.42(39.1)$ & $6.88(0.48)$ & $88.58(84.12)$ & $587.78(234.15)$ & $3(5.64)$ & $7.95(2.01)$ \\
\hline USGS-02132000 & $\mathrm{SC}$ & 2014 & 19 & $\mathrm{Te}$ & $.11)$ & $.02)$ & (7.06) & 63.7 & $6.51(0.32)$ & $(26.23)$ & 93.28) & 4.18) & 1.71) \\
\hline SANT-SC-033 & $\mathrm{C}$ & $98-2000$ & 20 & $\mathrm{Te}$ & 8) & $*$ & $.05(7.04)$ & 6) & $2(0.46)$ & $156.06(48.94)$ & $.20(272.11)$ & $8(6.29)$ & $.82)$ \\
\hline USGS-02202040 & GA & $2002-2007$ & 24 & $\mathrm{Te}$ & $*$ & $0.04(0.02)$ & 8.95 (7.49) & $97.63(16.98)$ & $7.26(0.30)$ & $(16.62)$ & 16.3) & 5.62) & 8.05 (1.96) \\
\hline 500 & GA & -2003 & 25 & $\mathrm{Te}$ & D) & 3) & (6.4) & 4.51) & $2(0.22)$ & $2.48)$ & $2.43)$ & 6) & $.36)$ \\
\hline USGS-02202190 & GA & 2005-2015 & 91 & $\mathrm{Te}$ & $0.81(0.28)$ & $0.16(0.1)$ & $19.68(7.9)$ & $117.25(36.14)$ & $7.16(0.44)$ & $22.71(23.33)$ & $511.52(297.29)$ & $1015.10(6.11)$ & $7.85(1.74)$ \\
\hline USGS-02198920 & GA & 2011-2015 & 32 & $\mathrm{Te}$ & $89(0.28)$ & $20(0.11)$ & $9.50(6.59)$ & $4272.34(4625.24)$ & $7.24(0.27)$ & $1037.19(352.72)$ & $536.22(250.91)$ & $6(4.90)$ & $2.12)$ \\
\hline USGS-02226010 & GA & 2006-2015 & 99 & $\mathrm{Te}$ & $0.82(0.2)$ & $0.11(0.05)$ & $21.02(7.26)$ & $229.26(121.03)$ & $7.24(0.35)$ & $224.3(212.32)$ & $493.82(253.24)$ & $1015.26(5.13)$ & $7.23(1.67)$ \\
\hline 0.7n-0 & GA & 1998-2003 & 17 & $\mathrm{Te}$ & 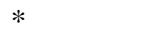 & $18(0.07)$ & $.33(6.02)$ & 141.2 & 23) & 2.3 & $537.38(209.38)$ & 36) & .22) \\
\hline USGS-02226582 & GA & $2007-2015$ & 72 & $\mathrm{Te}$ & 1.35 & $0.15(0.06)$ & $19.97(6.29)$ & $106.71(30.91)$ & $6.07(0.46)$ & $10.50(11.4)$ & $419.92(250.08)$ & $1016.40(4.85)$ & $7.00(1.62)$ \\
\hline USGS-02246435 & FL & $2000-2005$ & 19 & $\mathrm{Te}$ & $*$ & $0.10(0.05)$ & $20.52(4.58)$ & $229.63(70.53)$ & $7.04(0.34)$ & $0.13(0.21)$ & 328.05 (155.94) & $1014.43(4.76)$ & 4.09 (1.29) \\
\hline bLSJWM-SJRCC & FL & 2003-2005 & 45 & $\mathrm{Te}$ & $1.31(0.21)$ & $*$ & $23.45(5.6)$ & 752.38 (197.35) & $7.70(0.44)$ & $*$ & $679.63(231.32)$ & $1017.50(5.77)$ & $7.04(2.08)$ \\
\hline${ }^{c} W Q X-28010879$ & FL & 2001-2011 & 37 & $\mathrm{Te}$ & $1.14(0.36)$ & $*$ & $26.92(3.84)$ & $8364.08(10626.83)$ & $7.44(0.21)$ & $*$ & $624.24(243.45)$ & $1015.41(3.28)$ & $5.18(1.90)$ \\
\hline${ }^{\mathrm{d}} \mathrm{WQX}-\mathrm{C} 23 \mathrm{~S} 48$ & FL & 2009-2013 & 84 & $\mathrm{Te}$ & $1.40(0.51)$ & $*$ & $25.37(3.72)$ & $781.82(252.1)$ & $7.37(0.38)$ & $*$ & $489.70(190.86)$ & $1017.60(3.35)$ & $5.30(1.48)$ \\
\hline bLSFWM-G303 & FL & 2002-2009 & 132 & $\operatorname{Tr}$ & $3.36(1.11)$ & $0.14(0.07)$ & $25.31(4.44)$ & $1068.03(273.04)$ & $7.70(0.30)$ & $*$ & $655.26(2$ & 1015.78 & $4.68(2.40)$ \\
\hline bLSFWM-G253C & FL & 1998-2008 & 147 & $\operatorname{Tr}$ & $2.54(0.9)$ & $0.10(0.09)$ & $24.27(4.76)$ & $1066.23(271.11)$ & $7.64(0.41)$ & $*$ & $619.80(240.90)$ & $1016.30(3.89)$ & $3.60(2.73)$ \\
\hline bLSFWM-G308 & FL & 09 & 107 & $\operatorname{Tr}$ & $25(0.5)$ & $.05)$ & 8) & 7) & ) & $*$ & 497. & 7) & .08) \\
\hline${ }^{\mathrm{d} W Q X-S 39}$ & FL & 2009-2013 & 55 & $\operatorname{Tr}$ & $1.42(0.37)$ & $*$ & $27.29(3.12)$ & $567.34(224.73)$ & $7.59(0.34)$ & $*$ & $581.12(228.91)$ & $1016.62(3.55)$ & $5.04(1.92)$ \\
\hline bLSFWM-G409 & FL & 2000-2009 & 301 & $\operatorname{Tr}$ & $*$ & $(0.03)$ & $24.46(4.07)$ & $666.52(151.18)$ & 30) & $*$ & 636.6 & 4.16) & $6.07(1.77)$ \\
\hline 21FLBROW-11 & FL & 2001-2008 & 26 & $\operatorname{Tr}$ & $1.23(0.26)$ & $*$ & $26.55(3.87)$ & $3855.77(4524.53)$ & $7.6(0.23)$ & $*$ & $619.85(254.58)$ & $1017.83(3.26)$ & $5.84(1.52)$ \\
\hline bLSFWM-S332D & FL & -2007 & 132 & $\operatorname{Tr}$ & $0.86(0.19)$ & $\begin{array}{l}0.01 \\
(0.002)\end{array}$ & $25.56(2.09)$ & $541.94(43.36)$ & $7.32(0.22)$ & $*$ & $676.98(204.92)$ & $1016.69(3.44)$ & $2.44(1.90)$ \\
\hline WQX-S18C & FL & 2009-2013 & 116 & $\operatorname{Tr}$ & $0.64(0.07)$ & $*$ & $25.68(2.5)$ & $541.80(23.5)$ & $7.47(0.31)$ & $*$ & $643.82(242.17)$ & 1016.44 (3.17) & $5.00(2.05)$ \\
\hline
\end{tabular}

Note: '*' indicates missing information. 'KC' refers to Köppen Climate. 'Te' and ' $\mathrm{Tr}$ ', respectively, refer to temperate and tropical climate. TN, TP, TW, SC, Q, $\mathrm{SR}$, and AP, respectively, refer to total nitrogen, total phosphorus, temperature of water, specific conductance, flow rate, solar radiation, and atmospheric pressure. a, b, c, and d refer to, respectively, 21S, 21F, 21FLWPB_, and 21FLSFWM_. 'n' represents sample size. 


\subsubsection{Data sets}

The study used temporal data (1998-2015) of stream water quality collected mostly at quarterly scale across the year (Table 6.1). Grab sample stream water quality data of USGS NWIS and EPA STORET were gathered from National Water Quality Monitoring Council (NWQMC) databases (NWQMC, 2017), along with the concurrent stream flow (Q). The selection of the 18year of study period was based on the high availability of reliable data, and incorporated the seasonal and multi-year temporal gradients on stream water quality dynamics. Selected stream water quality variables were the dissolved oxygen (DO) alongside the corresponding drivers: total nitrogen (TN), total phosphorus (TP), temperature of water (TW), specific conductance (SC), and $\mathrm{pH}$. The set of the participatory variables was selected based on preliminary data analysis and current understanding of stream water quality processes. Solar radiation (SR) and atmospheric pressure (AP) data were collected from 4 x $4 \mathrm{~km}$ grid cells of National Solar Radiation Data Base (NSRDB) (NSRDB, 2017). The outlier from the data were removed using interquartile range (IQR) criteria as $P_{25}-2 \times I Q R$ and $P_{75}+2 \times I Q R$; where, $P_{25}$ and $P_{75}$ are, respectively, $25^{\text {th }}$ and $75^{\text {th }}$ percentiles.

The data sets represented diverse environmental process components to control stream water quality. The control of 'nutrient' component on DO was represented by TN and TP — two key nutrients for the primary production and eutrophication in aquatic ecosystem (Elser et al., 1990; Chapra, 1997; Howarth and Marino, 2006). The 'climatic' component was represented by TW and SR, and, the 'hydro-atmosphere' component was represented by Q and AP. Further, SC (a surrogate of salinity) and $\mathrm{pH}$ were incorporated to investigate the control from 'redox' component on stream water quality. The final data sets of DO and the associated drivers for the 
51 sites were summarized (Table 6.1), representing wide ranges and considerable gradients of diverse hydro-climatic and biogeochemical conditions of the stream water quality processes.

Spatial data of the corresponding stream water quality sites were generated to analyze the controls of watershed land use and topography on stream water quality processes. Watershed drainage area for each stream water quality site and corresponding watershed slope (S) were generated using $10 \mathrm{~m}$ digital elevation model (United States Geological Survey (USGS), 2017a) in ESRI ArcGIS 10.2 platform. The mean percentages of watershed land uses corresponding to the period of temporal data were estimated from the $30 \mathrm{~m}$ data of National Land Cover Database (NLCD) for 2001, 2006, and 2011 (NLCD, 2017). Based on the guidelines of NLCD (2017), land uses were classified into six broad categories as follows: (1) built-up land (BUL), (2) agricultural land (AGR), (3) waterbody (WAT), (4) vegetated land (VEG), (5) open land (OPN), and (6) wetland (WET). The spatial data summary (see Table A6.1 in Appendix 6) showed a wide range of watershed land uses and topography across the study area.

\subsubsection{The data analytics methodology}

A systematic data analytics framework (Ishtiaq and Abdul-Aziz, 2015; Abdul-Aziz and Ahmed, 2017) was employed with four layers of multivariate techniques (Figure 6.2) to synthesize and complement converging information from different layers, achieving the overall outcomes. The four layers of data analytics techniques are (i) Pearson correlation matrix, (ii) principal component analysis (PCA), (iii) factor analysis (FA), and (iv) partial least squares regression (PLSR). All the data were first logarithmically $\left(\log _{10}\right)$ transformed to account for the non-linear interactions, and then standardized to bring the participatory variables into a similar comparable

reference scale (dimensionless Z-score). The Z-score was calculated as: $Z=(X-\bar{X}) / s_{X}$, where 
$X=\log _{10}$-transformed variable, $\bar{X}=$ mean of $X$, and $s_{X}=$ standard deviation of $X$. All layers of the data analytics were performed in MATLAB.

Pearson correlation matrix was first employed to develop initial understanding on the mutual correspondences among the water quality, hydrologic, and environmental variables. The relative linkages of the water quality and corresponding drivers alongside their interrelationships were then examined using PCA and FA by resolving multicollinearity in the orthogonal (independent) domain (Jolliffe, 2002). Although, both PCA and FA are developed based on orthogonal entities, their statistical derivations are distinctively different (Jolliffe, 2002). PCA derives the orthogonal entities known as principal components (PCs) as a linear combination of all original variables. However, FA decomposes the original variables into a smaller set of latent entities known as factors. The factors are typically optimized using a "varimax" orthogonal rotation — maximizing the total data-system variance by redistributing the variance of each variable. An eigenvalue criteria such as eigenvalue $\geq 1$ was applied to determine the optimal number of factors describing most of the data variances. At the final step of the data analytics, the relative linkages between $\mathrm{DO}$ and the corresponding drivers were quantified employing PLSR models—combining features from PCA and multiple linear regressions (Wold et al., 2001). PLSR is advantageous over conventional principal component regression, since it derives the orthogonal partial least squares (PLS) components of predictors and fits them with the response through a simultaneous decomposition of all predictors alongside the response variables (Schumann et al., 2013). The optimal PLSR model appropriately resolves the multicollinearity among the predictors through the transformed orthogonal planes (Kuhn and Johnson, 2013). 


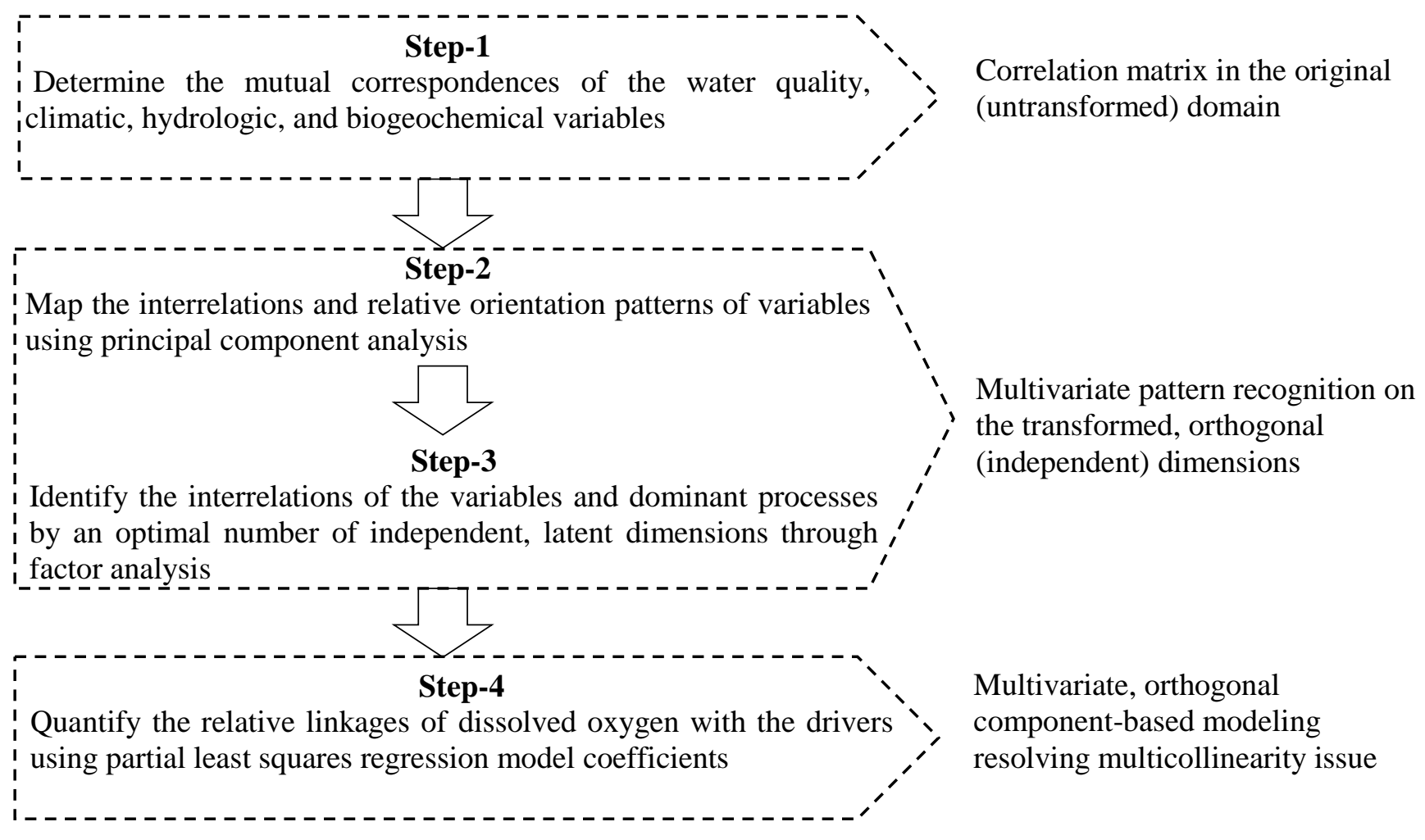

Figure 6.2. The data analytics framework to quantify the relative linkages of dissolved oxygen with the hydro-climatic and biogeochemical drivers.

The Z-score based PLSR model was developed for each site using SIMPLS algorithm (de Jong, 1993) and 10-fold cross-validation (Kuhn and Johnson, 2013), to robustly estimate the model parameters. The PLSR models were optimized by employing optimal number of PLS components. The optimal PLSR components were determined from a synthesis of the minimum Akaike Information Criterion (AIC) (Akaike, 1974, Abdul-Aziz and Ahmed, 2017), maximum Nash-Sutcliffe efficiency (NSE) criterion (Nash and Sutcliffe, 1970; Abdul-Aziz and Ahmed, 2017), and eigenvalue $\geq 1$ criterion. Data uncertainty in each PLSR model was accounted by repeating the model 1000 times using bootstrap Monte-Carlo resampling. The 1000 model estimations were averaged to determine the Z-score model coefficients $(\beta)$, representing the relative linkages of the environmental drivers with DO at each site. Model parameter 
uncertainties were measured as the standard deviations from the corresponding 1000 estimations. Predictors with higher absolute values of $\beta$ indicated stronger relative linkages of the drivers with DO. The sign (positive or negative) of the $\beta$ indicated the direction of the relationships (i.e., increasing or decreasing) between the response and predictor variables. The model fitting efficiency was measured by NSE, and the model accuracy was determined by the ratio of rootmean-square error to the standard deviation of the observations (RSR). According to Moriasi et al. (2007), the RSR values of $0-0.5,0.5-0.6,0.6-0.7$, and $>0.70$ indicate respectively, "very good", "good", "satisfactory", and "unsatisfactory" models. The model $\beta$ of the drivers were aggregated to estimate the relative linkages of DO with different environmental process components. The aggregated relative linkages of 'nutrient' $\left(\beta_{N}\right)$, 'climate' $\left(\beta_{C}\right)$, 'hydroatmosphere' $\left(\beta_{\mathrm{H}}\right)$, and 'redox' $\left(\beta_{\mathrm{R}}\right)$ components were calculated using the method of vector summation as follows:

$\beta_{N}=\sqrt{\beta_{T N}^{2}+\beta_{T P}^{2}}$

$\beta_{C}=\sqrt{\beta_{T W}^{2}+\beta_{S R}^{2}}$

$\beta_{H}=\sqrt{\beta_{Q}^{2}+\beta_{A P}^{2}}$

$\beta_{R}=\sqrt{\beta_{p H}^{2}+\beta_{S C}^{2}}$

The standard deviations of the aggregated relative linkages were measured from the corresponding 1000 estimations, to represent the associated uncertainties. 


\subsection{Results}

\subsubsection{Mutual relationships among DO, hydro-climatic, and biogeochemical drivers}

The correspondences of DO with the hydroclimatic and in-stream drivers were determined for all sites using correlation coefficients. Analysis of the correlation matrices categorized the sites into three distinct environmental regimes based on the dominant stream water quality processes (see Figure A6.1 in Appendix 6). The environmental regimes are: (1) 'temperature dominated' regime showing strongest control of TW (located in northern part of the temperate zone), (2) 'redox dominated' regime having strongest control of $\mathrm{pH}$ (located in the tropical zone), and (3) 'transitional' regime dominated by both $\mathrm{TW}$ and $\mathrm{pH}$ (located in between temperate and tropical zones). The ensemble mean correlation coefficients (r) between DO and the drivers were summarized for each regime to describe the outcomes of the correlation analysis (Table 6.2). Further, the regime-specific box plots (see Figure A6.2 in Appendix A6) showed the variations of the correlation coefficients of DO with the environmental drivers across the stations in each environmental regime.

Table 6.2. Pearson correlation coefficients ( $\mathrm{r}$ ) between DO and hydro-climatic/biogeochemical drivers in the environmental regimes.

\begin{tabular}{lcccccccc}
\hline Environmental Regime & TN & TP & TW & SC & pH & Q & SR & AP \\
\hline Temperature dominated & -0.07 & -0.34 & -0.88 & -0.04 & -0.03 & 0.28 & -0.27 & 0.24 \\
Transitional & -0.36 & -0.31 & -0.58 & 0.30 & 0.62 & -0.27 & -0.16 & 0.34 \\
Redox dominated & -0.04 & 0.01 & -0.39 & 0.08 & 0.70 & $*$ & 0.08 & 0.28 \\
\hline
\end{tabular}

Notes: The regime-specific mean correlations were obtained by averaging the site-specific correlations over each environmental regime. TN, TP, TW, SC, Q, SR, and AP, respectively, refer to total nitrogen, total phosphorus, temperature of water, specific conductance, flow rate, solar radiation, and atmospheric pressure. '*' indicates missing values. 
Based on the mean correlation coefficients, DO had strongest correlation with TW ( $\mathrm{r}=$ 0.88) in 'temperature dominated' regime - indicating an environmental regime dominated by the climate. Further, while moderate correlation with DO was found with TP $(r=-0.34)$, relatively weak correlations were found with other variables. However, in 'transitional' regime, DO had strong correlation with both TW $(\mathrm{r}=-0.58)$ and $\mathrm{pH}(\mathrm{r}=0.62)$ - suggesting stream water quality in this regime is dominated by both climate and redox processes. Further, relatively moderate correlations with DO were found with the nutrients $(r=-0.31$ to -0.36$), \mathrm{SC}(\mathrm{r}=0.30)$, and AP ( $\mathrm{r}$ $=0.34$ ). Unlike the 'temperature dominated' and 'transitional' regime, 'redox dominated' regime showed strong correlation $(\mathrm{r}=0.70)$ of $\mathrm{DO}$ with only $\mathrm{pH}$-indicating domination of redox chemistry on stream water quality process. Further, moderate correlations with DO were also found with TW $(r=-0.39)$. The three environmental regimes with varying dominant drivers from temperate to tropical climate might suggest a strong influence of climatic gradient on the stream water quality dynamics across the east coast. The dominant controls of the TW versus $\mathrm{pH}$ on stream DO across the stations in respective regimes were found to be consistent in the regimespecific boxplots of correlation coefficients (see Figure A6.2 in Appendix A6).

The correlation matrices (Table A6.2-A6.4 in Appendix A6; calculated as regime-specific mean) demonstrated high mutual correspondences among the hydro-climatic and biogeochemical drivers, manifesting strong multicollinearity in the data matrices. For example, moderate to strong negative correlations $(\mathrm{r}=-0.54$ to -0.70$)$ were found between $\mathrm{Q}$ and SC across the regimes - indicating that higher freshwater discharge from upstream reduces the salinity induced from downstream saltwater intrusion (Shrestha and Kazama, 2007; Xie et al., 2017). Moderate to strong positive correlations $(\mathrm{r}=0.29$ to 0.61$)$ were found between $\mathrm{TN}$ and TP across the regimes; which might suggest their common primary sources. Further, weak to moderate negative 
correlations ( $\mathrm{r}=-0.25$ to -0.51$)$ between TW and AP might suggest that higher temperature reduces the atmospheric pressure by reducing the density of air.

\subsubsection{Relative controls of the drivers and their interrelations}

\subsubsection{Relative controls and interrelations based on PCA}

Across the 51 study sites, the first two PCs (PC1 and PC2) explained, respectively, 29-52\% and 15-33\% of the total data variances (see Table A6.5 in Appendix 6). The presence of the three environmental regimes found in correlation analysis was also supported by the PCA. Three example study sites - representing three environmental regimes of dominant stream water quality processes - were chosen to describe the outcomes through biplots of PCA (Figure 6.3).

Based on the relative orientations and length of the vectors, TW showed strong negative linkage with DO in 'temperature dominated' regime (Figure 6.3a) — suggesting domination of climatic control on stream DO. Further, moderate negative linkages of DO with TP indicated consumption of DO by nutrient enrichment. Nearly orthogonal orientation of DO with both SC and $\mathrm{pH}$ suggested their weak linkages. With relatively shorter length of the vectors in the plane of PC1 and PC2, weak to moderate linkages of DO were manifested by TN, SR, and AP. Unlike 'temperature dominated' regime, biplot of the 'transitional' regime (Figure 6.3b) showed strong

linkages of DO with both $\mathrm{pH}$ and TW, which was respectively, positive and negative-indicating their opposite direction of linkages with stream DO. With relatively shorter length of the vectors, weak to moderate linkages of DO were observed with TP, SR, and AP. Further, nearly orthogonal orientation of DO with both TN and SC suggested their weak linkages. However, in 'redox dominated' regime (Figure 6.3c), strongest control on $\mathrm{DO}$ was found with $\mathrm{pH}$-indicating domination of redox chemistry. Moderate positive and negative linkages of DO with, respectively, AP and TW, suggested their opposite direction of linkages with DO. Further, with 
nearly linear orientation but relatively shorter length of the vector, moderate linkage of DO was found with TN. However, with nearly orthogonal orientation, weak linkages of DO were found with SR and SC. Overall, the presence of 'temperature dominated' regime in temperate zone and 'redox dominated' regime in tropical zone was further supported by the transitional regime located in between temperate and tropical latitude — dominated by both climate and redox processes.

The mutual correspondences among the drivers of DO were also apparent from the biplots. With moderately linear but opposite orientation, TW and AP showed moderate to strong negative linkage across the regimes, supporting the fact that higher temperature reduces the density of air lowering the atmospheric pressure. Moderate positive linkage of SR and TW across the regimes indicated the positive effect of solar radiation to increase stream temperature. $\mathrm{SC}$ and $\mathrm{pH}$ formed a cluster in the 'temperature dominated' and 'transitional' regimes, indicating their notable positive linkage. Strong negative linkage of Q with SC (Figure 6.3a) suggested the dilution of downstream salinity with increasing upstream flow rate. Moderate positive linkages of Q with nutrients (TN and TP) might indicate the enrichment of in-stream nutrient by upstream flow and watershed runoff in the corresponding stream. Further, moderate negative linkage of Q with TW might suggest that higher flow rate has reduced water temperature by turbulence induced atmospheric heat exchange. 
(a)

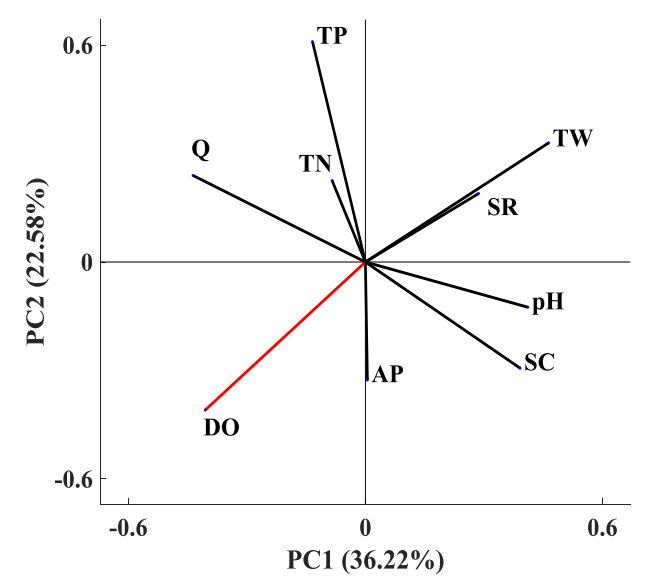

(b)

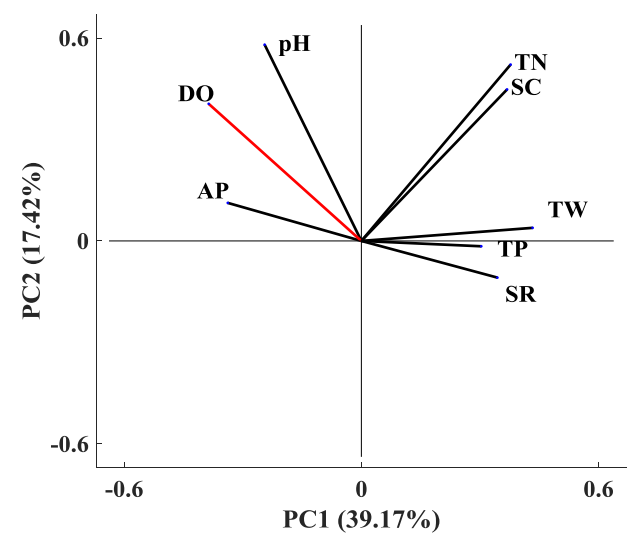

(c)

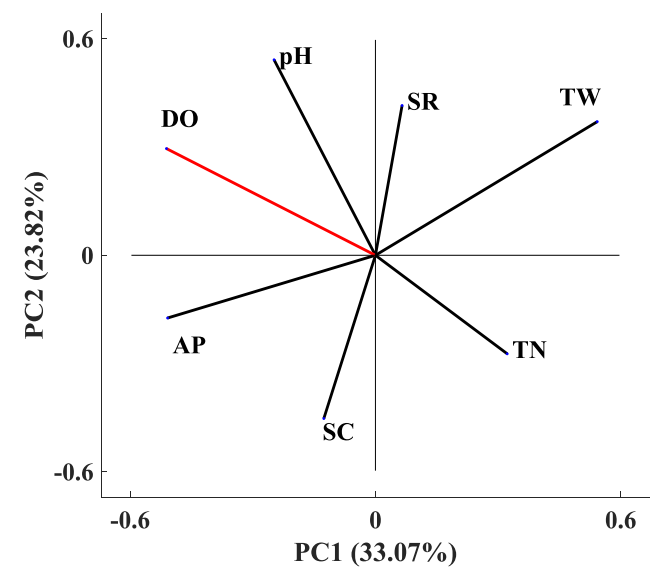

Figure 6.3. Biplots from principal component analysis, showing the interrelations of the water quality and hydro-climatic/biogeochemical variables for example sites of (a) temperature dominated, (b) transitional, and (c) redox dominated regimes. Percent variance explained by each $\mathrm{PC}$ is shown in parentheses. 


\subsubsection{Relative controls and interrelations based on independent latent factors}

The eigenvalue $\geq 1$ criteria led to 3 to 4 independent factors that optimally explained the total variances of the data matrices across the study sites. FA complemented the findings of the three environmental regimes from correlation analysis and PCA, while offering more detailed insights into the interrelations among the drivers. The similar example study sites—leveraged to describe PCA (see section 3.2) - were chosen representing the three different environmental regimes to describe the outcomes of FA (Table 6.3).

Table 6.3. Major latent factors with their optimized loadings on the participatory variables for example sites of three environmental regimes.

\begin{tabular}{llrrrrrrrrr}
\hline $\begin{array}{l}\text { Environmental } \\
\text { Regime }\end{array}$ & Factor & TN & TP & TW & SC & pH & Q & SR & AP & $D O$ \\
\hline Temperature & F1 & -0.05 & 0.3 & $\mathbf{0 . 9 6}$ & 0.18 & 0.36 & -0.3 & $\mathbf{0 . 4 2}$ & -0.32 & $\mathbf{- 0 . 9 5}$ \\
dominated & F2 & 0.07 & $\mathbf{- 0 . 6 5}$ & 0.19 & $\mathbf{0 . 9 1}$ & $\mathbf{0 . 4 1}$ & $\mathbf{- 0 . 8 4}$ & -0.02 & 0.13 & -0.10 \\
& F3 & $\mathbf{0 . 9 1}$ & $\mathbf{0 . 5 6}$ & -0.04 & 0.07 & -0.26 & -0.02 & -0.09 & -0.09 & -0.06 \\
& F4 & -0.09 & 0.08 & 0.15 & 0.03 & 0.39 & -0.08 & $\mathbf{0 . 6 6}$ & $\mathbf{0 . 5 1}$ & 0.00 \\
Transitional & F1 & 0.34 & 0.25 & $\mathbf{0 . 9 8}$ & 0.11 & -0.03 & $*$ & 0.36 & $\mathbf{- 0 . 5 4}$ & $\mathbf{- 0 . 4 2}$ \\
& F2 & $\mathbf{0 . 7 3}$ & 0.21 & 0.19 & $\mathbf{0 . 9 9}$ & -0.03 & $*$ & 0.25 & -0.13 & -0.15 \\
& F3 & 0.03 & -0.19 & -0.07 & -0.08 & $\mathbf{0 . 9 7}$ & $*$ & -0.25 & 0.16 & $\mathbf{0 . 5 8}$ \\
Redox & F1 & 0.25 & $*$ & $\mathbf{1 . 0 0}$ & -0.37 & 0.10 & $*$ & 0.29 & $\mathbf{- 0 . 6 9}$ & $\mathbf{- 0 . 4 4}$ \\
dominated & F2 & -0.12 & $*$ & -0.01 & -0.11 & $\mathbf{0 . 9 9}$ & $*$ & 0.01 & 0.08 & $\mathbf{0 . 7 3}$ \\
& F3 & $\mathbf{0 . 7 3}$ & $*$ & 0.02 & 0.35 & -0.04 & $*$ & $\mathbf{- 0 . 4 3}$ & -0.24 & -0.09 \\
\hline
\end{tabular}

Notes: (1) Bold values indicate variables having moderate to high loadings on factors (F); F1-4 refer to four independent factors. (2) TN, TP, TW, SC, Q, SR, and AP, respectively, refer to total nitrogen, total phosphorus, temperature of water, specific conductance, flow rate, solar radiation, and atmospheric pressure. '*' indicates missing information.

In 'temperature dominated' regime, DO loaded most strongly (-0.95) on factor 1 which also had high loading of TW (0.96), suggesting strong control of TW on DO. Factor 2 had moderate to strong loadings of $\mathrm{pH}(0.41), \mathrm{SC}(0.91)$, TP (-0.65), and Q (-0.84)—indicating their 
moderate to strong interrelations. However, relatively weak loading of factor 2 with DO suggested its weak linkages with the corresponding variables. Moderate interrelation between the nutrient variables (TN and TP) was apparent from their moderate to strong loadings on factor 3; which, however had weak loading of DO—suggesting corresponding weak linkages. 'Transitional' regime showed strongest loading ( 0.58$)$ of DO on factor 3, which also had high loading $(0.97)$ of $\mathrm{pH}$-suggesting their strong linkages. Further, DO loaded moderately $(-0.42)$ on factor 1, which had strong loading of TW (0.98) and moderate loading of AP (-0.54)manifesting their respective moderate to strong linkages with DO. Strong interrelation between TN and SC was apparent from their strong loadings (0.73 to 0.99) on factor 2, which however, had weak loading (-0.15) of DO. The 'redox dominated' regime manifested strongest loading of DO (0.73) on factor 2 , which had strong loading of $\mathrm{pH}(0.99)$ - suggesting domination of $\mathrm{pH}$ on DO. Strong interrelation between AP and TW was apparent from their strong loadings on factor 1 (-0.69 and 1.00, respectively), which, however, had moderate loading (-0.44) of DO, suggesting corresponding moderate linkages. Further, weak loading of DO was found on factor 3 , which had strong loading of TN and moderate loading of SR, indicating their weak linkages with DO.

\subsubsection{Quantification of the relative linkages of $D O$ with the drivers}

PLSR models of DO were optimized based on the synthesis of the minimum AIC, maximum NSE, and eigenvalue $\geq 1$ criterion — which led to the inclusion of first three to four PLS components (see Figure A6.3 in Appendix 6). The optimized models—obtained from 1000 bootstrap Monte-Carlo estimations - showed good fitting efficiencies (NSE $=0.53-0.98)$ and accuracies $(\operatorname{RSR}=0.15-0.68)$. PLSR model coefficients $(\beta)$ reiterated the presence of the three environmental regimes - based on the dominant stream water quality drivers to control DO. The 
model coefficients $(\beta)$ of all the sites across the environmental regimes were presented through boxplots (see Figure A6.4 in Appendix 6). The regime-specific ensemble means and corresponding standard deviations of $\beta$ across the environmental regimes (Table 6.4) suggested stability of the estimated relative linkages of DO with the dominant hydro-climatic and biogeochemical drivers.

Table 6.4. Ensemble means and standard deviations (in parentheses) of the PLSR model coefficients $(\beta)$, representing the regime-specific relative linkages of DO with the drivers.

\begin{tabular}{lccc}
\hline Drivers & $\begin{array}{c}\text { Temperature } \\
\text { dominated }\end{array}$ & Transitional & $\begin{array}{c}\text { Redox } \\
\text { dominated }\end{array}$ \\
\hline TN & $0.02(0.07)$ & $-0.06(0.09)$ & $-0.05(0.08)$ \\
TP & $-0.14(0.07)$ & $-0.08(0.11)$ & $0.01(0.05)$ \\
TW & $-0.74(0.08)$ & $-0.44(0.12)$ & $-0.23(0.07)$ \\
$\mathrm{SC}$ & $0.02(0.07)$ & $0.03(0.12)$ & $0.02(0.08)$ \\
$\mathrm{pH}$ & $0.12(0.08)$ & $0.48(0.13)$ & $0.67(0.07)$ \\
$\mathrm{Q}$ & $0.08(0.07)$ & $0.17(0.14)$ & $*$ \\
$\mathrm{SR}$ & $0.01(0.08)$ & $0.01(0.10)$ & $0.10(0.08)$ \\
$\mathrm{AP}$ & $0.04(0.08)$ & $-0.01(0.11)$ & $0.04(0.08)$ \\
\hline Optimum PLS & $3-4$ & 3 & 3 \\
components & & & \\
$\mathrm{NSE}$ & 0.87 & 0.71 & 0.63 \\
$\mathrm{RSR}$ & 0.34 & 0.52 & 0.60 \\
\hline
\end{tabular}

Notes: The regime-specific statistics were computed from the corresponding site-specific $\beta$, as obtained from 1000 Monte-Carlo estimations. The regime-specific mean NSE and RSR were reported. TN, TP, TW, SC, Q, SR, and AP, respectively, refer to total nitrogen, total phosphorus, temperature of water, specific conductance, flow rate, solar radiation, and atmospheric pressure. '*' indicates missing values.

In 'temperature dominated' regime, TW showed the strongest linkage ( $\beta=-0.74)$ with DO-indicating domination of climatic control on DO in this regime. However, in 'transitional' regime, strong linkages with DO were found with both TW $(\beta=-0.44)$ and $\mathrm{pH}(\beta=0.48)$, suggesting domination of both climate and redox processes. Unlike 'temperature dominated' and 
'transitional' regime, 'redox dominated' regime showed strongest linkage of $\mathrm{DO}$ with $\mathrm{pH}$ ( $\beta=$ $0.67)$ and moderate linkage with TW ( $\beta=-0.23)$. The strong dominations of TW and $\mathrm{pH}$ on stream DO were consistent across the stations in the respective regimes-apparent from the boxplots of the model coefficients (see Figure A6.4 in Appendix 6). Among the other environmental drivers, TP had moderate negative linkages ( $\beta=-0.08$ to -0.14$)$ with DO in all but 'redox dominated' regime where it showed relatively weak linkage $(\beta=0.01)$. TN showed relatively weak linkages with DO across the regimes-indicating TP as the primary driver for eutrophication in majority of the streams. $\mathrm{Q}$ had moderate positive linkage ( $\beta=0.08$ to 0.17 ) with DO, referring to its contribution to stream DO through reaeration. SR showed weak linkages with DO in all but 'redox dominated' regime, where it showed moderate positive linkage ( $\beta=0.10$ ) —suggesting moderate contribution to DO by photosynthesis. However, both SC and AP had relatively weak linkages with DO across the regimes.

Ensemble means of the aggregated relative linkages (calculated with Equation 1-4) of DO with different environmental process components were computed directly from the corresponding site-specific (1000 Monte-Carlo) estimations of $\beta$ across the environmental regimes (Table 6.5). The domination of TW in 'temperature dominated' regime eventually led to highest linkage of 'climatic' component with DO-having approximately ( ) 3.5 to 4 times stronger controls than 'nutrient' $\left(\beta_{N}\right)$, 'hydro-atmospheric' $\left(\beta_{H}\right)$, and 'redox' $\left(\beta_{R}\right)$ components. 'Transitional' regime showed strong linkages of DO with both 'climatic' and 'redox' component $—$ having $\sim 3$ to 3.5 times stronger linkages than $\beta_{N}$ and $\beta_{H}$. However, in 'redox dominated' regime, only 'redox' component showed strong linkage with DO—having 2.5 times stronger linkage than $\beta_{C}$ and $\sim 6$ times stronger linkage than $\beta_{N}$ and $\beta_{H}$. 
Table 6.5. Ensemble mean and standard deviation (in parentheses) of the aggregated relative linkages of DO with the four environmental process components in different environmental regimes.

\begin{tabular}{llll}
\hline $\begin{array}{l}\text { Environmental process } \\
\text { component }\end{array}$ & $\begin{array}{l}\text { Temperature } \\
\text { dominated }\end{array}$ & Transitional & $\begin{array}{l}\text { Redox } \\
\text { dominated }\end{array}$ \\
\hline Nutrient $\left(\beta_{N}\right)$ & $0.22(0.07)$ & $0.16(0.08)$ & $0.12(0.06)$ \\
Climate $\left(\beta_{C}\right)$ & $\mathbf{0 . 7 5}(0.08)$ & $\mathbf{0 . 4 7}(0.11)$ & $0.28(0.07)$ \\
Hydro-atmosphere $\left(\beta_{H}\right)$ & $0.19(0.07)$ & $0.15(0.08)$ & $0.12(0.06)$ \\
Redox $\left(\beta_{R}\right)$ & $0.22(0.07)$ & $\mathbf{0 . 5 4}(0.11)$ & $\mathbf{0 . 6 9}(0.07)$ \\
& \multicolumn{2}{c}{ Ratio to the strongest aggregated $\beta$} \\
& $\beta_{C} / \beta_{N}=3.4$ & $\beta_{R} / \beta_{N}=3.4$ & $\beta_{R} / \beta_{N}=5.8$ \\
& $\beta_{C} / \beta_{H}=3.9$ & $\beta_{R} / \beta_{C}=1.2$ & $\beta_{R} / \beta_{C}=2.5$ \\
& $\beta_{C} / \beta_{R}=3.4$ & $\beta_{R} / \beta_{H}=3.6$ & $\beta_{R} / \beta_{H}=5.8$ \\
\hline
\end{tabular}

Notes: The regime-specific statistics were computed directly from the corresponding site-specific (1000 Monte-Carlo) estimations of $\beta$. The aggregated relative linkages of the 'nutrient' $\left(\beta_{N}\right)$, 'climatic; $\left(\beta_{C}\right)$, 'hydro-atmospheric' $\left(\beta_{H}\right)$, and 'redox' $\left(\beta_{R}\right)$ components were computed, respectively, from Eq. 1-4.

\subsection{Discussion}

The 4-step data analytics manifested a detailed and corroborative representation of the interrelations among the drivers and their relative linkages with DO. Overall, the data analytics categorized the stream water quality sites into three different environmental regimes based on the dominant stream water quality process - (1) 'temperature dominated' regime located in northern part of temperate zone, (2) 'redox dominated' regime located in tropical zone, and (3) both TW and $\mathrm{pH}$ dominated 'transitional' regime located in between the temperate and tropical zones. This indicates a strong effect of the climatic gradient (temperate to tropical) on the primary stream water quality processes across the US East Coast. 
Stream DO in the northern part of the temperate zone (e.g., northeast coast) had strongest linkage (see Table 6.4) with TW—indicating an environmental regime dominated by climatic control. The strong negative control of TW on DO was further manifested by the site-specific average value of DO and TW (Table 6.1), showing relatively lower DO of the streams having higher TW. The strong negative linkage between DO and TW might be due to decreasing solubility of oxygen in water with increasing temperature (Caccia and Boyer, 2005; Shrestha and Kazama, 2007)—representing the strong thermodynamic relationship between TW and DO. Further, higher water temperature increases the microbial decomposition of organic matter in water (see references in Murdoch et al., 2000; Schaefer and Hollibaugh, 2017), that fuels the biological oxygen demand reducing oxygen availability. This corroborates the findings from the previous studies reporting strong negative effect of temperature on stream DO in different parts of the temperate climate zones. For example, Shrestha and Kazama (2007) found a clear inverse relationship between DO and temperature in Fuji River, Japan, and attributed it to the reduced solubility of DO in higher water temperature. Nelson et al. (2017) reported decreasing DO with increasing temperature in the Rhode River located in Maryland, U.S.A. Further, Jacobs et al. (2009) found strong negative correlation of DO with water temperature in the coastal bays of Maryland and Virginia.

Unlike northern part of the temperate zone, majority of the streams in the tropical zone showed domination of $\mathrm{pH}$ to control $\mathrm{DO}$ - suggesting an environmental regime dominated by the stream redox process. Tropical zone is characterized by constantly high temperature throughout the year, with annual average temperature of $18^{\circ} \mathrm{C}(\mathrm{KCC}, 2017)$ — close to the optimum temperature $\left(20\right.$ to $\left.30^{\circ} \mathrm{C}\right)$ for algal photosynthesis (Mosser and Brock, 1976; Konopka and Brock, 1978). Increased algal photosynthesis increases DO and consumes carbon dioxide 
resulting in an increase in pH (Zang et a., 2011; Frieder et al., 2012)—manifested by the strong positive linkage between DO and $\mathrm{pH}$ (see Table 6.4). Further, increased microbial decomposition in higher temperature consumes DO and produces carbon dioxide lowering pH (Cai et al., 2011) - that might also have led to the positive linkage between DO and pH. In a relevant study, strong positive linkage of DO with pH was reported by Cai et al. (2011) in the northern Gulf of Mexico located near the tropical zone. Further, Wetz et al., (2016) reported lack of correlation between DO and water temperature in subtropical estuary of Oso Bay, Texas, which supported the results of this study. However, the strong control of redox process on stream DO might not be prevalent in all tropical streams, due to low temperature imposed by the surrounding physical characteristics of the stream (e.g., high turbidity, riparian vegetation). The presence of the 'redox dominated' regime in tropical zone alongside the 'temperature dominated' regime in northern temperate zone were further supported by the 'transitional' regime-located in between temperate and tropical zones and having domination of both TW and $\mathrm{pH}$.

Watershed characteristics and land uses were also found to influence the controls of environmental process components on DO. For example, the relative linkages of $\mathrm{pH}$ was found to decrease with increasing watershed slope (see Figure A6.5 Appendix 6). This might be because nutrients from land uses (e.g., agricultural land) with steeper slope has less contact time with surface runoff and therefore, lower potential to contribute for nutrients-leading to decreased microbial decomposition. This is consistent with the findings of Wan et al. (2014a), reporting that agricultural land with flatter slope contributes more to in-stream nutrients (e.g., total nitrogen, total phosphorus) in Xitiaoxi River watershed, China. Apart from the watershed slope, control of $\mathrm{pH}$ was found to increase with increasing percentage of agricultural land (see Figure A6.6 in Appendix 6). The agricultural land might have contributed to increased nutrient- 
leading to higher microbial decomposition, represented by relatively stronger linkage of DO with $\mathrm{pH}$. The contribution of agricultural land to the in-stream nutrient of the coastal water in different parts of US East Coast is well documented in literature. For example, Wan et al. (2014b) found agricultural land as a strong source of in-stream nutrients (e.g., phosphorus, nitrogen) in the Indian River Lagoon Watershed, located at east coast of Florida. Further, Caccia and Boyer (2007) showed strong linkage of agricultural land with the nitrogen load in the canals of Biscayne Bay watersheds, Florida.

The overall positive linkage of DO with Q (see Table 6.4) across the regimes indicated increased reaeration by turbulence from higher stream discharge (Dyar and Alhadeff, 2005). Both of the 'temperature dominated' and 'transitional' regimes showed overall moderate and weak linkages of DO, respectively, with TP and TN—indicating TP as the limiting nutrient in majority of the streams. The moderate negative linkage of DO with TP indicated eutrophication induced consumption of oxygen, corroborating the findings from the previous studies (see references in Wang and Linker (2009)). Solar radiation did not have substantial linkage with DO across the regimes, suggesting solar radiation was not limiting for photosynthetic production of DO in seasonal scale. The relatively weak linkage of atmospheric pressure and salinity with DO across the regimes indicated their low influence to control site-specific stream DO in majority of the stream sites.

The knowledge of the dominant hydro-climatic and biogeochemical drivers and environmental regimes would guide developing policy interventions for efficient management of stream water quality under dynamic climate and development pressure across the U.S. East Coast. The aggregated relative linkages quantitatively showed the importance of one environmental process component over other to manage stream water quality. Further, the 
identified environmental regimes suggested urgency of different management strategies in different climatic zones. In northern temperate latitude, the strongest adverse impact on stream DO was found from stream temperature; therefore, stream water quality would be most vulnerable during high temperature period to get highest management priority. However, in tropical latitude, highest management priory should be given to control the redox processes (e.g., microbial decomposition) to have efficient control on stream water quality. Due to higher potential of microbial decomposition, biological treatment of wastewater through constructed wetland would be more efficient in tropical latitude than that of temperate latitude. Since, stream temperature showed moderate to strong control on DO across the regimes, strong management priority should be given to reduce stream temperature by controlling thermal pollution from industrial discharge alongside introducing riparian vegetation. Further, proper land use management should also be taken to reduce the urban heat island effect. The study suggested that controlling the increasing rate of nutrient enrichment in coastal water from watershed land uses (e.g., agricultural land) should also get management priority to minimize eutrophication induced hypoxia (Diaz and Rosenberg, 2008; Cai et al., 2011) across the East Coast.

\subsection{Conclusions}

The dynamic controls of the coastal stream DO in diverse hydro-climatic and biogeochemical conditions were investigated considering a large spatial scale across the U.S. East Coast. Based on the dominant drivers, the data analytics categorized the streams into three distinct environmental regimes following the climatic gradient (temperate to tropical) across the East Coast. Stream sites located in the northern part of the temperate zone (e.g., northeast coast) had the strongest linkage of DO with water temperature; indicating an environmental regime with dominant climatic control. In contrast, majority of the streams in the tropical zone (e.g., 
southeast Florida) showed strongest linkage of DO with $\mathrm{pH}$; suggesting an environmental regime likely driven by redox process. Further, a transitional regime — dominated by both water temperature and $\mathrm{pH}$ - was identified in between the temperate and tropical zone. The identified environmental regimes in distinctive climate zones suggested a strong effect of climatic gradient on stream DO dynamics across the East Coast. Further, notable linkages of stream DO were found with total phosphorus and stream flow, while weak controls were found from solar radiation, specific conductance, and atmospheric pressure in majority of the streams. The quantified relative linkages of the drivers were aggregated to estimate the relative linkages of DO with four environmental process components. The 'climatic' component showed approximately 3.5 to 4 times stronger control on DO than 'nutrient', 'hydro-atmospheric', and 'redox' components in 'temperature dominated' regime. However, in 'redox dominated' regime, 'redox' component had approximately 2.5 to 6 times stronger linkages than the other components.

Moderate to strong control of water temperature on DO across the regimes suggested urgency of strong management priority to reduce stream temperature by controlling thermal pollution from industrial discharge and urban heat island effect alongside introducing riparian vegetation. Further, the study suggested that in tropical latitude, highest management priory should be given to control the redox processes (e.g., microbial decomposition, eutrophication) to have efficient control on stream water quality. Controlling the increasing rate of nutrient enrichment in coastal water from watershed land uses was also found important to minimize eutrophication-induced hypoxia. The identified environmental regimes and the regime-specific relative linkages would guide effective planning and management of coastal stream water quality and ecosystem health under dynamic climate and development pressures. 


\section{Acknowledgments}

The research was funded by the National Science Foundation (NSF) CAREER Award to Dr. Omar

I. Abdul-Aziz (NSF CBET Environmental Sustainability Award Number 1561942/1454435). 


\section{Appendix 6}

Table A6.1. Summary of the watershed land use and topographic data across the 51 stream water quality monitoring sites.

\begin{tabular}{lrrrrrrr}
\hline Variables & Mean & $\begin{array}{r}\text { Standard } \\
\text { Deviation }\end{array}$ & Minimum & $\begin{array}{r}\text { 25th } \\
\text { Percentile }\end{array}$ & $\begin{array}{r}\text { 50th } \\
\text { Percentile }\end{array}$ & $\begin{array}{r}\text { 75th } \\
\text { Percentile }\end{array}$ & Maximum \\
\hline S (\%) & 6.39 & 5.52 & 0.04 & 1.54 & 5.57 & 9.51 & 23.05 \\
WAT (\%) & 3.22 & 9.41 & 0.00 & 0.27 & 0.71 & 2.04 & 63.90 \\
BUL (\%) & 17.02 & 22.20 & 0.00 & 5.18 & 8.04 & 16.11 & 87.82 \\
OPN (\%) & 0.18 & 0.19 & 0.00 & 0.01 & 0.17 & 0.27 & 0.85 \\
VEG (\%) & 43.06 & 27.67 & 0.08 & 13.15 & 50.45 & 66.55 & 83.49 \\
AGR (\%) & 18.38 & 18.80 & 0.00 & 6.38 & 14.20 & 24.52 & 93.86 \\
WTL (\%) & 18.15 & 21.18 & 0.22 & 5.54 & 10.90 & 20.20 & 91.55 \\
\hline
\end{tabular}

Notes: S, WAT, BUL, OPN, VEG, AGR, WTL respectively, refer to watershed slope, waterbody, builtup land, open land, vegetated land, agricultural land, and wetland.

Table A6.2: Correlation matrix representing mean correlation coefficients of DO and hydroclimatic/instream variables for the 'temperature dominated' regime.

\begin{tabular}{llllllllll}
\hline & $\mathrm{TN}$ & $\mathrm{TP}$ & $\mathrm{TW}$ & $\mathrm{SC}$ & $\mathrm{pH}$ & $\mathrm{Q}$ & $\mathrm{SR}$ & $\mathrm{AP}$ & $\mathrm{DO}$ \\
\hline $\mathrm{TN}$ & 1.00 & $\mathbf{0 . 5 2}$ & 0.05 & 0.00 & -0.16 & 0.13 & -0.02 & -0.06 & -0.07 \\
$\mathrm{TP}$ & $\mathbf{0 . 5 2}$ & 1.00 & 0.32 & -0.04 & -0.10 & 0.10 & 0.05 & -0.18 & -0.34 \\
$\mathrm{TW}$ & 0.05 & 0.32 & 1.00 & 0.10 & 0.16 & -0.38 & 0.37 & -0.25 & $\mathbf{- 0 . 8 8}$ \\
$\mathrm{SC}$ & 0.00 & -0.04 & 0.10 & 1.00 & 0.39 & $\mathbf{- 0 . 5 4}$ & -0.01 & 0.04 & -0.04 \\
$\mathrm{pH}$ & -0.16 & -0.10 & 0.16 & 0.39 & 1.00 & -0.48 & 0.11 & 0.03 & -0.03 \\
$\mathrm{Q}$ & 0.13 & 0.10 & -0.38 & $\mathbf{- 0 . 5 4}$ & -0.48 & 1.00 & -0.11 & 0.01 & 0.28 \\
$\mathrm{SR}$ & -0.02 & 0.05 & 0.37 & -0.01 & 0.11 & -0.11 & 1.00 & 0.06 & -0.27 \\
AP & -0.06 & -0.18 & -0.25 & 0.04 & 0.03 & 0.01 & 0.06 & 1.00 & 0.24 \\
DO & -0.07 & -0.34 & $\mathbf{- 0 . 8 8}$ & -0.04 & -0.03 & 0.28 & -0.27 & 0.24 & 1.00 \\
\hline
\end{tabular}

Note: The regime-specific mean correlations were obtained by averaging the site-specific correlations. 
Table A6.3: Correlation matrix representing mean correlation coefficients of DO and hydroclimatic/instream variables for the 'transitional' regime.

\begin{tabular}{llllllllll}
\hline & TN & TP & TW & SC & pH & Q & SR & AP & DO \\
\hline TN & $\mathbf{1 . 0 0}$ & 0.29 & 0.30 & -0.14 & -0.41 & $*$ & 0.06 & -0.16 & -0.36 \\
TP & 0.29 & $\mathbf{1 . 0 0}$ & 0.42 & -0.25 & -0.20 & 0.35 & 0.10 & -0.23 & -0.31 \\
TW & 0.30 & 0.42 & $\mathbf{1 . 0 0}$ & -0.10 & -0.27 & 0.29 & 0.32 & $\mathbf{- 0 . 5 1}$ & $\mathbf{- 0 . 5 8}$ \\
SC & -0.14 & -0.25 & -0.10 & $\mathbf{1 . 0 0}$ & $\mathbf{0 . 5 2}$ & $\mathbf{- 0 . 7 0}$ & 0.12 & 0.11 & 0.30 \\
pH & -0.41 & -0.20 & -0.27 & $\mathbf{0 . 5 2}$ & $\mathbf{1 . 0 0}$ & $\mathbf{- 0 . 5 5}$ & -0.04 & 0.28 & $\mathbf{0 . 6 2}$ \\
Q & $*$ & 0.35 & 0.29 & $\mathbf{- 0 . 7 0}$ & $\mathbf{- 0 . 5 5}$ & $\mathbf{1 . 0 0}$ & -0.12 & -0.30 & -0.27 \\
SR & 0.06 & 0.10 & 0.32 & 0.12 & -0.04 & -0.12 & $\mathbf{1 . 0 0}$ & -0.02 & -0.16 \\
AP & -0.16 & -0.23 & $\mathbf{- 0 . 5 1}$ & 0.11 & 0.28 & -0.30 & -0.02 & $\mathbf{1 . 0 0}$ & 0.34 \\
DO & -0.36 & -0.31 & $\mathbf{- 0 . 5 8}$ & 0.30 & $\mathbf{0 . 6 2}$ & -0.27 & -0.16 & 0.34 & $\mathbf{1 . 0 0}$ \\
\hline
\end{tabular}

Note: The regime-specific mean correlations were obtained by averaging the site-specific correlations.

Table A6.4: Correlation matrix representing mean correlation coefficients of DO and hydroclimatic/instream variables for the 'redox dominated' regime.

\begin{tabular}{llllllllll}
\hline & TN & TP & TW & SC & pH & Q & SR & AP & DO \\
\hline TN & $\mathbf{1 . 0 0}$ & $\mathbf{0 . 6 1}$ & 0.09 & $\mathbf{0 . 5 7}$ & 0.08 & $*$ & -0.08 & -0.18 & -0.04 \\
TP & $\mathbf{0 . 6 1}$ & $\mathbf{1 . 0 0}$ & 0.01 & 0.23 & 0.06 & $*$ & -0.08 & -0.10 & 0.01 \\
TW & 0.09 & 0.01 & $\mathbf{1 . 0 0}$ & -0.03 & -0.20 & $*$ & 0.18 & -0.48 & -0.39 \\
SC & $\mathbf{0 . 5 7}$ & 0.23 & -0.03 & $\mathbf{1 . 0 0}$ & 0.11 & $*$ & -0.01 & -0.08 & 0.08 \\
pH & 0.08 & 0.06 & -0.20 & 0.11 & $\mathbf{1 . 0 0}$ & $*$ & 0.04 & 0.17 & $\mathbf{0 . 7 0}$ \\
Q & $*$ & $*$ & $*$ & $*$ & $*$ & $*$ & $*$ & $*$ & $*$ \\
SR & -0.08 & -0.08 & 0.18 & -0.01 & 0.04 & $*$ & $\mathbf{1 . 0 0}$ & -0.02 & 0.08 \\
AP & -0.18 & -0.10 & -0.48 & -0.08 & 0.17 & $*$ & -0.02 & $\mathbf{1 . 0 0}$ & 0.28 \\
DO & -0.04 & 0.01 & -0.39 & 0.08 & $\mathbf{0 . 7 0}$ & $*$ & 0.08 & 0.28 & $\mathbf{1 . 0 0}$ \\
\hline
\end{tabular}

Note: The regime-specific mean correlations were obtained by averaging the site-specific correlations. 
Table A6.5: Ranges of percent variance explained by each principal component (PC) for the three environmental regimes.

\begin{tabular}{llll}
\hline $\begin{array}{l}\text { Principal } \\
\text { component }\end{array}$ & $\begin{array}{l}\text { Temperature } \\
\text { dominated regime }\end{array}$ & $\begin{array}{l}\text { Transitional } \\
\text { regime }\end{array}$ & $\begin{array}{l}\text { Redox dominated } \\
\text { regime }\end{array}$ \\
\hline 1 & $29-52$ & $36-52$ & $30-39$ \\
2 & $17-33$ & $15-29$ & $19-25$ \\
3 & $10-17$ & $11-15$ & $14-17$ \\
4 & $6-12$ & $7-13$ & $10-13$ \\
5 & $4-10$ & $5-9$ & $7-11$ \\
6 & $2-7$ & $3-6$ & $3-6$ \\
7 & $1-5$ & $1-4$ & $1-4$ \\
8 & $0-3$ & $1-2$ & $1-3$ \\
9 & $0-1$ & 0 & 0 \\
\hline
\end{tabular}




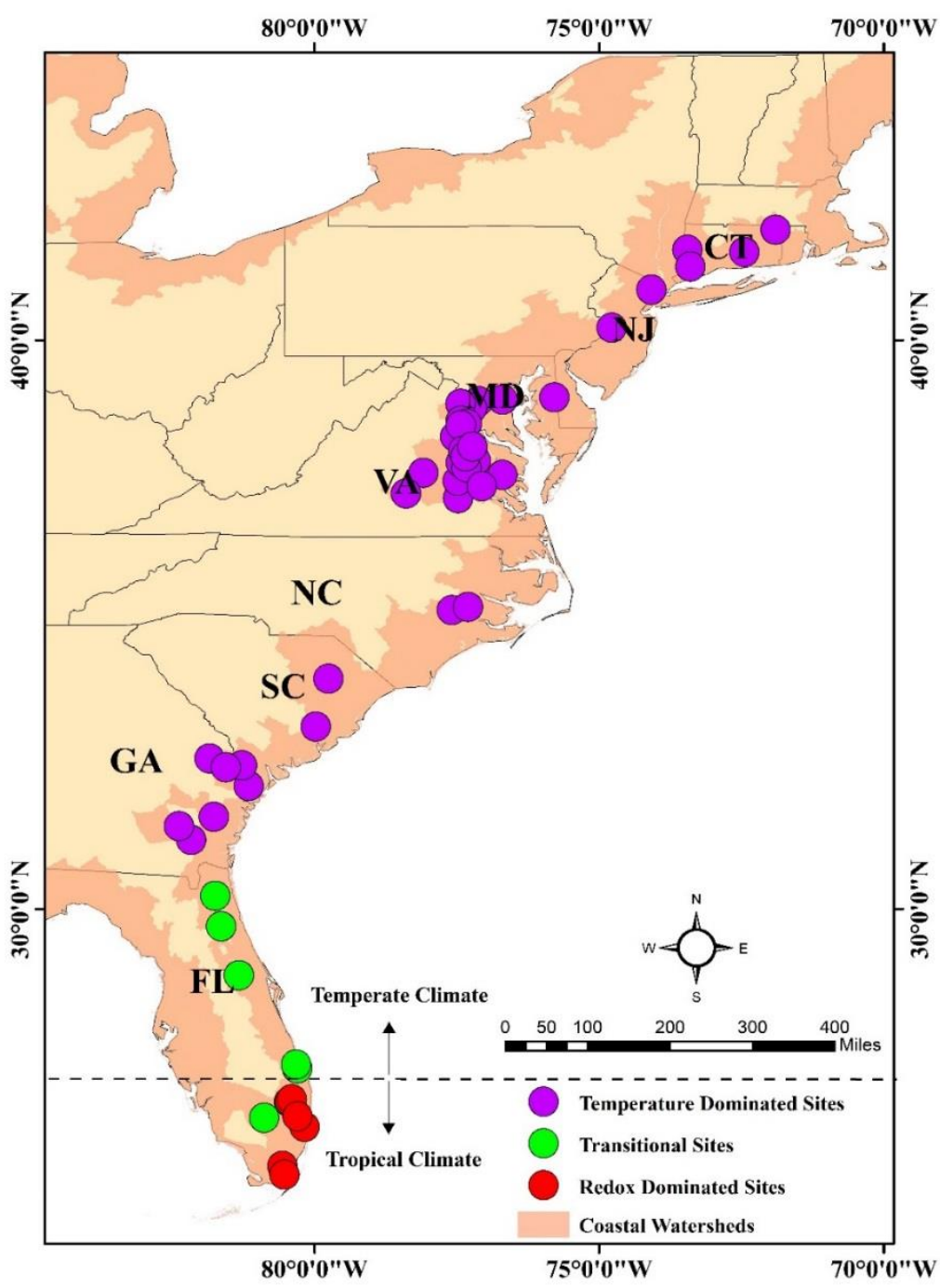

Figure A6.1. Locations of the coastal stream water quality monitoring stations in three different environmental regimes across the U.S. East Coast. 
(a) 'Temperature dominated' regime

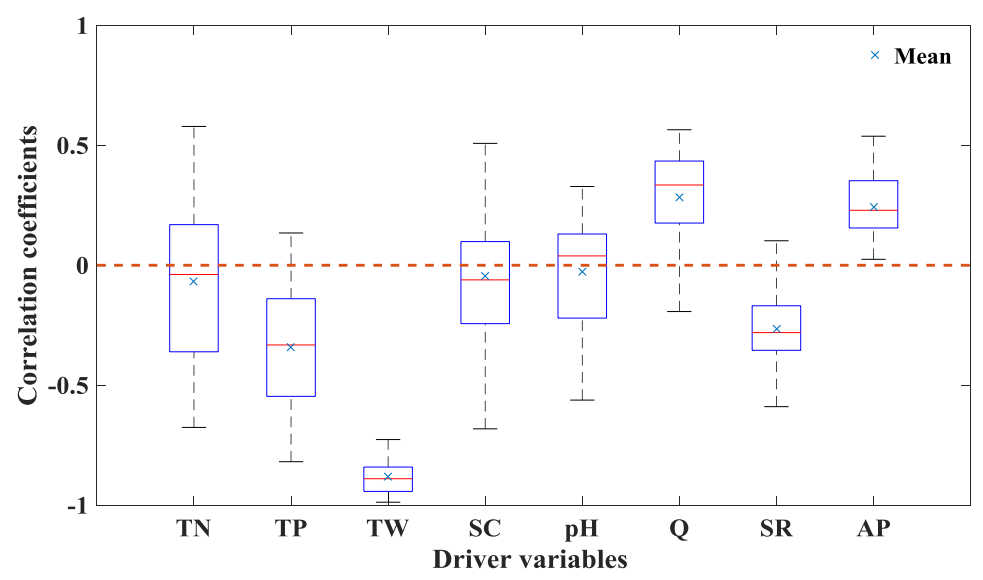

(b) 'Transitional' regime

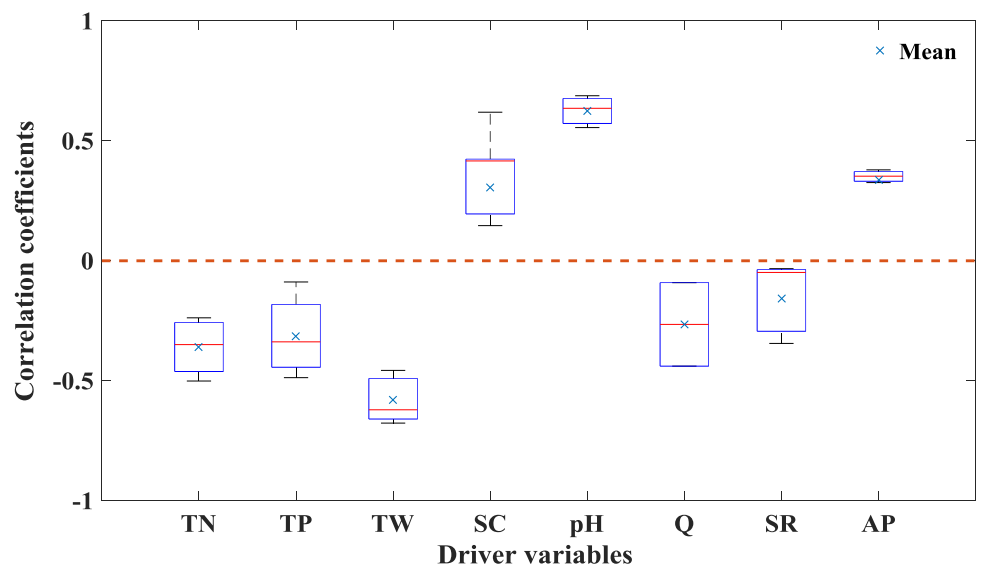

(c) 'Redox dominated' regime

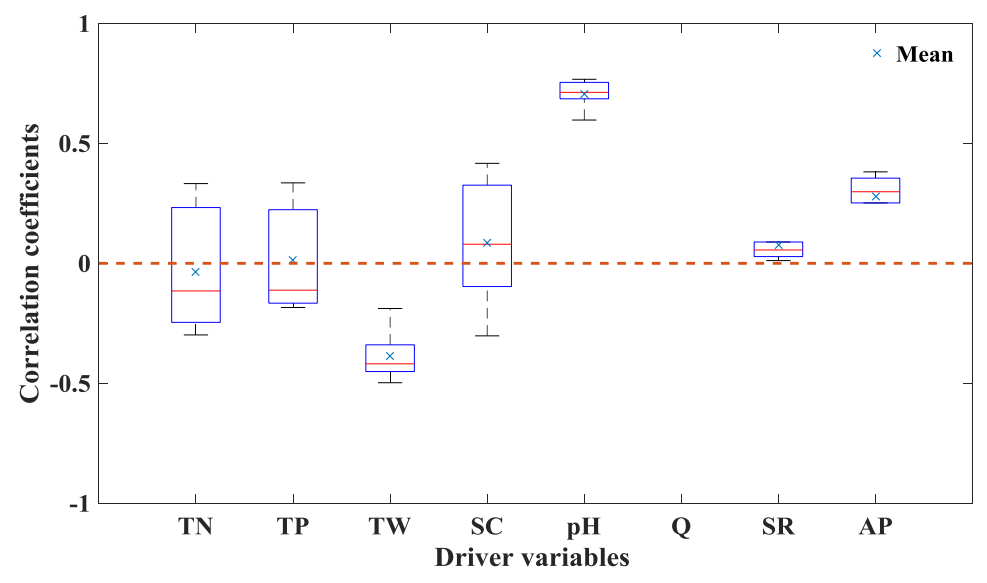

Figure A6.2. Boxplots of the Pearson correlation coefficients (r) between DO and hydroclimatic/biogeochemical drivers in the three environmental regimes across all the stream water quality monitoring sites. 
(a)

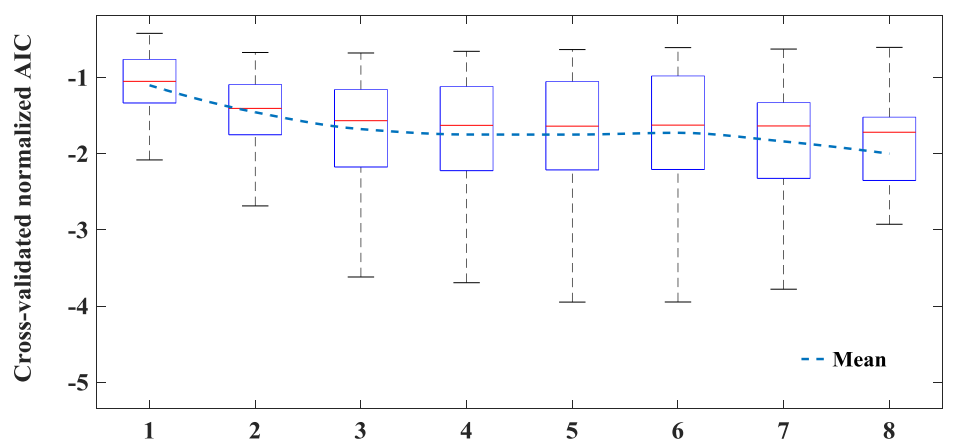

(b)

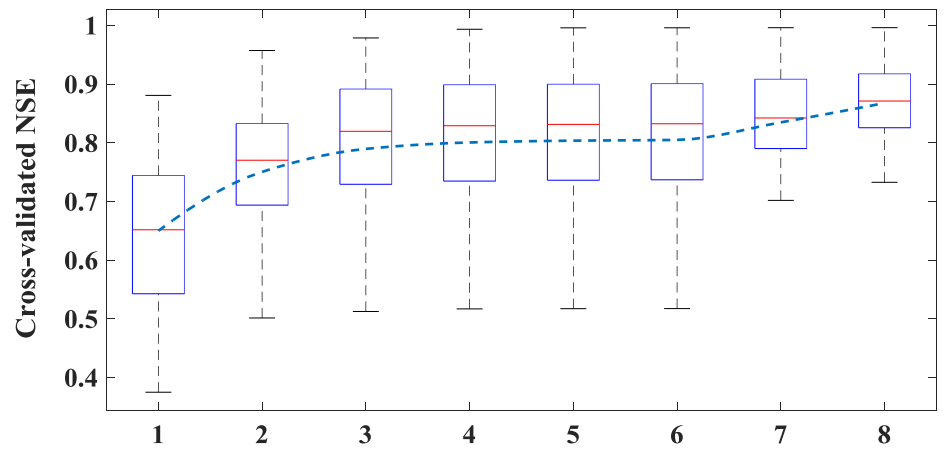

(c)

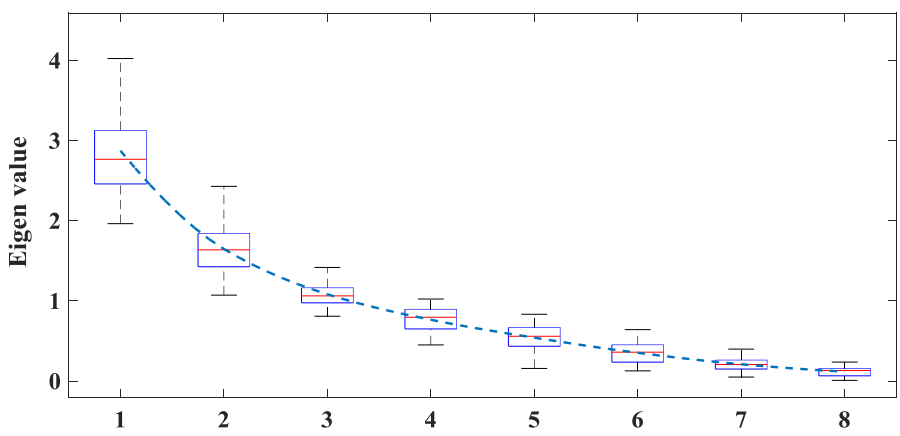

Number of partial least squares (PLS) components

Figure A6.3. Boxplots of cross-validated (a) normalized AIC and (b) Nash-Sutcliffe efficiency (NSE), and (c) eigenvalues of the data matrix with the number of partial least squares (PLS) components across the 51 water quality sites. 
(a) 'Temperature dominated' regime

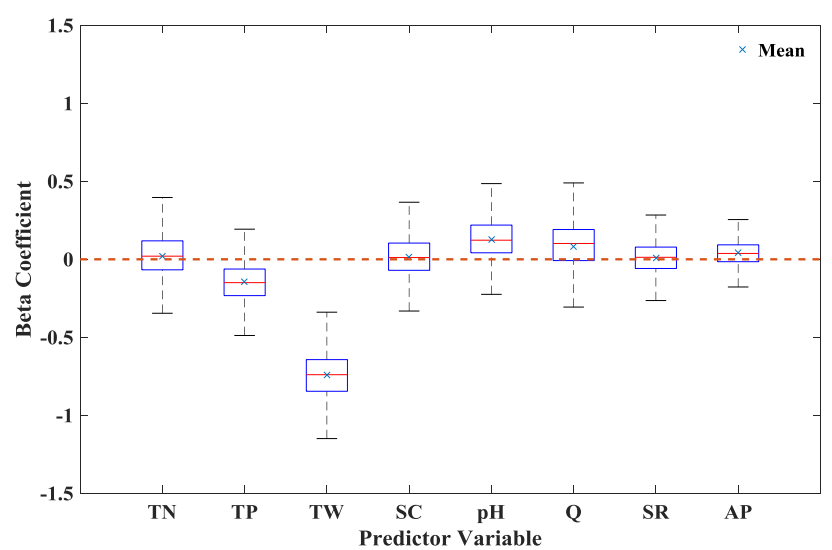

(b) 'Transitional' regime

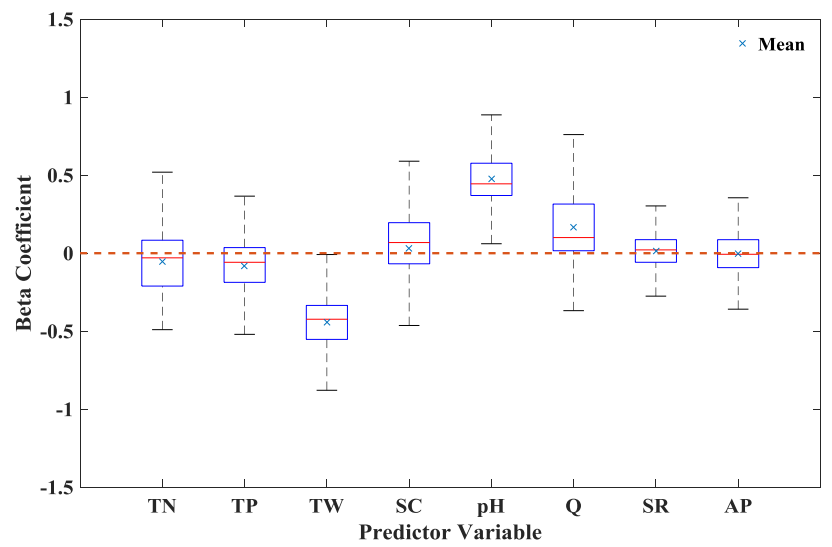

(c) 'Redox dominated' regime

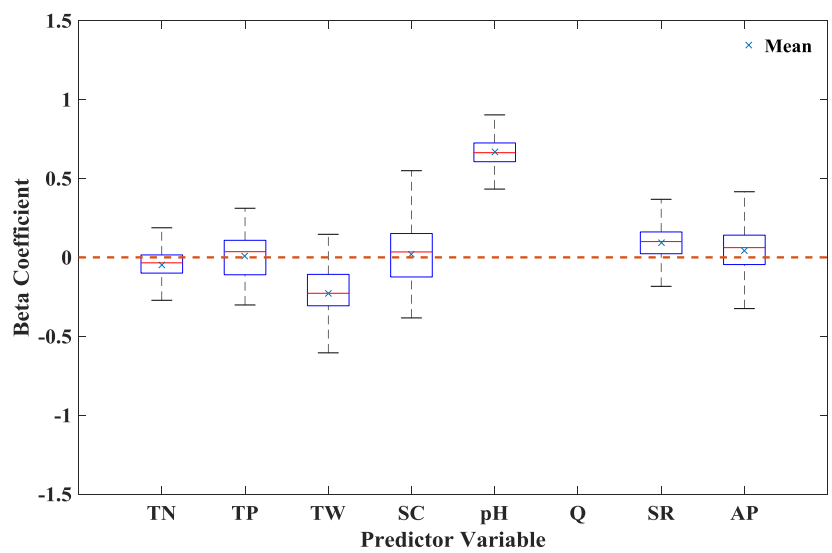

Figure A6.4. Boxplots of the PLSR model coefficients as obtained from 1000 Monte-Carlo estimations for the 51 water quality sites in the three environmental regimes. 


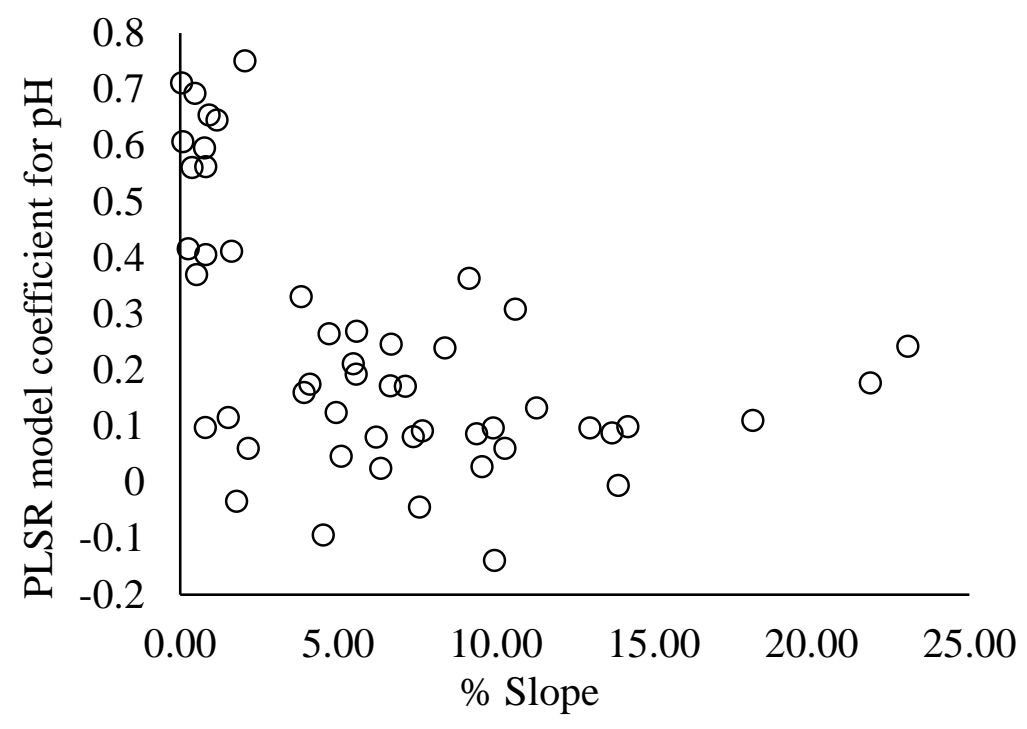

Figure A6.5. Plot of PLSR model coefficients of pH vs. \% slope of watershed.

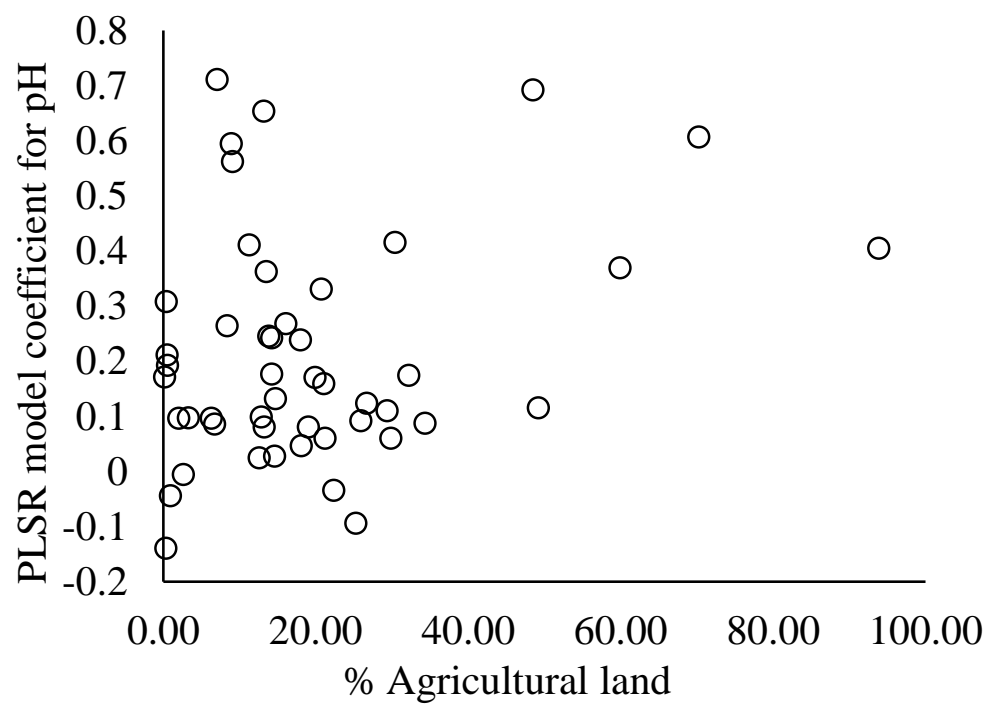

Figure A6.6. Plot of PLSR model coefficients of pH vs. \% agricultural land. 


\title{
Chapter 7: Similitude and scaling of stream dissolved oxygen with the hydro-climatic and biogeochemical drivers across the East Coast of U.S.A.
}

\begin{abstract}
The study investigates the similitude and scaling of stream dissolved oxygen (DO) with the hydro-climatic and biogeochemical drivers-incorporating a large spatial scale across the east coast of U.S.A. Dimensional analysis was employed to formulate mechanistically meaningful dimensionless numbers representing interactions of various hydro-climatic (temperature, atmospheric pressure, stream geometry) and biogeochemical (total phosphorus, $\mathrm{pH}$, salinity) drivers. The graphical exploration of the dimensionless numbers with the normalized DO showed collapse of data from diverse environments - revealing clear emergent patterns. The emergent patterns supported the hypothesis that stream water quality follows distinct biogeochemical-ecological similitude and scaling. The dimensionless curve revealed two environmental regimes - having distinct characteristics of 'climatic' versus 'metabolic' controls. In 'low consumption' regime, DO was close to saturation point-indicating a stream water quality system which is only dominated by 'climatic' control, and not favorable for microbial decomposition. However, in the 'high consumption' regime, DO was below the saturation point, and had domination of both 'metabolic' and 'climatic' controls. The emergent patterns and similitude were leveraged to develop scaling relationship among the dimensionless numbers under diverse environments. The scaling relationship was successfully leveraged to develop nonlinear empirical model of stream DO across the East Coast of U.S.A. (Nash-Sutcliffe Efficiency $=0.82$ ). The emergent pattern and developed scaling relationship are expected to provide crucial
\end{abstract}


knowledge on coastal stream water quality dynamics that would guide for effective management of coastal ecosystems.

\subsection{Introduction}

Dissolved oxygen (DO) is crucial for the proper functioning of aquatic life and a key component to assess the health of aquatic ecosystem and stream water quality to manage and protect the water resources (Cox, 2003; Markfort and Hondzo, 2009). However, stream DO is controlled by multitude of climatic, hydrologic, and biogeochemical drivers having complex interactions among them — especially in the highly dynamic coastal environments. Therefore, the complex interactions among the numerous process drivers of stream DO make it challenging to develop a generalized process understanding in diverse environmental conditions. An important research question is whether the intricate interactions of major process drivers of DO can be combined to get emergent similitude (parametric reductions) and scale-invariant patterns. How the sources versus sinks of DO mutually interacts to collectively control stream DO? Similitude and dimensional analysis can be leveraged in these regards to combine the interactions of important hydro-climatic and biogeochemical drivers into mechanistically meaningful dimensionless numbers-leading to emergent similitude and scaling of stream water quality dynamics (Warnaars et al., 2007; Miragliotta, 2011).

The major sources of stream DO are reaeration by air-water oxygen mass transfer and photosynthesis by the aquatic autotroph (Correa-González el al., 2014; Dick et al., 2016). On the other hand, major sinks of stream DO are autotrophic and heterotrophic respiration (CorreaGonzález el al., 2014) alongside the eutrophication, resulting from nutrient enrichment in water (Diaz and Rosenberg, 2008). Furthermore, stream DO can be reduced due to the 
thermodynamic/physical property of water-reducing solubility with increasing stream temperature. Temperature can also reduce DO by increasing respiration rate. However, the control of a single driver on DO is intricate since it is affected by other factors such as temperature, flow, and $\mathrm{pH}$. For example, similar nutrient concentration may not have similar control on DO subjected to different hydro-climatic and biogeochemical condition in aquatic environment because of the non-nutrient factors. Therefore, the combined interactions of important physicochemical and biological processes - rather than a single process componentshould properly be incorporated to investigate the stream DO dynamics for scaling and modeling.

Previous research on coastal water reported nutrient induced eutrophication and higher temperature as the primary driver for depletion of DO. Dyar and Alhadeff (2005) reported that stream DO characteristics are directly controlled by stream temperature, based on the study of statewide 31 water quality monitoring stations in Georgia. Shrestha and Kazama (2007) reported distinct inverse relationship between DO and temperature in Fuji River, Japan. Schaefer and Hollibaugh (2017) found strong negative relationship between DO and temperature in the coastal water of Georgia. Tyler et al. (2009) found that the longest periods of severe hypoxia in the Delaware Coastal Bays were linked with the higher temperature alongside other abiotic factors (low insolation, high streamflow). Cai et al. (2011) reported nutrients as the major drivers for eutrophication and subsequent reduction of DO in Gulf of Mexico and the East China Sea. Dodds (2006) reported that the nutrient (nitrogen, phosphorus) runoff from the Mississippi River and its tributaries is a potential cause of DO depletion in northern Gulf of Mexico. Wan et al. (2014b) reported substantial linkage of DO with nutrients $\left(\mathrm{PO}_{4}-\mathrm{P}, \mathrm{NH}_{4}-\mathrm{N}\right.$, and total phosphorus) in the managed canals of the southern Indian River Lagoon watersheds, Florida. 
The other hydrologic and non-nutrient factors have also been reported to control stream DO in many studies. Graves et al. (2004) reported the low ratio of channel surface area to cross area as a potential cause of low DO concentration due to reduced reaeration in the coastal watersheds of Indian River Lagoon (IRL), located in the southeast coast of Florida, U.SA. Hondzo et al. (2013) found linkage of stream DO with channel geometry (width, depth) in Minnehaha Creek, Minnesota. While salinity has been found to directly affect DO by reducing oxygen solubility (see reference in Knauth (2005)), it can also indirectly affect DO by controlling many biogeochemical reaction in aquatic environment (Zhang and Huang, 2011)which eventually affects the DO.

The previous research on stream DO are mostly on local scale, which does not incorporate the intricate interactions of the hyro-climatic and biogeochemical drivers across a large spatial scale. However, the study of combined effect from mutual interactions of different hydro-climatic and biogeochemical drivers across a large spatial scale could result in emerging patterns - leading to robust scaling and modeling of stream DO. In this regard, similitude and dimensional analysis can be leveraged to study how stream DO is collectively controlled by the interactions of major environmental process components, which can help to develop robust models (Miragliotta, 2011; Hondzo et al., 2013). Having the property of dimensional independence (Warnaars et al., 2007), dimensionless numbers can help to form a basis of similarity among different environmental processes at different spatio-temporal scales (Potter et al., 2002).

Similitude is the dimensionless formulation and parametric reduction of physical system (Kundu and Cohen, 2004), that has been widely used in field of fluid mechanics. Similitude and dimensional analysis has been used in previous studies to investigate the interactions of various 
environmental process components (both biotic and abiotic) to develop knowledge on the dynamics of stream water quality. For example, Warnaars et al. (2007) investigated the interactions of stream biotic and abiotic factors employing similitude and dimensional analysis in various streams and rivers across North America. Hondzo et al. (2013) applied dimensional analysis to study the control of both biotic/metabolic (photosynthesis and respiration) and abiotic (advection, dispersion, and aeration) components on dissolved oxygen mass balance in the Minnehaha Creek, Minnesota. Zeleňáková et al. (2013) developed water quality model by employing dimensional analysis to estimate nutrient concentration from hydrologic and climatic drivers in the River Laborec located in eastern Slovakia. Barnes et al. (2007) applied dimensional analysis and hydro-geomorphologic scaling laws to upscale river biomass in South Fork Eel River located in northern California. Hondzo et al. (2013) applied dimensional analysis of DO mass balance to study the dominance of stream metabolic activities, advection, re-aeration, and dispersion in Minnehaha Creek, Minnesota. A spatiotemporally robust empirical model was developed using dimensionless DO by Abdul-Aziz and Ishtiaq (2014), to predict the diurnal cycle of stream dissolved oxygen from a single reference observation.

The goal of the study is to investigate the similitude and emergent patterns in coastal stream water quality dynamics. The research tests a fundamental hypothesis that coastal stream water quality follows distinct biogeochemical-ecological similitude and scaling-incorporating a large spatial scale across the East Coast of U.S.A. The dimensional analysis was employed to formulate important dimensionless numbers representing the interactions of different environmental process components. The dimensionless numbers were then leveraged to develop characteristic process diagrams to investigate potential emergent patterns-leading to scaling and robust modeling of coastal stream water quality dynamics. The emergent patterns and scaling are 
expected to provide crucial knowledge on coastal stream water quality dynamics that would guide for effective management of coastal ecosystems across the U.S. East Coast and similar regions.

\subsection{Materials and methods}

\subsubsection{Study sites and data sets}

The study area incorporates a large spatial scale across the east coast of U.S.A., including 30 stream water quality monitoring sites located in NOAA's coastal watersheds (Percy Pacheco, personal communications, 2016) (Figure 7.1). Having a large geographical scale, the study area incorporated eight different U.S. states: (i) Connecticut; (ii) New Jersey; (iii) Maryland; (iv) Virginia; (v) North Carolina; (vi) South Carolina; (vii) Georgia; and (viii) Florida. The study area incorporates diverse ecoregions starting from "northeastern coastal zone" in the northern part and "southern coastal plain" in the southern part (Omernik and Griffith, 2014)_ representing a wide range of hydrology, land uses, soils, and geology (USGS, 2018).

Temporal data (1998-2015) (Table 7.1) of grab sample stream water quality of USGS NWIS were gathered from National Water Quality Monitoring Council (NWQMC) databases (NWQMC, 2017). Temporal data were collected mostly at quarterly interval across the year. Concurrent stream flow (Q) data were also collected from the similar source. The study period was selected based on the availability of reliable data incorporating seasonal and multi-year temporal gradients on stream water quality dynamics. The stream water quality data set include stream DO, total phosphorus (TP), temperature of water (TW), Salinity (Sal), and pH. Salinity was estimated from specific conductance following Schemel (2001). Atmospheric pressure (AP) data were collected from 4 x 4 km grid cells of National Solar Radiation Data Base (NSRDB) 
(NSRDB, 2017). Saturated concentration of dissolved oxygen ( $\left(\mathrm{DO}_{\text {sat }}\right)$ was estimated as a function of TW, Sal, and AP following Chapra (2008). Temporal data of dynamic stream cross sectional area (A) and top width (W) were collected from USGS (USGS, 2017b). Average stream depth (D) was calculated leveraging temporal data of ' $\mathrm{A}$ ' and ' $\mathrm{W}$ ' assuming trapezoidal cross section. Concurrent data of stream geometric variables (e.g., W, D, A) with the corresponding stream water quality data were estimated based on the regressions with stream flow. The extreme values (outliers) in the data were detected and removed using the criteria of interquartile range (IQR) (e.g., $P_{25}-2 \times I Q R$ and $P_{75}+2 \times I Q R$, where, $P_{25}$ and $P_{75}$ are, respectively, $25^{\text {th }}$ and $75^{\text {th }}$ percentiles).

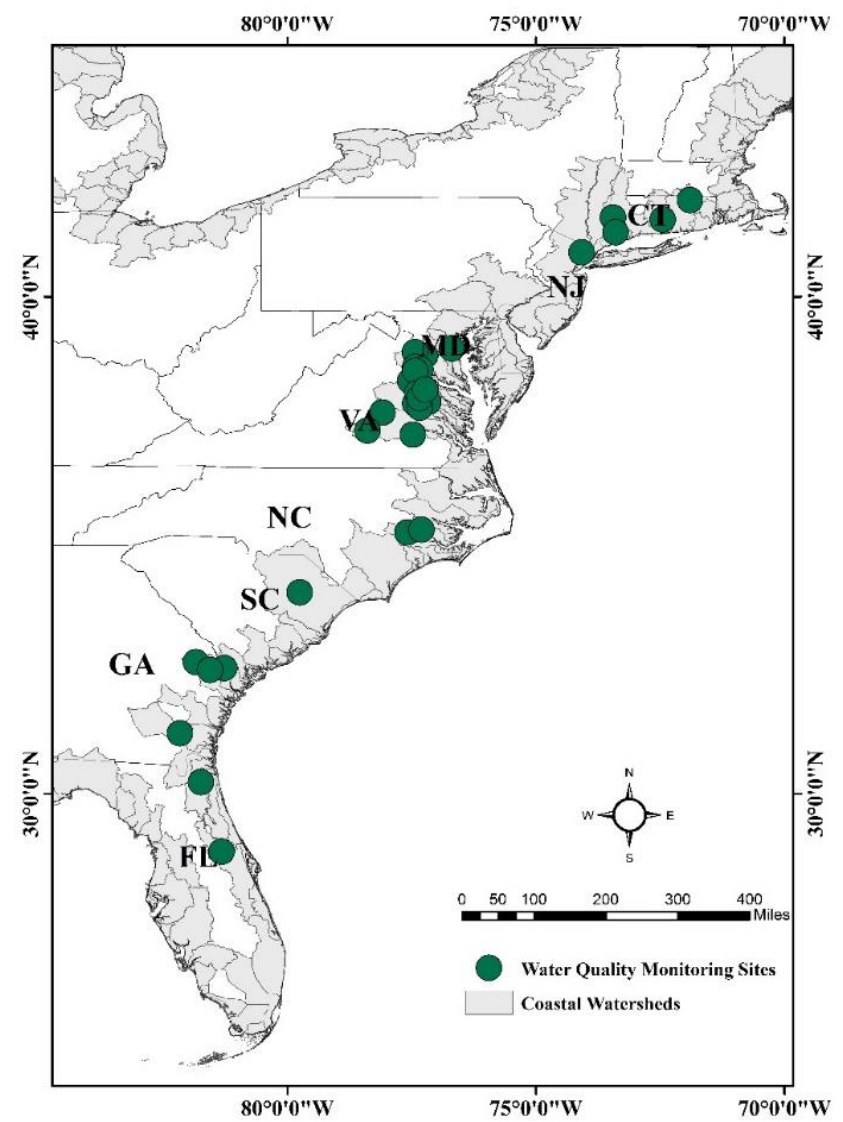

Figure 7.1. Locations of the coastal stream water quality monitoring stations across the U.S. East Coast. 
The dataset incorporated major environmental process components to control coastal stream water quality. For example, TW and AP represented the climatic control, while TP, pH, and Sal represented the biogeochemical/metabolic control. Further, the hydrologic control (e.g., reaeration) was represented by stream depth and width. The final data set (Table 7.1) represented wide ranges of diverse hydro-climatic and biogeochemical conditions to control the stream water quality dynamics.

Table 7.1. Data summary of the stream water quality variables and its drivers in all the stream water quality sites across the U.S. East Coast representing diverse environmental conditions.

\begin{tabular}{lrrrrrrr}
\hline Variables & Mean & $\begin{array}{r}\text { Standard } \\
\text { Deviation }\end{array}$ & Minimum & $\begin{array}{r}25 \text { th } \\
\text { Percentile }\end{array}$ & $\begin{array}{r}50 \text { th } \\
\text { Percentile }\end{array}$ & $\begin{array}{r}75 \text { th } \\
\text { Percentile }\end{array}$ & Maximum \\
\hline TP $(\mathrm{mg} / \mathrm{L})$ & 0.09 & 0.15 & 0.004 & 0.03 & 0.05 & 0.10 & 1.74 \\
$\mathrm{TW}\left({ }^{\circ} \mathrm{C}\right)$ & 15.28 & 7.97 & 0.10 & 8.50 & 15.50 & 22.10 & 32.30 \\
$\mathrm{Sal}(\mathrm{mg} / \mathrm{L})$ & 94.22 & 101.63 & 11.80 & 42.96 & 59.46 & 112.18 & 1220.29 \\
$\mathrm{pH}$ & 7.19 & 0.60 & 4.60 & 6.80 & 7.20 & 7.60 & 9.30 \\
$\mathrm{AP}(\mathrm{mbar})$ & 1009.81 & 8.69 & 976.90 & 1004.63 & 1010.41 & 1015.62 & 1035.45 \\
$\mathrm{D}(\mathrm{ft})$ & 4.69 & 4.33 & 0.10 & 1.57 & 3.51 & 6.30 & 26.71 \\
$\mathrm{~W}(\mathrm{ft})$ & 180.54 & 171.19 & 2.66 & 65.62 & 120.67 & 219.23 & 657.15 \\
$\mathrm{Q}\left(\mathrm{ft}{ }^{3} / \mathrm{s}\right)$ & 1422.34 & 2960.10 & 0.07 & 75.00 & 373.00 & 1330.00 & 27700.00 \\
$\mathrm{DO}(\mathrm{mg} / \mathrm{L})$ & 9.39 & 2.35 & 1.70 & 7.60 & 9.20 & 11.20 & 16.00 \\
$\mathrm{DO}{ }_{\text {sat }}(\mathrm{mg} / \mathrm{L})$ & 10.26 & 1.81 & 7.27 & 8.68 & 9.94 & 11.67 & 14.71
\end{tabular}

Note: Sample size, $\mathrm{n}=2405$. TP, TW, Sal, Q, W, D, AP, DO ${ }_{\text {sat }}$, and DO, respectively, refer to total phosphorus, temperature of water, salinity, flow rate, stream width, stream depth, atmospheric pressure, saturated dissolved oxygen, dissolved oxygen.

\subsubsection{Analysis methodology}

\subsubsection{Dimensional analysis and similitude}

Dimensionless numbers are developed based on the principle of dimensional homogeneity. We formulated the dimensionless numbers using Buckingham's pi theorem (Finnemore and Franzini 
2002; Kundu and Cohen, 2002). It states that if ' $n$ ' dimensional variables has ' $r$ ' number of relevant fundamental dimensions, then they can be combined to form (n-r) dimensionless (pi or П) numbers. The set of ' $n$ ' dimensionless numbers was formed by incorporating mechanistically relevant and important stream water quality variables. Further, specific heat of water $\left(c_{p}=4184 \mathrm{~J}\right.$ $\mathrm{kg}^{-1}{ }^{\circ} \mathrm{C}^{-1}$ ) has been incorporated for unit conformity with TW. For $\mathrm{pH}$, unit was incorporated by converting it to the hydrogen ion concentration $(\mathrm{H})$. A functional relationship can be formed among stream DO and the important hydro-climatic and biogeochemical drivers as follows:

$$
f\left(D O, D O_{s a t}, T P, H, S a l, W, D, T W, A P, c_{p}\right)=0
$$

In this case, total number of variables, $n=10$; number of relevant fundamental dimensions, $r=4$ (mass: M; length: L; Time: T; temperature: K) (see Table 7.2 for the dimensions and units of the variables used for dimensional analysis). Therefore, the number of dimensionless numbers can be formed from the set is six $(n-r=6)$. This six dimensionless numbers can be used to reform the Eq. (1) as follows:

$$
\phi\left(\Pi_{1}, \Pi_{2}, \Pi_{3}, \Pi_{4}, \Pi_{5}, \Pi_{6}\right)=0
$$

Table 7.2. List of variables used in dimensional analysis.

\begin{tabular}{lll}
\hline Variables & Units & Dimensions \\
\hline Dissolved oxygen (DO) & $\mathrm{kg} \mathrm{m}^{-3}$ & {$\left[\mathrm{ML}^{-3}\right]$} \\
Saturated concentration of dissolved oxygen $\left(\mathrm{DO}_{\text {sat }}\right)$ & $\mathrm{kg} \mathrm{m}^{-3}$ & {$\left[\mathrm{ML}^{-3}\right]$} \\
Total phosphorus (TP) & $\mathrm{kg} \mathrm{m}^{-3}$ & {$\left[\mathrm{ML}^{-3}\right]$} \\
Concentration of hydrogen ion $(\mathrm{H})$ & $\mathrm{kg} \mathrm{m}^{-3}$ & {$\left[\mathrm{ML}^{-3}\right]$} \\
Salinity (Sal) & $\mathrm{kg} \mathrm{m}^{-3}$ & {$\left[\mathrm{ML}^{-3}\right]$} \\
Stream width (W) & $\mathrm{m}$ & {$[\mathrm{M}]$} \\
Stream depth (D) & $\mathrm{m}$ & {$[\mathrm{M}]$} \\
Stream water temperature $(\mathrm{TW})$ & ${ }^{\circ} \mathrm{C}$ & {$\left[\mathrm{K}^{-3}\right.$} \\
Atmospheric pressure $(\mathrm{AP})$ & $\mathrm{Kg} \mathrm{m}^{-1} \mathrm{~s}^{-2}$ & {$\left[\mathrm{ML}^{-1} \mathrm{~T}^{-2}\right]$} \\
Specific heat of water $\left(\mathrm{c}_{\mathrm{p}}\right)$ & $\mathrm{J} \mathrm{kg}^{-1} \mathrm{C}^{-1}$ & {$\left[\mathrm{~L}^{2} \mathrm{~T}^{-2} \mathrm{~K}^{-1}\right]$} \\
\hline
\end{tabular}


According to the pi theorem, four $(r=4)$ 'repeating variables' were selected in a way that together they contain all the fundamental dimensions and they do not form dimensionless numbers among themselves. A combination of the repeating variables with one of the remaining variables was selected to form each dimensionless number. If we select the repeating variables as $\mathrm{TW}, \mathrm{W}, \mathrm{AP}$, and $\mathrm{c}_{\mathrm{p}}$ with TP as the remaining variable, then the first dimensionless number can be formulated as:

$\Pi_{1}=T W^{a} W^{b} A P^{c} c_{p}^{d} T P$

According to the principle of dimensional homogeneity:

$$
M^{0} L^{0} T^{0} K^{0}=(K)^{a}(L)^{b}\left(M L^{-1} T^{-2}\right)^{c}\left(L^{2} T^{-2} K^{-1}\right)^{d}\left(M L^{-3}\right)=M^{c+1} L^{b-c+2 d-3} T^{-2 c-2 d} K^{a-d}
$$

Equating the exponents on both sides, we get $\mathrm{a}=1, \mathrm{~b}=0 ; \mathrm{c}=-1 ; \mathrm{d}=1$; therefore,

$$
\Pi_{1}=T W^{1} W^{0} A P^{-1} c_{p}^{1} T P^{1}=\left(\frac{c_{p} \cdot T W \cdot T P}{A P}\right) \operatorname{or}\left(\frac{A P}{c_{p} \cdot T W \cdot T P}\right)
$$

Similarly, the other dimensionless numbers $\left(\Pi_{2}\right.$ to $\left.\Pi_{6}\right)$ were formulated as follows:

$$
\Pi_{2}=\left(\frac{A P}{c_{p} \cdot T W \cdot H}\right) ; \Pi_{3}=\left(\frac{A P}{c_{p} \cdot T W \cdot S a l}\right) ; \quad \Pi_{4}=\left(\frac{A P}{c_{p} \cdot T W \cdot D O}\right) ; \quad \Pi_{5}=\left(\frac{A P}{c_{p} \cdot T W \cdot D O_{s a t}}\right) ; \quad \Pi_{6}=\left(\frac{W}{D}\right)
$$

The parametric reduction of ten original variables to fewer (i.e., six) dimensionless numbers can be termed as 'stream biogeochemical-ecological similitude' in this research (Kundu and Cohen, 2002).

We combined the relevant dimensionless numbers to form mechanistically meaningful new dimensionless numbers as follows:

$$
\left(\frac{A P}{c_{p} \cdot T W \cdot D O_{\text {sat }}}\right) \div\left(\frac{A P}{c_{p} \cdot T W \cdot D O}\right)=\left(\frac{D O}{D O_{\text {sat }}}\right)
$$


$\left(\frac{A P}{c_{p} \cdot T W \cdot T P}\right) \times\left(\frac{A P}{c_{p} \cdot T W \cdot H}\right) \times\left(\frac{A P}{c_{p} \cdot T W \cdot S a l}\right) \times\left(\frac{W}{D}\right)=\left(\frac{A P^{3} \cdot W}{c_{p}^{3} \cdot T W^{3} \cdot T P \cdot H \cdot S a l \cdot D}\right)$

The dimensionless number $\mathrm{DO} / \mathrm{DO}_{\text {sat }}$ represented the concentration of $\mathrm{DO}$ normalized by corresponding oxygen dissolution capacity of water. The dimensionless concentration establishes a generalized entity to bring stream DO of different spatiotemporal scale to a similar reference scale with respect to its dissolution capacity at diverse environmental conditions. The other dimensionless numbers - formed with the environmental drivers - represented the interactive controls of different hydro-climatic and biogeochemical processes. For example, the interactions of TP, H, and Sal with the TW and AP were represented, respectively, by $(A P) /\left(c_{p} \cdot T W \cdot T P\right)$, $(A P) /\left(c_{p} \cdot T W \cdot H\right)$, and $(A P) /\left(c_{p} \cdot T W \cdot S a l\right)$. The width vs. depth ratio $W / D$ represented the reaeration potential of the stream. Further, the collective control of the hydro-climatic and biogeochemical drivers on stream water quality was represented by $\left(A P^{3} \cdot W\right) /\left(c_{p}^{3} \cdot T W^{3} \cdot T P \cdot H \cdot S a l \cdot D\right)$.

\subsubsection{Investigation of emergent patterns and environmental regimes}

The mechanistically meaningful dimensionless numbers developed from the dimensional analysis were plotted on semi-logarithmic and normal papers combining all the data across the stations to investigate emergent patterns. Graphical explorations were also performed with the bin-based average data to get more clear patterns. For bin-based average data, $\mathrm{x}$-axis values have been divided into equal size bins, and then, corresponding $\mathrm{x}$ - and $\mathrm{y}$-axis values were averaged. A potential collapse of the data from diverse environmental conditions in a generalized characteristic curve would indicate the emergent pattern. The generalized characteristic curves were investigated for various environmental regimes by following any mechanistically meaningful transition in their patterns. 


\subsubsection{Characterization of the environmental regimes}

The characteristics of the identified environmental regimes were further investigated by identifying the relative controls of the drivers on DO in each regime. Participatory variables for the analysis were selected based on the similitude and process-based knowledge of stream water quality dynamics. The dominant drivers were identified by estimating the relative linkages of DO with the environmental drivers - employing partial least squares regression (PLSR) models in each regime. The PLSR models were employed on logarithmically $\left(\log _{10}\right)$ transformed and then standardized (dimensionless Z-score) data, respectively, to account for the non-linear interactions and bring the variables of different units into a comparable reference scale. The Z-scores were estimated as: $Z=(X-\bar{X}) / s_{X}$, where $X=\log _{10}$-transformed variable, $\bar{X}=$ mean of $X$, and $s_{X}=$ standard deviation of $X$. PLSR derives the orthogonal (i.e., independent) partial least squares (PLS) components of predictors and fits them with the response by simultaneous decomposition of all the predictor and response variables (Schumann et al., 2013) —and thus, is advantageous over conventional principal component regression. The PLSR model—upon optimization - appropriately resolves the multicollinearity among the predictors through the transformed orthogonal planes (Kuhn and Johnson, 2013). We developed the Z-score based PLSR models using SIMPLS algorithm (de Jong, 1993) and 10-fold cross-validation (Kuhn and Johnson, 2013) for robust estimation of the model parameters. PLSR model optimization was performed using a synthesis of the minimum Akaike Information Criterion (AIC) (Akaike, 1974; Abdul-Aziz and Ahmed, 2017) and maximum Nash-Sutcliffe efficiency (NSE) criterion (Nash and Sutcliffe, 1970; Abdul-Aziz and Ahmed, 2017).

The sign (positive or negative) of the Z-score model coefficients $(\beta)$ indicated the direction of the linkages (i.e., increasing or decreasing) among the response and predictor 
variables. The fitting efficiency of the developed model was estimated by NSE, while the model accuracy was indicated by the ratio of root-mean-square error to the standard deviation of the observations (RSR). Moriasi et al. (2007) defined the RSR values as 0-0.5, 0.5-0.6, 0.6-0.7, and $>0.70$, respectively, for "very good", "good", "satisfactory", and "unsatisfactory" models.

\subsubsection{Development of scaling relationship}

The nonlinear scaling relationship $\left(Y \propto X^{b}\right.$ ) of normalized DO with the important dimensionless number was investigated using Levenberg-Marquardt non-linear least squares algorithm. The model parameters were robustly estimated by employing cross validation ( $80 \%$ data for calibration and $20 \%$ data for validation) — repeating the model 1000 times using bootstrap Monte-Carlo resampling. The 1000 model estimations were averaged to determine the robust estimates. The model parameters/shape factors (i.e., b) indicated the potential scaling relationship among the response and predictor dimensionless number. The identified scaling relationship was leveraged to develop non-linear model of stream DO under diverse environmental conditions.

\subsection{Results}

\subsubsection{Emergent patterns and environmental regimes}

The graphical exploration of normalized DO with the mechanistically meaningful dimensionless numbers in semi-logarithmic and regular arithmetic scales indicated potential collapse of data.

The increasing trends of the plots of DO/DO sat with $A P /\left(c_{p} \cdot T W \cdot T P\right), A P /\left(c_{p} \cdot T W \cdot H\right)$, and $A P /\left(c_{p} \cdot T W \cdot S a l\right)$ (see Figure A7.1 to A7.3 in Appendix A7) indicated how the interactions of, respectively, TP, H, and Sal with stream temperature and atmospheric pressure

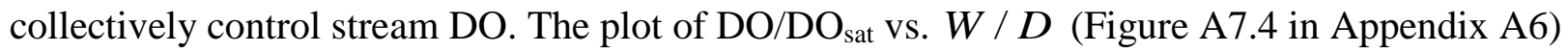


also showed an increasing trend-indicating stream DO increases with higher width to depth ratio of stream due to higher potential for reaeration. The four dimensionless numbers-when combined together (i.e., $\left.\left(A P^{3} \cdot W\right) /\left(c_{p}^{3} \cdot T W^{3} \cdot T P \cdot H \cdot S a l \cdot D\right)\right)$ - had the interactions of all important hydro-climatic and biogeochemical drivers; showing their collective control on DO. The plot of normalized DO vs. $\left(A P^{3} \cdot W\right) /\left(c_{p}^{3} \cdot T W^{3} \cdot T P \cdot H \cdot S a l \cdot D\right)$ (Figure $\left.7.2 \mathrm{a}, \mathrm{b}\right)$ showed collapse of the data from diverse environmental conditions-leading to a clear emergent pattern. Two environmental regimes (Figure 7.2b)—separated by a transitional point ( $\left.\log _{10}\left[\left(A P^{3} \cdot W\right) /\left(c_{p}^{3} \cdot T W^{3} \cdot T P \cdot H \cdot S a l \cdot D\right)\right]=16\right)$ - were emerged that was not apparent in the dimensional domain. The environmental regime corresponding to $\log _{10}\left[\left(A P^{3} \cdot W\right) /\left(c_{p}^{3} \cdot T W^{3} \cdot T P \cdot H \cdot S a l \cdot D\right)\right]>16$ had stream DO close to its saturation point. This indicated an environmental condition where metabolic consumption of DO was low, and therefore, were termed as 'low consumption' regime. However, the environmental regime corresponding to $\log _{10}\left[\left(A P^{3} \cdot W\right) /\left(c_{p}{ }^{3} \cdot T W^{3} \cdot T P \cdot H \cdot S a l \cdot D\right)\right] \leq 16$ suggested an environmental condition favorable for higher metabolic consumption of DO, and thus, were termed as 'high consumption' regime. The numerator and denominator of the dimensionless number indicated, respectively, sources (i.e., reaeration and atmospheric gas exchange) and sinks (i.e., stream temperature, microbial consumption, and salinity) of DO-leading to the increasing trend of $\mathrm{DO} / \mathrm{DO}_{\text {sat }}$ with the driver dimensionless number. Therefore, the combined dimensionless number indicated how the interactions of sources and sinks in diverse hydro-climatic and biogeochemical conditions led to the emergent patterns in stream DO dynamics. 
(a)

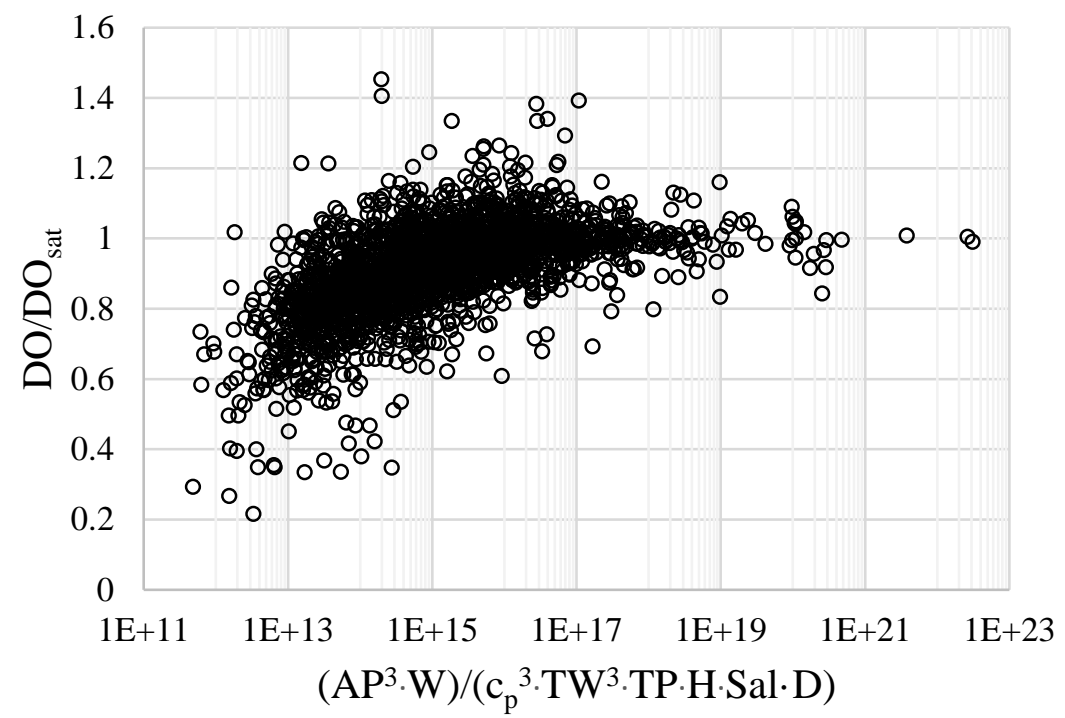

(b)

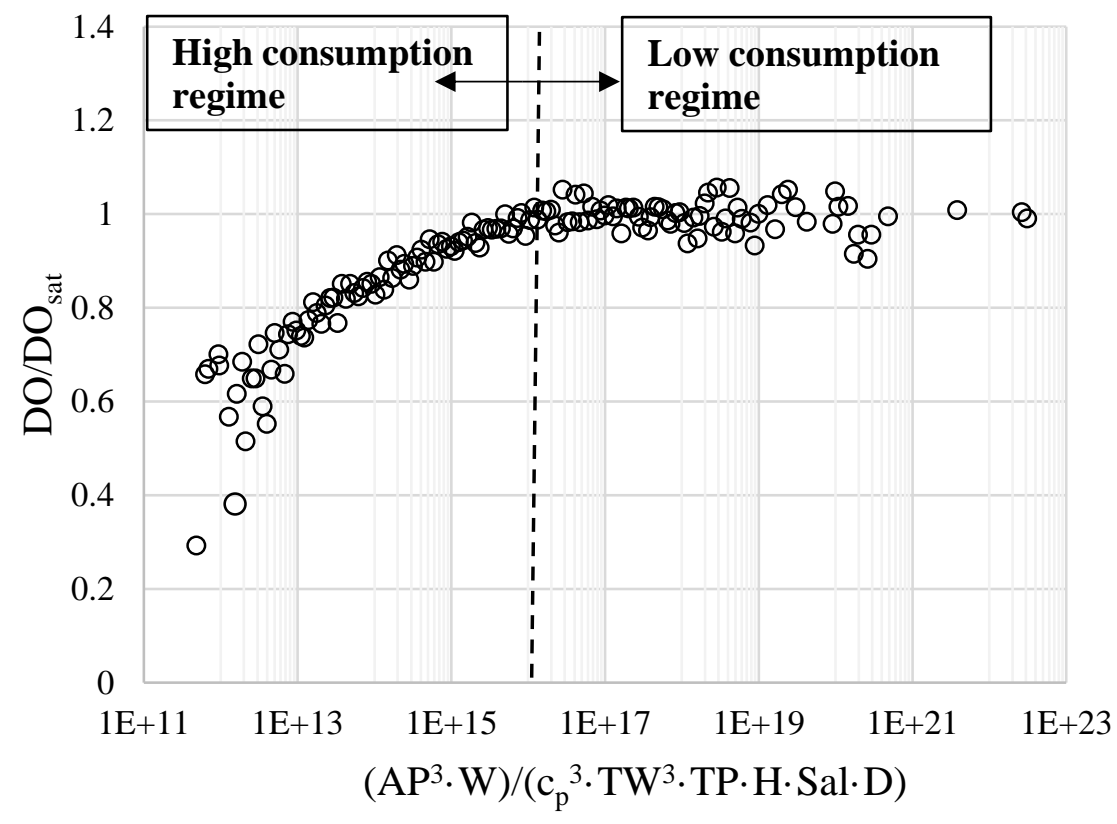

Figure 7.2. Plot of $\left(A P^{3} \cdot W\right) /\left(c_{p}^{3} \cdot T W^{3} \cdot T P \cdot H \cdot S a l \cdot D\right)$ vs. normalized DO (DO/DO sat) with (a) original data and (b) bin-based averaged data, revealing emergent patterns. 


\subsubsection{Characteristics of the environmental regimes}

The Z-score based PLSR models for both 'low consumption' and 'high consumption' regimes successfully identified their distinct characteristics. Based on the synthesis of minimum AIC and acceptable NSE, four PLS components were selected to optimize the PLSR models. The model filling efficiency ( $\mathrm{NSE}=0.68$ to 0.75$)$ and accuracy $(\mathrm{RSR}=0.50$ to 0.56$)$ suggested good performance of the optimized models. The optimized PLSR models were significant at the $95 \%$ confidence level. The estimated relative linkages of DO with its drivers were represented by the regression coefficients of PLSR models (Table 7.3).

Table 7.3. Relative linkages from PLSR model coefficients ( $\beta$ ) across the environmental regimes.

\begin{tabular}{lrr}
\hline Predictors & $\begin{array}{r}\text { Low consumption } \\
\text { regime }\end{array}$ & $\begin{array}{r}\text { High consumption } \\
\text { regime }\end{array}$ \\
\hline TW & -0.95 & -0.78 \\
pH & 0.14 & 0.33 \\
Sal & 0.04 & -0.12 \\
TP & -0.13 & -0.22 \\
Q & 0.12 & 0.10 \\
AP & 0.08 & -0.03 \\
& Model Statistics & \\
PLS components & 4 & 4 \\
NSE & 0.75 & 0.68 \\
RSR & 0.50 & 0.56 \\
\hline
\end{tabular}

Note: Sample size (n) for 'low consumption' and 'high consumption' regimes are respectively, 541 and 1864.

Strong linkage ( $\beta=-0.78$ to 0.95$)$ of DO was found with TW across the regimes. However, interesting contrasts were found in the relative linkages of other variables between the regimes. For example, while weak to moderate linkage $(\beta=0.14)$ of $\mathrm{DO}$ was found with $\mathrm{pH}$ in 'low consumption' regime, strong linkage $(\beta=0.33)$ of $\mathrm{pH}$ was demonstrated in 'high 
consumption' regime. Further, the weak to moderate linkage of $\mathrm{TP}(\beta=-0.13)$ in 'low consumption' regime was found strong $(\beta=-0.22)$ in 'high consumption' regime. The relative linkage of Sal was also found to increase in 'high consumption' regime. The results further suggested weak to moderate linkages of discharge with DO across the regimes. Overall, the PLSR results implied that in 'low consumption' regime, DO was primarily dominated by climatic control. However, in 'high consumption' regime, DO was dominated by climatic alongside the metabolic (i.e., $\mathrm{pH}, \mathrm{TP}$ ) controls.

\subsubsection{Scaling and predictions}

The scaling relationship of normalized DO with $\frac{A P^{3} \cdot W}{c_{p}{ }^{3} \cdot T W^{3} \cdot T P \cdot H \cdot S a l \cdot D}$ was formulated leveraging the bin-based average data in the following equation:

$$
Y=1-a X^{b}
$$

where, $Y=\left(\frac{D O}{D O_{\text {sat }}}\right)$ and $X=\left(\frac{A P^{3} \cdot W}{c_{p}^{3} \cdot T W^{3} \cdot T P \cdot H \cdot S a l \cdot D}\right)$

The model (Table 7.4) shape factor value (i.e., $b=-0.27$ ) represented significant scaling relationship between the response and predictor dimensionless numbers. The model showed good performance to predict normalized DO (model calibration NSE $=0.88$ and validation NSE $=0.86$; calibration $\mathrm{RSR}=0.34$ and validation $\mathrm{RSR}=0.36)($ Table 7.4 ; Figure A7.5 in Appendix 7). The model parameters were significant at the $95 \%$ confidence level. 
Table 7.4. The predictive modeling results with the dimensionless numbers

\begin{tabular}{cc}
\hline Model parameters & Estimates \\
\hline $\mathrm{a}$ & 872.13 \\
$\mathrm{~b}$ & -0.27 \\
\multicolumn{2}{c}{ Model Statistics } \\
NSE & $0.88(0.86)$ \\
RSR & $0.34(0.36)$ \\
\hline
\end{tabular}

Note: Parentheses indicate model validation results. Sample size, $n=150$.

The developed equation (Equation 5) with dimensionless numbers can be written as a function of DO as:

$D O=D O_{\text {sat }}\left(1-872.13\left(\frac{A P^{3} \cdot W}{c_{p}^{3} \cdot T W^{3} \cdot T P \cdot H \cdot S a l \cdot D}\right)^{-0.27}\right)$

The model (Equation 6) was used to predict DO in original domain (Figure 7.3). Good performance of the model $(\mathrm{NSE}=0.82$ and $\mathrm{RSR}=0.43)$ to predict $\mathrm{DO}$ under diverse environmental conditions across the regimes suggested its spatiotemporal robustness.

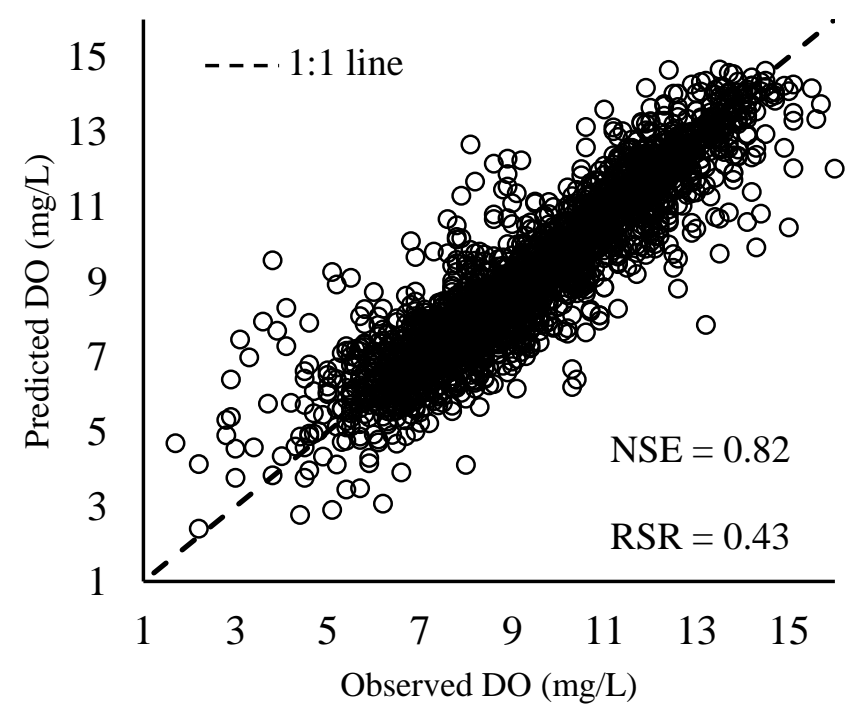

Figure 7.3. Observed vs. predicted values of stream DO across the East Coast of U.S.A 


\subsection{Discussion}

The graphical exploration of the dimensionless numbers showed collapse of data from diverse hydro-climatic and biogeochemical conditions, revealing clear emergent patterns. Having the sources and sinks of DO, respectively, in the numerator and denominator, the dimensionless number showed how the interactions of the sources (i.e., reaeration and atmospheric diffusion) and sinks (i.e., stream temperature, microbial decomposition, and salinity) controlled normalized concentration of DO. The climatic and biogeochemical drivers in the predictor dimensionless number brought different streams of diverse environmental conditions in a similar comparable scale. Further, the width vs. depth ratio (W/D) brought various streams of different geometric shapes in a similar comparable reference scale in terms of reaeration potential of the streams. Two environmental regimes (i.e., saturated vs. under-saturated DO) separated by a threshold value of the predictor dimensionless number were revealed which were not apparent in dimensional domain. The shape of the dimensionless curve and regime-specific relative linkages indicated distinct characteristics of the environmental regimes to control DO.

The dimensionless curve of the 'low consumption' regime corresponded to near saturation point of DO (i.e., DO/DO sat $~ 1)$ —indicating an environmental system where DO had weak/no control from stream metabolic activity. This might be because in 'low consumption' regime, the interactions of the hydro-climatic and biogeochemical drivers develop an environmental condition which is not favorable for microbial decomposition-leading DO to its saturation point. It suggests that stream DO in this regime is primarily driven by climatic control only. Interestingly, these findings are further corroborated by the regime-specific relative linkages of DO with the drivers. The strong linkage of DO was found with only TW in 'low consumption' regime, while the other drivers showed weak to moderate linkages - reiterating the 
dominant climatic control only. The negative linkage of DO with TW indicated the thermodynamic property of water, which reduces oxygen solubility with increasing temperature (Caccia and Boyer, 2005; Shrestha and Kazama, 2007). The adverse effect of temperature on stream DO is comprehensively documented in literature. For example, DO was reported to have strong negative correlation with water temperature in the coastal bays of Maryland and Virginia by Jacobs et al. (2009). Further, Nelson et al. (2017) found adverse effect of temperature on DO in the Rhode River located in Maryland, U.S.A.

Unlike 'low consumption' regime, the under-saturated DO (i.e., DO/DO ${ }_{\text {sat }}<1$ ) in 'high consumption' regime indicated substantial controls of interacting metabolic drivers leading to an environmental condition which is favorable for microbial consumption of DO that reduced DO below the saturation point. The strong metabolic control of 'high consumption' regime is supported by the findings of relative linkages, which—unlike 'low consumption' regimeshowed strong linkages of stream metabolic activity on DO alongside the temperature. The positive linkage of $\mathrm{DO}$ with $\mathrm{pH}$ might suggest their concurrent decrease with higher microbial decomposition. Higher microbial decomposition reduces both $\mathrm{DO}$ and $\mathrm{pH}$, respectively, by consuming oxygen and producing carbon dioxide (Cai et al., 2011)-leading to their positive linkage. In a relevant study, Cai et al. (2011) also reported strong positive linkage between DO and $\mathrm{pH}$ in the northern Gulf of Mexico. The strong negative linkage of DO with TP suggested increased eutrophication — which led to higher turbidity and oxygen demanding waste to reduce DO. The adverse control of TP on stream DO is comprehensively documented in literature (see references in Wang and Linker (2009)). Further, the negative linkage of TW with stream DO in 'high consumption' regime suggested increased microbial decomposition of organic matter with higher temperature (Schaefer and Hollibaugh, 2017)—reducing oxygen availability. The 
negative control of salinity might have suggested its adverse effect by reducing solubility of DO and inhibiting algal photosynthesis by imposing biological stress (Satoh et al., 1983).

The research provided new knowledge on the similitude of coastal stream water quality processes by reducing 10 original water quality variables to only 2 meaningful dimensionless numbers. The developed scaling relationship between the response and predictor dimensionless numbers - under diverse environments across the regimes - implied that coastal stream water quality processes follow distinct 'biogeochemical-ecological' similitude and scaling across the US East Coast. Further, the effectiveness of the scaling relationship to predict stream DOacross the regimes with good model fitting efficiency and accuracy—validated the hypothesis that the emergent similitude and scaling can lead to robust modeling of coastal stream water quality.

The similitude and emergent patterns identified by the study are expected to aid efficient management of coastal stream water quality to achieve healthy coastal ecosystems across the US East Coast. The spatiotemporally robust scaling relationship is advantageous for the water managers to determine the dynamic response of the stream under changing climate and development pressure. For example, the scaling relationship can effectively be used to identify the changes in stream health due to the changes in climate, stream metabolism, and saltwater intrusion alongside altered geometric shape (i.e., width and depth) of the stream. Further, it would suggest the managers how the stream water quality drivers (e.g., temperature, nutrient, and salinity) should be managed to transform a stream from low to high level of DOfacilitating restoration of aquatic ecosystem. For example, a hypoxic stream with certain geometric shape can be restored to desired DO level by controlling the water quality drivers following the scaling-based robust stream water quality model. Unlike the local stream water 
quality models, the unique feature of the scaling-based robust model is its ability to predict stream DO under diverse environments which can lead to better cost-benefit analysis of engineering alternatives for economic/efficient management of coastal aquatic ecosystems.

\subsection{Conclusions}

The study investigates the similitude, emergent patterns, and scaling of coastal stream water quality dynamics to study the complex interactions of hydro-climatic and biogeochemical drivers controlling stream DO. A large spatial scale across the east coast of U.S.A. was incorporated representing diverse environmental conditions. The study tests a fundamental hypothesis that coastal stream water quality follows distinct 'biogeochemical-ecological' similitude and scaling. Dimensional analysis was employed to formulate mechanistically meaningful dimensionless numbers. The predictor dimensionless numbers represented complex interactions among diverse hydro-climatic (temperature, atmospheric pressure, and stream geometry) and biogeochemical (nutrient, redox reaction) drivers to control stream DO. The concentration of DO was normalized with its saturated concentration to bring DO of numerous streams in a similar comparable scale in terms of its solubility in water. The graphical exploration of the dimensionless numbers with the normalized DO revealed clear emergent pattern-by collapsing data from diverse environments. The emergent pattern validated the hypothesis that stream water quality follows distinct 'biogeochemical-ecological' similitude and scaling. Further, two environmental regimes were revealed from the emergent patterns - separated by a transitional point in the dimensionless curve.

Power-law based PLSR models with standardized data were developed for each environmental regime to study their characteristics. The relative linkages implied distinct 
characteristics of 'climatic' versus 'metabolic' controls in the regimes. In 'low consumption' regime, DO showed strong linkage with water temperature (TW) and weak linkage with metabolic drivers - indicating a stream water quality system that is primarily dominated by 'climatic' control, and not favorable for microbial decomposition. However, the 'high consumption' regime had strong controls from $\mathrm{TW}, \mathrm{pH}$, and $\mathrm{TP}$ — suggesting domination of 'metabolic' alongside 'climatic' controls.

The emergent patterns in the dimensionless numbers were leveraged to develop scaling relationship under diverse environments across the regimes. The scaling relationship in the dimensionless domain was successfully leveraged to develop non-linear empirical model of stream DO across the East Coast of U.S.A. (Nash-Sutcliffe Efficiency $=0.82$ ). The scaling-based model of DO validated the hypothesis that the emergent similitude and scaling can lead to robust modeling of coastal stream water quality across the US East Coast. The similitude and scaling relationship are expected to advance the knowledge of coastal stream water quality dynamics which would guide for effective management of coastal aquatic ecosystems.

\section{Acknowledgments}

The research was funded by the National Science Foundation (NSF) CAREER Award to Dr. Omar I. Abdul-Aziz (NSF CBET Environmental Sustainability Award Number 1561942/1454435). 


\section{Appendix 7}

(a)

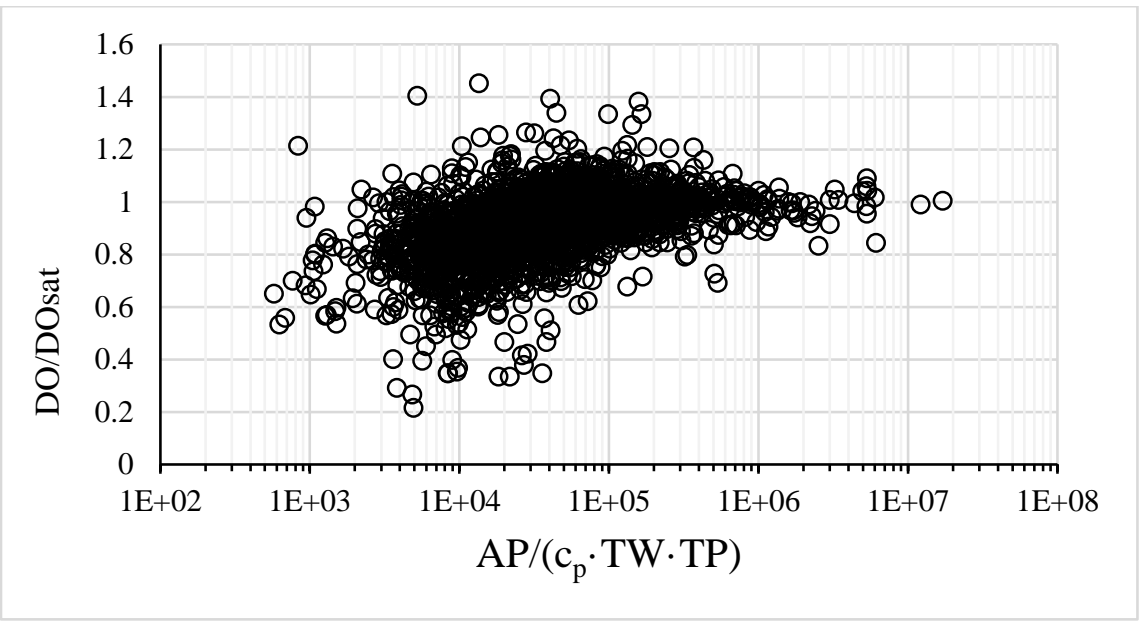

(b)

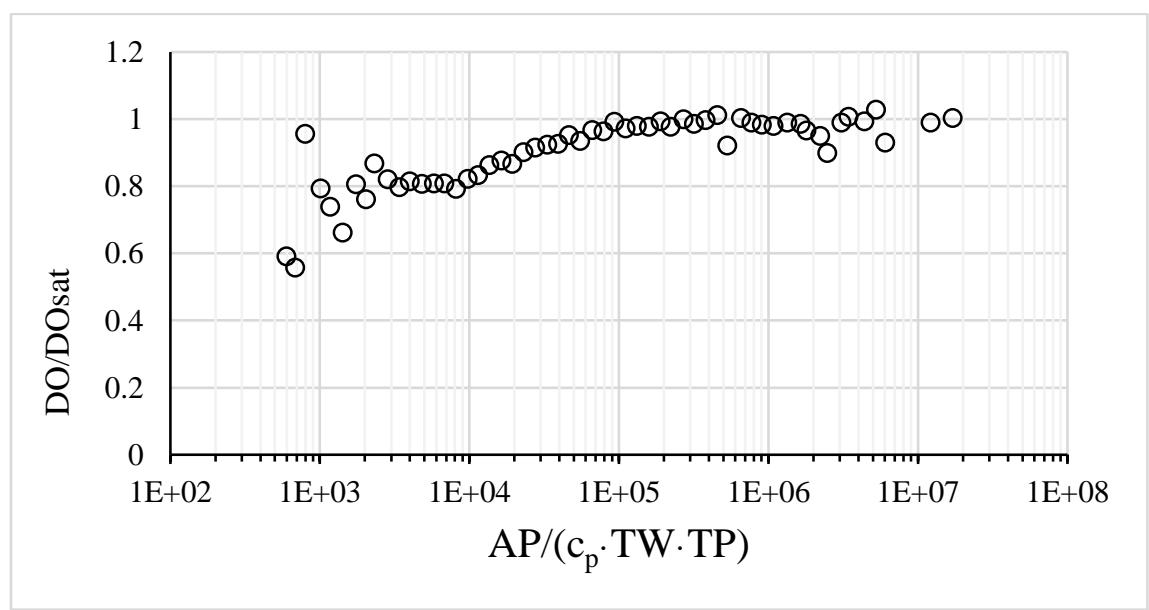

Figure A7.1. Plot of normalized DO vs. AP/( $\left.c_{p} \cdot T W \cdot T P\right)$ with (a) original data and (b) bin-based averaged data. 
(a)

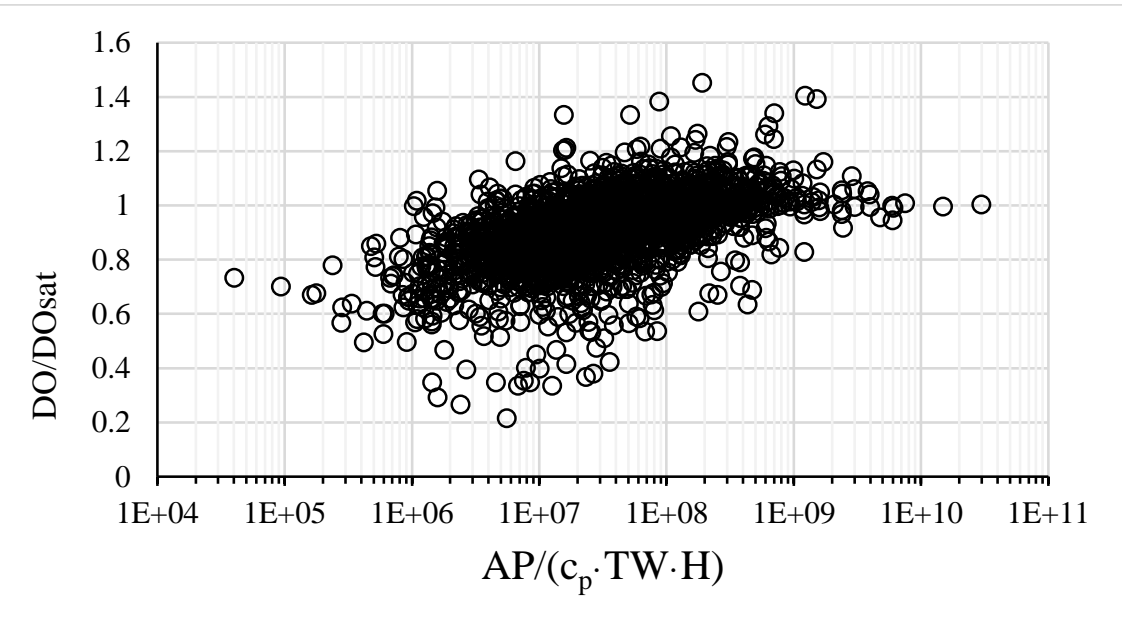

(b)

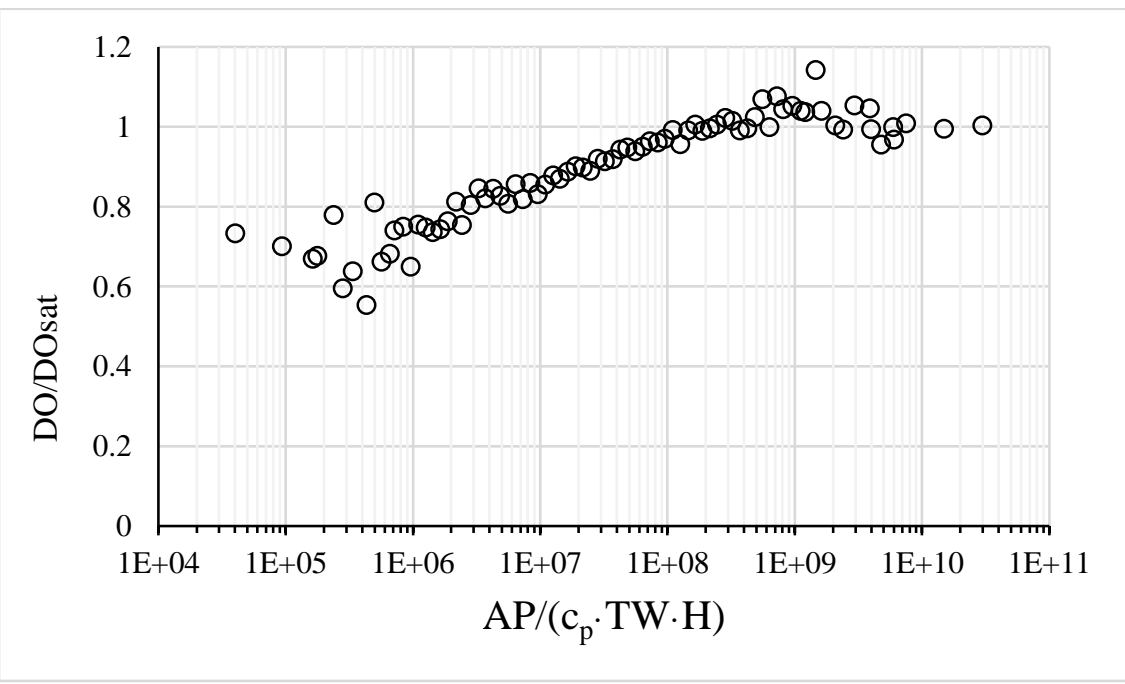

Figure A7.2. Plot of normalized DO vs. AP/( $\left.c_{\mathrm{p}} \cdot \mathrm{TW} \cdot \mathrm{H}\right)$ with (a) original data and (b) bin-based averaged data. 
(a)

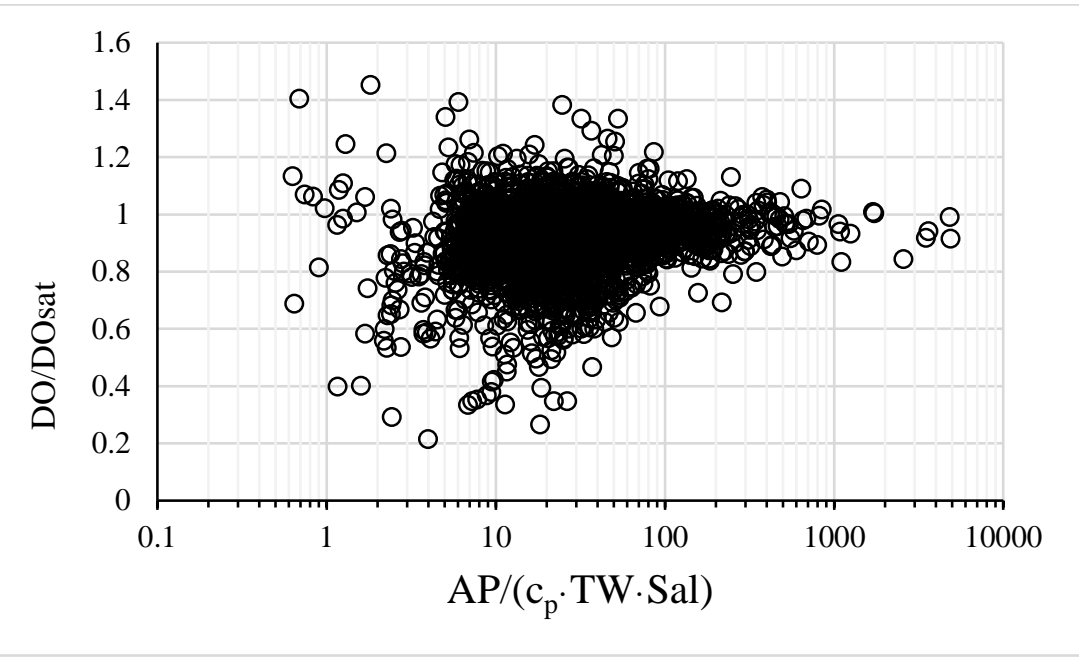

(b)

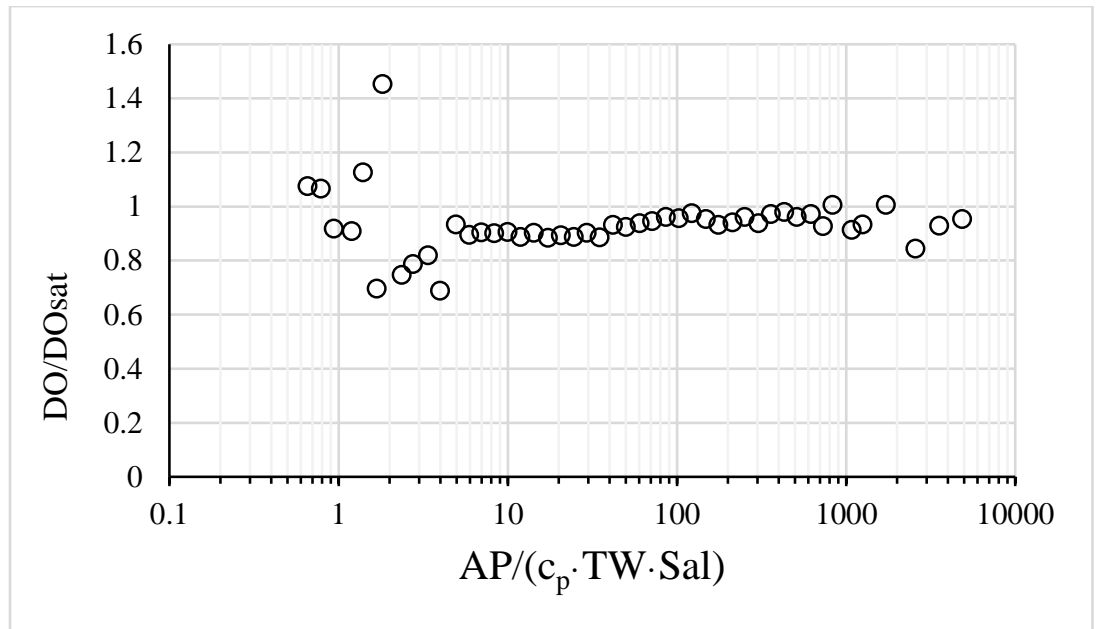

Figure A7.3. Plot of normalized DO vs. AP/( $\left.c_{\mathrm{p}} \cdot \mathrm{TW} \cdot \mathrm{Sal}\right)$ with (a) original data and (b) bin-based averaged data. 
(a)

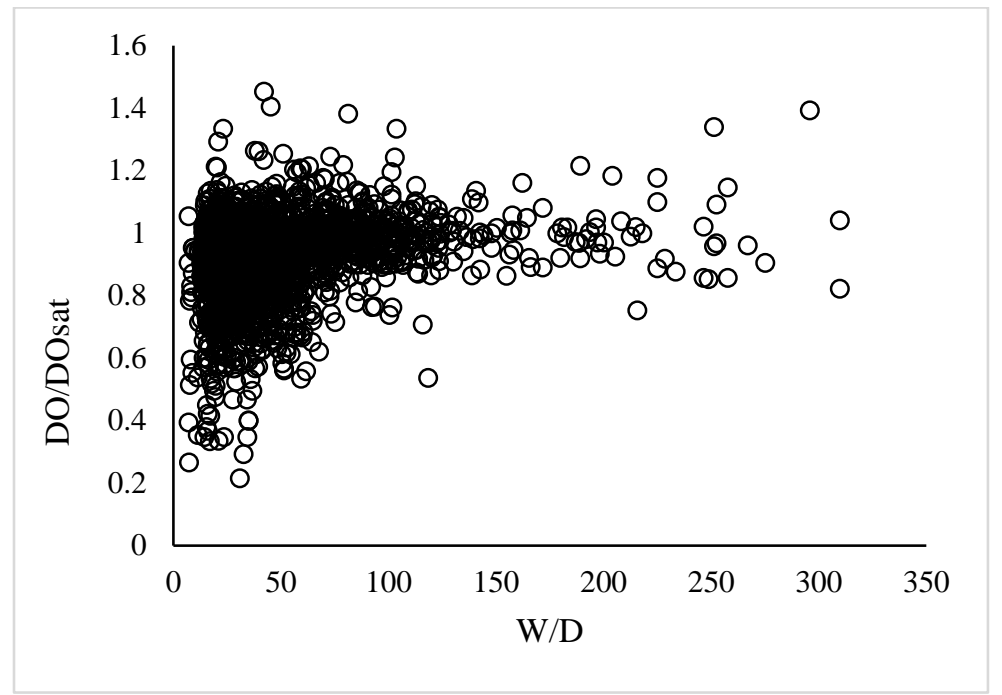

(b)

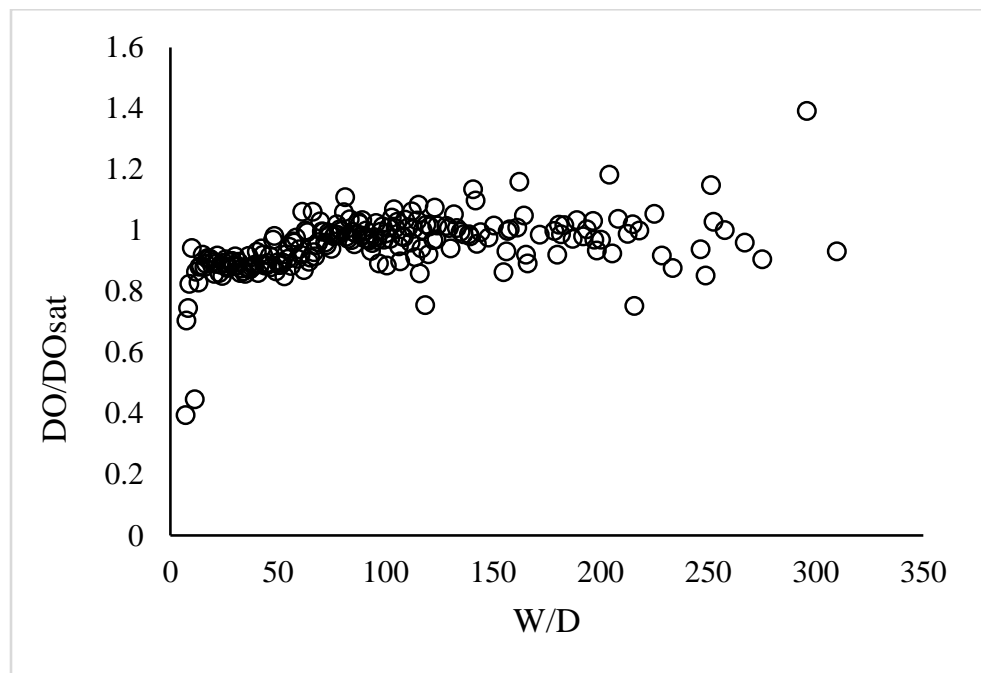

Figure A7.4. Plot of normalized DO vs. W/D with (a) original data and (b) bin-based averaged data. 


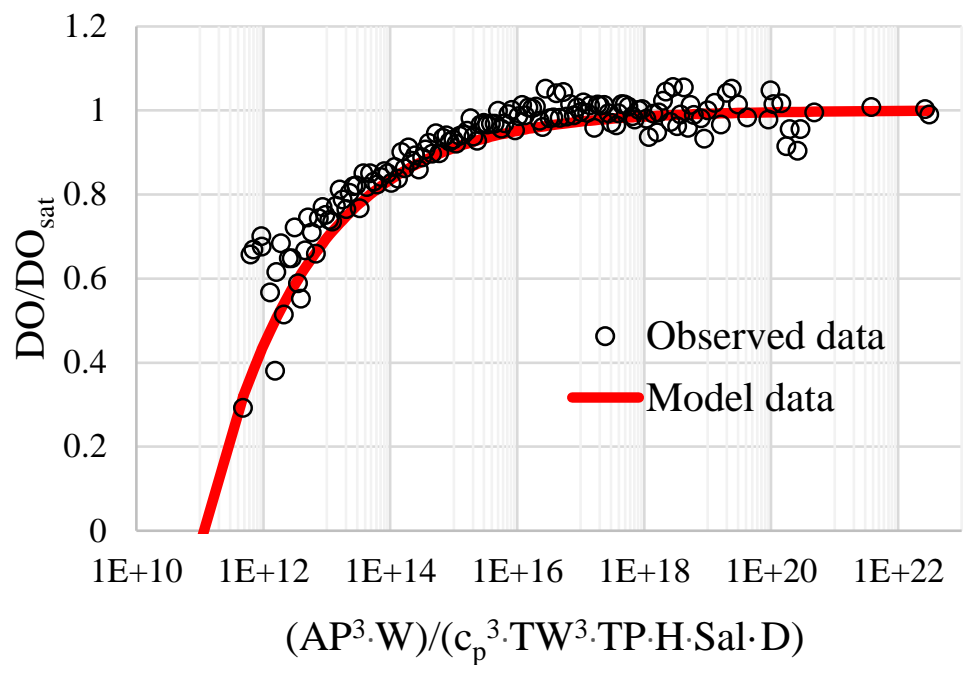

Figure A7.5. Comparison of the model and observed data in the plot of normalized DO vs. $\left(\mathrm{AP}^{3} \cdot \mathrm{W}\right) /\left(\mathrm{c}_{\mathrm{p}}{ }^{3} \cdot \mathrm{TW}^{3} \cdot \mathrm{TP} \cdot \mathrm{H} \cdot \mathrm{Sal} \cdot \mathrm{D}\right)$ using bin-based averaged data. 


\section{Chapter 8: Summary and conclusions}

The dissertation investigated the dominant spatiotemporal controls and scaling of stream water quality under diverse coastal environments. The central research hypothesis was that biogeochemical-ecological processes of coastal stream water quality follow emergent similitude and scale-invariant patterns (scaling laws) across the East Coast of U.S.A. The dominant spatiotemporal controls were identified by quantifying the relative linkages of coastal stream water quality with its environmental drivers employing a systematic data analytics technique. The knowledge of the dominant drivers was leveraged to formulate dimensionless numbers to investigate similitude and emergent patterns in coastal stream water quality dynamics. The dominant drivers, similitude, and scaling are expected to guide efficient management of coastal stream water quality under diverse environmental conditions.

Chapter 2 tested the first hypothesis by quantifying the relative linkages of land use and hydrologic drivers with the important stream water quality indicators (total nitrogen, total phosphorus, chlorophyll a, dissolved oxygen) in the coastal-urban watersheds of southeast Florida. The complex interactions and relative linkage patterns were investigated by employing a systematic utilization of multivariate data analytics technique. The relative linkages were estimated by employing power-law based partial least squares regression (PLSR) models to appropriately resolve multicollinearity. The results showed strong controls of land uses and Everglades on the stream water quality which contributed to stream nutrients (e.g., nitrogen, phosphorus). The relative linkage patterns of algal biomass with the drivers indicated total phosphorus as the limiting nutrient. Agricultural land was the most substantial watershed source of in-stream nutrients, despite the predominantly built-up fraction (74\%) of the study area. 
Stream dissolved oxygen (DO) was most strongly influenced by the adjacent groundwater depth and watershed land uses, respectively, in the wet and dry seasons. The results supported the hypothesis that complex interactions of coastal stream water quality processes are mainly controlled by a small set of dominant environmental drivers.

Chapter 3 investigated the contrasting hydrologic and land use controls of coastal-urban stream water quality by formulating similitude and dimensionless numbers considering southeast Florida as a prototype of growing coastal-urban watersheds. The knowledge of the dominant drivers from chapter 2 was leveraged in dimensional analysis to formulate mechanistically meaningful dimensionless numbers, and the most important dimensionless numbers were then identified using the data analytics framework. The predictor dimensionless numbers represented collective controls from the interactions of multitude of environmental processes. The data analytics framework implied that the 'hydrologic control number', 'land use number', 'salinity number', and 'hyporheic number' had been the most important to control coastal stream water quality. The research validated the hypothesis that coastal-urban stream water quality processes follow distinct 'biogeochemical-ecological' similitude (parametric reductions)—by reducing 9 original variables of coastal stream water quality processes into 5 meaningful dimensionless numbers.

Chapter 4 further examined the first hypothesis by expanding the study area to a large spatial scale across the East Coast of U.S.A. The chapter investigated the spatiotemporal controls of coastal stream DO in relation to the land use, hydro-climatic, and biogeochemical drivers by employing the data analytics framework. Results showed strong controls of redox drivers (e.g., $\mathrm{pH}$, specific conductance) on stream DO in wet season—suggesting domination of metabolic activity (e.g., microbial decomposition) and salinity. However, in dry season, metabolic control 
was reduced suggesting decreased stream metabolism due to lower temperature. Further, strong negative linkage of stream temperature with DO across the seasons suggested dominant climatic control. The results validated the hypothesis that the major stream water quality processes across the U.S. East Coast are mainly driven by a small set of dominant environmental drivers.

Chapter 5 investigated the interactive controls from diverse land use, hydro-climatic, and biogeochemical drivers on stream DO across the East Coast of U.S.A by employing similitude and dimensional analysis. The knowledge of the dominant controls from chapter 4 was leveraged to formulate dimensionless numbers representing interactive controls of diverse stream water quality processes. The research validated the hypothesis that coastal stream water quality processes follow distinct similitudes (parametric reductions) — by reducing a large number of original variables of stream water quality into a smaller set of meaningful pi numbers. The data analytics implied strong controls of 'metabolic number' and 'salinity number' on stream DO indicating that the stream water quality was primarily driven by the interactive controls of stream metabolism, salinity, and climatic drivers. The substantial linkage of 'slope number' with normalized DO indicated the important role of watershed hydrology to control stream DO by aeration. Further, substantial control of 'land use number' on normalized DO implied in-stream nutrient enrichment by agricultural land and their dilution by runoff from built-up land.

Chapter 6 comprehensively tested the first hypothesis by investigating the dynamic controls of different hydro-climatic and biogeochemical drivers on stream DO of numerous stream sites across the East Coast of U.S.A. The comparison of the dominant drivers across the stream sites led to their categorization into three distinct environmental regimes, which followed the climatic gradient (temperate to tropical) across the East Coast. Stream sites located in the northern part of the temperate zone (e.g., northeast coast) showed strongest linkage of DO with 
water temperature - suggesting an environmental regime dominated by climatic control. In contrast, majority of the streams in the tropical zone (e.g., southeast Florida) showed strongest linkage of $\mathrm{DO}$ with $\mathrm{pH}$ - indicating an environmental regime likely driven by redox processes. Further, a transitional regime — having strong controls of both temperature and $\mathrm{pH}$ - was found in between the temperate and tropical zone. The results validated the hypothesis that the coastal stream water quality is mainly driven by a small set of dominant environmental drivers across the East Coast of U.S.A.

Chapter 7 examined the second and third hypothesis through objective 2 and 3 . The chapter leveraged the knowledge of the dominant stream water quality drivers from previous chapters to investigate the biogeochemical-ecological similitude, emergent patterns, and scaling across the East Coast of U.S.A. Dimensional analysis was successfully employed to formulate mechanistically meaningful dimensionless numbers representing interactions of diverse hydroclimatic and biogeochemical drivers. The graphical exploration of the driver dimensionless numbers with the normalized DO revealed clear emergent patterns by collapsing the data from diverse environments. Two environmental regimes ('climatic' versus 'metabolic' controls) were revealed based on the critical threshold of the driver dimensionless number. The 'low consumption' regime was dominated by 'climatic' control only, while the 'high consumption' regime had domination of both 'metabolic' and 'climatic' controls. The emergent patterns in the dimensionless numbers were leveraged to develop scaling relationship across the regimes. The developed scaling relationship led to the prediction of stream DO under diverse environments with good model fitting efficiency and accuracy. The emergent patterns and scaling validated the hypotheses that coastal stream water quality follows distinct 'biogeochemical-ecological' 
similitude and scaling which can lead to generalized model of coastal stream water quality across the East Coast of U.S.A.

Future research is necessary to further enhance the understanding of the spatiotemporal controls of coastal stream water quality across the other U.S. coasts (e.g., Gulf Coast, Pacific Coast) along a gradient of the hydro-climatic and biogeochemical drivers. The dominant spatiotemporal controls should be leveraged to investigate similitude and scaling of stream water quality in the corresponding coastal environments. The major spatiotemporal controls and scaling relationships in different coastal environments should be compared to investigate their robustness across the U.S. coasts.

The study advanced the knowledge of coastal stream water quality processes by identifying the major spatiotemporal controls and complex interactions under diverse environments. The research contributed to new knowledge on stream 'biogeochemicalecological' similitude and scaling by combining the intricate interactions of major stream water quality drivers-leading to scale-invariant patterns and robust modeling of stream water quality. The dominant spatiotemporal controls, similitude, and scaling identified in this dissertation can aid in developing effective management targets and priorities under dynamic climate and development pressures to achieve/maintain healthy stream ecosystems across the East Coast of U.S.A. and similar regions around the world. 


\section{References}

Abdul-Aziz, O. I., and Ahmed, S. (2017). Relative linkages of stream water quality and environmental health with the land use and hydrologic drivers in the coastal-urban watersheds of southeast Florida. GeoHealth, 1, 180-195, doi:10.1002/2017GH000058.

Abdul-Aziz, O. I., and Ishtiaq, K. S. (2014). Robust empirical modeling of dissolved oxygen in small rivers and streams: Scaling by a single reference observation. Journal of Hydrology, $511,648-657$.

Abdul-Aziz, O. I., Wilson, B. N., and Gulliver, J. S. (2007a). An extended stochastic harmonic analysis (ESHA) algorithm: Application for dissolved oxygen. Water Resources Research, 43(8), W08417, doi: 10.1029/2006WR005530.

Abdul-Aziz, O. I., Wilson, B. N., and Gulliver, J. S. (2007b). Calibration and validation of an empirical dissolved oxygen model. Journal of Environmental Engineering, 133(7), 698-710.

Ahn, J. H., Grant, S. B., Surbeck, C. Q., DiGiacomo, P. M., Nezlin, N. P., and Jiang, S. (2005). Coastal water quality impact of stormwater runoff from an urban watershed in southern California. Environmental Science \& Technology, 39(16), 5940-5953.

Akaike, H. (1974). A new look at the statistical model identification. IEEE Transactions on Automatic Control, 19(6), 716-723.

Alexander, R. B., Boyer, E. W., Smith, R. A., Schwarz, G. E., and Moore, R. B. (2007). The role of headwater streams in downstream water quality. Journal of the American Water Resources Association, 43(1), 41-59. 
Álvarez-Cabria, M., Barquín, J., and Peñas, F. J. (2016). Modelling the spatial and seasonal variability of water quality for entire river networks: Relationships with natural and anthropogenic factors. Science of the Total Environment, 545, 152-162.

Andersen, C. B., Lewis, G. P., and Sargent, K. A. (2004). Influence of wastewater-treatment effluent on concentrations and fluxes of solutes in the Bush River, South Carolina, during extreme drought conditions. Environmental Geosciences, 11(1), 28-41.

Badruzzaman, M., Pinzon, J., Oppenheimer, J., and Jacangelo, J. G. (2012). Sources of nutrients impacting surface waters in Florida: a review. Journal of Environmental Management, 109, $80-92$.

Barnes, E. A., Power, M. E., Foufoula-Georgiou, E., Hondzo, M., and Dietrich, W. E. (2007). Upscaling river biomass using dimensional analysis and hydrogeomorphic scaling. Geophysical Research Letters, 34(24).

Bay, S., Jones, B. H., Schiff, K., and Washburn, L. (2003). Water quality impacts of stormwater discharges to Santa Monica Bay. Marine Environmental Research, 56(1), 205-223.

Best, M. A., Wither, A. W., and Coates, S. (2007). Dissolved oxygen as a physico-chemical supporting element in the Water Framework Directive. Marine Pollution Bulletin, 55(1), 5364.

Boyer, J. N. (2006). Shifting N and P limitation along a north-south gradient of mangrove estuaries in South Florida. Hydrobiologia, 569(1), 167-177.

Boyer, J. N., Fourqurean, J. W., and Jones, R. D. (1997). Spatial characterization of water quality in Florida Bay and Whitewater Bay by multivariate analyses: zones of similar influence. Estuaries and Coasts, 20(4), 743-758. 
Boyer, J. N., Kelble, C. R., Ortner, P. B., and Rudnick, D. T. (2009). Phytoplankton bloom status: Chlorophyll a biomass as an indicator of water quality condition in the southern estuaries of Florida, USA. Ecological Indicators, 9, S56-S67.

Bradner, A., McPherson, B. F., Miller, R. L., Kish, G., and Bernard, B. (2005). Quality of ground water in the Biscayne aquifer in Miami-Dade, Broward, and Palm Beach Counties, Florida, 1996-1998, with emphasis on contaminants. U.S. Geological Survey Open File Report, 2004-1438, Reston, VA.

Brand, L. E. (2002). The transport of terrestrial nutrients to South Florida coastal waters, in The Everglades, Florida Bay and Coral Reefs of the Florida Keys: An Ecosystem Sourcebook, edited by J.W. Porter and K.G. Porter, pp. 361-414, CRC Press, Washington, D.C.

Briceño, H. O., Boyer, J. N., Castro, J., and Harlem, P. (2013). Biogeochemical classification of South Florida's estuarine and coastal waters. Marine Pollution Bulletin, 75(1), 187-204.

Brock, D. A. (2001). Nitrogen budget for low and high freshwater inflows, Nueces Estuary, Texas. Estuaries, 24(4), 509-521.

Broward County (2016). Environmental assessment team. Available online at http://www.broward.org/NaturalResources/Lab/AboutUs/Pages/EnvironmentalAssessmentTe am.aspx (Accessed on April 04, 2016).

Broward County Development of Planning and Environmental Protection (BCDPEP) (2001). Broward County, Florida historical water quality atlas: 1972-1997, Technical Report Series TR: 01-03, BCDPEP. 
Broward County Environmental Planning and Community Resilience Division (BCEPCRD) (2015). Broward County's ambient water quality program. Available online at http://www.broward.org/NaturalResources/Lab/Pages/canalwaterquality.aspx (Accessed on March 31, 2015).

Broward County Environmental Protection Department (BCEPD) (2007). Broward County Florida water quality atlas: Freshwater Canals 1998-2003. Technical Report Series TR: 0703, BCEPD.

Bu, H., Meng, W., Zhang, Y., and Wan, J. (2014). Relationships between land use patterns and water quality in the Taizi River basin, China. Ecological Indicators, 41, 187-197.

Caccia, V. G., and Boyer, J. N. (2005). Spatial patterning of water quality in Biscayne Bay, Florida as a function of land use and water management. Marine Pollution Bulletin, 50(11), 1416-1429.

Caccia, V. G., and Boyer, J. N. (2007). A nutrient loading budget for Biscayne Bay, Florida. Marine Pollution Bulletin, 54(7), 994-1008.

Cai, W. J., Hu, X., Huang, W. J., Murrell, M. C., Lehrter, J. C., Lohrenz, S. E., Chou, W. C., Zhai, W., Hollibaugh1, J. T., Wang, Y., Zhao, P., Guo, X., Gundersen, K., Dai, M., and Gong, G. C. (2011). Acidification of subsurface coastal waters enhanced by eutrophication. Nature Geoscience, 4(11), 766-770.

Carey, R. O., Hochmuth, G. J., Martinez, C. J., Boyer, T. H., Dukes, M. D., Toor, G. S., and Cisar, J. L. (2013). Evaluating nutrient impacts in urban watersheds: Challenges and research opportunities. Environmental Pollution, 173, 138-149. 
Carey, R. O., Migliaccio, K. W., and Brown, M. T. (2011a). Nutrient discharges to Biscayne Bay, Florida: Trends, loads, and a pollutant index. Science of the Total Environment, 409(3), $530-539$.

Carey, R. O., Migliaccio, K. W, Li, Y., Schaffer, B., Gregory, A. K., and Brown, M. T. (2011b). Land use disturbance indicators and water quality variability in the Biscayne Bay watershed, Florida. Ecological Indicator, 11(5), 1093-1104.

Carstens, D., and Amer, R. M. (2017). A GIS-based model for urban change and implications for water quality in the Pontchartrain basin. Oral session presented at the meeting of the American Geophysical Union, New Orleans, LA.

Chang, H. (2008). Spatial analysis of water quality trends in the Han River basin, South Korea. Water Research, 42, 3285-3304.

Chapra, S. C. (1997). Surface Water Quality Modeling. Waveland Press, Long Grove, Illinois.

Chapra, S. C. (2008). Surface Water-Quality Modeling. Waveland press, Long Grove, Illinois.

Chen, D., Lu, J., Wang, H., Shen, Y., and Kimberley, M. O. (2010). Seasonal variations of nitrogen and phosphorus retention in an agricultural drainage river in East China. Environmental Science and Pollution Research, 17(2), 312-320.

Childers, D. L., Boyer, J. N., Davis, S. E., Madden, C. J., Rudnick, D. T., and Sklar, F. H. (2006). Relating precipitation and water management to nutrient concentrations in the oligotrophic "upside-down" estuaries of the Florida Everglades. Limnology and Oceanography, 51(1), 602-616.

Childs, C. (2004). Interpolating surfaces in ArcGIS spatial analyst. ArcUser, 32-35. 
Cloern, J. E. (1987). Turbidity as a control on phytoplankton biomass and productivity in estuaries. Continental Shelf Research, 7(11-12), 1367-1381.

Cooper, R. M., and Lane, J. (1987). South Florida Water Management District (SFWMD) Water Resources Division. An atlas of Eastern Broward County surface water management basins. Technical Memorandum, DRE 231.

Corkum, L. D. (1996). Responses of chlorophyll-a, organic matter, and macroinvertebrates to nutrient additions in rivers flowing through agricultural and forested land. Archiv fur Hydrobiologie, 136, 391-411.

Correa-González, J. C., del Carmen Chávez-Parga, M., Cortés, J. A., and Pérez-Munguía, R. M. (2014). Photosynthesis, respiration and reaeration in a stream with complex dissolved oxygen pattern and temperature dependence. Ecological Modelling, 273, 220-227.

Costelloe, J. F., Peterson, T. J., Halbert, K., Western, A. W., and McDonnell, J. J. (2015). Groundwater surface mapping informs sources of catchment baseflow. Hydrology and Earth System Sciences, 19(4), 1599-1613.

Cox, B. A. (2003). A review of currently available in-stream water-quality models and their applicability for simulating dissolved oxygen in lowland rivers. Science of the Total Environment, 314, 335-377.

Daniel, F. B., Griffith, M. B., and Troyer, M. E. (2010). Influences of spatial scale and soil permeability on relationships between land cover and baseflow stream nutrient concentrations. Environmental Management 45, 336-350. 
Dauer, D. M., Ranasinghe, J. A., and Weisberg, S. B. (2000). Relationships between benthic community condition, water quality, sediment quality, nutrient loads, and land use patterns in Chesapeake Bay. Estuaries, 23(1), 80-96.

de Jong S. (1993). SIMPLS: An alternative approach to partial least squares regression. Chemometrics and Intelligent Laboratory Systems, 18, 251-263.

de Winter, J. C. F., Dodou, D., and Wieringa, P. A. (2009). Exploratory factor analysis with small sample sizes. Multivariate Behavioral Research, 44, 147-181.

Diaz, R. J., and Rosenberg, R. (2008). Spreading dead zones and consequences for marine ecosystems. Science, 321(5891), 926-929.

Dick, J. J., Soulsby, C., Birkel, C., Malcolm, I., and Tetzlaff, D. (2016). Continuous dissolved oxygen measurements and modelling metabolism in peatland streams. Plos One, 11(8), e0161363.

Dodds, W. K. (2006). Nutrients and the "dead zone": the link between nutrient ratios and dissolved oxygen in the northern Gulf of Mexico. Frontiers in Ecology and the Environment, 4(4), 211-217.

Dyar, T. R., and Alhadeff, S. J. (2005). Dissolved-oxygen characteristics of Georgia streams. In K. J. Hatcher (Ed.), Proceedings of the Georgia Water Resources Conference, April 25-27, 2005, University of Georgia.

Elser, J. J., Marzolf, E. R., and Goldman, C. R. (1990). Phosphorus and nitrogen limitation of phytoplankton growth in the freshwaters of North America: a review and critique of experimental enrichments. Canadian Journal of Fisheries and Aquatic Sciences, 47(7), 14681477. 
Fan, M., and Shibata, H. (2015). Simulation of watershed hydrology and stream water quality under land use and climate change scenarios in Teshio River watershed, northern Japan. Ecological Indicators, 50, 79-89.

Federal Water Pollution Control Act (FWPCA) (2002). Federal Water Pollution Control Act, as amended through P.L. 107-303, November 27, 2002, in US Congress, Washington, DC.

Finnemore, E. J., and Franzini, J. B. (2002). Fluid Mechanics with Engineering Applications. 10th Edition, McGraw-Hill, New York.

Florida Department of Environmental Protection (FDEP) (2012). Safe drinking water program laboratory reporting format. Reporting Format 62-550.730.

Florida Department of Environmental Protection (FDEP) (2016). Florida department of environmental protection geospatial open data. Available online at http://geodata.dep.state.fl.us/datasets/d3bb23dc9507422a86c95eb5efc964c9_0 (Accessed on October 10, 2016).

Fox, L. E., Sager, S. L., and Wofsy, S. C. (1986). The chemical control of soluble phosphorus in the Amazon estuary. Geochimica et Cosmochimica Acta, 50(5), 783-794.

Frieder, C. A., Nam, S. H., Martz, T. R., and Levin, L. A. (2012). High temporal and spatial variability of dissolved oxygen and $\mathrm{pH}$ in a nearshore California kelp forest. Biogeosciences, 9(10), 3917-3930.

Gao, K., and Zheng, Y. (2010). Combined effects of ocean acidification and solar UV radiation on photosynthesis, growth, pigmentation and calcification of the coralline alga Corallina sessilis (Rhodophyta). Global Change Biology, 16(8), 2388-2398. 
Garcia, A. M., Vieira, J. P., and Winemiller, K. O. (2003). Effects of 1997-1998 El Niño on the dynamics of the shallow-water fish assemblage of the Patos Lagoon Estuary (Brazil), Estuarine. Coastal and Shelf Science, 57(3), 489-500

Gardner, W. S., McCarthy, M. J., An, S., Sobolev, D., Sell, K. S., and Brock, D. (2006). Nitrogen fixation and dissimilatory nitrate reduction to ammonium (DNRA) support nitrogen dynamics in Texas estuaries. Limnology and Oceanography, 51(1, part 2), 558-568.

Goovaerts, P. (1997). Geostatistics for Natural Resources Evaluation. 1st Edition, Oxford University Press, New York.

Graves, G. A., Wan, Y., and Fike, D. L. (2004). Water quality characteristics of storm water from major land uses in South Florida. Journal of the American Water Resources Association, 40(6), 1405-1419.

Guentzel, K. S., Hondzo, M., Badgley, B. D., Finlay, J. C., Sadowsky, M. J., and Kozarek, J. L. (2014). Measurement and modeling of denitrification in sand-bed streams under various land uses. Journal of Environmental Quality, 43(3), 1013-1023.

Hart, B. T., Bailey, P., Edwards, R., Hortle, K., James, K., McMahon, A., Meredith, C., and Swadling, K. (1991). A review of the salt sensitivity of the Australian freshwater biota. Hydrobiologia, 210, 105-144.

Herbst, D. B. (1998). Potential salinity limitations on nitrogen fixation in sediments from Mono Lake, California. International Journal of Salt Lake Research, 7(3), 261-274. 
Hondzo, M., Feyaerts, T., Donovan, R., and O'Connor, B. L. (2005). Universal scaling of dissolved oxygen distribution at the sediment-water interface: A power law. Limnology and Oceanography, 50(5), 1667-1676.

Hondzo, M., Voller, V. R., Morris, M., Foufoula-Georgiou, E., Finlay, J., Ganti, V., and Power, M. E. (2013). Estimating and scaling stream ecosystem metabolism along channels with heterogeneous substrate. Ecohydrology, 6(4), 679-688.

Hondzo, M., and Wang, H. (2002). Effects of turbulence on growth and metabolism of periphyton in a laboratory flume. Water Resources Research, 38(12).

Howarth, R. W., and Marino, R. (2006). Nitrogen as the limiting nutrient for eutrophication in coastal marine ecosystems: evolving views over three decades. Limnology and Oceanography, 51(1part2), 364-376.

Huang, J., Huang, Y., Pontius, R. G., and Zhang, Z. (2015). Geographically weighted regression to measure spatial variations in correlations between water pollution versus land use in a coastal watershed. Ocean \& Coastal Management, 103, 14-24.

Hubert, M., and Branden, K. V. (2003). Robust methods for partial least squares regression. Journal of Chemometrics, 17(10), 537-549.

Ishtiaq, K. S., and Abdul-Aziz, O. I. (2015). Relative linkages of canopy-level CO2 fluxes with the climatic and environmental variables for US deciduous forests. Environmental Management, 55(4), 943-960.

Jackson, C. R., and Vallaire, S. C. (2009). Effects of salinity and nutrients on microbial assemblages in Louisiana wetland sediments. Wetlands, 29(1), 277-287. 
Jacobs, J., Rhodes, M., Sturgis, B., and Wood, B. (2009). Influence of environmental gradients on the abundance and distribution of Mycobacterium spp. in a coastal lagoon estuary. Applied and Environmental Microbiology, 75(23), 7378-7384.

Johnson, R. A., and Wichern, D. W. (2007). Applied Multivariate Statistical Analysis. 6th Edition, Prentice-Hall, Englewood Cliffs, Upper Saddle River, New Jersey.

Jolliffe, I. T. (2002). Principal Component Analysis. 2nd Edition, pp. 150-165, Springer, New York.

Jordan, T. E., Cornwell, J. C., Boynton, W. R., and Anderson, J. T. (2008). Changes in phosphorus biogeochemistry along an estuarine salinity gradient: The iron conveyer belt. Limnology and Oceanography, 53(1), 172-184.

Kang, J. H., Lee, S. W., Cho, K. H., Ki, S. J., Cha, S. M., and Kim, J. H. (2010). Linking landuse type and stream water quality using spatial data of fecal indicator bacteria and heavy metals in the Yeongsan river basin. Water Research, 44(14), 4143-4157.

King, K. W., Williams, M. R., Macrae, M. L., Fausey, N. R., Frankenberger, J., Smith, D. R., Kleinman, P. J. A., and Brown, L. C. (2015). Phosphorus transport in agricultural subsurface drainage: A review. Journal of Environmental Quality, 44(2), 467-485.

Knauth, L. P. (2005). Temperature and salinity history of the Precambrian ocean: implications for the course of microbial evolution. Geobiology: Objectives, Concepts, Perspectives, 219(1), 5369.

Konopka, A., and Brock, T. D. (1978). Effect of temperature on blue-green algae (cyanobacteria) in Lake Mendota. Applied and Environmental Microbiology, 36(4), 572-576. 
Köppen Climate Classification (KCC) (2017). Available online at http://www.plantmaps.com/koppen-climate-classification-map-united-states.php (Accessed on January 05,2017$)$.

Kuhn, M., and Johnson, K. (2013). Applied Predictive Modeling. Springer, New York.

Kundu, P. K., and Cohen, I. M. (2004). Fluid Mechanics. 3rd Edition, Elsevier Academic Press, New York.

Kundu, P. K., and Cohen, I. M. (2002). Fluid Mechanics. 2nd Edition, Elsevier Academic Press, California.

Lapointe, B. E., and Bedford, B. J. (2010). Ecology and nutrition of invasive Caulerpa brachypus f. parvifolia blooms on coral reefs off southeast Florida, USA. Harmful Algae, 9(1), 1-12.

Li, S., Gu, S., Tan, X., and Zhang, Q. (2009). Water quality in the upper Han River basin, China: the impacts of land use/land cover in riparian buffer zone. Journal of Hazardous Materials, $165,317-324$.

Lietz, A. C. (1999). Methodology for estimating nutrient loads discharged from the east coast canals to Biscayne Bay, Miami-Dade County, Florida. Water-Resources Investigations Report 99-4094, U.S. Geological Survey, Tallahassee, Florida.

Liu, D., Chen, X., and Lou, Z. (2010). A model for the optimal allocation of water resources in a saltwater intrusion area: a case study in Pearl River delta in China. Water Resources Management, 24(1), 63-81.

Magalhães, C. M., Joye, S. B., Moreira, R. M., Wiebe, W. J., and Bordalo, A. A. (2005). Effect of salinity and inorganic nitrogen concentrations on nitrification and denitrification rates in 
intertidal sediments and rocky biofilms of the Douro River estuary, Portugal. Water Research, 39(9), 1783-1794.

Mahbub, P., Goonetilleke, A., and Ayoko, G. A. (2011). Prediction model of the buildup of volatile organic compounds on urban roads. Environmental Science \& Technology, 45(10), 44534459.

Markfort, C. D., and Hondzo, M. (2009). Dissolved oxygen measurements in aquatic environments: the effects of changing temperature and pressure on three sensor technologies. Journal of Environmental Quality, 38(4), 1766-1774.

Menció, A., and Mas-Pla, J. (2008). Assessment by multivariate analysis of groundwater-surface water interactions in urbanized Mediterranean streams. Journal of Hydrology, 352(3), 355366.

Miragliotta, G. (2011). The power of dimensional analysis in production systems design. International Journal of Production Economics, 131(1), 175-182.

Moriasi, D. N., Arnold, J. G., Van Liew M. W., Bingner, R. L., Harmel, R. D., and Veith, T. L. (2007). Model evaluation guidelines for systematic quantification of accuracy in watershed simulations. Transactions of the ASABE, 50(3), 885-900.

Morris, M. W., and Hondzo, M. (2013). Glossosoma nigrior (Trichoptera: Glossosomatidae) respiration in moving fluid. Journal of Experimental Biology, 216(16), 3015-3022.

Mosser, J. L., and Brock, T. D. (1976). Temperature optima for algae inhabiting cold mountain streams. Arctic and Alpine Research, 8(1), 111-114. 
Murdoch, P. S., Baron, J. S., and Miller, T. L. (2000). Potential effects of climate change on surface-water quality in North America. Journal of the American Water Resources Association, 36(2), 347-366.

Nagy, R. C., Lockaby, B. G., Kalin, L., and Anderson, C. (2012). Effects of urbanization on stream hydrology and water quality: The Florida Gulf Coast, Hydrological Processes, 26(13), 2019-2030.

Nash, J. E., and Sutcliffe, J. V. (1970). River flow forecasting through conceptual models part I—A discussion of principles. Journal Hydrology, 10(3), 282-290.

National Land Cover Database (NLCD) (2015). Available online at http://www.mrlc.gov/nlcd11_data.php (Accessed on August 25, 2015).

National Land Cover Database (NLCD) (2017). Available online at https://www.mrlc.gov/ (Accessed on November 26, 2017).

National Research Council (NRC) (2002). Florida Bay research programs and their relation to the comprehensive Everglades restoration plan. Washington, DC. doi:10.17226/10479.

National Research Council (NRC) (2012). Challenges and opportunities in the hydrologic sciences. Washington, DC.

National Solar Radiation Data Base (NSRDB) (2017). Available online at https://maps.nrel.gov/nsrdb-viewer/ (Accessed on January 15, 2017).

National Water Quality Monitoring Council (NWQMC) (2017). Available online at https://www.waterqualitydata.us/portal/ (Accessed on January 10, 2017). 
Nelson, N. G., Munoz-Carpena, R., Neale, P. J., Tzortziou, M., and Megonigal, J. P. (2017). Temporal variability in the importance of hydrologic, biotic, and climatic descriptors of dissolved oxygen dynamics in a shallow tidal-marsh creek. Water Resources Research, 53, doi:10.1002/2016WR020196.

Newcomer, T. A., Kaushal, S. S., Mayer, P. M., Shields, A. R., Canuel, E. A., Groffman, P. M., and Gold, A. J. (2012). Influence of natural and novel organic carbon sources on denitrification in forest, degraded urban, and restored streams. Ecological Monographs, 82(4), 449-466.

Nikroo, L., Kompani-Zare, M., Sepaskhah, A. R., and Shamsi, S. R. F. (2010). Groundwater depth and elevation interpolation by kriging methods in Mohr Basin of Fars province in Iran. Environmental Monitoring and Assessment 166(1-4), 387-407.

Noe, G. B., Childers, D. L., and Jones, R. D. (2001). Phosphorus biogeochemistry and the impact of phosphorus enrichment: Why is the Everglades so unique? Ecosystems, 4(7), 603-624.

North American Monsoon Experiment (NAME) (2018). Available online at https://www.eol.ucar.edu/system/files/NAME_sci_impl.pdf (Accessed on January 18, 2018).

O'Connor, B. L., and Hondzo, M. (2008). Dissolved oxygen transfer to sediments by sweep and eject motions in aquatic environments. Limnology and Oceanography, 53(2), 566-578.

Omernik, J. M., and Griffith, G. E. (2014). Ecoregions of the conterminous United States: evolution of a hierarchical spatial framework. Environmental Management, 54(6), 12491266. 
Palma, F., López-Gómez, M., Tejera, N. A., and Lluch, C. (2013). Salicylic acid improves the salinity tolerance of Medicago sativa in symbiosis with Sinorhizobium meliloti by preventing nitrogen fixation inhibition. Plant Science, 208, 75-82.

Pena, M. A., Katsev, S., Oguz, T., and Gilbert, D. (2010). Modeling dissolved oxygen dynamics and hypoxia. Biogeosciences, 7(3), 933-957.

Peres-Neto, P. R., Jackson, D. A., and Somers, K. M. (2003). Giving meaningful interpretation to ordination axes: assessing loading significance in principal component analysis. Ecology, 84(9), 2347-2363.

Potter, M. C., Wiggert, D. C., Hondzo, M., and Shih, T. I. P. (2002), Mechanics of Fluids. 3rd Edition, Brooks/Cole, Pacific Grove, Calif.

Prasad, M. B. K., Long, W., Zhang, X., Wood, R. J., and Murtugudde, R. (2011). Predicting dissolved oxygen in the Chesapeake Bay: applications and implications. Aquatic Sciences, 73(3), 437-451.

Rabalais, N. N., Turner, R. E., Gupta, B. S., Boesch, D. F., Chapman, P., and Murrell, M. C. (2007). Hypoxia in the northern Gulf of Mexico: Does the science support the plan to reduce, mitigate, and control hypoxia? Estuaries and Coasts, 30(5), 753-772.

Rietz, D. N., and Haynes, R. J. (2003). Effects of irrigation-induced salinity and sodicity on soil microbial activity. Soil Biology and Biochemistry, 35(6), 845-854.

Robinson, C. T., Schuwirth, N., Baumgartner, S., and Stamm, C. (2014). Spatial relationships between land-use, habitat, water quality and lotic macroinvertebrates in two Swiss catchments. Aquatic Sciences, 76(3), 375-392. 
Rudnick, D. T., Chen, Z., Childers, D. L., and Fontaine, T. D. (1999). Phosphorus and nitrogen inputs to Florida Bay: the importance of the Everglades watershed. Estuaries, 22(2), 398-416.

Sanger, D., Blair, A., DiDonato, G., Washburn, T., Jones, S., Riekerk, G., Wirth, E., Stewart, J., White, D., Vandiver, L., and Holland, A. F. (2015). Impacts of coastal development on the ecology of tidal creek ecosystems of the US Southeast including consequences to humans. Estuaries and Coasts, 38(1), 49-66.

Satoh, K., Smith, C. M., and Fork, D. C. (1983). Effects of salinity on primary processes of photosynthesis in the Red Alga Porphyra perforata. Plant Physiology, 73(3), 643-647.

Schaefer, S. C., and Hollibaugh, J. T. (2017). Temperature decouples ammonium and nitrite oxidation in coastal waters. Environmental Science \& Technology, 51(6), 3157-3164.

Schemel, L. E. (2001). Simplified conversions between specific conductance and salinity units for use with data from monitoring stations. Interagency Ecological Program Newsletter, 14(1), 17-18.

Schueler, T. (2003). Impacts of impervious cover on aquatic systems. Center for Watershed Protection. Ellicott City, Maryland.

Schumann, S., Nolte, L. P., and Zheng, G. (2013). Comparison of partial least squares regression and principal component regression for pelvic shape prediction. Journal of Biomechanics, 46(1), 197-199.

Shrestha, S., and Kazama, F. (2007). Assessment of surface water quality using multivariate statistical techniques: A case study of the Fuji river basin, Japan. Environmental Modelling \& Software, 22(4), 464-475. 
Simeonov, V., Stratis, J. A., Samara, C., Zachariadis, G., and Voutsa, D. (2003). Assessment of the surface water quality in northern Greece. Water Research, 37(17), 4119-4124.

Sinsabaugh, R.L. (1997). Large-scale trends for stream benthic respiration. Journal of the North American Benthological Society, 16, 46-50.

South Florida Water Management District (SFWMD) (2011). 2009 South Florida Water Management District photointerpretation key (Version 1.5).

South Florida Water Management District (SFWMD) (2015a). Available online at http://www.sfwmd.gov/portal/page/portal/levelthree/weather\%20\%20water (Accessed on March 01, 2015).

South Florida Water Management District (SFWMD) (2015b). Available online at http://sfwmd.maps.arcgis.com/home/item.html?id=989eb66b1b3b43fc9ddd30d29eaf0904 (Accessed on March 02, 2015).

South Florida Water Management District (SFWMD) (2016c). Available online at http://my.sfwmd.gov/dbhydroplsql/show_dbkey_info.show_dbkeys_matched?v_station=WC A2F4 (Accessed on April 11, 2016).

Sprague, L. A. (2005). Drought effects on water quality in the South Platte River Basin, Colorado. Journal of the American Water Resources Association, 41(1), 11-24.

Sundareshwar, P. V., and Morris, J. T. (1999). Phosphorus sorption characteristics of intertidal marsh sediments along an estuarine salinity gradient. Limnology and Oceanography, 44(7), 1693-1701. 
Todd, M. J., Vellidis, G., Lowrance, R. R., and Pringle, C. M. (2009). High sediment oxygen demand within an instream swamp in southern Georgia: Implications for low dissolved oxygen levels in coastal blackwater streams. Journal of the American Water Resources Association, 45(6), 1493-1507.

Tran, C. P., Bode, R. W., Smith, A. J., and Kleppel, G. S. (2010). Land-use proximity as a basis for assessing stream water quality in New York State (USA). Ecological Indicators, 10(3), 727-733.

Tu, J. (2009). Combined impact of climate and land use changes on streamflow and water quality in eastern Massachusetts, USA. Journal of Hydrology, 379(3-4), 268-283.

Tufford, D. L., Samarghitan, C. L., McKellar, H. N., Porter, D. E., and Hussey, J. R. (2003). Impacts of urbanization on nutrient concentrations in small southeastern coastal streams. Journal of the American Water Resources Association, 39(2), 301-312.

Tyler, R. M., Brady, D. C., and Targett, T. E. (2009). Temporal and spatial dynamics of dielcycling hypoxia in estuarine tributaries. Estuaries and Coasts, 32(1), 123-145.

Uehlinger, U., Konig, C., and Reichert, P. (2000). Variability of photosynthesis-irradiance curves and ecosystem respiration in a small river. Freshwater Biology, 44(3), 493-507.

United States Geological Survey (USGS) (2015a). Available online at http://viewer.nationalmap.gov/viewer/ (Accessed on March 01, 2015).

United States Geological Survey (USGS) (2015b). Available online at http://maps.waterdata.usgs.gov/mapper/index.html (Accessed on April 22, 2015). 
United States Geological Survey (USGS) (2017a). Available online at https://viewer.nationalmap.gov/launch/ (Accessed on December 28, 2017).

United States Geological Survey (USGS) (2017b), National water information system. Available online at https://maps.waterdata.usgs.gov/mapper/index.html (Accessed on November 17, 2017).

United States Geological Survey (USGS) (2018), Land cover change in the Eastern United States. Available online at https://landcovertrends.usgs.gov/east/regionalSummary.html (Accessed on January 01, 2018).

Wan, R., Cai, S., Li, H., Yang, G., Li, Z., and Nie, X. (2014a). Inferring land use and land cover impact on stream water quality using a Bayesian hierarchical modeling approach in the Xitiaoxi River watershed, China. Journal of Environmental Management, 133, 1-11.

Wan, Y., Qian, Y., Migliaccio, K. W., Li, Y., and Conrad, C. (2014b). Linking spatial variations in water quality with water and land management using multivariate techniques. Journal of Environmental Quality, 43(2), 599-610.

Wang, P., and Linker, L. C. (2009). Assessment of nitrogen and phosphorus control trade-offs using a water quality model with a response surface method. Journal of Water Resources Planning and Management, 135(3), 171-177.

Warnaars, T. A., Hondzo, M., and Power, M. E. (2007). Abiotic controls on periphyton accrual and metabolism in streams: Scaling by dimensionless numbers. Water Resources Research, 43: W08425, doi:10.1029/2006WR005002. 
Wetz, M. S., Hayes, K. C., Fisher, K. V., Price, L., and Sterba-Boatwright, B. (2016). Water quality dynamics in an urbanizing subtropical estuary (Oso Bay, Texas). Marine Pollution Bulletin, 104(1-2), 44-53.

Wold, S., Sjöström, M., and Eriksson, L. (2001). PLS-regression: A basic tool of chemometrics. Chemometrics and Intelligent Laboratory Systems, 58(2), 109-130.

Wood, K. L., and Kaushal, S. (2017). Urban streams as transporters or transformers of carbon and nutrients: does size matter? Oral session presented at the meeting of the American Geophysical Union, New Orleans, Los Angeles.

Woodcock, T., Mihuc, T., Romanowicz, E., and Allen, E. (2006). Land-use effects on catchment-and patch-scale habitat and macroinvertebrate responses in the Adirondack uplands. American Fisheries Society Symposium, 48, 395-411.

Xiao, R., Wang, G., Zhang, Q., and Zhang, Z. (2016). Multi-scale analysis of relationship between landscape pattern and urban river water quality in different seasons. Scientific Reports, 6. doi: 10.1038/srep25250.

Xie, R., Pang, Y., Luo, B., Li, J., Wu, C., Zheng, Y, Sun, Q., Zhang, P., and Wang, F. (2017). Spatiotemporal variability in salinity and hydraulic relationship with salt intrusion in the tidal reaches of the Minjiang River, Fujian Province, China. Environmental Science and Pollution Research, 24(12), 11847-11855.

Xu, Z., and Xu, Y. J. (2016). A deterministic model for predicting hourly dissolved oxygen change: Development and application to a shallow eutrophic lake. Water, 8(2), 41. 
Yan, B., Fang, N. F., Zhang, P. C., and Shi, Z. H. (2013). Impacts of land use change on watershed streamflow and sediment yield: An assessment using hydrologic modelling and partial least squares regression. Journal of Hydrology, 484, 26-37.

Yu, S., Xu, Z., Wu, W., and Zuo, D. (2016). Effect of land use types on stream water quality under seasonal variation and topographic characteristics in the Wei River basin, China. Ecological Indicators, 60, 202-212.

Zang, C., Huang, S., Wu, M., Du, S., Scholz, M., Gao, F., Lin, C., Guo, Y., and Dong, Y. (2011). Comparison of relationships between $\mathrm{pH}$, dissolved oxygen and chlorophyll a for aquaculture and non-aquaculture waters. Water, Air, \& Soil Pollution, 219, 157-174.

Zeleňáková, M., Čarnogurská, M., Šlezingr, M., Słyś, D., and Purcz, P. (2013). A model based on dimensional analysis for prediction of nitrogen and phosphorus concentrations at the river station Ižkovce, Slovakia. Hydrology and Earth System Sciences, 17(1), 201-209.

Zhang, J. Z., and Huang, X. L. (2011). Effect of temperature and salinity on phosphate sorption on marine sediments. Environmental Science \& Technology, 45(16), 6831-6837.

Zhang, J. Z., Kelble, C. R., Fischer, C. J., and Moore, L. (2009). Hurricane Katrina induced nutrient runoff from an agricultural area to coastal waters in Biscayne Bay, Florida. Estuarine, Coastal and Shelf Science. 84(2), 209-218.

Zhang, J., Gilbert, D., Gooday, A. J., Levin, L., Naqvi, S. W. A., Middelburg, J. J., Scranton, M., Ekau, W., Pena, A., Dewitte, B., Oguz, T., Monteiro, P. M. S., Urban, E., Rabalais, N. N., Ittekkot, V., Kemp, W. M., Ulloa, O., Elmgren, R., Escobar-Briones, E., and Van der Plas, A. K. (2010). Natural and human-induced hypoxia and consequences for coastal areas: synthesis and future development. Biogeosciences, 7, 1443-1467. 
Zhou, P., Huang, J., Pontius, R. G., and Hong, H. (2016). New insight into the correlations between land use and water quality in a coastal watershed of China: Does point source pollution weaken it? Science of The Total Environment, 543, 591-600. 